NUREG/CR-1603

UCRL-53000

\title{
Evaluation of Cracking in Feedwater Piping Adjacent to the Steam Generators in Nine Pressurized Water Reactor Plants
}

Alfred Goldberg, Ronald D. Streit, and Robert G. Scott

Prepared for

U.S. Nuclear Regulatory Commission

\section{DO NOT MICROFILM COVER}
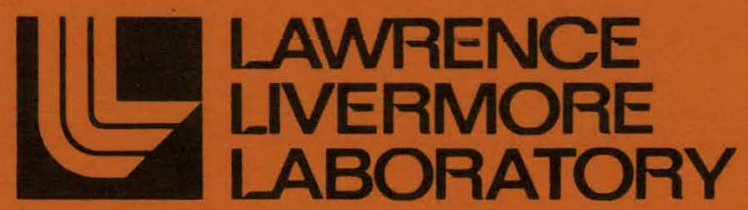


\section{DISCLAIMER}

This report was prepared as an account of work sponsored by an agency of the United States Government. Neither the United States Government nor any agency Thereof, nor any of their employees, makes any warranty, express or implied, or assumes any legal liability or responsibility for the accuracy, completeness, or usefulness of any information, apparatus, product, or process disclosed, or represents that its use would not infringe privately owned rights. Reference herein to any specific commercial product, process, or service by trade name, trademark, manufacturer, or otherwise does not necessarily constitute or imply its endorsement, recommendation, or favoring by the United States Government or any agency thereof. The views and opinions of authors expressed herein do not necessarily state or reflect those of the United States Government or any agency thereof. 


\section{DISCLAIMER}

Portions of this document may be illegible in electronic image products. Images are produced from the best available original document. 


\section{The following pages are an exact representation of what is in the original document folder.}




\section{NOTICE}

This report was prepared as an account of work sponsored by an agency of the United States Government. Neither the United States Government nor any agency thereof, or any of their employees, makes any warranty, expressed or implied, or assumes any legal liability or responsibility for any third party's use, or the results of such use, of any information, apparatus product or process disclosed in this report, or represents that its use by such third party would not infringe privately owned rights.

This work was supported by the United States Nuclear Regulatory Commission under a Memorandum of Understanding with the United States Department of Energy.

\section{DO NUI iNICROFILM COVER}

Available from

GPO Sales Program

Division of Technical Information and Document Control

U.S. Nuclear Regulatory Commission

Washington, D.C. 20555

and

National Technical Information Service

Springfield, Virginia 22161 
NUREG/CR-1603

UCRL-53000

R1, R5

\section{Evaluation of Cracking in Feedwater Piping Adjacent to the Steam Generators in Nine Pressurized Water Reactor Plants}

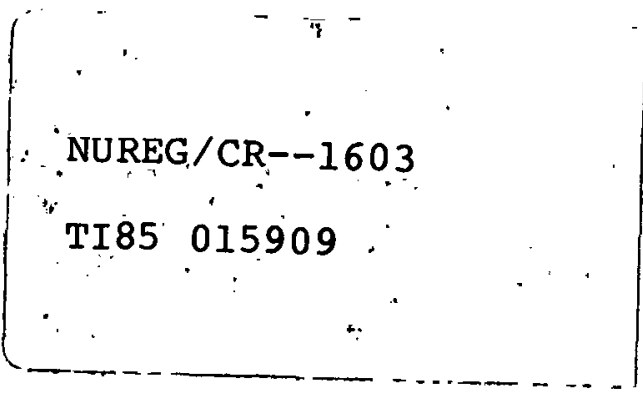

Manuscript Completed: June 25, 1980

Date Publlshed:

Prepared by

Alfred Goldberg, Ronald D. Streit, and Rubert G. Scott

Lawrence Livermore Laboratory $700 n$ East Avenue

Livermore, CA 94550

\section{Prepared for}

Office of Nuclear Reactor Regulation U.S. Nuclear Regulatory Commission Washington, D.C. 20555

NRC FIN No. A0225

$$
\text { . }
$$

\section{DISCLAIMER}

This

Government. Neithered as an account of work sponsored by an agency of the Innited States employees, makes any. Whe United States Government nor any agency thereof, nor any of their bility for the accuracy, warranty, express or implied, or assumes any legal liability or responsiprocess disclosed, or , completeness, or usefulness of any information, apparatus, product, or ence herein to any specific conts that its use would not infringe privately owned rights. Refermanufacturer, or otherwise does not necesarily process, or service by trade name, trademark ensarily constitute or imply its endorsement, recomand opinions of authors Inited States Government or any agenoy theroof nocessarily state or reflect those of the 
-

THIS PAGE

\section{WAS INTENTIONALLY \\ LEFT BLANK}




\section{ACKNOWLEDGMENTS}

We wish to acknowledge the valuable discussions held with NRC staff, especially R. A. Hermann, W. S. Hazelton, A. Taboada and V. S. Noonan, and with R. R. Vandervoort of LLNL. We also wish to acknowledge the contributions provided by the following LLNL personnel in completing this evaluation: S. L. Digiallonardo for TEM, A. W. Casey for SEM/EDS, W. J. Steele for SEM/EDS/EMA, W. L. Ping and C. L. Farrell for x-ray diffraction, A. R. Ulrich and R. P. Kershaw for light microscopy, and D. S. Hiromoto, J. C. Stone, and G. P. Vayer for mechanical properties testing.

Funding was provided by the Office of Nuclear Reactor Regulation of the U.S. Nuclear Regulatory Comission. 
Cracking in ASTM Al06-B and Al06-C. feedwater piping was detected near the inlet to the steam generators in a number of pressurized water reactor plants. We received sections with cracks from nine of the plants with the objective of identifying the cracking mechanism and assessing various factors that might contribute to this cracking.

We observed variations in (1) piping surface irregularities, (2) corrosionproduct, pit, and crack morphology, (3) surface elemental and crystal structure analyses, and (4) steel microstructures and mechanical properties. However, with but two exceptions, namely, arrest bands and major surface irregularities, we were unable to relate the extent of cracking to any of these factors. Tensile and fracture toughness ( $\mathrm{J}_{\mathrm{Ic}}$ and tearing modulus) properties were measured over a range of temperatures and strain rates. No unusual properties or microstructures were observed that could be related to the cracking problem. All crack surfaces contained thick oxide deposits and showed evidence of cyclic events in the form of arrest bands. Using transmission electron microscopy, we clearly observed fatigue striations on replicas of cleaned crack surfaces from one plant and possibly from three others. Calculations based on the observed striation spacings gave a value of $\Delta \sigma=150 \mathrm{MPa}(22 \mathrm{ksi})$. for one of the major cracks. The direction of crack propagation was invariably related to the piping surface and not to the piping axis. These two factors are consistent with the proposed concept of thermally induced, cyclic, tensile surface stresses.

Although surface irregularities and corrosion pits were sources for crack initiation and corrosion may have contributed to crack propagation, we propose that the overriding factor in the cracking problem was the presence of unforeseen cyclic loads. 
EXECUTIVE SUMMARY

Cracks have been detected in the feedwater piping near the inlet to the steam generator in 15 pressurized water reactor (PWR) plants. Cracking invariably occurred in the transition region between the piping and generator inlet. We received sections from nine of these. PWR plants for metallurgicail and mechanical properties evaluation. The objective was to identify the cracking mechanism and assess the various factors that might contribute to this cracking. The nine plants are San Onofre, Ginna, H. B. Robinson-2, Palisades, Point Beach-2, Kewaunee, Beaver Valley-1, Salem-1, and D. C. Cook-2.

We examined in considerable detall the following: (1) conditions of the inside diameter piping surfaces, (2) corrosion, pitting and crack morphologies of longitudinal cross sections through the pipe walls, (3) fractography of fractured crack surfaces, (4) morphology, chemistry, and crystallography of corrosion products, (5) microstructure of steel phases and inclusions, and (6) tensile and fracture-toughness properties of available piping material.

We observed that major cracks developed at abrupt changes in cross section such as at the bottom of the counterbore slope,* at weld-to-base metal interfaces, and/or at irregularities along the weld surface. In addition, minor cracks originated at corrosion pits and especially at machining grooves. The extent of both major and minor cracking varied considerably for piping sections from different plants. Arrest bands were detected on all crack surfaces, and these are most likely indicative of perlodic changes in reactor operating conditions. Evidence of fatigue cracking in the form of classical fatigue striations with tear ridges was clearly present on the D. C. Cook crack surface. Such evidence was also present, but to a lesser degree, in cracks from three additional plants.

All crack surfaces contained iron oxide deposits with traces of a number of elements. X-ray diffraction of the i.d. surfaces showed that the oxides ranged from essentially all $\mathrm{Fe}_{3} \mathrm{O}_{4}$ to essentially all $\mathrm{Fe}_{2} \mathrm{O}_{3}$ depending on the reactor plant. The oxide is indicative of the relative oxidation potential of the feedwater. There were some variations between the different plant

\footnotetext{
*Counterboring of the inside diameter served to eliminate any sharp dimensional change across the piping-to-inlet weld junotion.
} 
sections in crack-related morphologies such as in localized corrosion, corrosion spikes, crack branching, and mode of crack propagation. Excessive corrosion obscured some of the cracking,history. Although corrosion may play an important role in the development of much of the morphology, we believe that in most cases it plays only a minor role in the actual driving of the crack.

The steels were relatively clean and the microstructures, although varied, were within the $r$ ange expected under allowable ASTM manufacturing practices. With but one minor exception (Salem), the tensile properties fall.within ASTM Al06-B specifications. Except for the relatively low toughness exhibited by Ginna material, the fracture toughness values are consistent with published data for these steels. The in-service cracking behavior of Salem and Ginna sections was not especially unique, and we conclude that any differences in mechanical properties are not pertinent to the cracking problem. We did note, however, a rough trend between UTS and crack depth. One would expect a relationship with yield strength rather than with UTS, if the strength values were a factor here. We examined the possibility of relationships existing between major crack depth and a number of factors: surface finish and cross section discontinuities of the piping, pitting, corrosion, corrosion products, minor cracks, crack morphology, arrest bands, plant operating time, available plant information, estimated crack growth rate, steel properties, and steel microstructures. Except for a definite trend of crack depth with the number of arrest bands and to a lesser extent with surface discontinuities, correlations were nonexistent or very limited. Correlations were also attempted, unsuccessfully, between the various factors listed.

The direction of crack propagation continued invariably normal to the piping surface and not necessarily to the piping axis. Calculations using the average observed fatigue striations spacing gave a value of $\Delta \sigma=150 \mathrm{MPa}$ (22 ksi) for the D. C. Cook crack. These two results are consistent with the proposed concept of thermally induced, cyclic, tensile stresses, such as may be caused by striping or stratification of the feedwater. The general lack of correlation of cracking with the various metallurgical and property analyses or with known plant histories suggests that the major causes for cracking are related to undocumented loading events. We therefore conclude that although surface irregularities and corrosion pits were sources for crack initiation and that corrosion may have contributed to crack propagation, the overriding 
factor in the cracking problem was the presence of unforeseen cyclic loads. We therefore believe that the integrity of the feedwater piping will primarily depend on the elimination of these extraneous loads and on the improvement of the i.d. surface finish and geometry at the piping-to-inlet counterbore and weld regions. Obviously, improvement in the properties of the materials and in the water chemistry should further add to the piping life.

We include in this report an analysis in response to NRC's interest in evaluating a utility company request to continue operation of a reactor plant with possible cracks in the feedwater piping. We applied J-integral and tearing modulus concepts to the feedwater system in Millstone-2 and showed, for a postulated 152-mm (6-in.) through-wall crack, that although the crack may initiate under design basis earthquake conditions, the tearing should be stable and the crack is likely to arrest. 


\section{THIS PAGE \\ WAS INTENTIONALLY \\ LEFT BLANK}




\section{LIST OF TABLES}

2.1. Background information on piping sections . . . . . . . . 8

3.1. Location and depths of major cracks . • . . • . . • . $\quad 25$

3.2. Total number of cracks and spikes along i.d. surface . • • . . 26

3.3. Summary of attempted correlations of various factors with crack depth, crack-growth rate, and reactor plant life . . . . 27

3.4. Evaluation and ranking relative to cyclic events . . . . . . 28

3.5. Lattice constants and their deviations from literature values for the $\mathrm{Fe}_{3} \mathrm{O}_{4}$ and $\mathrm{Fe}_{2} \mathrm{O}_{3}$ structures.$\quad \cdot \quad \cdot \quad \cdot \quad \cdot \quad \cdot \quad \cdot \quad 29$

3.6. Elements detected on as-corroded crack surfaces by EDS . • . . 30

4.1. Microstructural characterization of piping . . . . . . . $\quad$. 80

5.1. Fracture toughness and tensile properties of PWR feedwater piping at room temperature and standard loading rates . . . . 91

5.2. Fracture toughness and tensile properties of D. C. Cook

feedwater piping at various temperatures and loading rates . . . 92

c.1. Cracking related to surface conditions . . . . . . . . . 119

c.2. Cracking related to pitting and corrosion . . . . . . . . 120

C.3. Ranking based on estimated crack-growth rate . . . . . . . 121

C.4. Evaluation and ranking relative to cross-section morphology of major cracks . • . . . . . • . . . • . 122

G.1. 'Ienslle properties of feedwater piping materials
from six nuclear power plants . . . . . . . . . . . . . . . 154

G.2. Tensile properties of $\mathrm{D}$. C. Cook elbow material at various
ctrain rates and temperatures. . . . . . . . . . . . 156

G.3. Transverse tensile properties of D. C. Cook elbow material; tensile axis normal to elbow axis . . . . . . . . . . . 157 


\section{LIST OF ILLUSTRATIONS}

3.1. Photographs of Ginna material showing abrupt change in cross section and deep machining grooves along the counterbore . . . 31

3.2. Photomicrographs of Ginna material showing cracks initiating from machining grooves

3.3. Photographs of Palisades material illustrating the presence

3.4. Mounted cross sections from longitudinal slices used for

light microscopy examination of San Onofre, Ginna, and

H. B. Robinson material

3.5. Mounted cross sections from longitudinal slices used for light microscopy examination of Palisades, Point Beach,

3.6. Mounted cross sections from longitudinal slices used for light microscopy examination of Beaver Valley, Salem, and D. C. Cook material

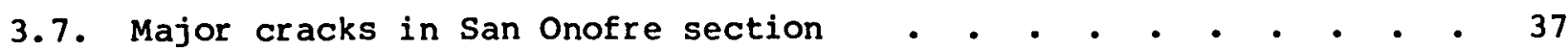

3.8. Major crack in Ginna section . . . . . . . . . . . . 38

3.9. Major crack in H. B. Robinson section _ . . . . . . . . . 39

3.10. Major crack in Palisades section, Crack A, initiates at pipe-to-weld interface

3.11. Major crack, Crack B, in pipe of Palisades section

initiates at discontinuity at bottom of counterbore slope . . .

3.12. Major crack, Crack $C$, in safe-end of Palisades section initiates at discontinuity at bottom of counterbore slope

3.13. Major crack in Point Beach section initiates at discontinuity at bottam of counterbore slope of reducer . . . .

3.14. Major crack, Crack $A$, initiates at pipe-to-weld interface (85X) and Crack $B$ initiates at discontinuity at bottom of counterbore slope (100X) in Kewaunee section

3.15. Major crack in Beaver Valley section initiates at discontinuity at bottom of counterbore slope of elbow . . .

3.16. Major crack in Salem section initiates at discontinuity at bottom of counterbore slope of reducer

3.17. Crack in D. C. Cook section at botton of counterbore slope . 
3.18. Small branched cracks near bottom of crack at bottom of counterbore slope in. D. C. Cook section . . . . . . . . . 48

3.19. Macroscopic views of crack surfaces from San Onofre, Ginna, and H. B. Robinson sections showing arrest bands . . . . . .

3.20. Macroscopic views of crack surfaces of three cracks along a

3.21. Macroscopic views of crack surfaces of additional cracks along a Palisades section

3.22. Macroscopic views of crack surfaces from Point Beach, Kewaunee, and Beaver Valley sections showing arrest bands . . .

3.23. Macroscopic views of crack surfaces from Salem and D. C. Cook sections showing arrest bands

3.24. SEM fractographs of as-corroded crack surfaces from H. B. Robinson, Beaver Valley, and D. C. Cook showing wavy striations suggesting cyclic events

3.25. SEM fractographs of as-corroded crack surface from Beaver Valley showing crater-like, parallel ridges suggesting cyclic events

3.26. SEM fractographs of as-corroded crack surface from Ginna . . . 56

3.27. SEM views showing typical morphology of corrosion nodules on crack surfaces for sections from San Onofre, H. B. Robinson, and D. C. Cook - . . . . . . . . . . 57

3.28. SEM views showing typical morphology of corrosion nodules on crack surfaces for sections from Ginna, Palisades, and Kewaunee

3.29. SEM views taken across interface from plant crack to laboratory fracture of crack surfaces from sections from Palisades, Point Beach, and D. C. Cook

3.30. SEM fractographs of crack surface of D. C. Cook section showing crazed surface of corrosion product at crack tip and crack center

3.31. TEM fractographs of replicas of a crack tip from the cleaned crack surface of a D. C. Cook section . . . . . . .

3.32. TEM fractographs of replicas obtained near the crack origin of the cleaned crack surface of a D. C. Cook section

3.33. Branched crack tip propagating at grain boundary after mostly transgranular cracking in a D. C. Cook section . . .

3.34. TFM Eractographs typical of replicas of crack tip of cleaned crack surfaces from H. B. Robinson, Kewaunee, and Ginna 
3.35. TEM fractographs typical of replicas of crack tips of cleaned crack surfaces from San Onofre, Palisades, Point Beach, Beaver Valley, and Salem

3.36. Tracing of raw data spectrum output from the $x$-ray diffractometer (using $\mathrm{Cu}$ radiation) for the corroded inside diameter surface of a Beaver Valley section . . . . . . . 66

3.37. SEM fractographs near the crack origin for a crack along the safe-end of a Palisades section

3.38. EDS spectra of spots identified in Fig. 3.37 for a Palisades crack

3.39. Large residual silicate inclusion from steel or corrosion deposit giving a strong $\mathrm{Si}$ line in both the scan and spot modes.

3.40. Areas at crack tip and near crack tip that show similar EDS

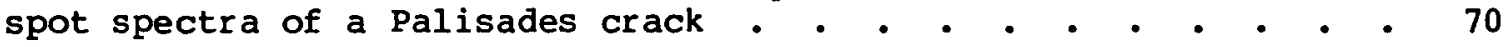

3.41. Area near crack origin of a Ginna crack that shows a variety of EDS spectra

3.42. SEM fractographs taken near the crack origin in a Beaver Valley specimen

3.43. Electron microprobe traces of $\mathrm{Cl}, \mathrm{P}$, and $\mathrm{Fe}$ made across the pit near the origin of a deep crack in the safe-end of a Palisades cross section

3.44. Electron microprobe traces of $\mathrm{Al}, \mathrm{Si}$, and $\mathrm{Cr}$ made across the pit near the origin of a deep crack in the safe-end of Palisades cross section

3.45. Electron microprobe traces of $\mathrm{S}, \mathrm{Ni}$, and $\mathrm{Cu}$ made across the pit near the origin of a deep crack in the safe-end of a Palisades cross section

4.1. Examples of inclusions in sections from San Onofre and Salem .

4.2. Photomicrographs showing differences in the morphology of inclusions in the pipe'and safe-end of a Palisades section . . .

4.3. Photomicrographs showing various degrees of banding across the wall thickness in a section from Beaver Valley . .

4.4. Photomicrographs showing only a trace of banding near the inside diameter for a Salem section and widmanstätten (oriented) ferrite and no banding for a corresponding Kewaunee section

4.5. Photomicrographs of laminar and spheroidized pearlite . . . . 85

4.6. Photomicrographs showing differences in morphology of the steel phases in the pipe and safe-end of a Palisades section 
A.1. Kewaunee, San Onofre, and Salem counterbore sections used for crack evaluation and Salem reducer section used for mechanical properties testing

A.2. Point Beach and D. C. Cook sections used for crack evaluation; and Beaver Valley and H. B. Robinson sections used for crack evaluation and mechanical properties testing

A.3. Sections from D. C. Cook used for mechanical properties testing .

B.1. Photomacrographs showing the surface condition of as-received sections from San Onofre, Kewaunee, and Palisades

B.2. Photomacrographs showing the condition of the counterbore surface in the vicinity of a major crack in as-received sections from D. C. Cook, Point Beach, and Salem

B.3. Photomacrographs showing the condition of the counterbore surface in the vicinity of a major crack in as-received sections from H. B. Robinson and Beaver Valley

B.4. Photomacrographs showing typical original inside diameter surfaces of cut section slices used for analyses . : . . .

C.1. Examples of corrosion pits and corrosion spikes (most likely small corrosion-filled cracks) in Palisades, San Onofre, Beaver Valley, and Kewaunee sections

C.2. Corrosion pits identified as cross sections of machining grooves from an H. B. Roblnson section

c.3. Ranking relative to (estimated) crack-growth rate of major crack in section versus ranking of various inside diameter surface observations

C.4. Ranking relative to (estimated) crack-growth rate of major crack in piping versus ranking of various inside diameter surface observations

C.5. Ranking relative to crack depth of major crack in section versus ranking of various factors that should relate to

c.6. Ranking relative to crack depth of major crack in piping versus ranking of various factors that should relate to corrosion/cracking degradation . . . . . . . . . . .

C.7. Ranking relative to crack depth of major crack in section versus ranking of various observations made along corresponding crack

C.8. Ranking relative to extent of degradation seen on inside diameter surface along crack versus ranking relative to estimated corresponding reactor plant life 
D.1. Photomicrographs showing corrosion, pits, and cracks along the inside diameter surface of a San Onofre section

D.2. Photomicrographs of an H. B. Robinson section showing surface and major crack along counterbore . . . . . . . . 133

D.3. Photomicrographs of a Palisades section showing the appearance of corrosion, pits, and cracks . . . . . . . . 134

D.4. Photomicrographs showing cracks initiating at weld-HAz interfaces corresponding to points of discontinuous changes in a Palisades section

D.5. Photomicrographs of a Palisades section showing corrosion, pits, and cracks along the counterbore of the safe-end

D.6. Photomicrographs showing cracks at discontinuous cross-sectional changes in a Point Beach section

D.7. Photomicrographs showing cracks at discontinuous changes in a Kewaunee section

D.8. Photomicrographs showing a crack at the bottom of the counterbore slope in two longitudinal sections taken from two different regions along the circumference of the elbow from Beaver Valley . . . . . . . . . . . . .

E.1. Correlations between distribution of craters and corrosion irregularities in a polished-and-etched specimen and of arrest bands in a fractured fractography specimen for Crack $A$ of Palisades section

F.1. SEM fractographs of a cathodically cleaned crack surface of an H. B. Robinson section.

F.2. SEM fractographs of areas in Fig. F.l showing distinct pearlite at higher magnifications in an H. B. Robinson section

F.3. SEM fractographs of a polished-and-cleaned surface of an

H. B. Robinson section

F.4. SEM fractographs across the interface from a plant crack to the laboratory fracture of a cathodically cleaned crack surface from an H. B. Robinson section

G.1. D. C. Cook feedwater piping elbow section indicating the general location of compact-tension fracture toughness specimens and tensile specimens

G.2. Photograph of as-received D. C. Cook elbow section (2-3-4-5 of Fig. G.1) and drawing of layout of specimens for mechanical properties characterization 
G.3. Upper yield strength (or 0.2 percent of set strength), as a function of temperature for piping material from six plants tested at the standard strain rate

G.4. Lower yield strength (or 0.2 percent offset strength) as a function of temperature for piping material from six plants tested at the standard strain rate . . . . . . . . . . 161

G.5. Tensile strengths as a function of temperature for piping material from six plants tested at the standard strain rate • 162

G.6. Elongation as a function of temperature for piping material from six plants tested at the standard strain rate . . . . . 163

G.7. Effect of strain rate on upper yield strength (or 0.2 percent offset strength) for D. C. Cook elbow material . . 164

G.8. Effect of strain rate on lower yield strength (or 0.2 percent offset strength) for D. C. Cook elbow material • . 165

G.9. Effect of strain rate on tensile strength for D. C. Cook elbow material

G.10. Correlation of estimated crack-growth rate (normalized for section thickness) as a function of strength data at three temperatures for six plants . . . . . . . . . . .

G.11. Correlation of depth of major crack in piping as a function of strength data at three temperatures for six plants . . . . 168

H.1. Development of $\mathrm{J}-\Delta \mathrm{a}$ curve for the determination of $\mathrm{J}_{\mathrm{IC}} \cdot \bullet^{-} \quad \cdot \quad \cdot 175$

H.2. Example of high load-rate test showing the load-displacement record

H.3. Fracture-toughness compact-tension specimen . . • • . • . 177

H. 4. J versus $\Delta a$ (linear regression line) for A-106 feedwater piping from five reactor plạts . . • . . • . . • . . 178

H.5. J-resistance curve for D. C. Cook feedwater piping at $22 \mathrm{C}$ (72 F) and standard load rate . . . . . . . . . . . . 179

H.6. J-resistance curve for D. C. Cook feedwater piping at $3 \mathrm{C}$ (37 F) and standard load rate

H.7. J-resistance curve for D. C. Cook feedwater piping at $218 \mathrm{C}$ (425 F) and standard load rate

H. 8. J-resistance curve for D. C. Cook feedwater piping at $22 \mathrm{C}$ (72 F) and high load rate 
H.9. J-resistance curve for D. C. Cook feedwater piping at $3 \mathrm{C}$

(37 F) and high load rate . . . . . . . . . . . . . 183

H.10. Data obtained for high-temperature, $218 \mathrm{C}$ (425 F),

high load-rate J-resistance curve of D. C. Cook

feedwater material . . . . . . . . . . . . . . . 184

H.11. J-resistance curve for Salem feedwater piping at $22 \mathrm{C}$

$(72 \mathrm{~F})$ and standard load rate . . . . . . . . . . . 185

H.12. J-resistance curve for Salem feedwater piping at $3 \mathrm{C}$

(37 F) and standard load rate . . . . • . • . . . . . 186 
1. INTRODUCTION

Cracks have been found in the feedwater piping adjacent to the steam. generators in 15 of the 32 pressurized water reactor (PWR) plants that have been inspected. Cracking invariably occurred in the transition region between the feedwater piping (pipe, elbow, or reducer) and generator inlet (nozzle or safe-end). The piping is carbon steel, either ASTM Al06-B or Al06-C, while the inlet is low-alloy steel such as ASTM A508-1 or A508-2. To avoid a sharp transition across the piping-to-inlet junction, the section with the smaller inside diameter (i.d.) was counterbored. The piping was then welded to the inlet. We received sections from 9 of the 15 plants for metallurgical and mechanical properties evaluation. The nine plants are San Onofre, Ginna, H. B. Robinson-2, Palisades, Point Beach-2, Kewaunee, Beaver Valley-1, Salem-1, and D. C. Cook-2.

The objective of our evaluation was to identify the cracking mechanisms and to assess various factors that may contribute to this cracking. To complete this work, we defined a number of tasks:

1. Examination of piping surfaces,

2. Morphology of cross sections of cracks,

3. Morphology of corrosion and pitting,

4. Fractography of crack surfaces,

5. Corrosion-product chemistry and crystallography,

6. Evaluation of the steel microstructures,

7. Evaluation of tensile and toughness properties of the piping material, testing over a range of temperatures, strain rates, and loading rates,

8. Extensive mechanical properties testing of material from one plant to determine if any unusual tensile or toughness behavior may occur over the range of temperatures and loading rates experienced in reactor plants.

An analysis of operating conditions in the reactor plants suggests that fatigue is the most probable cause for cracking. ${ }^{l}$ Results from recently instrumented, feedwater-piping at several plants have shown that temperature differences of over $200 \mathrm{C}(392 \mathrm{~F})$ between the top (hot) and bottom (cold) of the piping can develop adjacent to the steam generator inlet during hot standby. Somewhat lower temperature differences occur on start-up from a cold shuldown. The temperaturc gradients originate from the cold make-up water in 
the auxiliary feed that is required to restore the steam-generator water level. Tensile stresses near yield have been calculated. ${ }^{l}$ Thus, hot standby conditions and frequent start-ups can result in fatigue stresses. If on-off valve control is used during feedwater make-up, additional cycling is introduced since the magnitude of the temperature gradients is affected by the flow rate of the auxiliary feed. In addition to the circumferential. temperature gradients, temperature variations were recorded at any given point with cycling frequencies of the order of seconds. These local variations could result in significant fatigue stresses. Full-scale tests at Westinghouse Research, ${ }^{1}$ in attempting to simulate the flow conditions in feedwater piping during auxiliary feed, used brine and water to approximate the relative densities of cold and hot water, respectively, and demonstrated the formation of flowing stratified layers. They also showed that oscillations-- of the order of one hertz--developed at the interface between the two fluids; these oscillations were transmitted through the fluids to cause striping, consistent with the two types of temperature variations described in the above for the instrumented plants.

The implication here is that the addition of the fatigue stresses to the normal static operating stresses is the major factor in cracking. It is our understanding that the static stresses during operation were well within the design specifications. ${ }^{1}$ Vibrations and water hamers, both of which have been reported for most plants, are also cyclic events. Thus, in our analyses, we attempted to address particularly the question of cyclic events, especially evidence for corrosion fatigue (CF) in contrast to stress-corrosion cracking (SCC) or stress-assisted corrosion (SAC).

There are similarities, as well as differences, between CF and SCC. Both result from the conjoint action of stress and electrochemical or chemical corrosion. However, metals that are, susceptible to corrosion are invariably susceptible to CF; by contrast, SCC occurs only in very specific environments, especially with reference to the electrochemical potential. A sustained stress may manifest itself in accelerated pitting and as such may be referred to as SAC. Similarly, accelerated corrosion may occur at the tip of a crack following the interruption of a cyclic event, and this is also referred to as SAC. Cracking in $\mathrm{CF}$ is usually transgranular, relatively straight (normal to the tensile direction), and with virtually no branching. However, inpurities in the grain boundaries can result in intergranular CF. By contrast, branching 
is common in SCC; however, either intergranular and transgranular cracking may occur, depending on the exact metal-environment-stress combination. Branching in SCC occurs over a range of stress intensities where the crack growth rate is environmentally controlled, independent of the stress intensity, $\mathrm{K}_{\mathrm{I}^{\prime}}$ and therefore a number of cracks can readily propagate simultaneously. from a single crack tip. However, below or above this stress. intensity range, the growth rate is strongly dependent on $\mathrm{K}_{I}$ and branching is minimized. Furthermore, at (cyclic) stress intensities above K ISCC' both SCC and CF are active.

Microscopic striations, running approximately normal to the direction of crack propagation, are the most definitive evidence of fatigue and $\mathrm{CF}$. Beach marks or arrest bands, usually identifiable by naked eye, also attest to cyclic events. Although these events are usually associated with changes in average stress level, they may also be due to environmental changes affecting corrosion. Fatigue morphology studies have shown that at very low crack growth rates $(l \circ w \Delta K)$, of the order of below $10^{-5} \mathrm{~mm}\left(4 \times 10^{-7} \mathrm{in}\right.$ ) /cycle, striations cannot be identified; at very high stresses (or high $\Delta K$ ) striations again disappear as microvoid coalescence and localized cleavage become the dominant failure mechanisms. ${ }^{2}$ It is to be expected that the detection of striations is also limited in CF to some limited $\Delta \mathrm{K}$ range. Finally, corrosion either concurrent with or following crack propagation may eradicate striations on the metal surface or at. least limit their detection to the crack tip. However, cyclic markings resulting from the opening and closing of the crack could develop on the surface of the corrosion products.

It should be clear from the above discussion that the absence of fatigue striations does not necessarily indicate that CF did not occur. Similarly, the formation of fatigue striations does not preclude the existence of scl. In fact, in our analysis, we detected microscopic evidence ranging from strong indications to none that fatigue (or CF) was present.

We observed that major cracks developed at abrupt changes in cross section such as at the bottom of the counterbore slope, at weld-to-base metal interfaces, and/or at irregularities'along the weld surface. Lesser cracks and corrosion spikes originated at corrosion pits and especially at machining grooves but to different degrees in the different sections received from the corresponding plants. In addition to the main crack at the counterbore slope discontinuity in the piping, some plants contained many shallow cracks or 
corrosion spikes, <0.25 $\mathrm{mm}$ (0.010 in.) deep (San Onofre, Ginna, Palisades, and Kewaunee), and some contained a number of intermediate size cracks, 0.25 to $0.99 \mathrm{~mm}$ (0.010 to $0.039 \mathrm{in.}$ ) deep (San Onofre, Ginna and Point Beach, Palisades, and Salem). Three of the plants contained very few spikes or cracks other than the main crack (H. B. Robinson, Beaver Valley, and D. C. Cook). Classical fatigue striations with tear ridges were observed at the crack tip of a cleaned crack surface from D. C. Cook. With decreasing clarity, indications of fatigue were also detected for H. B. Robinson, Kewaunee, and Ginna. Observations of the cleaned crack surface for the remaining plants do not show fatigue markings. Using an observed average striation spacing of $0.10 \mu \mathrm{m}\left(3.9 \times 10^{-6} \mathrm{in.}\right)$ yields a value of $\Delta \sigma \simeq 150 \mathrm{MPa}(22 \mathrm{ksi})$. In all cases, the cracking was either primarily or entirely transgranular.

Arrest bands were seen on all crack surfaces indicative of changes in operating conditions. Although we propose that corrosion in most cases is an important factor in the development of these bands, we believe that in many cases corrosion plays only a minor role in the actual driving of the crack. Wavy type striations were observed on the as-corroded crack surfaces for all plants. However, we question the reliability of these markings as being indicative of fatigue behavior. In all plants, the corrosion products consisted almost entirely of iron oxides ranging from essentially all $\mathrm{Fe}_{3} \mathrm{O}_{4}$ to all $\mathrm{Fe}_{2} \mathrm{O}_{3}$. Deviations from published lattice constants indicate the presence of foreiqn elements in these two lattices, and we detected traces of a variety of elements in the corrosion product. However, we were unable to relate the extent of cracking to the corrosion products, either to the elements detected or to the relative amounts of the two oxides. The lower oxide, $\mathrm{Fe}_{3} \mathrm{O}_{4}$, indicates a lower oxidation potentlal of the feedwater, and it is also usually more protective than is the $\mathrm{Fe}_{2} \mathrm{O}_{3}$. Foreign elements may affect the protective nature that these oxides may have. Characterization of the various materials did not reveal any unusual microstructures that could be related to the tendency for cracking. The steels were relatively clean; they had various pearlitic-ferritic-spheroidal microstructures that would be expected for the $r$ ange of ASTM manufacturing practices allowed for these specific grares of steels. The tensile propertiee of six materials were measured. They are within the room-temperature specifications for ASTM Al06-B, but the yield strength of Salem material at elevated temperatures falls below that for ASTM Al06-B. Fracture toughness 
values were obtained for five of the materials and they are considered to be normal for these steels. However, we did observe some surprises in the effects of temperature and strain rate or loading rate on tensile properties and fracture toughness. At a strain rate of $10^{-3} / \mathrm{s}$, a minimum in the ultimate tensile strengths (UTS) occurs at about $150 \mathrm{C}(300 \mathrm{~F})$. The values, increase as the temperature either drops to $4 \mathrm{C}(39 \mathrm{~F})$ or rises to $285 \mathrm{C}$ (545 F). Consistent with this observation is that the UTS values decrease with an increase in strain rate at higher temperature, but they increase with an increase in strain rate at lower temperatures. As expected, the yield strengths increased at all temperatures with increased strain rate. At high loading rates, we observed a decrease in the fracture toughness ( $J_{I c}$ ), but there was a corresponding increase in the tearing slope.

We examined the relationship between crack depth and a number of factors: piping thickness and local geometry, piping surface finish, pitting, corrosion, corrosion products, crack morphology, piping service life, available plant information, estimated crack growth rate, steel properties, and steel microstructures. Although these factors should and likely do play contributing roles to the cracking problem, the overriding driving force in most cases, e.g., for D. C. Cook, must be the additional operating stresses above those that were considered in the system design; but documentation of the magnitude, the time interval, and the nature of these stresses during plant operation is not available. We conclude that the integrity of the feedwater piping adjacent to the steam generator depends primarily on the elimination of these extraneous stresses and on the improvement of the i.d. surface finish and geometry at the piping-to-inlet counterbore and weld regions. Obviously, improvements in the properties of the materials and in the water chemistry should further add to the piping life. 


\section{MATERIALS}

Table 2.1 lists the reactor plants from which materials were received. The plants are listed in chronological sequence relative to initial date of criticality. Piping from Salem was listed as Al06-C, the remainder as Al06-B. Sections from only three plants (San Onofre, Kewaunee, and Palisades) included the transition region from the nozzle or safe-end across the weld to the piping. The remaining sections contained piping cut at the heat-affected zone (HAz) or at the weld. The nozzles of San Onofre and Kewaunee were specified as A508-Class 2, the safe-end of Palisades as A508-Class 1.

According to the information received, post-weld stress relief was performed at five of these plants (Ginna, Palisades, Beaver Valley, Salem, and D. C. Cook) at approximately $620 \mathrm{C}(1150$ F) for about 1 hour. Stress relief was not done at two plants (San Onofre and Point Beach), and information was lacking for the two remaining plants (H. B. Robinson and Kewaunee). Since only three sections from the nine plants contained the weld region, and the stress relief of one of these is unknown, we do not consider residual stresses as one of the parameters in our evaluation of the cracking problem.

Section sizes from three plants (San Onofre, Point Beach, and Kewaunee) allowed only metallographic and surface analysis and this is indicated in Tahle 2.l. as "Metallography." Only tensile properties could be determined for the Palisades material. Both tensile and fracture toughness (J-integral testing) data could be obtained on material from the remaining five plants. Sufficient piping (elbow) material was available from D. C. Cook to evaluate its tensile and fracture-toughness properties over a matrix of temperatures and strain rates or loading rates. 
TABLE 2.1. Background information on piping sections.

\begin{tabular}{|c|c|c|c|c|c|}
\hline Reactor plant & $\begin{array}{c}\text { Date of } \\
\text { initial } \\
\text { criticality }\end{array}$ & $\begin{array}{l}\text { Sections } \\
\text { received }^{\text {a }}\end{array}$ & $\begin{array}{l}\text { Circumferential } \\
\text { location from } \\
\text { top clockwise }\end{array}$ & $\begin{array}{c}\text { Evaluations } \\
\text { possible }\end{array}$ & $\begin{array}{l}\text { Regions other } \\
\text { than piping }\end{array}$ \\
\hline San Onofre & $\begin{array}{l}\text { June } 14, \\
1967\end{array}$ & $\begin{array}{l}\text { Reducer-to-nozzle } \\
\text { transition }\end{array}$ & Unknown & Metallography & Nozzle, weld \\
\hline Ginna & $\begin{array}{l}\text { November } 8, \\
1969\end{array}$ & $\begin{array}{l}\text { Elbow (cut from } \\
\text { inlet) }\end{array}$ & $180^{\circ}$ & $\begin{array}{l}\text { Metallography } \\
\text { Mechanical }\end{array}$ & HAZ of elbow \\
\hline H. B. Robinson-2 & $\begin{array}{l}\text { September 20, } \\
1970\end{array}$ & $\begin{array}{l}\text { Reducer (cut from } \\
\text { inlet) }\end{array}$ & $30^{\circ}$ & $\begin{array}{l}\text { Metallography } \\
\text { Mechanical }\end{array}$ & None \\
\hline Palisades & $\begin{array}{l}\text { May 24, } \\
1971\end{array}$ & $\begin{array}{l}\text { Pipe-to-safe-end } \\
\text { transition }\end{array}$ & $300^{\circ}$ & $\begin{array}{l}\text { Metallography } \\
\text { Mechanical }\end{array}$ & Safe-end, welo \\
\hline Point Beach-2 & $\begin{array}{l}\text { May } 30 \\
1972\end{array}$ & $\begin{array}{l}\text { Reducer (cut from } \\
\text { inlet) }\end{array}$ & Section 43 & Metallography & Part of weld \\
\hline $\begin{array}{c}\text { Kewaunee-2 } \\
\text { Loop A }\end{array}$ & $\begin{array}{l}\text { March 7, } \\
1974\end{array}$ & $\begin{array}{l}\text { Pipe-to-nozzle } \\
\text { transition }\end{array}$ & $270-300^{\circ}$ & Metallography & Nozzle, weld \\
\hline Beaver Valley-1 & $\begin{array}{l}\text { May 10, } \\
1976\end{array}$ & $\begin{array}{l}\text { Elbow (cut from } \\
\text { inlet) }\end{array}$ & $105^{\circ}$ & $\begin{array}{l}\text { Metallography } \\
\text { Mechanical }\end{array}$ & HAZ of elbow \\
\hline Salem-1 & $\begin{array}{l}\text { December 11, } \\
1976\end{array}$ & $\begin{array}{l}\text { Reducer (cut from } \\
\text { pipe connected to } \\
\text { inlet) }\end{array}$ & $30^{\circ}$ & $\begin{array}{l}\text { Metallography } \\
\text { Mechanical }\end{array}$ & None \\
\hline D. C. Cook-2 & $\begin{array}{l}\text { March 10, } \\
1978\end{array}$ & Elbow & $20-30^{\circ}$ & $\begin{array}{l}\text { Metallography } \\
\text { Mechanical }\end{array}$ & Part of weld \\
\hline
\end{tabular}

${ }^{a}$ Inlet is used where nozzle or safe-end not identified.

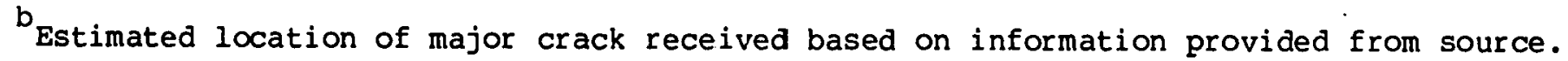

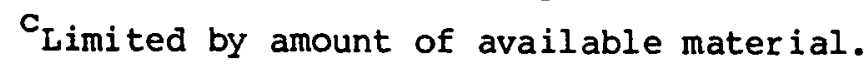




\section{METALLOGRAPHY AND SURFACE ANALYSES}

\subsection{DOCUMENTATION AND SPECIMEN PREPARATION PROCEDURES}

Low magnification views were taken to document the shapes, surface conditions, and crack locations of the as-received sections. Areas were selected for metallography, surface analysis, mechanical testing, and $x$-ray diffraction. The $x$-ray diffraction was used to identify the crystal structures of the corrosion product formed along the i.d.; the $x$-ray beam traversed an area of about 10 by $10 \mathrm{~mm}(0.4 \times 0.4 \mathrm{in.})$. Longitudinal sections containing cracks and measuring from 4 to $6 \mathrm{~mm}(0.16$ to 0.25 in.) thick were then dry-cut out of the as-received sections, parallel to the piping axis. One of each of these sections was mounted for metallographic cross-section examination by light microscopy. One or more of the adjacent sections were used for fractography. The latter specimens were loaded and fractured in liquid nitrogen so that the fracture would propagate to open and expose the surface of a selected crack. Following fracture, specimens were washed in alcohol, dried off with a heat gun, and stored in a desiccator. Cross sections containing the piping-to-inlet transition region along the i.d. and the main cracks were documented by light microscopy at one or more magnifications (30 to $1000 \mathrm{x})$. We also documented cross-section areas at the i.d., midthickness, and o.d. of sections away from the counterbore in the as-polished and in the as-etched conditions for inclusions and for morphology of steel phases, respectively. Specimens were etched with 2 percent nital.

The fractured crack surfaces with their corrosion products were examined and documented using scanning electron microscopy (SEM) and energy dispersive system for $x$-ray elemental analysis (EDS). Transmission electron microscopy. (TEM) of replicas of the crack. surfaces was used, especially, to detect fatigue striations. Replicas were obtained by a sequence of cathodic cleaning and cellulose-acetate stripping, until the corrosion product was removed, and then heavy metal/carbon shadowing of the final strip. The cathodic cleaning technique was that recommended for the removal of oxide scale from ferrous materials. ${ }^{3}$ Fractured surfaces were also documented using light microscopy at low magnifications. 
The above procedures were established after the examination on the first two materials (San Onofre and Kewaunee) was initiated. Also, we first used nondestructive evaluation (NDE) techniques on three of the reactor materials to evaluate the usefulness of these techniques for the detection and characterization of the cracks. Comparisons with our metallographic observations showed excellent agreement between the two. However, since the information obtained by NDE did not contribute materially to our immediate problem, we discontinued its use.

\subsection{CRACK-INITIATION SITES AND CORRELATIONS \\ WITH CRACK DEPTH AND OPERATING TIME}

Examination of the i.d. surfaces of the different piping sections reveals the presence of numerous surface irregularities: These resulted largely from fabrication practices and they occur at weld surfaces, weld-to-piping or -inlet interfaces, machining grooves and discontinuous section changes along the counterbores. Pitting was also a contributing factor. Figures 3.1 and 3.2 contain views of the elbow section from Ginna illustrating the role of machining grooves and discontinuous section changes along the counterbore in initiating cracks. The major crack occurs at the discontinuous section change initiating at the root of a machining groove while numerous minor cracks are seen to propagate from a number of other similar grooves. One can also see a continuous corrosion layer with additional corrosion pits at crack origins. Some minor pits were present along the original i.d. (outside the counterbore) of the elbow. Some of these contained corrosion spikes (or very small cracks) up to a maximum of $12 \mu \mathrm{m}(0.0005 \mathrm{in.})$ deep, and are probably inconsequential. of all sections, the elbow section from Ginna contained the greatest damage from machining grooves.

Figure 3.3 is an example of cracks originating at various types of discontinuities in the section trom Palisades. This material contained a number of major cracks as well as numerous minor cracks and corrosion spikes. Very similar morphology was exhibited by the corresponding section from San Onofre. The most extensive corrosion pitting that we observed was on sections from these two plants. The origin of many of the large cracks here were located at corrosion pits as well as at discontinuities due to fabrication. 
Detailed discussions on all the major cracks are presented in subsequent sections. Additional documentation of as-received sections and their surface conditions for the remaining seven plants is presented in Appendixes A and B, respectively.

The maximum observed crack depths* (i.d. surface to crack tip) for both the complete cross sections and the piping cross sections (away from the weld and heat-affected zones. (HAZ)) are tabulated in Table 3.1. As in Table 2.1, the plants are listed in chronological order with the oldest plant at the top of the list. We attempted to uncover any trends that may exist between these cracks and the various factors that might be related to the cracking. We considered observations related to both i.d. surfaces and cross sections; details on many of these factors are described in subsequent sections. To facilitate making correlations, we ranked our observations from 1 to 9. The higher the number the more likely should the material be susceptible to cracking or the greater is the degradation--e.g., cracks, corrosion, pits, and fabrication defects.

We documented all the cracks along the i.d. surface of the counterbore(s) and weld regions. Table 3.2 lists the number of cracks (some of which may actually be corrosion spikes) according to being less than $0.25 \mathrm{~mm}(0.010 \mathrm{in}$.) deep below the surface, from $0.25 \mathrm{~mm}(0.010 \mathrm{in.)}$ to $0.99 \mathrm{~mm}(0.039 . \mathrm{in}$.) deep, and deeper than $0.99 \mathrm{~mm}$ (0.039 in.). Two plants, San Onofre and Palisades, contained a large number of cracks covering all three size ranges. Ginna contained many small and intermediate size cracks; Kewaunee contained many small size cracks and several intermediate size cracks; Salem contained a number of intermediate size cracks; three plants, Point Beach, H. B. Robinson, and Beaver Valley, contained very few cracks in addition to the main crack; finally, D. C. Cook had only the main crack. We based the ranking of cracking tendency on the combination of number and depth of cracks.

Table 3.3 lists the various factors we attempted to correlate. We grouped the results into three categories: no correlation, limited trend, and definite trend. We will clarify here the terms used in the table that are not selfexplanatory. Details of the evaluations made are presented in Appendix $C$.

\footnotetext{
*Crack depths significantly greater than we observed have been reported (Ref: 1) for H. R. Rnhinson and Beaver valley.
} 
The intersection angle refers to the angle formed at the intersection of the two contiguous i.d. surfaces at a crack origin. It should be a measure of the relative severity of a notch effect. The oxide ratio, $\mathrm{Fe}_{2} \mathrm{O}_{3} / \mathrm{Fe}_{3} \mathrm{O}_{4}$ is considered to be a measure of the relative protective nature of the corrosion product and of the relative oxidizing potential of the feedwater. Values were obtained by $x$-ray diffraction. The crack-pit area refers to the corrosion pit at the origin of a major crack. The arrest bands and corrosion. craters are features along a crack length; these two features are usually related and they are discussed in detail in a subsequent section. The crack growth rate is an average rate based on operating life and crack depth of the major crack. It assumes that cracking initiated at the start of operation.

Definite trends with respect to either crack length, crack-growth rate, or operating life were found to exist only for arrest bands and corrosion craters present along the crack lengths, and these reflect cyclic events. Intersection angle and, to a lesser extent, corrosion pits and evidence of general cracking tendency exhibited limited trends between groups of plants (five or more). However, most of the factors evaluated showed randomness in their correlations. Our assumption that crack life and reactor plant life are the same must account for at least some of the randomness. Nevertheless, the lack of significant correlations with surface factors and corrosion factors does not imply that surface conditions and corrosion are unimportant but, rather, that they are not likely to be the main cause of the cracking problem and in particular for the differences in cracking tendency between different plants.

\subsection{CRACK MORPHOLOGY--LIGHT MICROSCOPY}

Figures $3.4,3.5$, and 3.6 contain the mounted sections, from all nine plants, that were used to examine the cracks by light microscopy. The surfaces viewed are parallel to the piping axis and wall thickness. The sections are arranged in the same sequence as listed in the tables, i.e., in chronological order of date of initial criticality. The major cracks are identified by arrows. Those that initiated either in the weld or the heat-affected zones are labeled $A$. The major crack in the piping is labeled $B$, and the major crack in the safe-end or nozzle is labeled $C$. Details of the major cracks are shown in the photomicrographs in Figs. 3.7 through 3.18. Again, the figures follow in chronological sequence. Several features may be pointed out. Some 
of the cracks contain numerous corrosion craters along their lengths which attest to periods of increased corrosion activity and/or reduced stress. This is especially true for the San Onofre (Fig. 3.7) and Palisades cracks (Figs. 3.10 through 3.12). These craters are present to a much lesser extent along the cracks from the remaining plants. We have listed in Appendix $C$, Table C.4, the relative extent of such corrosion craters along with other features.

It may be noted that in many cases corrosion spikes are seen at the bottom of the corrosion craters. This suggests that these spikes were initiated during periods of increased corrosion activity. They were likely propagated for short distances as cracks by the applied stresses; however, only the most favorable one with respect to orientation and sharpness continues to propagate as the main crack. The propagation of the main spike relaxes the stresses on the remaining spikes, and subsequently they probably grow primarily by corrosion. An example of such a process is most clearly suggested by Cracks $A$ and $C$ of Palisades (Figs. 3.10 and 3.12).

We alsolsee corrosion spikes along other parts of the various cracks. Some of them run essentially normal to the principal direction of crack propagation, and most of these can be related to the steel morphology (Table C.4). The as-polished section of Ginna in Fig. 3.8(b) shows several horizontal spikes growing along zones rich in inclusions. Some branching is evident in five of the plant sections (Table C.4), and it is most pronounced in the lower half of the Beaver Valley crack, Fig. 3.15(c). The branching in the other four plants is minor and is usually close to the crack tips. We distinguish between a crack (or crack branching) and a corrosion spike depending on whether its growth appears to have involved primarily crack propagation or primarily corrosion, respectively.

The branching near the crack tip in the Ginna section, Fig. 3.8(c), appears to be following ferrite grain boundaries. We also saw some indication of intergranular propagation of spikes (cracks) in the sections from Kewaunee, D. C. Cook, Beaver Valley, and Salem. Because of the widening of a crack by corrosion, it was difficult to identify the propagation path of some of the major cracks, e.g., San Onofre, Palisades, and Point Beach. Of the three spikes (cracks) at the crack tip of D. C. Cook, only the deepest one has propagated through a grain boundary, but it had terminated within a grain. Intergranular activity can also be seen in the branching of the D. C. Cook 
crack, Fig. 3.18(b). Based on observations made of other cracks or spikes in these sections, as well as of the remaining major cracks, we conclude that cracking is basically transgranular for all plants. Additional observations on corrosion, pits, and cracks in cross sections are presented in Appendix D. The observations described in this section favor the interpretation of CF over SCC as the primary mechanism of cracking with possible intermittent periods of accelerated corrosive activity. More definitive evidence for CF is described below for TEM replicas.

\subsection{CRACK MORPHOLOGY--FRACTOGRAPHY}

\subsubsection{Macrofractography}

Figures 3.19 through 3.23 contain the photomacrographs showing the morphology along the crack surfaces that had developed during the operation of the plants. The cracks were opened by fracturing in liquid nitrogen. The photographs and figures are arranged, as previously, in chronological order with respect to the date of criticality. Specimens from all plants, except those from D. C. Cook, showed arrest bands (or beach marks)* on the as-corroded, fractured crack surfaces. Arrest bands were also revealed on the D. C. Cook crack after cathodic cleaning. However, we noted that the clarity of the arrest bands was usually reduced when the crack surfaces of the remaining plants were similarly cleaned. The individual cracks are identified as in Figs. 3.4, 3.5, and 3.6.

Corrosion fatigue failures are frequently characterized by a combination of arrest bands or beach markings, often with relatively smooth surfaces. The bands or markings result from variations in exposure time, environmental

\footnotetext{
*The distinction between arrest bands and beach marks is minor here. The latter suggests conical bands radiating from some nucleating point, whereas nucleating points are not obvious in "parallel" arrest bands. Both are usually visible with the naked eye. We will refer to all these markings as arrest bands. In fatigue testing, conical bands, resulting from variations in. striation spacings due to repeated changes in fatigue loading, are often referred to as beach marks.
} 
conditions, and/or loading conditions. The smoothness may result from rubbing during opening and closing of the crack. In our examples, the surfaces are not smooth. This may be due to the type of cyclic loading, the geometric constraints, and/or most probably excessive corrosion. The cross-section examinations described earlier, indicate that these bands most likely correspond to periods of accelerated corrosion. These periods are also likely associated with periods of reduced stress, whether static or cyclic.

Several features may be pointed out from these fractographs; some of the observations are summarized in Table 3.4. The table also includes information on vibrations and water-hammer events recorded for the plants. As we indicated previously, there is a close 1 to 1 relationship between the ranking of the number of arrest bands and crack depth. The average number of bands per unit crack length or inversely the average distance of crack propagation per cyclic event varies by less than a factor of 2.2 for the different plants. This suggests that the number of these cyclic events appears to be a dominant factor and that, on the average, the damage caused by each event does not vary significantly from plant to plant. Additional comments on craters and arrest bands are presented in Appendix E; those comments suggest that craters and arrest bands are more likely associated with corrosion fatigue or stresscorrosion cracking than with stress-assisted corrosion.

If corrosion were to be an important factor in this cracking problem, then one may expect some optimum damaging combination of stress and corrosion, such that for a given stress, crack propagation is at a maximum at some intermediate state of corrosion activity. Blunting occurs at to high a corrosion rate, and crack tip dissolution rate is reduced at excessively low corrosion rates. In the few cases we examined, we found that there was no consistent evidence for this. For Palisades, the cracks along the pipe were less severely corroded than the usually larger cracks at the weld or along the safe-end (Figs. 3.10, $3.11,3.12,3.20$, and 3.21). For Kewaunee, little difference in corrosion is observed between the cracks (Figs. 3.14 and 3.22), one at the weld and one in the piping. For San Onofre, the deepest crack, which is at the weld, shows less corrosion than the shallower, but deepest, crack in the piping. Thus, in most of these cases, corrosion probably plays a minor role in the actual driving of the crack after it is once initiated. 


\subsubsection{Scanning Electron Microscopy}

Wavy structures with fatigue-like striations were observed on the as-corroded crack surfaces examined by scanning electron microscopy (SEM) . The only exception was for samples taken from the D. C. Cook elbow section containing the deep crack. The three most lucid examples are shown in Fig. 3.24(a) for cracks from H. B. Robinson; in Fig. 3.24 (b) for cracks from Beaver Valley; and in Fig. 3.24 (c) for a relatively shallow crack, $0.83 \mathrm{~mm}$ ( 0.033 in.) deep, from D. C. Cook. * These wavy striations are somewhat similar to the markings reported for high-cycle axial fatigue of a normalized 4340 steel. $^{4}$ Another type of example suggestive of cyclic behavior and one that was only seen for samples from Beaver Valley is shown in Fig. 3.25 (a) at the crack-tip surface and in Fig. $3.25(b)$ is at the center of the crack. Here the periodicity appears as a series of parallel ridges. Similar ridges were developed in a nitralloy steel under high-cycle bending fatigue. 5 Spacings

such as those for the above striations and ridges, $\sim 0.1$ to $1 \mu \mathrm{m}\left(4 \times 10^{-6}\right.$ to $40 \times 10^{-6}$ in.), would appear to be related to fatigue stresses; the wide spacings of the arrest bands seen at low magnifications are most likely related to other periodic or intermittent changes in operating conditions.

The arrest bands seen in the low magnification SEM views closely correspond to those shown using light macroscopy (Figs. 3.19 through 3.23). An example of an SEM fractograph is shown in Fig. 3.26 (a) for the crack from the Ginna section. Figure 3.26 (b) shows the extensive porosity at an arrest band close to the crack tip in the Ginna crack.

The most common feature of the crack surfaces was the corrosion nodules. Examples are shown in Figs. 3.27 and 3.28. The morphology of the nodules varied considerably across any given crack surface, and they could not be related to any specific location along the depth of the crack. Corrosion nodules and craters extended to the crack tip. Figure 3.29 illustrates this for crack surfaces from three plants; the fractographs were taken across the

*We received a number of sections from D. C. Cook at different times. The first section we received and examined contained a shallow crack. Unless specifically indicated, reference is made to the section containing the deep crack. 
interface between the laboratory fracture and the field crack in each case. The various types of nodules--globular, spongy, faceted--could be found on virtually all the surfaces. The as-corroded surface of the deep crack from D. C. Cook had a morphology that was distinctly different from that seen for the remaining plants. This surface was extensively covered with patches of red rust which, on the SEM, resembled mud cracks or crazing. The extent of such crazing decreased in traversing from crack origin to crack tip. It is likely that the corrosion product, although crystalline, is colloidal-like and results from a very fine distribution of nucleation sites; and if so, why such fine nucleation should be present only at this crack is not clear. Examples of the surfaces are shown in Fig. 3.30 (a) for the crack tip and in Fig. 3.30 (b) for the crack center. One can also see some corrosion nodules on top of the crazed surface; the concentration of such nodules generally increases toward the crack tip. The range of grain sizes produced by the crazing roughly corresponds to the range of ferrite grain sizes of the steel (Figs. 3.17 and 3.18). Figure 3.30 (c) is of an area where the surface had partially flaked off revealing corrosion nodules dispersed through the thickness of the crazed surface rust layer. The flaking also revealed a morphology of corrosion nodules typical of that seen on the other crack surfaces. This crazed surface is not present on the corresponding shallow crack from D. C. Cook shown in Fige. 3.24 and 3.27. We therefore question whether differences in corrosive activity from top to bottom of the piping may have contributed to corresponding differences in cracking tendencies. Evaporation at the fluid surface-piping boundaries during shutdown may have concentrated corrosive impurities at these boundaries. Also, the concentration of oxygen may be significantly greater above the fluid surface. It may be worthwhile to explore for variations in the corrosion product around the circumference (from 0 to 360 degrees).

To obtain more definitive evidence of fatigue striations, we cleaned and then reexamined some of the crack surfaces. The surfaces were cathodically cleaned using the solution recommended for removal of iron-oxide scales. ${ }^{3}$ striations were more frequently and more clearly observed on the cleaned surfaces, however, many of these striations could be related to the steel pearlite spacing. Preferential attack of either the carbide or ferrite phase of the pearlite can readily occur under certain conditions, depending upon the corrodant. 6 The morphologies we observed on the cleaned surfaces are similar to those reported for corroded pearlite. ${ }^{6}$ The detailed evaluation, comparing 
the SEM "striations" with the pearlite structure, is presented in Appendix F. As a result of the uncertainty in attributing these SEM markings, unequivocally, to cyclic events, we discontinued the use of SEM to identify striations on cleaned crack surfaces. Instead we continued this evaluation using TEM which provides finer details of the metal surface.

\subsubsection{Transmission Electron Microscopy}

The only definitive evidence of high-cycle fatigue was obtained by transmission electron microscopy (TEM) for replicas of cathodically cleaned crack tips. Classical fatigue striations were observed for D. C. Cook; indications of fatigue striations were seen for H. B. Robinson and Kewaunee and possibly for Ginna. Observations by TEM on the remaining five plants did not give any indications of fatique.

Figure 3.31 contains TEM fractographs of three areas at the crack tip for D. C. Cook, each at two magnifications. Figures 3.31 (a) and 3.31 (b) show classical fatigue striations running roughly perpendicular to the direction of crack propagation, which is indicated by the arrows. The crack tip was profuse with such markings. Figure $3.31(c)$, also at the crack tip, is of a typical pearlite colony. Figure 3.32 contains TEM fractographs taken at about $1.6 \mathrm{~mm}$ (0.06 in.) from the crack origin. We noted areas having faceted surfaces intermixed with the more commonly seen corroded and striated morphologies. Figure $3.32(a)$ contains both types of morphology. Figure 3.32 (b) is of a faceted region containing well-defined pearlite areas. The facets are possibly due to some intergranular cracking. We see fine striations nn nne of the facets at the top of Fiq. $3.32(\mathrm{~b})$ at $5000 \mathrm{x}$, suggesting intergranular fatigue. Figure $3.32(\mathrm{c})$, typical of the cleaned "corroded" surface, shows markings that might be interpreted either as fatigue striations or pearlite; they are, however, predominately oriented normal to the direction of crack propagation. We were able to relate the faceted areas to the light etching patches shown in the corresponding macrograph in Fig. 3.23(d). Such patches can also be seen in the macrographs of other fractures. However, we only examined the crack tip region of the remaining cracks, and we did not encounter such faceted areas in any of these regions. We reexamined the cross section of the D. C. Cook crack in the region below the crack origin, corresponding to Fig. 3.32. We noted several spikes or branch cracks that had 
propagated through one or more grain boundaries. But, it appears that such boundaries fall along the path of a normal transgranular failure mode. This behavior is seen in Fig. 3.33. The tip, which had just propagated through a grain, has terminated at a grain boundary, but without any change in direction.

Figure 3.34 contains TEM fractographs typical of replicas from the cathodically cleaned crack tips from H. B. Robinson, Kewaunee, and Ginna. Indications of fatigue behavior decrease in this order. Figures $3.34(a)$ and 3.34(b) show numerous parallel striations that are appropriately oriented relative to the direction of crack propagation and these are most likely fatigue markings. Others, such as at the upper left-hand corner of Fig. 3.34(a), are likely to be pearlite. At the other extreme, the conical markings in the center of Fig. $3.34(\mathrm{e})$ may be fatigue striations. The top, center-right, of Fig. 3.34 (f) shows some fine striations that do not appear to be related to pearlite and suggest fatigue. Most other striations in this view are likely to be pearlite.

Figure 3.35 contains TEM fractographs typical of the replicas of the cleaned crack tips from each of the remaining plants: San Onofre, Palisades, Point Beach, Beaver Valley, and Salem. The TEM observations on fatigue striations are included in Table 3.4. There was no indication of fatigue striations in any of these replicas; some pearlite could be detected. Although wavy fatigue striations were most clearly seen on the as-corroded crack surfaces for Beaver Valley and H. B. Robinson, fatigue markings on replicas of cleaned surfaces were only seen for the deep crack from the D. C. Cook section.

The role of corrosion in completely obliterating fatigue markings is not too clear. Certainly, D. C. Cook, with the least degree of corrosion cratering showed the most definitive evidence of fatigue striations. H. B. Robinson was ranked next in corrosion craters (Table C.4), and it also followed next for evidence of fatigue; however, the next two, Kewaunee and Ginna, are out of line in comparing their relative ranking of corrosion craters with fatigue markings. If the indication of fatigue markings is compared to the ranking based on crack-tip sharpness, the role of corrosion becomes even more confusing; e.g., D. C. Cook is ranked in the middle. Thus, we cannot unequivocally state that excessive corrosion had obliterated evidence of fatigue markings in these cases where none were observed and where corrosion was relatively extensive. 


\subsection{ANALYSES OF CORROSION PRODUCTS}

\subsubsection{X-Ray Diffraction}

Diffraction patterns for crystal structure determinations were obtained on a Norelco diffractometer using a diffraction scan rate of 1 degree of $2 \theta$ per min over a range of $2 \theta$ from 12 to 135 degrees. Patterns were obtained on nine samples measuring 10 by $10 \mathrm{~mm}$ ( 0.4 by $0.4 \mathrm{in.})$, one from each plant. Figure 3.36 is an example of a typical pattern, which was obtained for the sample from Beaver Valley. Copper radiation, at $50 \mathrm{kV}$ and $30 \mathrm{~mA}$, was used. Peaks for $\mathrm{Fe}_{3} \mathrm{O}_{4}$ ( $m$, magnetite), $\mathrm{Fe}_{2} \mathrm{O}_{3}$ (h, hematite), and $\mathrm{Fe}$ ( $\alpha$, alpha ferrite phase) are indicated. Several trace peaks that could not be identified are also present. Unidentified trace peaks were seen in all patterns; for the Palisades sample, one of these lines coincided with the major line for $\mathrm{Cu}_{\mathrm{x}} \mathrm{s}$. The $\alpha-\mathrm{Fe}$ lines were present on all patterns indicating that the entire thickness of the corrosion layer was sampled in each case.

The lattice constant, $a_{0}$, for $\mathrm{Fe}_{3} \mathrm{O}_{4}$ is given as $0.83967 \mathrm{~nm}(8.3967 \mathrm{~A})$. Table 3.5 lists the lattice constant of the corrosion product, $a_{0}(\operatorname{cor} r)$, based on the $\mathrm{Fe}_{3} \mathrm{O}_{4}$ structure and the standard deviation. If the difference between the two $a_{0}$ values is greater than the standard deviation, then the lattice has been either expanded or contracted due to solid solution of other elements. However, a difference less than the deviation does not preclude the presence of other elements, since elements may be in solid solution that have opposing dimensional effects. On this basis, we see from Table 3.5 that foreign elements are present in the $\mathrm{Fe}_{3} \mathrm{O}_{4}$ lattice in at least five of the plants (Ginna, H. B. Robinson, Kewaunee, Palisades, and Beaver Valley). We calculated the ratios of $\mathrm{Fe}_{2} \mathrm{O}_{3}$ to $\mathrm{Fe}_{3} \mathrm{O}_{4}$ for all plants in terms of their relative peak heights of their strongest lines and these values were plotted versus crack lengths. (See Flgs. C.3 and C.4 in Appendix C.) 'The $\mathrm{Fe}_{2} \mathrm{U}_{3}$ is usually less protective than is $\mathrm{Fe}_{3} \mathrm{O}_{4}$; the former oxide also indicates the presence of a higher oxygen potential in the feedwater. But, only a limited trend was seen between crack depth of the major crack and oxide ratio (Appendix $C$ ). The presence of impurities in the iron oxide lattices may affect the degree to which these oxides are protective. ${ }^{7}$ Temperature cycling could crack the oxide layers and destroy 
their protective nature and thereby minimize any related differences expected in their behavior. Finally, $\mathrm{Fe}_{3} \mathrm{O}_{4}$ readily oxidizes to $\mathrm{Fe}_{2} \mathrm{O}_{3}$ in air, and any surface changes of the oxide during handling of the piping will have affected our observations. Lattice constants were also determined for the $\mathrm{Fe}_{2} \mathrm{O}_{3}$ structure of the corrosion product from D. C. Cook. The results are included in Table 3.5. Although the difference in the $a_{0}$ values is less than the standard deviation, that for $c_{0}$ is greater and indicates solid solution in the $\mathrm{Fe}_{2} \mathrm{O}_{3}$ lattice.

\subsubsection{Energy Dispersive System for} $\underline{X-R a y ~ E l e m e n t a l ~ A n a l y s i s ~}$

We used the energy dispersive system (EDS) attachment on the SEM to obtain elemental $x$-ray spectra of numerous regions along the as-corroded crack surfaces that were fractured in the laboratory. Table 3.6 lists the elements that we detected; $\mathrm{Fe}$ and traces of $\mathrm{Mn}$ were always present, and these are not included in the table. The spot mode was usually required to detect elements other than Fe. In a few cases, $\mathrm{Si}, \mathrm{Cu}$, and $\mathrm{S}$ were observed using the scan mode. Scan modes were typically made from $2 \mathrm{~K}$ to $10 \mathrm{~K}$ magnifications. The total effort probably represents taking some 500 spectra on 2 to 4 crack surfaces from cach plant. Wo found that, in general, the elements were unrelated to the morphology of the corrosion nodules. The presence of any of these elements was frequently localized to a few isolated areas on a given surface, and their detection was usually by chance and certainly by perseverance. Thus, the absence in Table 3.6 of an element does not necessarily imply that it is not present on a given crack surface. We especially concentrated along the crack tips, but we usually found that most of the elements were more often detected away from the crack tip, toward the crack origin. The presence of only small or trace quantities of these elements and in only very isolated regions (spots) is consistent with finding only the $\mathrm{Fe}_{3} \mathrm{O}_{4}$ and $\mathrm{Fe}_{2} \mathrm{O}_{3}$ crystal structures. We attempted to relate the information in Table 3.6 to the various factors listed in the previous tables, and we were unsuccessful in uncovering any systematic trends. The following figures are examples of EDS spectra from some of the crack surfaces. Figure 3.37 shows an area near the crack origin on a Palisades crack that had a wide range of spectra. The spots are identified in F1g. 3.37 (a) and 
at a higher magnification again in Figs. $3.37(\mathrm{~b}), 3.37(\mathrm{c})$, and $3.37(\mathrm{~d})$. The corresponding spectra are shown in Fig. 3.38. Both spots 1 and 6 consist of very similar faceted corrosion nodules. However, spot 6 indicates primarily Fe with only a trace of $\mathrm{Cu}$ and $\mathrm{S}$. By contrast, spot $\mathrm{l}$ shows mainly $\mathrm{Cu}$ and $\mathrm{S}$ and, in fact, is similar to the spectra from spot 5. Yet, the morphology of the corrosion nodules is quite different at 1 and 5 . We noted that $\mathrm{Cu}$ and $\mathrm{S}$, and at times $\mathrm{Ni}$ and $\mathrm{S}$, were usually present together, suggesting $\mathrm{Cu}_{x} \mathrm{~S}$ or $\mathrm{Ni}_{x} \mathrm{~S}$ deposits. The $\mathrm{Cu}$ and $\mathrm{Ni}$ probably originate from the tube wastage in the Monel condensers. Wastage of the Inconel 600 heat exchanger tubing in the steam generators can result in deposits containing $\mathrm{Al}, \mathrm{Cr}, \mathrm{Ni}, \mathrm{Si}, \mathrm{P}, \mathrm{Cu}$, and $\mathrm{Mn}$. The $\mathrm{Cr}$ and $\mathrm{Ni}$ could also originate from alloy steel components such as the safe-end or nozzle. Sulfur was detected on crack surfaces for all plants and it likely originated from the steel piping.

Figure 3.39 (a) shows a region containing a high concentration of $\mathrm{Si}$ in the center of the crack surface from Salem. Strong Si lines were obtained in both the scan, Fig. 3.39(b), and spot, Fig. 3.39(c) modes. The Si, which was present in all plants, may here be the residue of a silicate slag particle in the steel. The presence of $S i$ and $S$ at a crack tip of Palisades is shown in Fig. 3.40. Here, these elements could only be detected in the spot mode.

Figure 3.41 shows the spectra obtained from a number of spots in an area containing "spongy" corrosion nodules on a crack surface from Ginna. A number of elements are detected, $\mathrm{Cu}, \mathrm{Ni}, \mathrm{Fe}, \mathrm{Cr}, \mathrm{Ti}, \mathrm{Ca}$, and $\mathrm{Si}$; however, $\mathrm{S}$ was not present in this area, despite the presence of $\mathrm{Cu}$ and $\mathrm{Ni}$. Although the morphology of the corrosion nodules was virtually constant, the spectra were quite different from point to point in this small area. Another example of a high concentration of elements in a small area is shown in Fig. 3.42 for a crack surface from Beaver Valley. In addition to the elements listed above, $\mathrm{Na}, \mathrm{Mg}, \mathrm{Al}, \mathrm{P}, \mathrm{K}$, and $\mathrm{Cl}$ are present. The presence of the strong $\mathrm{Cl}$ line as well as the $\mathrm{Na}$ and $\mathrm{K}$ lines suggests the possibility of contamination; however, we were careful in the handling of these fractographic samples to avoid such contamination. Nonetheless, $\mathrm{Cl}$ could only be detected in these two areas, which were close to the crack origin.

We wish to emphasize again that, by far, the majority of spectra we saw along all the crack surfaces contained only the Fe lines (with usually a trace of $M(\mathrm{n})$. The disposition of all the various contaminating elements was indeed very spotty and highly localized. The presence of virtually only $\mathrm{Fe}_{2} \mathrm{O}_{3}$ 
and $\mathrm{Fe}_{3} \mathrm{O}_{4}$ with some solid solution is consistent with this observation. If any of the detected elements, such as $\mathrm{Cu}$, is in one of its higher states of oxidation while in the feedwater, it could contribute to the corrosion activity. Also, elements (ions) more noble than Fe could be reduced by the Fe. It is well known that only traces of $\mathrm{Cl}$ will induce or accelerate $\mathrm{CF}$ and sCC. However, we believe that the contribution of these contaminating elements to the current cracking problem is likely to be minor.

\subsubsection{Electron Microprobe Analyses}

We noted that some of the pits at the origin of large cracks contained distinct layers of corrosion product, e.g., the Palisades section. We therefore considered making traverses across such pits using electron microprobe analyses (EMA) to determine elemental distribution. We used a microprobe with a beam size of $1 \mu \mathrm{m}\left(40 \times 10^{-6}\right.$ in. $)$ diameter with 10 -second sampling counts at $10-\mu \mathrm{m}\left(400 \times 10^{-6}\right.$ in. $)$ intervals.

We selected one of the large pits along the counterbore slope of the safeend of the Palisades section. We obtained analyses along 40 spots in the pit section and at least four spots on each side of the pit into the steel. We analyzed for nine elements in groups of three as follows: ( $\mathrm{Cl}, \mathrm{P}$, and $\mathrm{Fe}$ ), $(\Lambda l, S i$, and $C r)$, and $(S, N i$, and $C u$ ). The results are plotted in Figs. 3.43, 3.44 and 3.45, respectively, for each of these groups. The pit boundaries for the first series are indicated by the drop (98 to 63 percent) and rise (63.to 98 percent), respectively, in the Fe content; for the third series they are indicated by the rise $(0.04$ to 0.4 percent) and drop ( 0.5 to 0.04 percent), respectively, of the $S$ content. The boundaries are not clearly defined in the second series.

Trace quantities of $\mathrm{Cl}$ are indicated; the fluctuations are less than the stability of the system. However, the appearance of $\mathrm{cl}$ in the original steel suggests the possibility of contamination in either preparing or examining the specimen.

The amounts of $\mathrm{Fe}$ in $\mathrm{Fe}_{3} \mathrm{O}_{4}$ and $\mathrm{Fe}_{2} \mathrm{O}_{3}$, which were virtually the only constituents (crystal structures) detected on the i.d. surface by $x-r a y$ diffraction, are 72.4 and 69.9 percent, by weight, respectively. An Fe level of $\sim 63$ percent is indicated in the pit. Substitution of $F e$ in the oxide lattices by elements such as $\mathrm{Cr}, \mathrm{Ni}$, and cu may account for some of this 
discrepancy. Another alternative may be that the hydroxide is present in the pit in that the dissolved Fe usually first hydrolyzes to $\mathrm{Fe}(\mathrm{OH})_{2}$ or $\mathrm{Fe}(\mathrm{OH})_{3}$ prior to forming the more stable $\mathrm{Fe}_{3} \mathrm{O}_{4}$ or $\mathrm{Fe}_{2} \mathrm{O}_{3}$. The corresponding $\mathrm{Fe}$ contents for the hydroxides are 62.2 and 52.3 percent, respectively. This could have been verified by $x$-ray diffraction, but we did not attempt to do this. The ASTM specification for A508-1, the safe-end material, lists the following compositional limitations in weight percent: S- $0.025 \max , \mathrm{P}--0.025$ max, Si--0.15 to $0.40, \mathrm{Ni}--0.40 \mathrm{max}, \mathrm{Cr}-0.25 \mathrm{max}$. The $\mathrm{Cu}$ and $\mathrm{Al}$ limits are not specified. The $P$ level in the steel was within the 0.025 percent limit with levels significantly above the value in the corrosion product, up to 0.1 percent. The $S$ in the steel was between 0.033 and 0.046 percent, somewhat above the specified limits, and rose to as high as 0.64 percent in the corrosion product. The $\mathrm{Si}$ content in the steel appears to be on the low side of the specifications. Except for one high spot of 1.2 percent, the Si content in the corrosion product does not depart significantly from the steel Si content. The high Si spot also corresponds to the spot for the only high Al content and suggests the residual of an aluminum-silicate steel inclusion. The $\mathrm{Cr}$ and $\mathrm{Ni}$ contents are within specifications, and continue essentially unchanged into the corrosion product with slight fluctuations. Except for several peaks, the $\mathrm{Cu}$ content in the corrosion product is, on the average, close to that shown in the steel. A peak value of 0.89 percent Cu also corresponds to where one of the $S$ peaks occurs, suggesting $\mathrm{Cu}_{\mathbf{x}} \mathrm{s}$.

If all elements from the steel were retained in place during corrosion, then, due to the addition of the corroding species from the feedwater, the relative quantity of each of these elements should decrease; e.g.. $\mathrm{Fe}$ in $\mathrm{Fe}_{3} \mathrm{O}_{4}$ versus $\mathrm{Fe}$ in steel. The increase in $\mathrm{P}, \mathrm{S}$, and $\mathrm{Cu}$ in the corrosion product over that present in the steel indicates that some of each of these elements were deposited from the feedwater. Nickel, $\mathrm{Cr}$, and $\mathrm{Al}$ would appear to originate essentially from the steel. The question of $\mathrm{Ni}$ and $\mathrm{Cr}$ would have been less ambiquous if we had selected a pit in the Al06-B piping. Nur rhnire was because the corrosion zones were most prominent in the weld and safe-end pits. Finally, we were unable to correlate any of the elemental fluctuations with the corrosion zones in the corresponding pit. Although the results did indicate that a number of elements (other than $O$ or $\mathrm{Cl}$ ) likely originated from the feedwater, we felt that the contribution to solving the cracking problem by examining additional pits was likely to be minimal, and the effort was discontinued. 
TABLE 3.1. Location and depths of major cracks.

\begin{tabular}{|c|c|c|c|c|c|c|c|}
\hline \multirow[b]{2}{*}{ Reactor plant } & \multicolumn{3}{|c|}{$\begin{array}{l}\text { Max. crack depth } \\
\text { in total section }\end{array}$} & \multirow{2}{*}{$\begin{array}{c}\text { Location of } \\
\text { deepest crack }\end{array}$} & \multicolumn{3}{|c|}{$\begin{array}{l}\text { Max. crack depth } \\
\text { in piping only }\end{array}$} \\
\hline & $\operatorname{mm}$ & in. & Rank & & $\mathrm{mm}$ & in. & Rank \\
\hline San Onofre & 1.75 & 0.069 & 5 & In weld & 1.01 & 0.040 & 3 \\
\hline Ginna & 2.20 & 0.087 & 6 & Counter bore- $\mathrm{D}^{\mathrm{b}}$ & 2.20 & 0.087 & 6 \\
\hline H. B. Robinson-2 & 0.70 & 0.028 & 1 & Counterbore-D & 0.79 & 0.028 & 1 \\
\hline Palisades & 4.40 & 0.173 & 8 & Weld-Interface ${ }^{C}$ & 2.43 & 0.096 & 8 \\
\hline Point Beach-2 & 1.40 & 0.055 & 4 & Counterbore-D & 1.40 & 0.055 & 5 \\
\hline Kewaunee-2 & 1.00 & 0.039 & 2 & Weld-Interface ${ }^{d}$ & 0.90 & 0.035 & 2 \\
\hline Beaver Valley-1 & 1.10 & 0.043 & 3 & Counterbore-D & 1.10 & 0.043 & 4 \\
\hline salem-1 & 2.30 & 0.091 & 7 & Counter bore-D & 2.30 & 0.091 & 7 \\
\hline D. C. Cook-2 & 8.80 & 0.346 & 9 & Counter bore-s ${ }^{e}$ & 8.80 & 0.346 & 9 \\
\hline
\end{tabular}

axcludes weld or heat-affected zones.

${ }^{b} \mathrm{D}$ refers to discontinuity at the bottom of the counterbore slope.

${ }^{C}$ Crack initiated in weld adjacent to piping.

${ }^{d}$ Crack initiated in piping adjacent to weld.

${ }^{e} s$ refers to bottom of counterbore slope, but $0.5 \mathrm{~mm}(0.02 \mathrm{in.})$ above discontinuity. 
TABLE 3.2. Total number of cracks and spikes along inside diameter surface.

\begin{tabular}{|c|c|c|c|c|c|c|c|c|c|c|}
\hline \multirow[b]{3}{*}{$\begin{array}{l}\text { Reactor } \\
\text { plant }\end{array}$} & \multicolumn{9}{|c|}{ Number of cracks and spikes at indicated crack depths } & \multirow{3}{*}{$\begin{array}{c}\text { Cracking } \\
\text { tendency } \\
\text { ranking }\end{array}$} \\
\hline & \multicolumn{3}{|c|}{ Piping counter bore } & \multicolumn{3}{|c|}{ Weld or weld interface } & \multicolumn{3}{|c|}{ Nozzle or safe-end (inlet) } & \\
\hline & $\begin{array}{l}<0.25 \mathrm{~mm} \\
(<0.010 \mathrm{in.})\end{array}$ & $\begin{array}{l}0.25 \text { to } 0.99 \mathrm{~mm} \\
(0.010 \text { to } 0.039 \mathrm{in.})\end{array}$ & $\begin{array}{l}\geq 1.00 \mathrm{~mm} \\
(\geq 0.039 \mathrm{in} .:\end{array}$ & $<0.25 \mathrm{~mm}$ & $\begin{array}{l}0.25 \text { to } \\
0.99 \mathrm{~mm}\end{array}$ & $\geq 1.00 \mathrm{~mm}$ & $<0.25 \mathrm{~mm}$ & $\begin{array}{l}0.25 \text { to } \\
0.99 \mathrm{~mm}\end{array}$ & $\geq 1.00 \mathrm{~mm}$ & \\
\hline $\begin{array}{l}\text { San } \\
\text { Onofre }\end{array}$ & $\begin{array}{l}3(0.14)^{a} \\
(22.2 \mathrm{~mm})^{b}\end{array}$ & $22(0.99)$ & $1(0.35)$ & $\begin{array}{l}1(0.09) \\
(11.7 \mathrm{~mm})\end{array}$ & $2(0.17)$ & $5(0.43)$ & 0 & $\begin{array}{l}10(0.40) \\
(25.2 \mathrm{~mm}\end{array}$ & $d^{1(0.04)}$ & 8 \\
\hline Ginna & $\begin{array}{l}29(1.09) \\
(26.7 \mathrm{~mm})\end{array}$ & $26(0.97)$ & $1(0.34)$ & -- & -- & -- & -- & -- & -- & 7 \\
\hline $\begin{array}{l}\text { H. B. } \\
\text { Robinson-2 }\end{array}$ & $\begin{array}{l}4(0.10) \\
(40 \mathrm{~mm})\end{array}$ & $1(0.03)$ & 0 & -- & -- & -- & -- & -- & -- & 3 \\
\hline Palisades & $\begin{array}{l}6(0.49) \\
(12.2 \mathrm{~mm})\end{array}$ & $5(0.41)$ & $4(0.33)$ & $\begin{array}{l}1(0.18) \\
(5.5 \mathrm{~mm})\end{array}$ & 0 & $3(0.55)$ & $\begin{array}{l}4(0.11) \\
(36 \mathrm{mn})\end{array}$ & $9(0.25)$ & $9(0.25)$ & 9 \\
\hline $\begin{array}{l}\text { Point } \\
\text { Beach-2 }\end{array}$ & $\begin{array}{l}2(0.05) \\
(42 \mathrm{~mm})\end{array}$ & $4(0.10)$ & $1(0.102)$ & $\begin{array}{c}0 \\
(2.0 \mathrm{~mm})\end{array}$ & 0 & 0 & -- & -- & -- & 4 \\
\hline Kewaunee-2 & $\begin{array}{l}46(2.84) \\
-(16.2 \mathrm{~mm})\end{array}$ & $3(0.19)$ & 0 & $\begin{array}{c}0 \\
(6.0 \mathrm{~mm})\end{array}$ & $1(0.17)$ & $1(0.17)$ & $\begin{array}{l}4(1.6) \\
(2.5 \mathrm{~mm})\end{array}$ & $1(0.40)$ & 0 & 5 \\
\hline $\begin{array}{l}\text { Beaver } \\
\text { Valley-1 }\end{array}$ & $\begin{array}{l}1(0.04) \\
(28 \mathrm{~mm})\end{array}$ & 0 & $1(0.04)$ & -- & -- & -- & -- & $\therefore$ & -- & 2 \\
\hline Salem-1 & $\begin{array}{c}0 \\
(12.5 \mathrm{~mm})\end{array}$ & $7(0.56)$ & $2(0.16)$ & -- & -- & -- & -- & -- & -- & 6 \\
\hline $\begin{array}{l}\text { D. C. } \\
\text { Cook-2 }\end{array}$ & $\begin{array}{c}0 \\
(24.5 \mathrm{~mm})\end{array}$ & 0 & $1(0.04)$ & -- & -- & -- & -- & -- & -- & 1 \\
\hline
\end{tabular}

${ }^{a}$ Numbers in parentheses refer to number per mm length of cross-section surface traversed.

bistance along piping counterbore where counts taken.

${ }^{C_{D i s t a n c e}}$ along weld where counts taken.

${ }^{d}$ Distance along inlet (nozzle or safe-end) where counts tak.ken. 
TABLE 3.3. Summary of attempted correlations of various factors with crack depth, crack-growth rate, and reactor plant life. ${ }^{a}$

\begin{tabular}{|c|c|c|c|}
\hline Correlating factor & $\begin{array}{c}\text { No } \\
\text { correlation }\end{array}$ & $\begin{array}{l}\text { Limi ted } \\
\text { trend }\end{array}$ & $\begin{array}{c}\text { Definite } \\
\text { trend }\end{array}$ \\
\hline Intersection angle & -- & $3 c$ & -- \\
\hline Machining grooves & $3 c$ & -- & -- \\
\hline Surface appearance & $2 a, 3 c$ & -- & -- \\
\hline Oxide ratio, $\mathrm{Fe}_{2} \mathrm{O}_{3} / \mathrm{Fe}_{3} \mathrm{O}_{4}$ & $3 b$ & $3 a$ & -- \\
\hline Operating life & $1 c$ & -- & -- \\
\hline General pitting & -- & $1 c, 2 a$ & -- \\
\hline General cracking tendency & -- & $1 c, 2 a$ & -- \\
\hline Crack pit area & $1 b, 2 a$ & la & -- \\
\hline Arrest bands & -- & -- & $1 a$ \\
\hline Corrosion along major crack & lc & -- & -- \\
\hline Craters along major crack & -- & la & $2 a$ \\
\hline Spikes along major crack & $1 a$ & -- & -- \\
\hline Crack-tip sharpness & $1 a$ & -- & $\cdot--$ \\
\hline \multicolumn{4}{|c|}{$\begin{array}{l}a_{1}=\text { Relative to crack depth } \\
2=\text { Relative to reactor plant life } \\
3=\text { Relative to estimated, normalized crack growth rate } \\
a=\text { Relative to total section only } \\
b=\text { Relative to piping section only } \\
c=\text { Relative to both a and } b \text { (total and piping). }\end{array}$} \\
\hline
\end{tabular}


TABLE 3.4. Evaluation and ranking relative to cyclic events.

\begin{tabular}{|c|c|c|c|c|c|c|c|c|}
\hline \multirow{3}{*}{$\begin{array}{l}\text { Reactor } \\
\text { plant }\end{array}$} & \multirow{3}{*}{$\begin{array}{l}\text { Reported } \\
\text { vibrations }\end{array}$} & \multirow{3}{*}{$\begin{array}{c}\text { Reported } \\
\text { water } \\
\text { hamers }\end{array}$} & \multicolumn{5}{|c|}{ Arrest Bands ${ }^{a}$} & \multirow{3}{*}{$\begin{array}{l}\text { TEM evidence } \\
\text { of fatigue } \\
\text { striations }\end{array}$} \\
\hline & & & \multicolumn{2}{|c|}{ Total number } & \multirow{2}{*}{$\begin{array}{l}\text { Clarity } \\
\text { Ranking }\end{array}$} & \multicolumn{2}{|c|}{ Number bands per } & \\
\hline & & & Number ${ }^{b}$ & Ranking & & $\operatorname{mm}$ & in. & \\
\hline San Onofre & $?$ & 2 & 8 & 5 & 7 & 4.6 & 116 & None \\
\hline Ginna & Number & 2 & $=2$ & 7 & 8 & 5.5 & 138 & Questionable \\
\hline H. B. Robinson-2 & $?$ & $?$ & 4 & 2 & 2 & 5.7 & 143 & $\begin{array}{l}\text { Moderately } \\
\text { strong }\end{array}$ \\
\hline Palisades & None & Wone & 22 & 8 & 9 & 5.0 & 127 & None \\
\hline Point Beach-2 & None & None & 7 & 4 & 5 & 5.0 & 127 & None \\
\hline Kewaunee-2 & 1 large & Wone & 4 & 3 & 6 & 4.0 & 103 & Moderate \\
\hline Beaver Valley-1 & $\begin{array}{l}2 \text { small } \\
1 \text { large }\end{array}$ & $?$ & 3 & 1 & 4 & 2.7 & 70 & None \\
\hline Salem-1 & $?$ & $?$ & $=0$ & 6 & 3 & 4.3 & 110 & None \\
\hline D. C. $\mathrm{C} \infty \mathrm{O} k-2$ & None & $\mathbf{L}$ & 26 & 9 & 1 & 3.0 & 75 & Strong \\
\hline
\end{tabular}

When more than one crack exist:s in a section, the deepest crack observed is used.

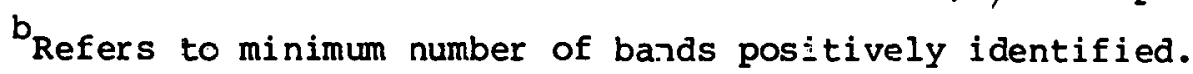


TABLE 3.5. Lattice constants and their deviations from literature values for the $\mathrm{Fe}_{3} \mathrm{O}_{4}$ and $\mathrm{Fe}_{2} \mathrm{O}_{3}$ structures.

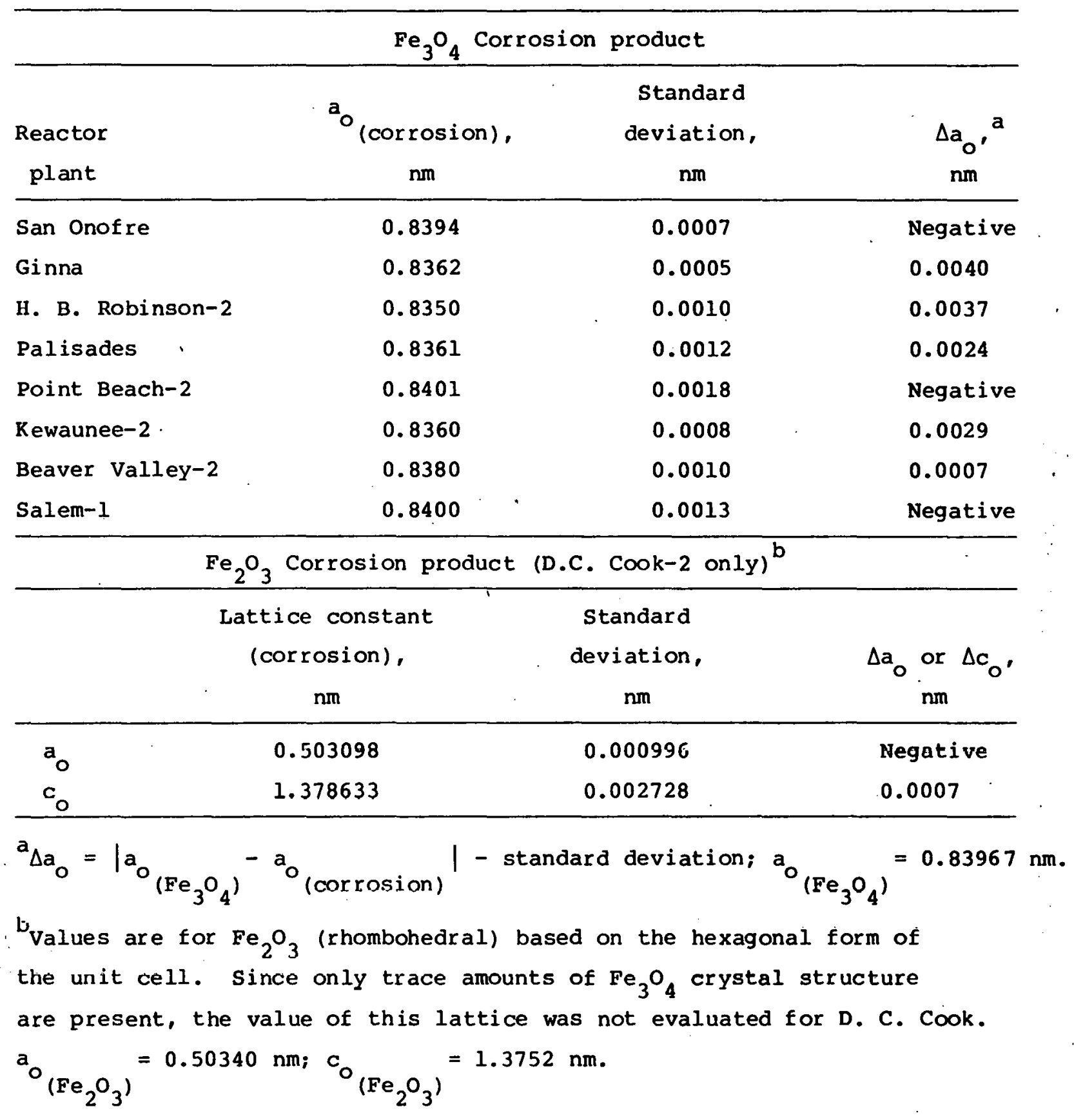


TABLE 3.6. Elements detected on as-corroded crack surfaces by EDS.

\begin{tabular}{|c|c|c|c|c|c|c|c|c|c|c|c|c|c|c|}
\hline \multirow{2}{*}{$\begin{array}{c}\text { Reactor } \\
\text { plant }\end{array}$} & \multicolumn{14}{|c|}{ Elements detected ${ }^{a, b}$} \\
\hline & $\mathrm{Na}$ & $\mathbf{M g}$ & Al & Si & $\mathbf{P}$ & $\mathbf{s}$ & $\mathrm{Cl}$ & $\mathrm{k}$ & $\mathrm{Ca}$ & $\mathrm{Ti}$ & $\mathrm{Cr}$ & $\mathrm{Ni}$ & $\mathrm{Cu}$ & $\mathrm{Zn}$ \\
\hline San Onofre & $\mathrm{VW}$ & - & -- & VW & -- & $\operatorname{Tr}$ & -- & -- & -- & -- & -- & -- & $\mathbf{M}$ & -- \\
\hline Ginna & -- & - & -- & $w$ & -- & $\mathbf{S}$ & -- & -- & $M$ & $w$ & $\mathrm{~W}$ & $\mathrm{~W}$ & $\mathbf{s}$ & -- \\
\hline H. B. Robinsor-2 & -- & - & $\operatorname{Tr}$ & $\operatorname{Tr}$ & -- & $\operatorname{Tr}$ & - & -- & -- & -- & -- & -- & -- & -- \\
\hline Palisades & -- & -- & $\operatorname{Tr}$ & $\mathbf{s}$ & $\mathrm{W}$ & $\mathbf{S}$ & -- & -- & -- & -- & $\mathrm{W}$ & $\mathrm{W}$ & $\mathbf{s}$ & -- \\
\hline Point Beach-2 & -- & -- & -- & $\operatorname{Tr}$ & - & $\mathbf{s}$ & - & -- & -- & -- & -- & -- & $\mathbf{s}$ & -- \\
\hline Kewaunee-2 & -- & - & vw & $\mathrm{W}$ & -- & $\mathbf{s}$ & VW & $\operatorname{Tr}$ & Vw & -- & -- & $w$ & $\mathbf{s}$ & vw \\
\hline Beaver Valley-l & $\operatorname{Tr}$ & lw & w & $\mathbf{s}$ & $\mathrm{VW}$ & $\mathbf{W}$ & $\mathbf{s}$ & $\mathbf{M}$ & $\mathbf{s}$ & $\operatorname{Tr}$ & $\mathbf{W}$ & $\operatorname{Tr}$ & -- & -- \\
\hline Salem-1 & -- & -- & $\mathrm{W}$ & $\mathbf{s}$ & -- & $W$ & -- & Vw & -- & -- & -- & -- & -- & - \\
\hline D. C. CoOk-2 & - & -- & $\operatorname{Tr}$ & $\operatorname{Tr}$ & -- & $\mathrm{W}$ & - & -- & -- & -- & -- & -- & -- & -- \\
\hline
\end{tabular}

$a_{F e}$ and $\dot{M}$ not included. Strong $F e$ peaks and $V W$ or $T r$ amounts of $M n$ present on all crack surfaces.

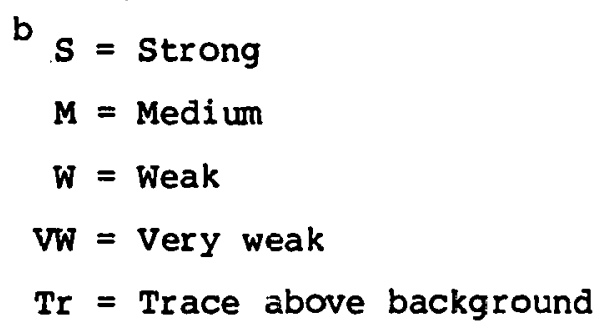




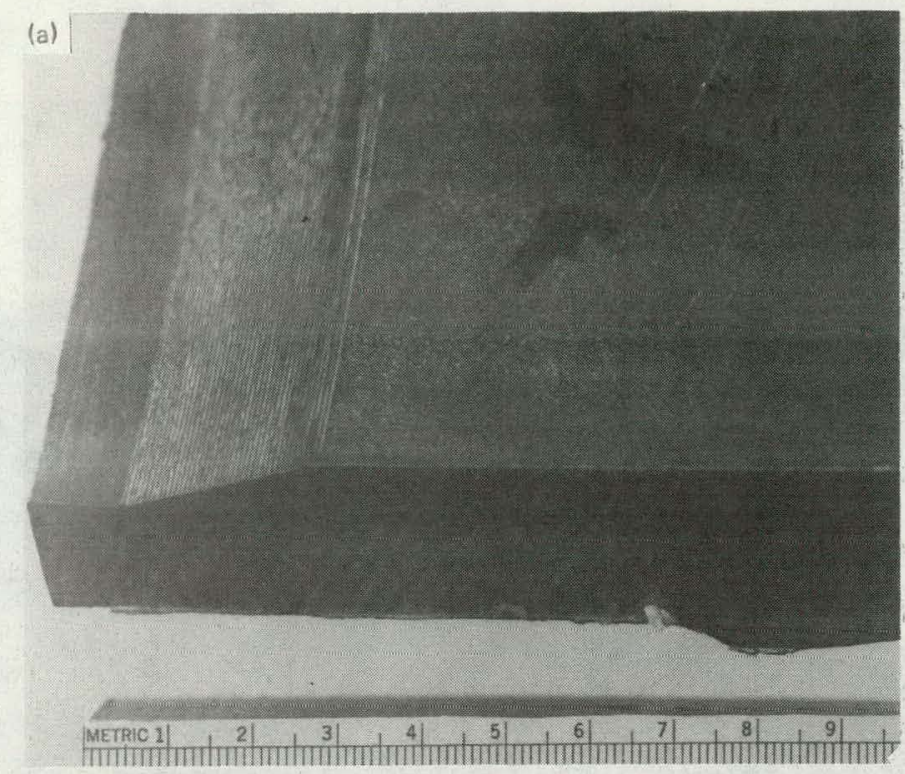

Part of

as-received

section

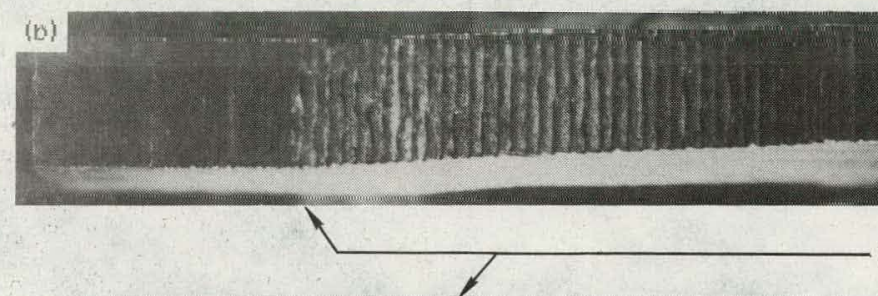

(c)

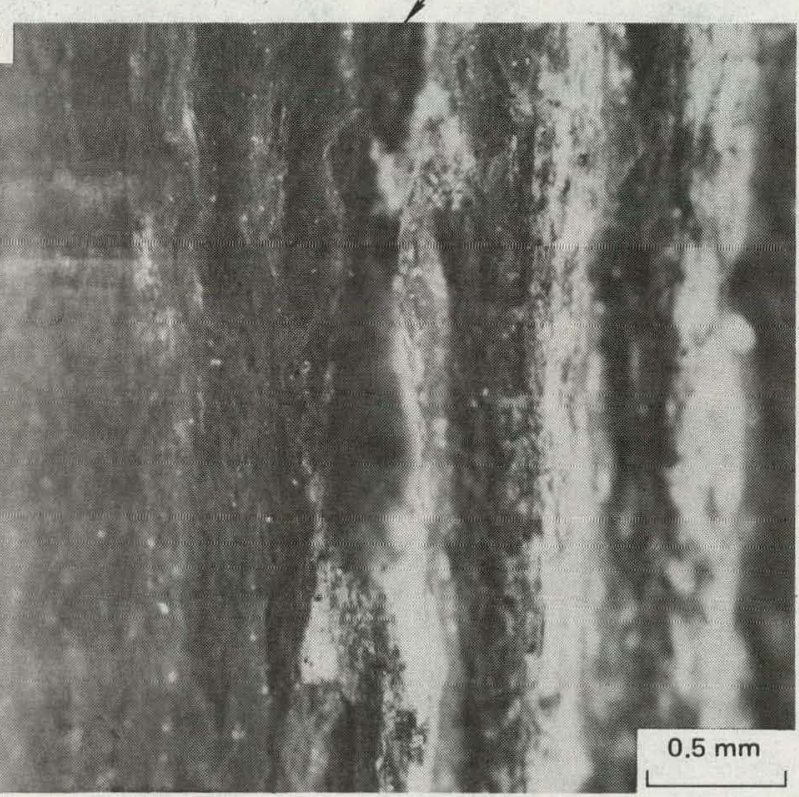

Crack origin at counterbore slope discontinuity

Longitudinal slice for metallography

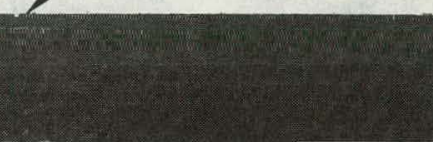

$5 \mathrm{~mm}$

Flow

FIG. 3.1. Photographs of Ginna material showing abrupt change in cross section and deep machining grooves along the counterbore. View (a) shows the abrupt change in cross section at the bottom of the counterbore slope. Views (b) and (c) show at higher magnifications machining grooves, corrosion pits, and crack origin along counterbore seen in view (a). 

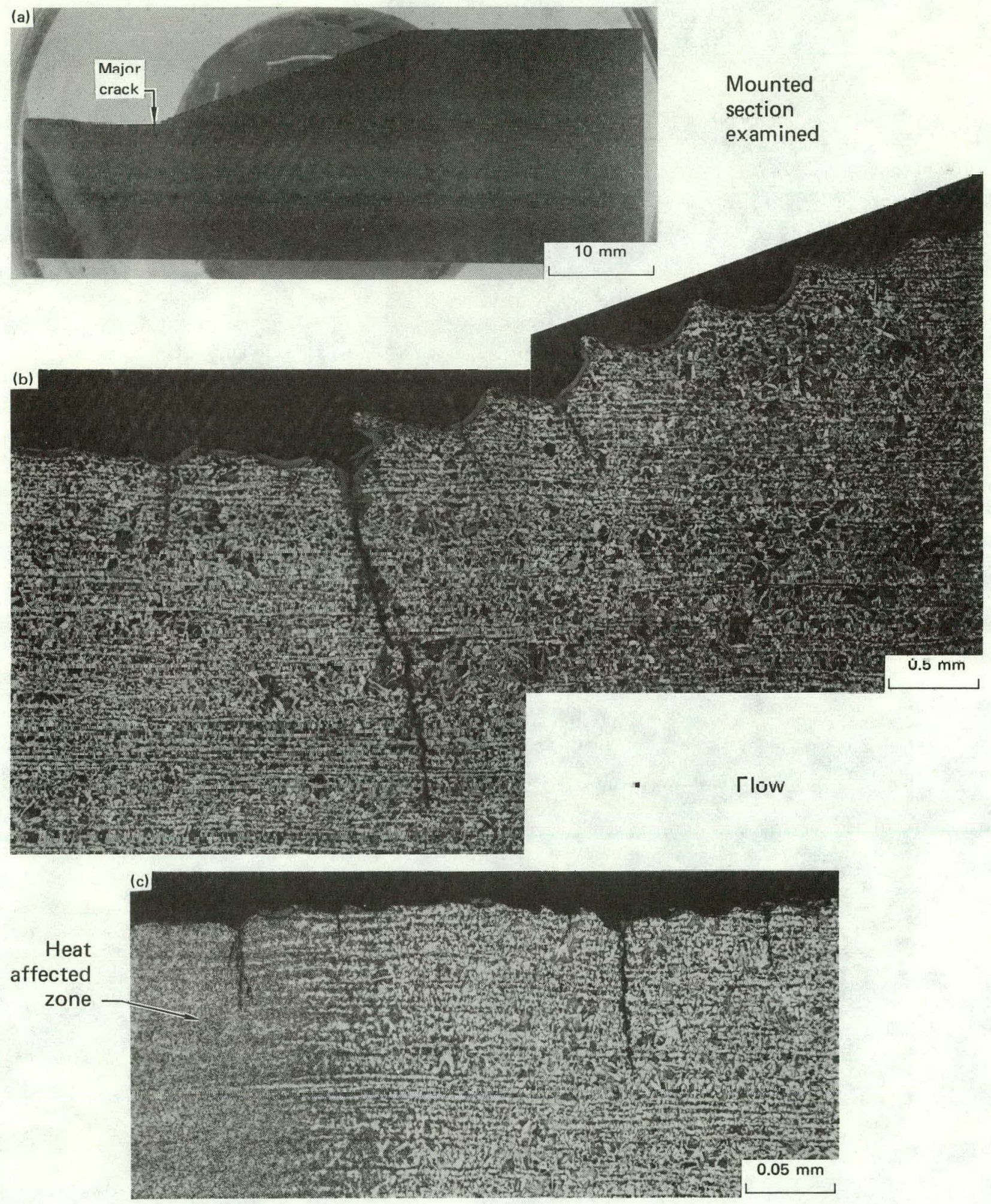

FIG. 3.2. Photomicrographs of Ginna material showing cracks initiating from machining grooves. Note that the major crack at the counterbore section change propagates in a direction that roughly bisects the angle between the normals to the two contiguous surfaces on either side of the crack. Also note corrosion pitting, especially at the crack origin. 


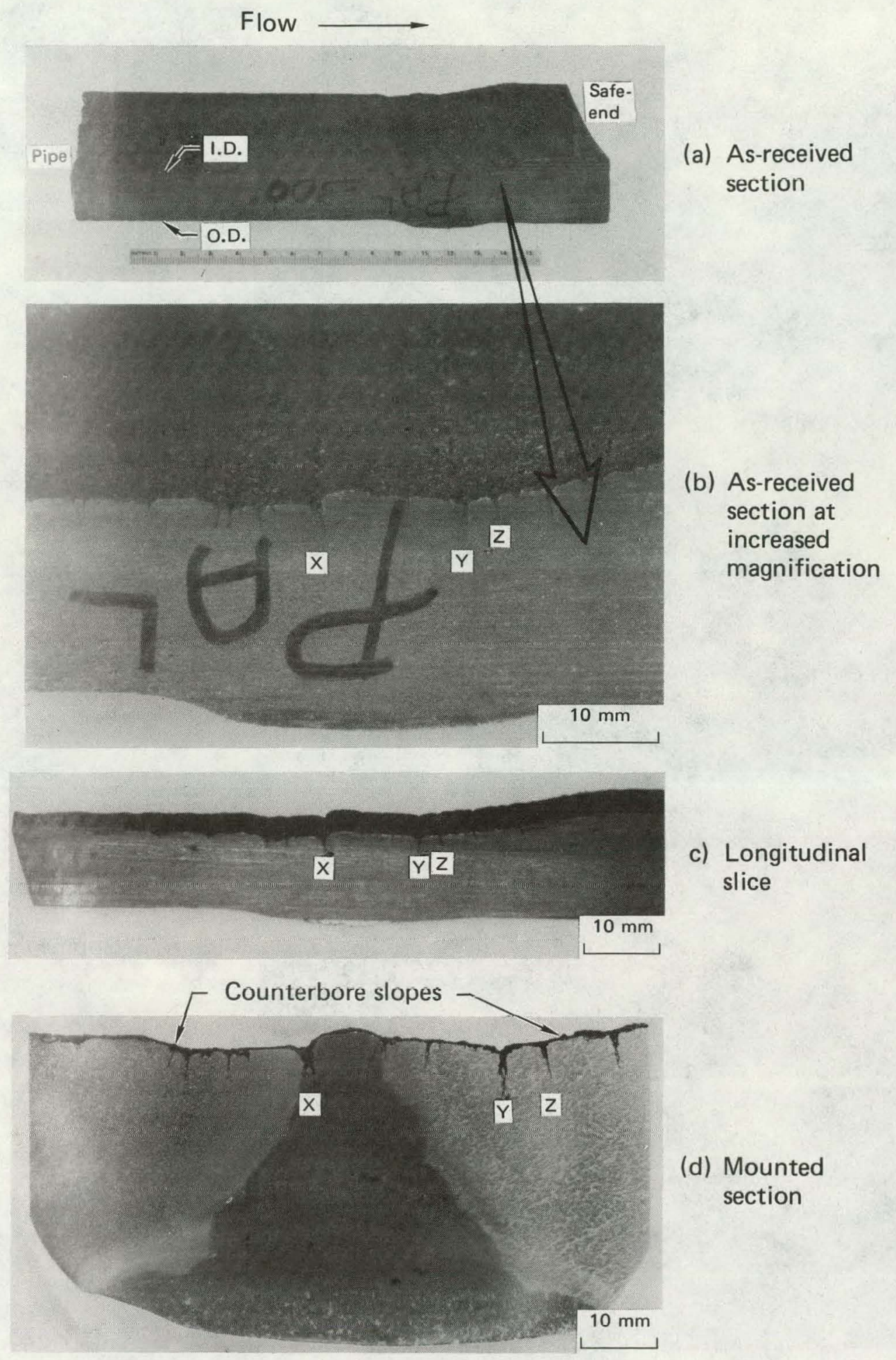

FIG. 3.3. Photographs of Palisades material illustrating the presence of numerous sites for crack initiation: change in section along both counterbores, weld to pipe and weld to safe-end interfaces, and corrosion pits. The three deepest cracks are indicated as $\mathrm{X}, \mathrm{Y}$, and $\mathrm{Z}$. 


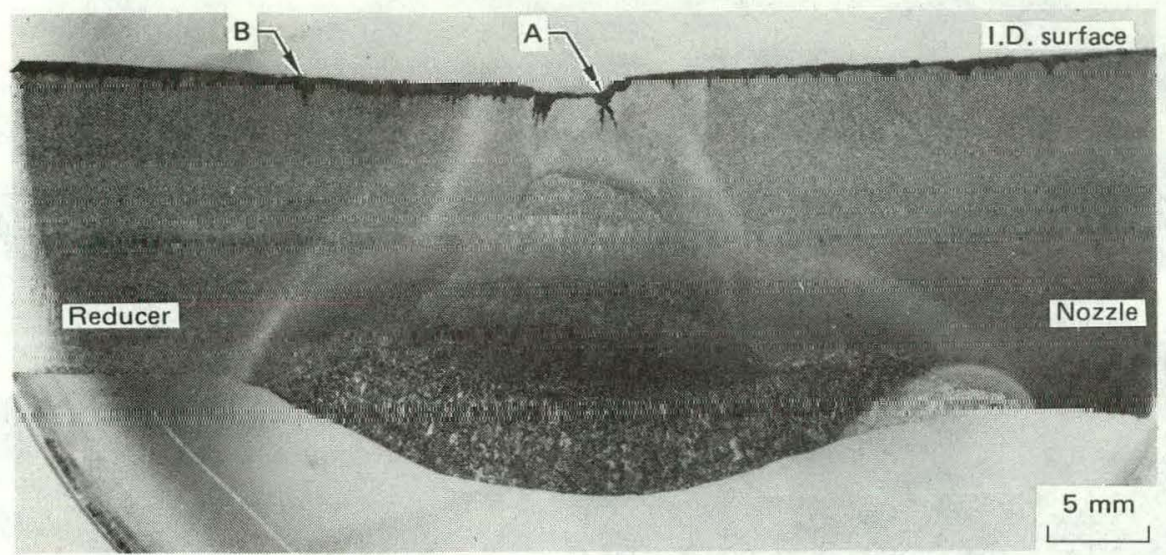

Flow

(a) San Onofre
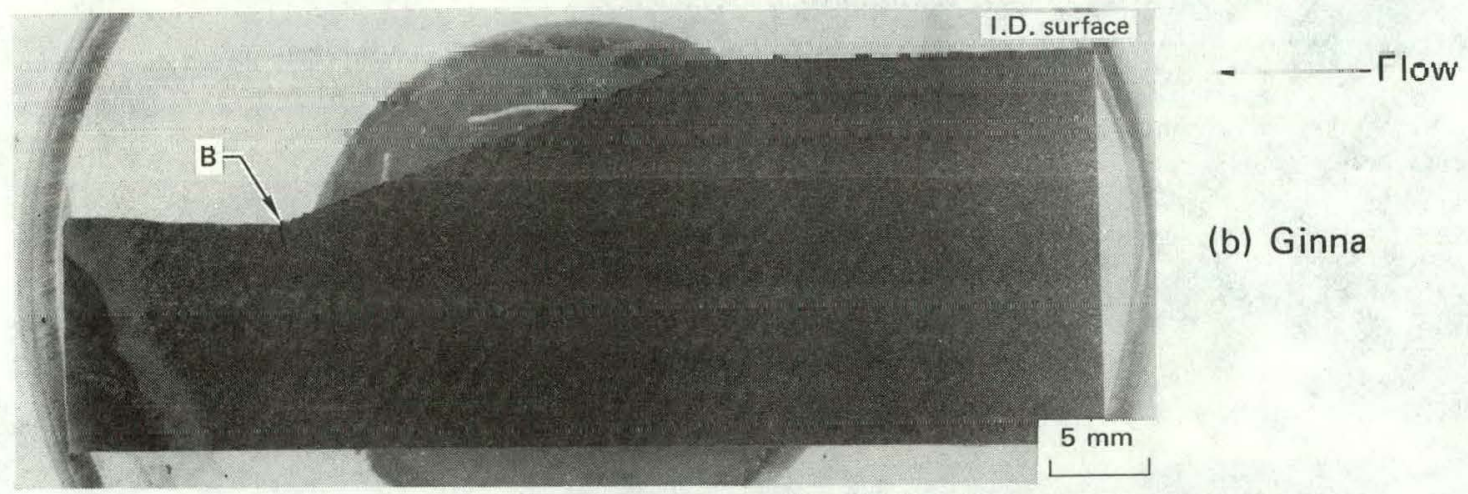

(b) Ginna

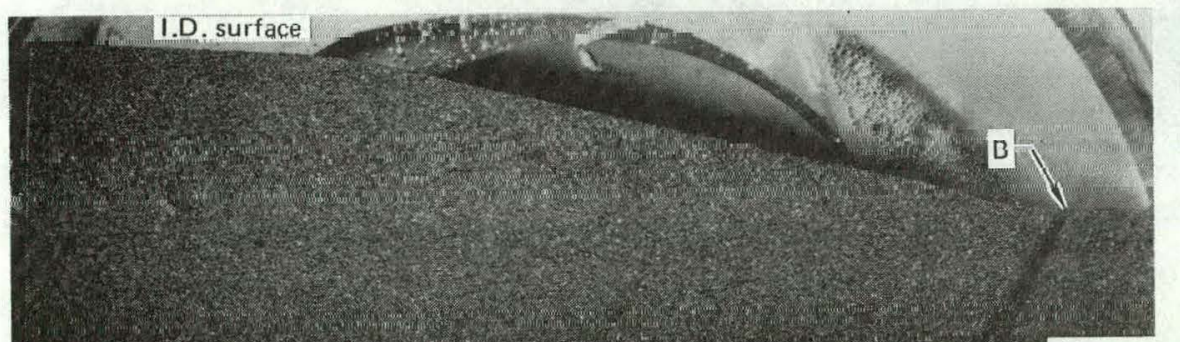

Flow

(c) H. B. Robinson
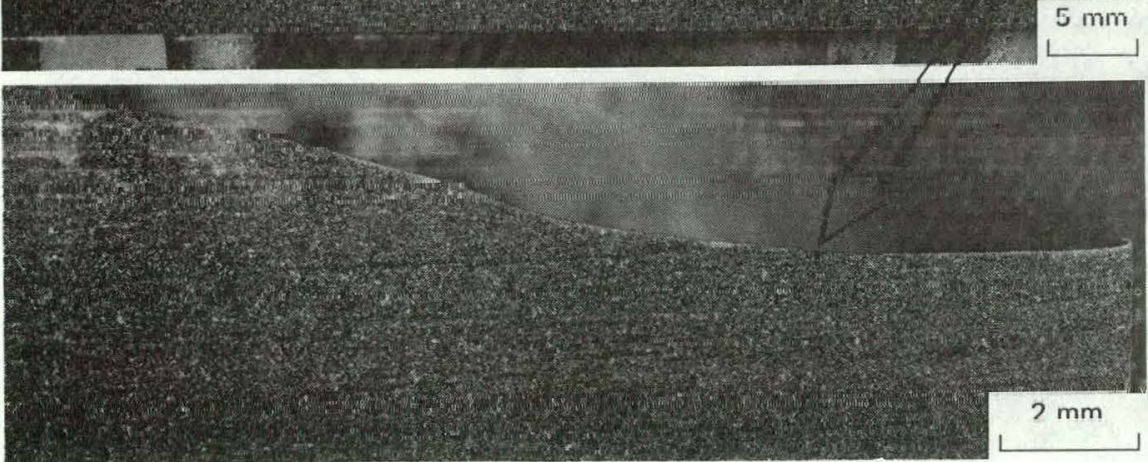

FIG. 3.4. Mounted cross sections from longitudinal slices used for light microscopy examination of San Onofre, Ginna, and H. B. Robinson material. Major cracks are indicated by arrows. Views are parallel to piping axis and wall thickness. 

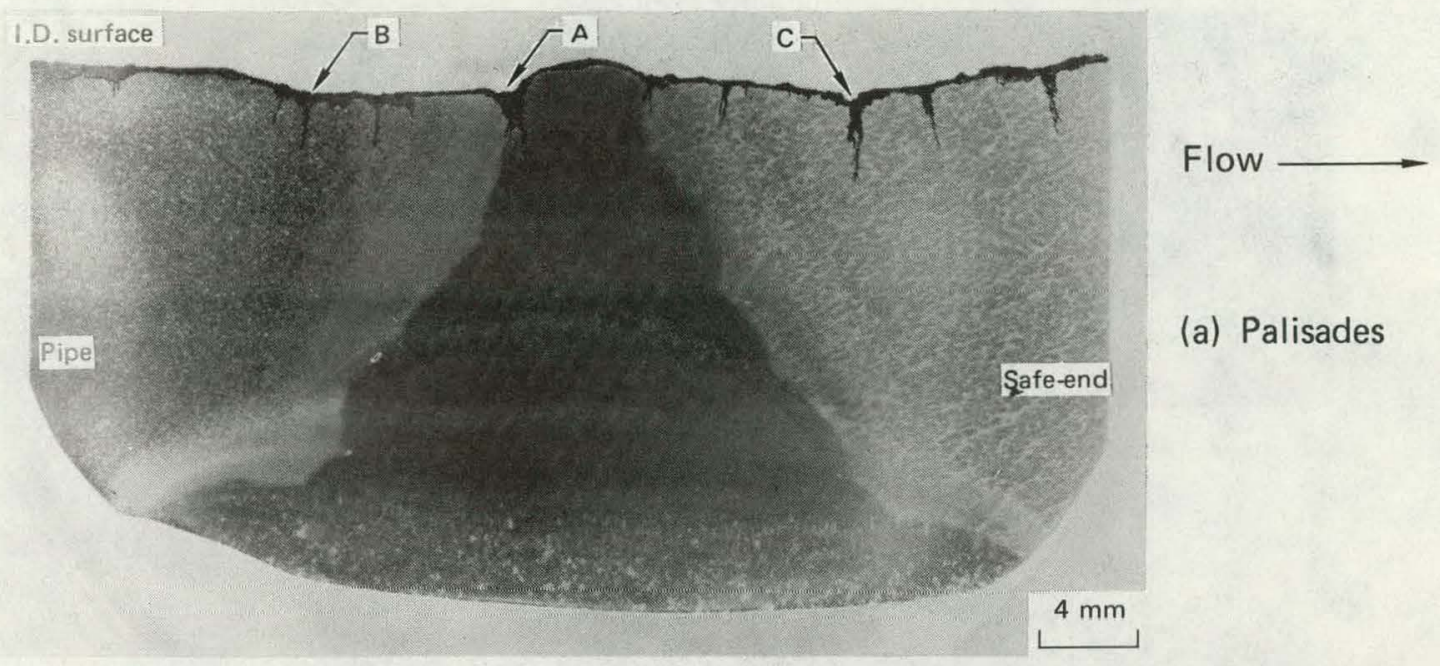

(a) Palisades
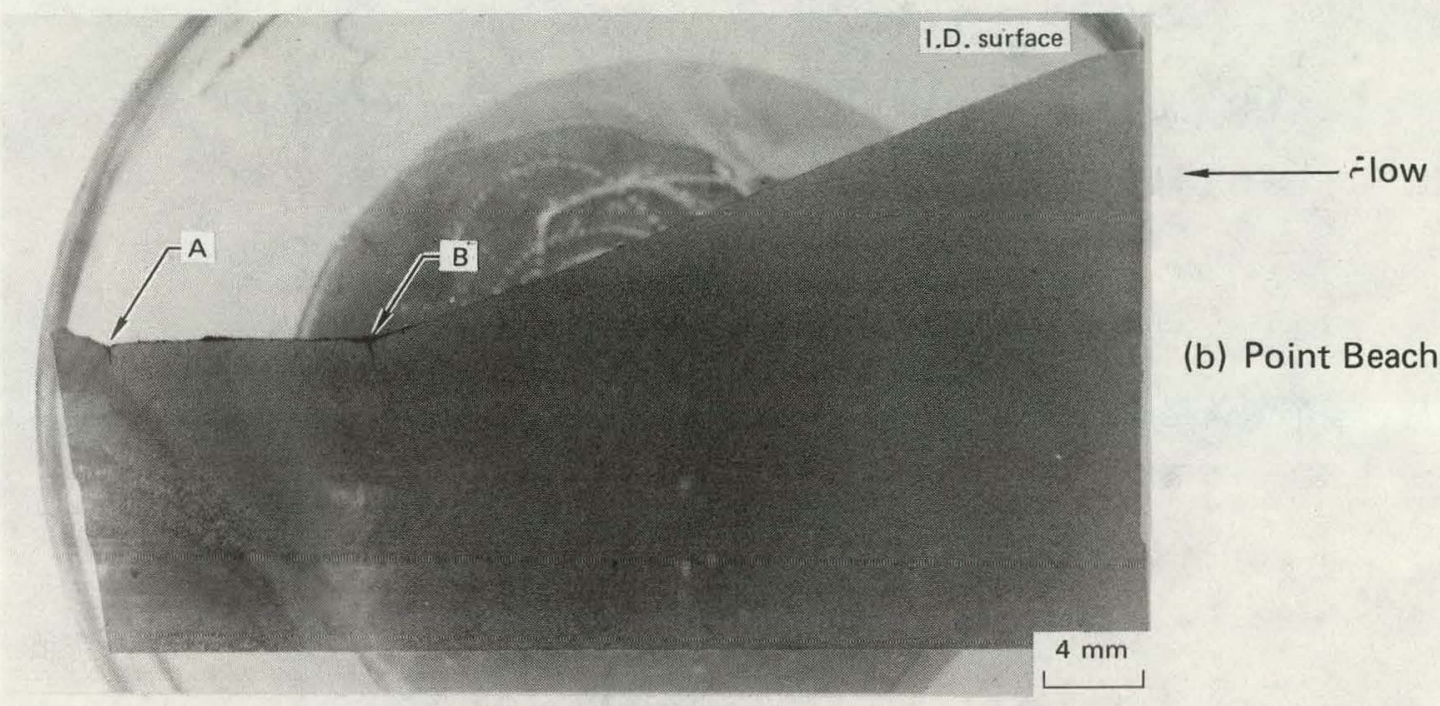

(b) Point Beach
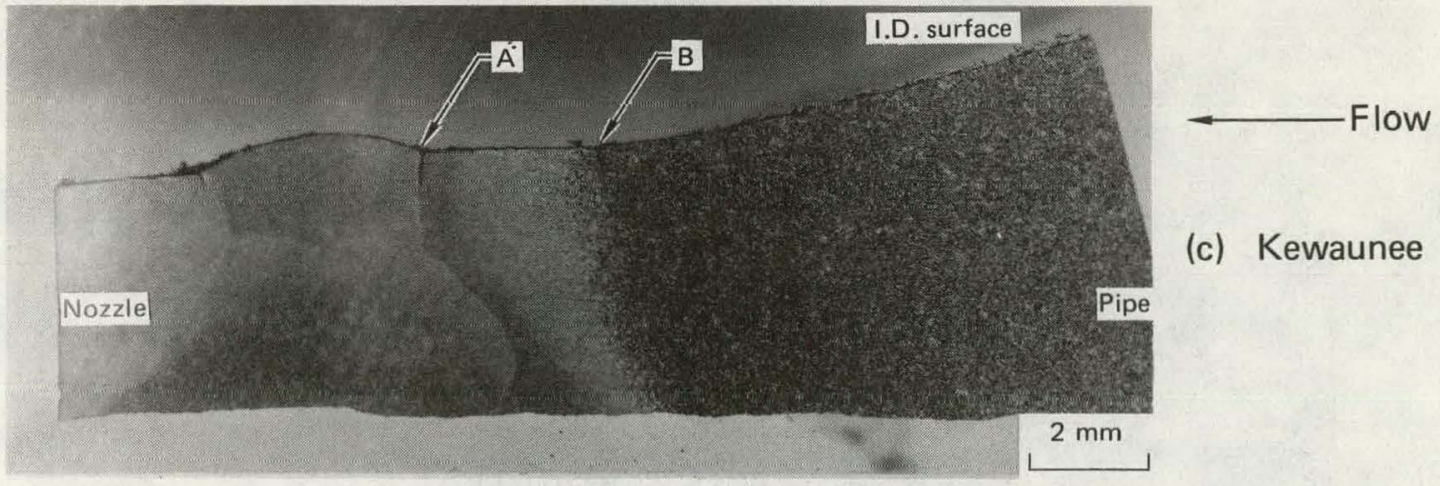

(c) Kewaunee

FIG. 3.5. Mounted cross sections from longitudinal slices used for light microscopy examination of Palisades, Point Beach, and Kewaunee material. Major cracks are indicated by arrows. Views are parallel to piping axis and wall thickness. 

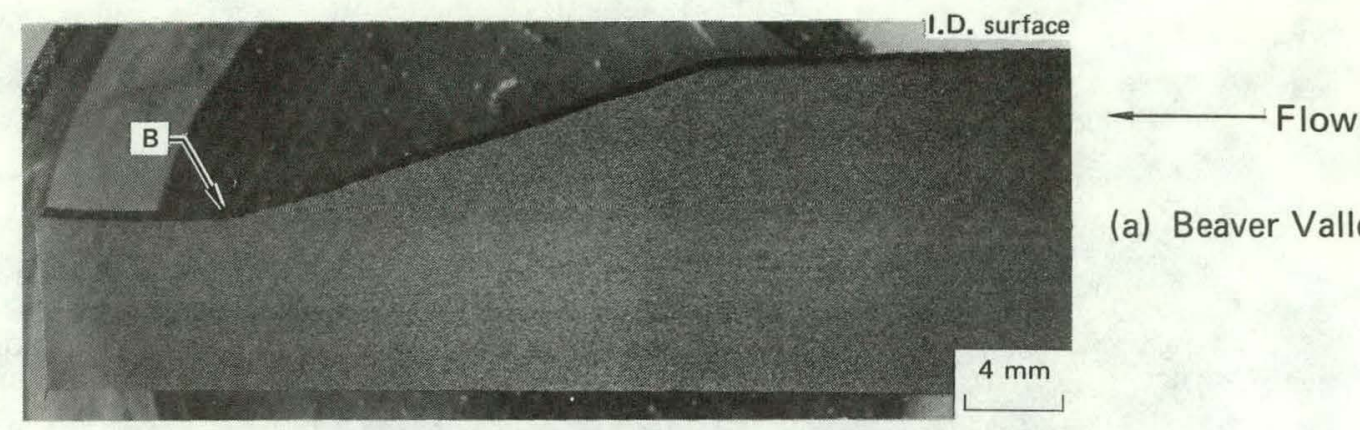

(a) Beaver Valley
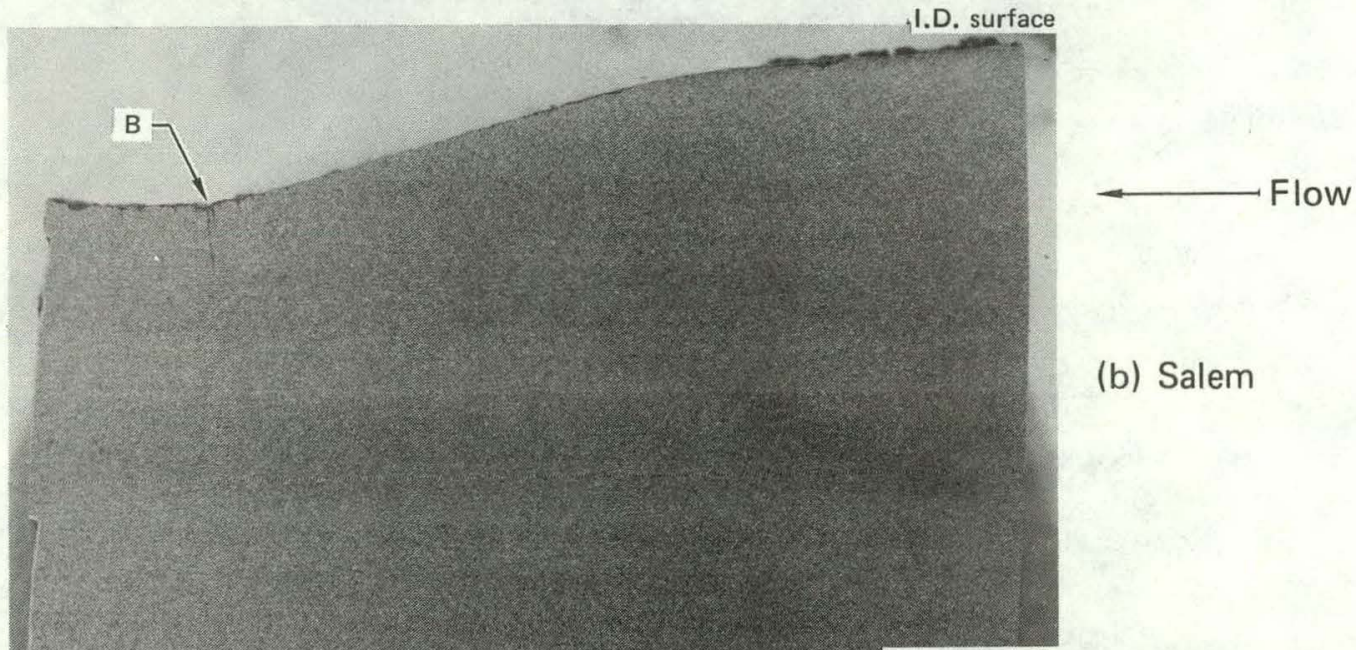

(b) Salem
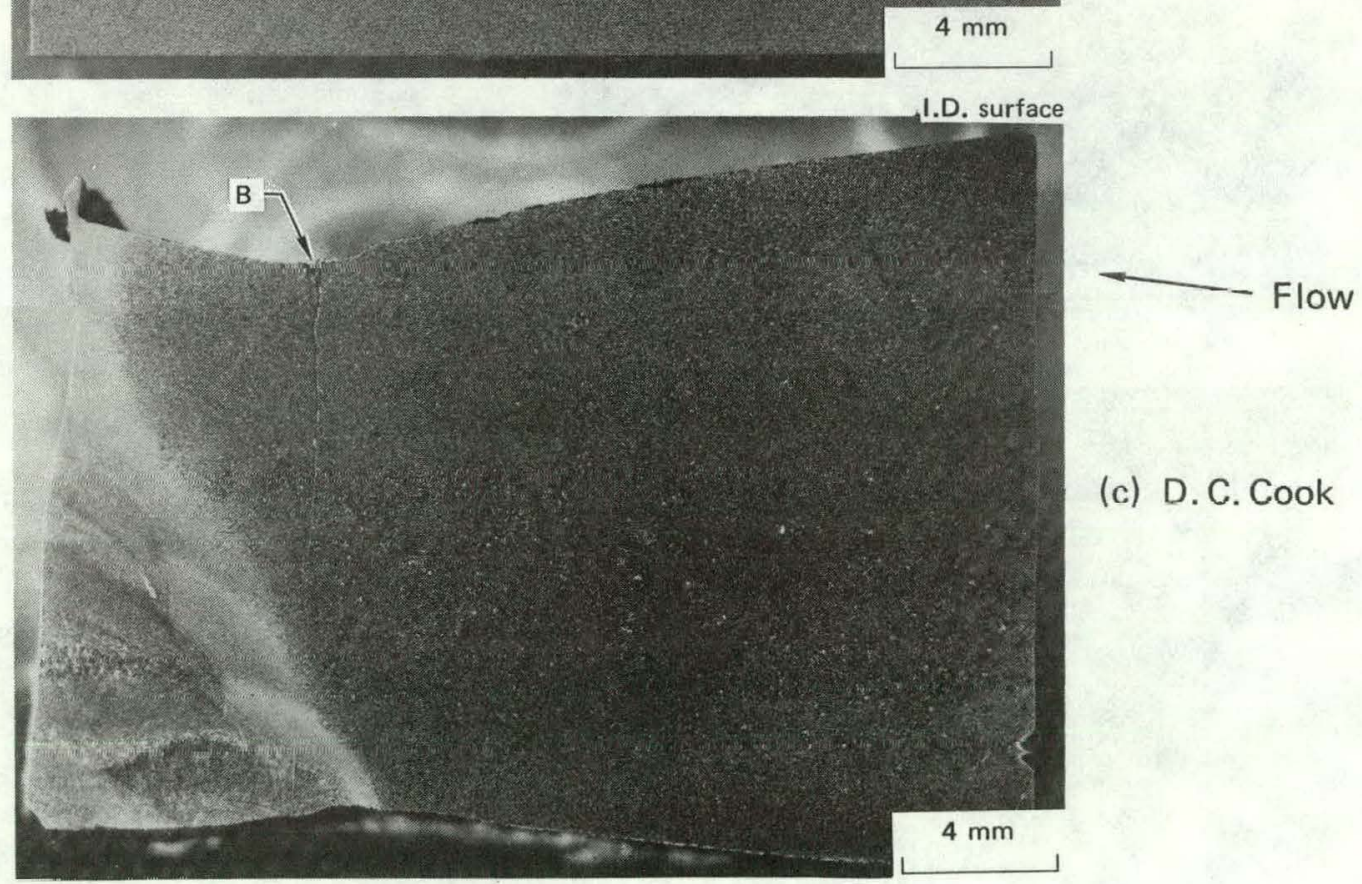

(c) D.C. Cook

FIG. 3.6. Mounted cross sections from longitudinal slices used for light microscopy examination of Beaver Valley, Salem, and D. C. Cook material. Major cracks are indicated by arrows. Views are parallel to piping axis and wall thickness. 


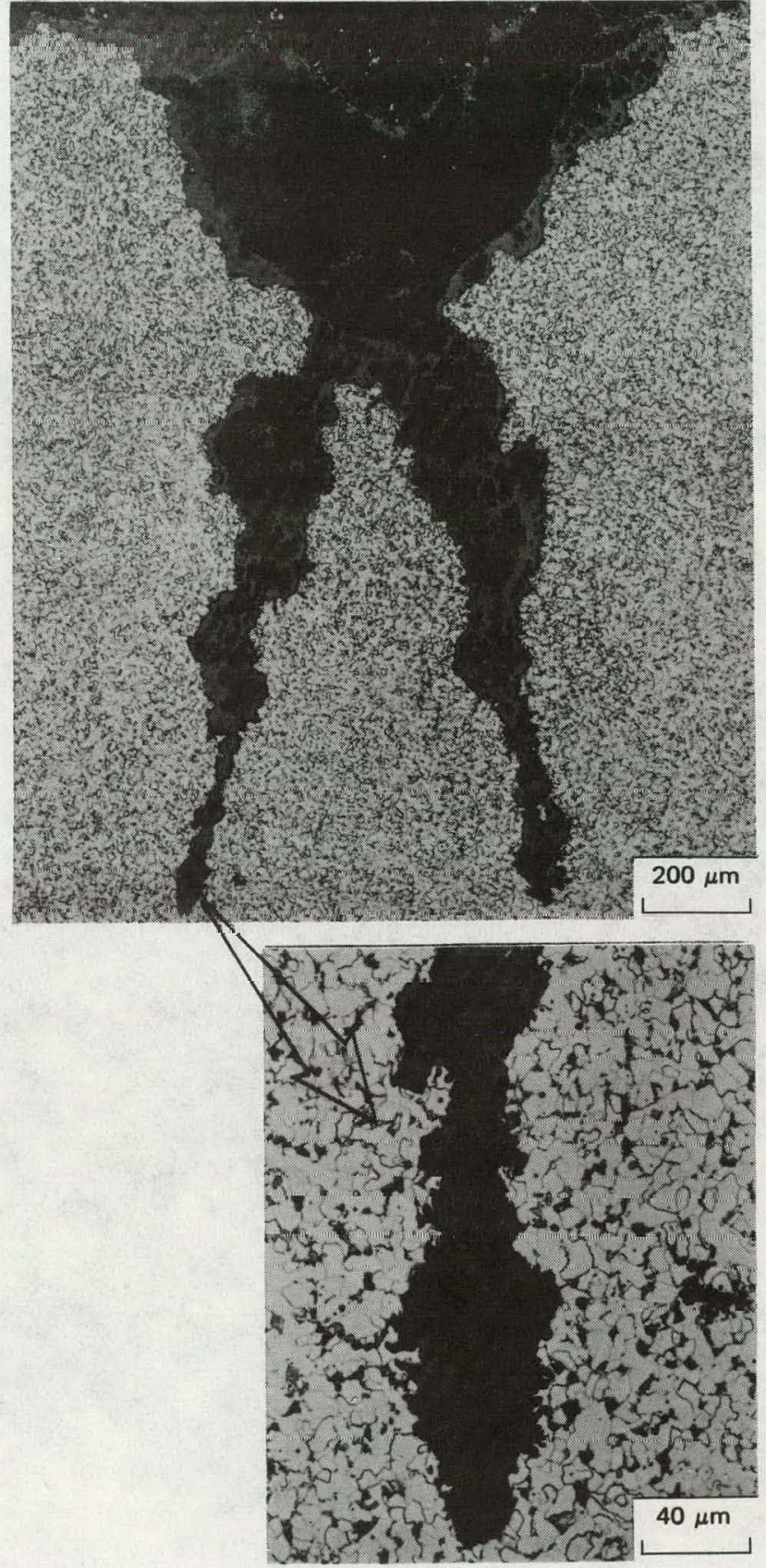

(a) Crack A

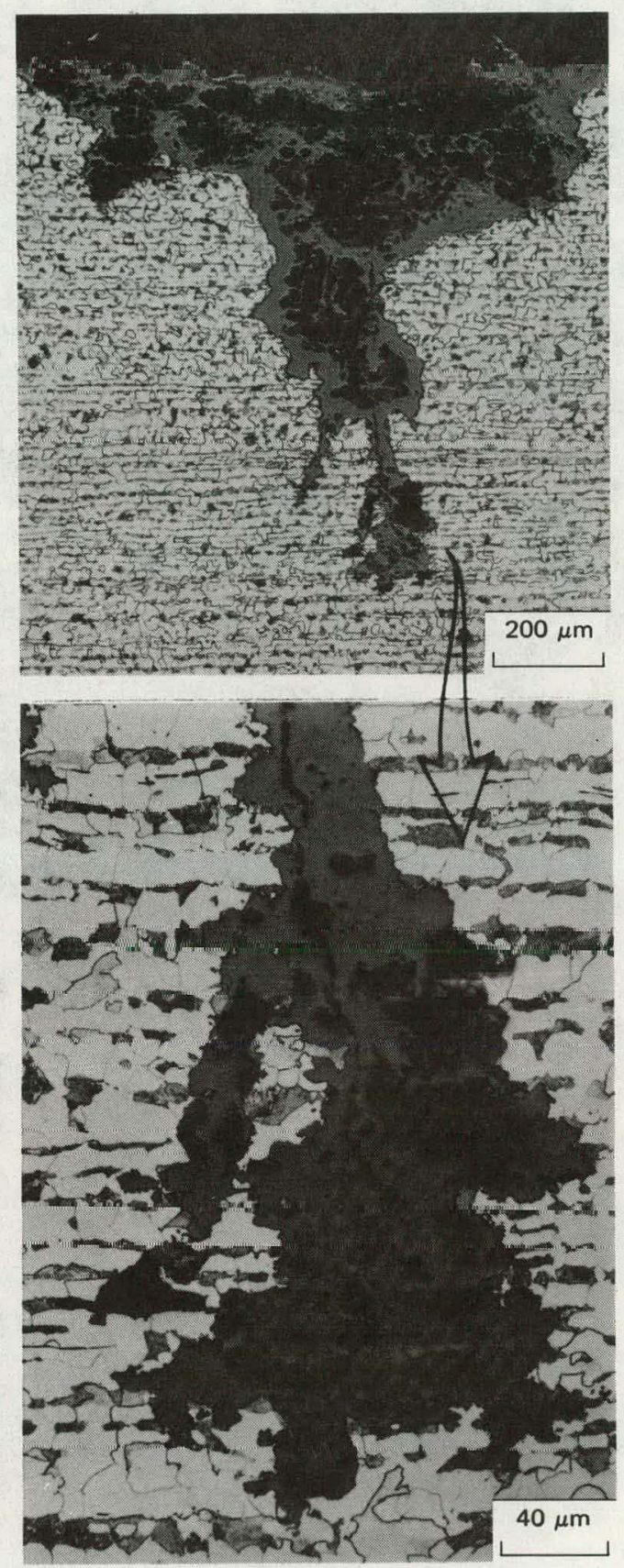

(b) Crack B

FIG. 3.7. Major cracks in San Onofre section. Refer to Fig. 3.4(a). Crack A initiates at large discontinuity at inside diameter surface of weld. Crack B is largest crack in reducer section; the overriding influence of corrosion is apparent in this crack. Both cracks contain large corrosion craters. 


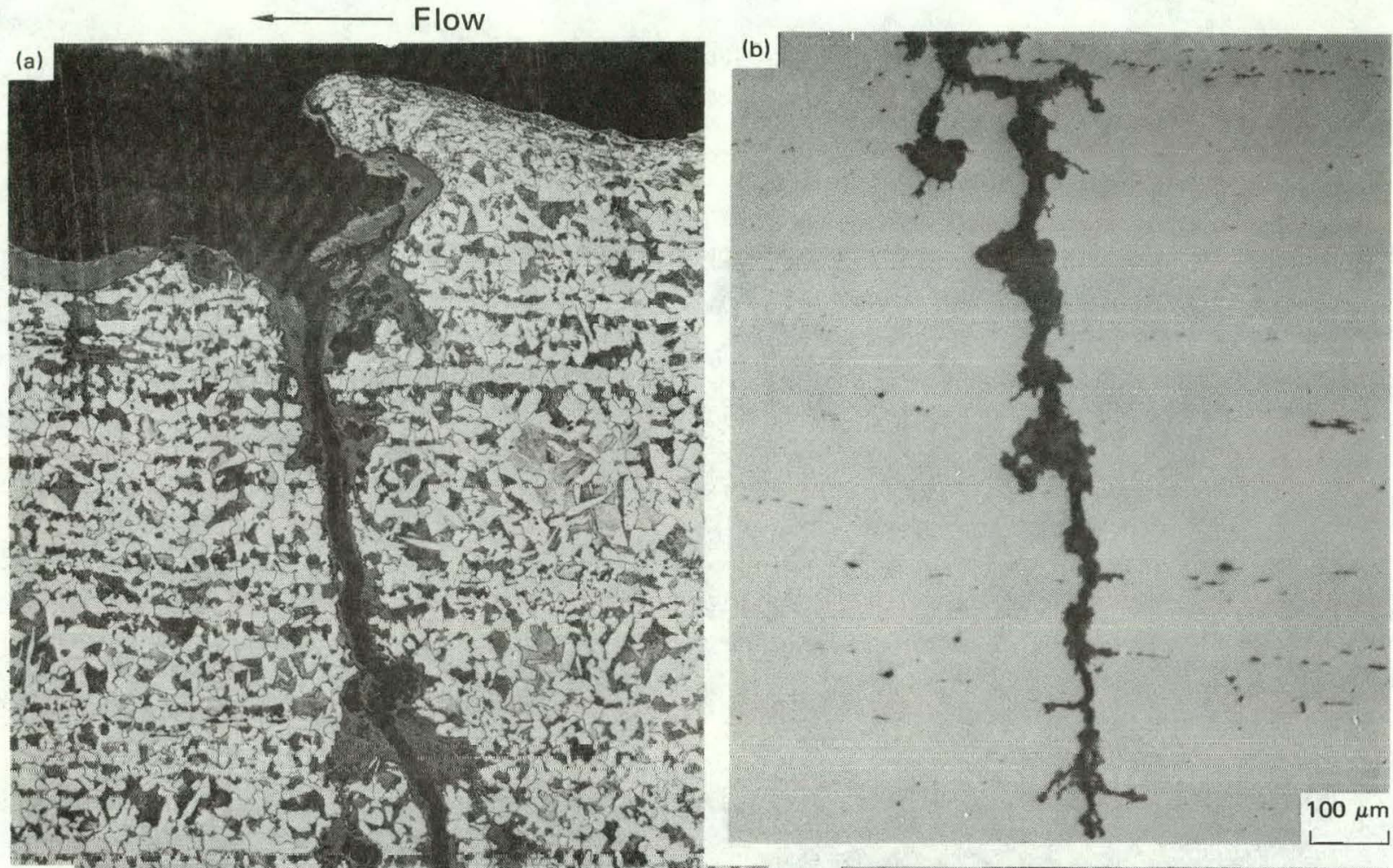

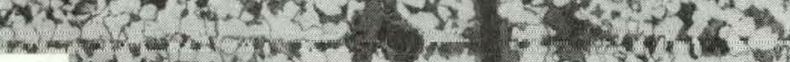

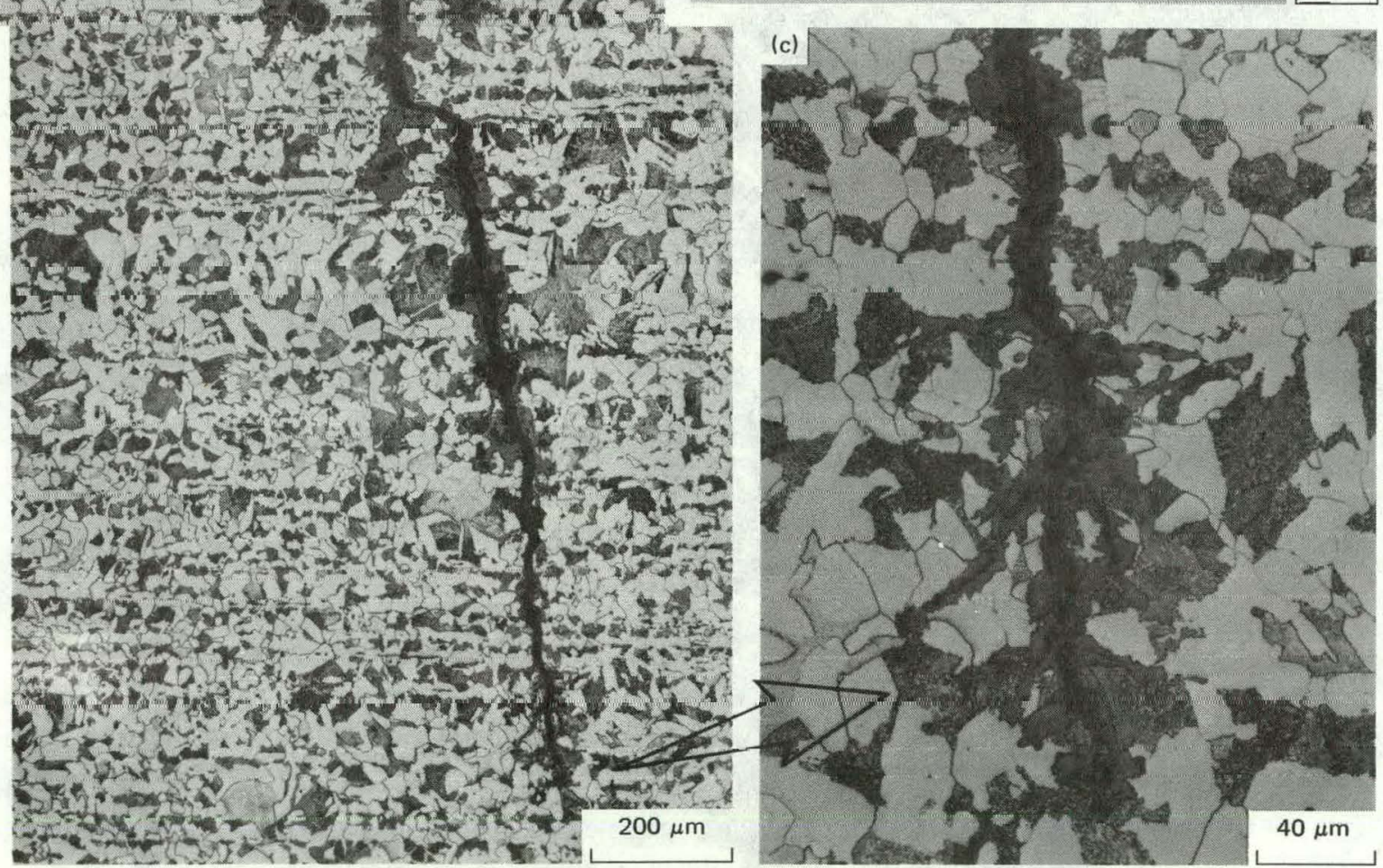

FIG. 3.8. Major crack in Ginna section. Refer to Fig. 3.4(b). In view (a), a major crack initiates at the root of the machining groove at the bottom of the counterbore slope; in view (b), an as-polished section shows lateral corrosion spikes at inclusions. Some branching is evident, especially near crack tip. Minor corrosion craters are present along most of crack. 
Flow
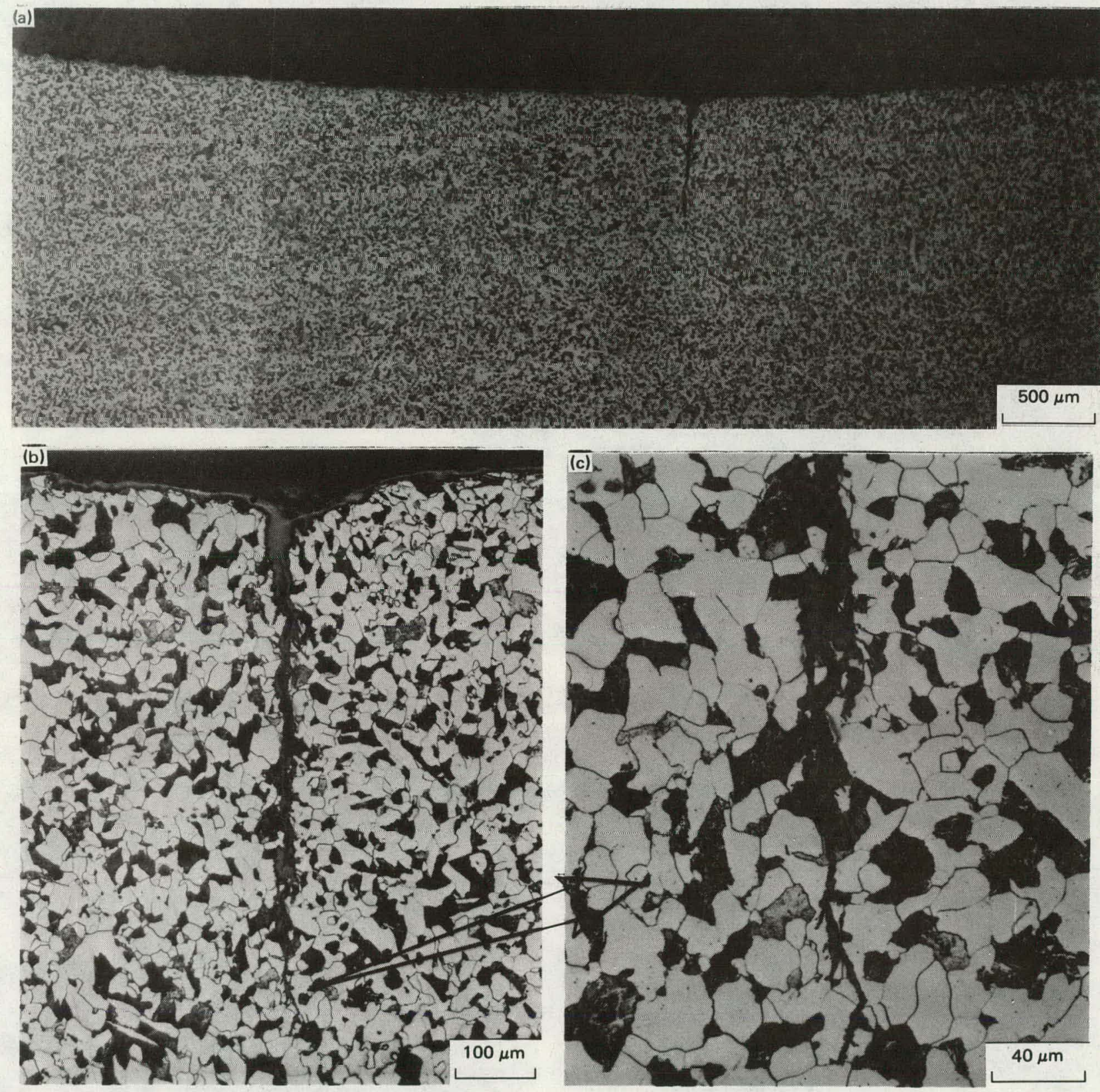

FIG. 3.9. Major crack in H. B. Robinson section. Refer to Fig. 3.4(c). In vicw (a), a major crack initiates at a small discontinuity along the counterbore bottom; in views (b) and (c), minor corrosion craters and minor branching are evident. 
Flow

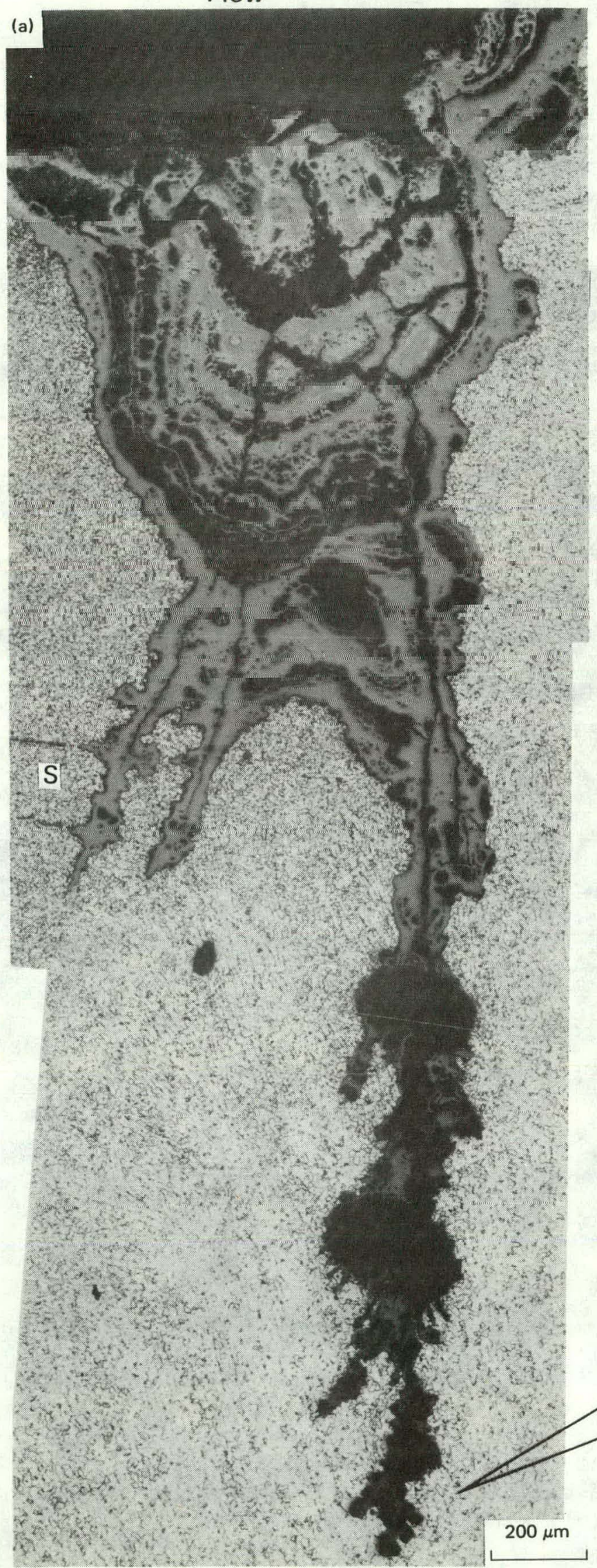

FIG. 3.10. Major crack in Palisades section, Crack A, initiates at pipeto-weld interface. Refer to Fig. 3.5(a). Note larqe corrosion craters with corrosion spikes. Some lateral corrosion spikes at inclusions at $S$ in view (a).

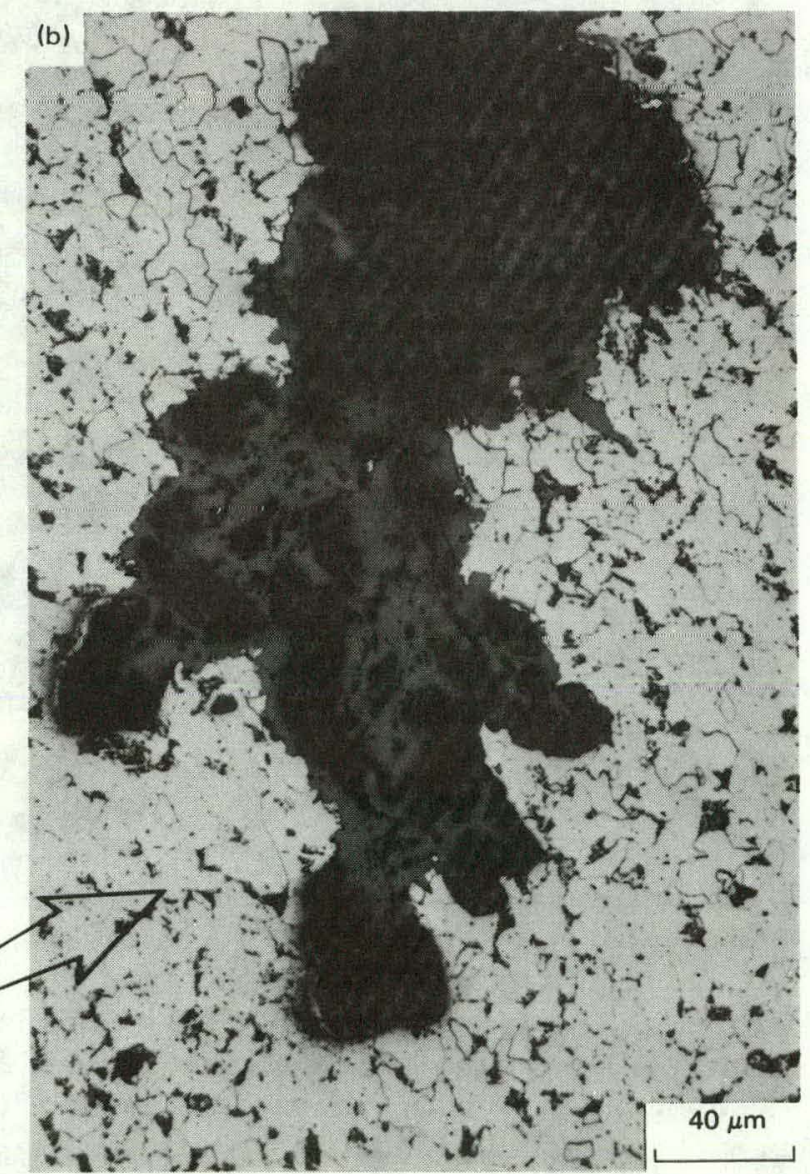




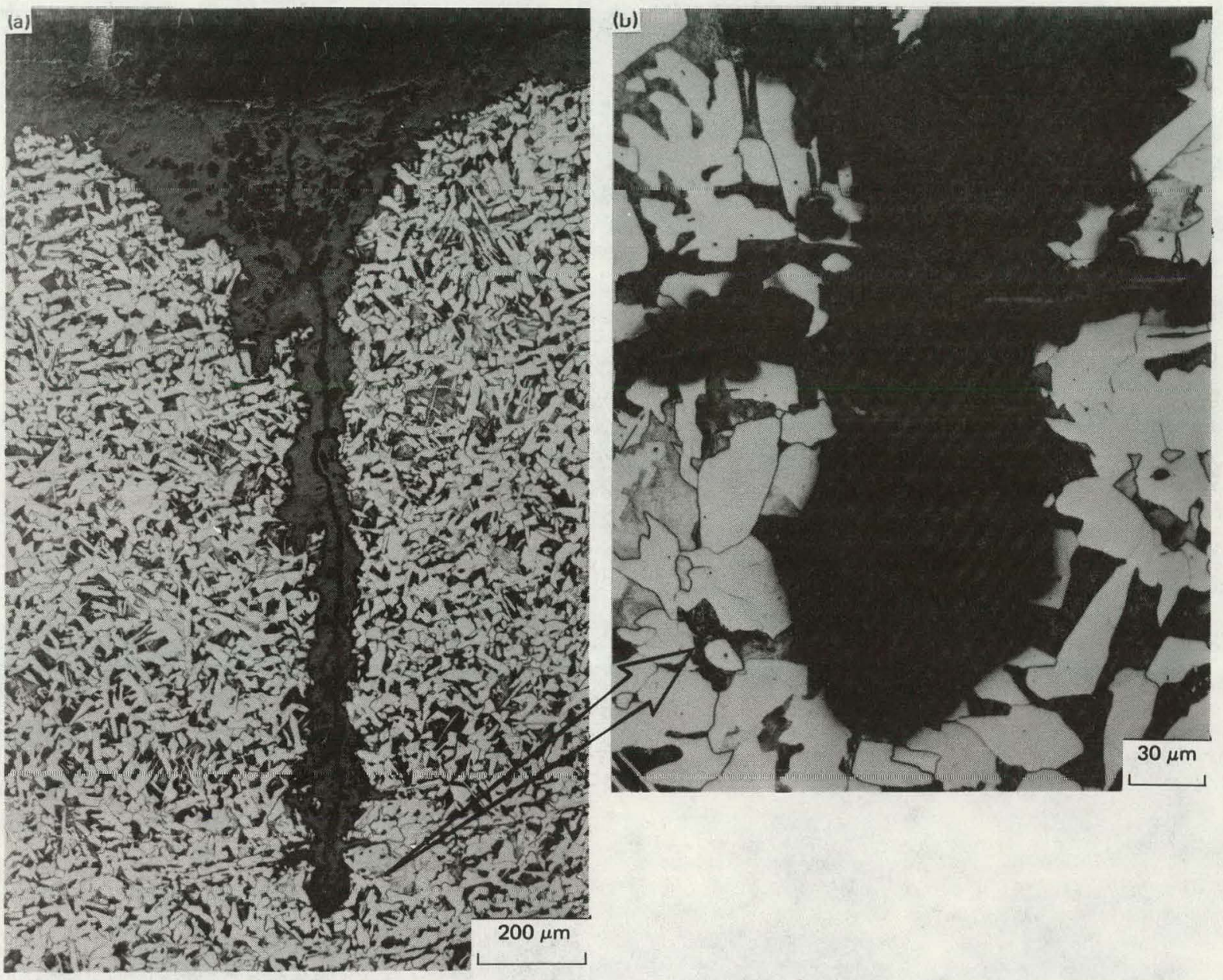

FIG. 3.11. Major crack, Crack B, in pipe of Palisades section initiates at discontinuity at bottom of counterbore slope. Refer to Fig. 3.5(a). See significant amount of corrosion along length of crack with periodic corrosion craters. Some corrosion spikes associated with both inclusions and craters. 
(a)

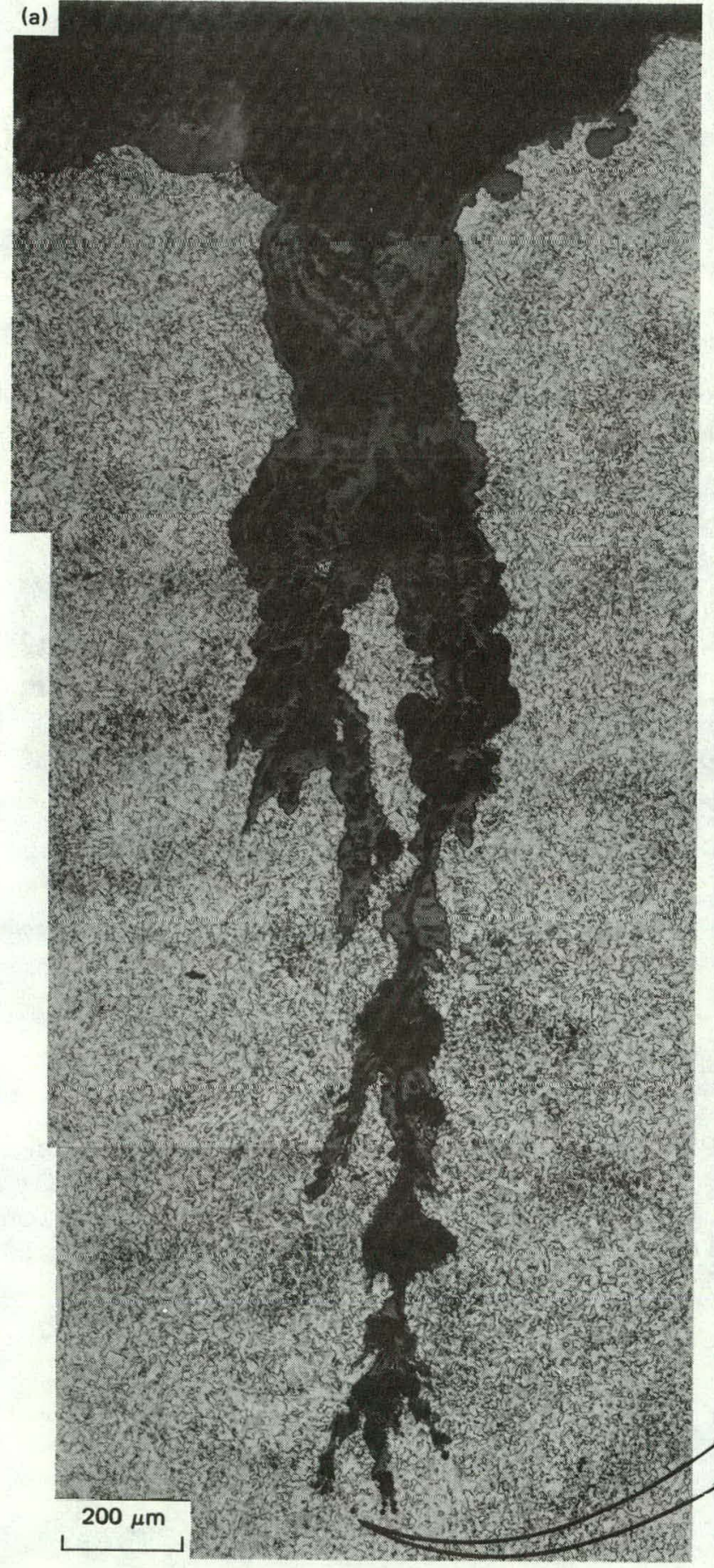

FIG. 3.12. Major crack, Crack C, in safe cnd of ralisades section initiates at discontinuity at bottom of counterbore slope. Refer to Fig. 3.5(a). Note large corrosion craters with corrosion spikes. Spikes at crack tip are suggestive of initial stage of branching.

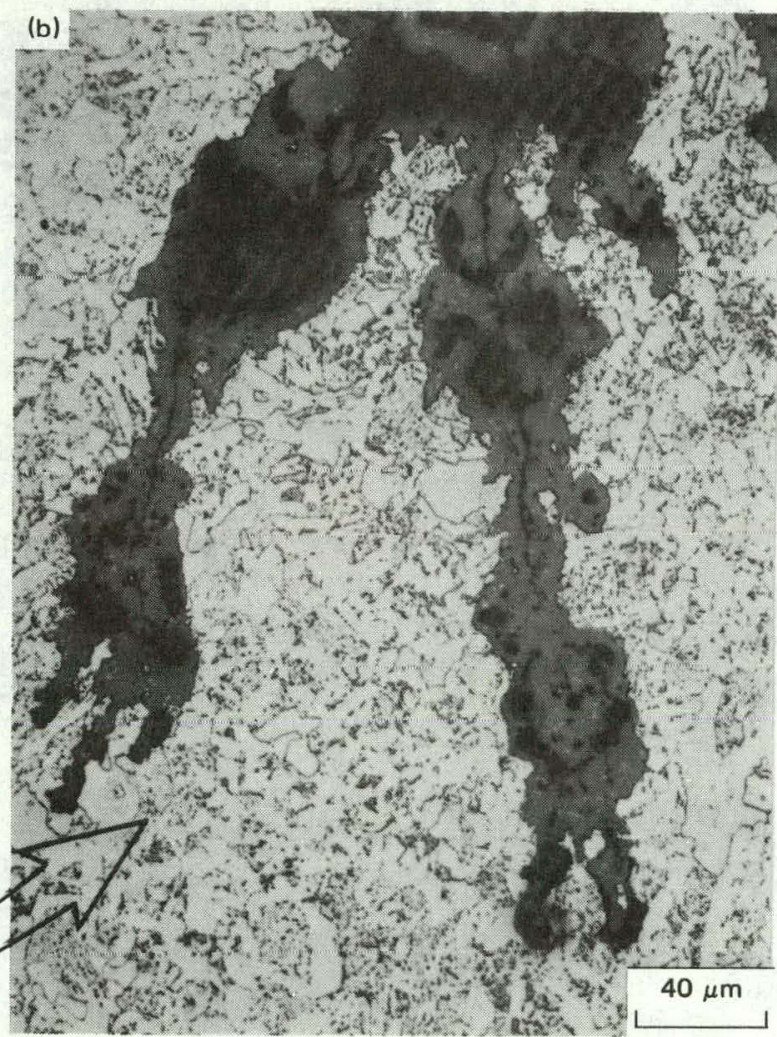




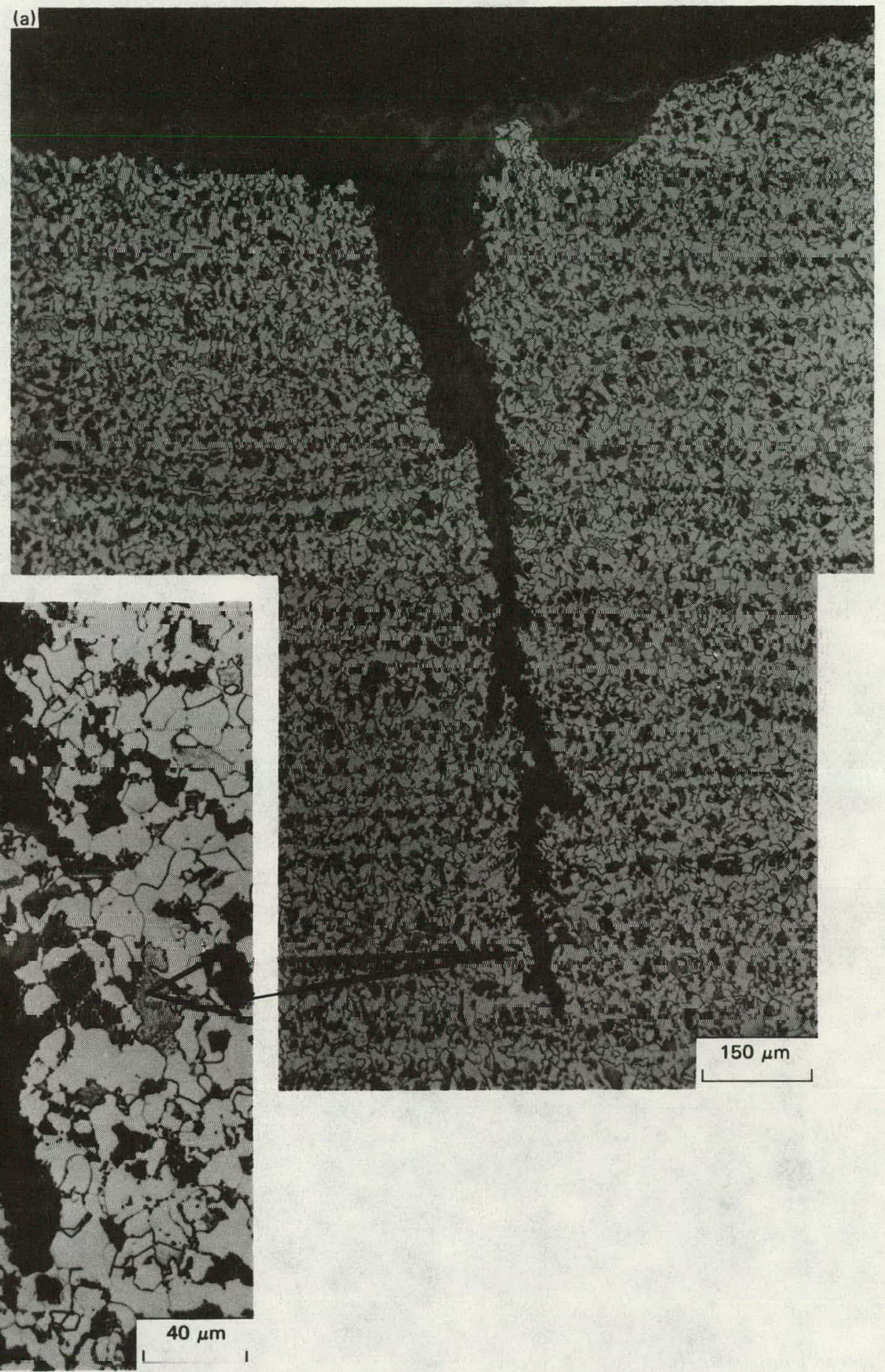

FIG. 3.13. Major crack in Point Beach section initiates at discontinuity at bottom of counterbore slope of reducer. Refer to Fig. 3.5(b). Note minor corrosion craters with corrosion spikes. 


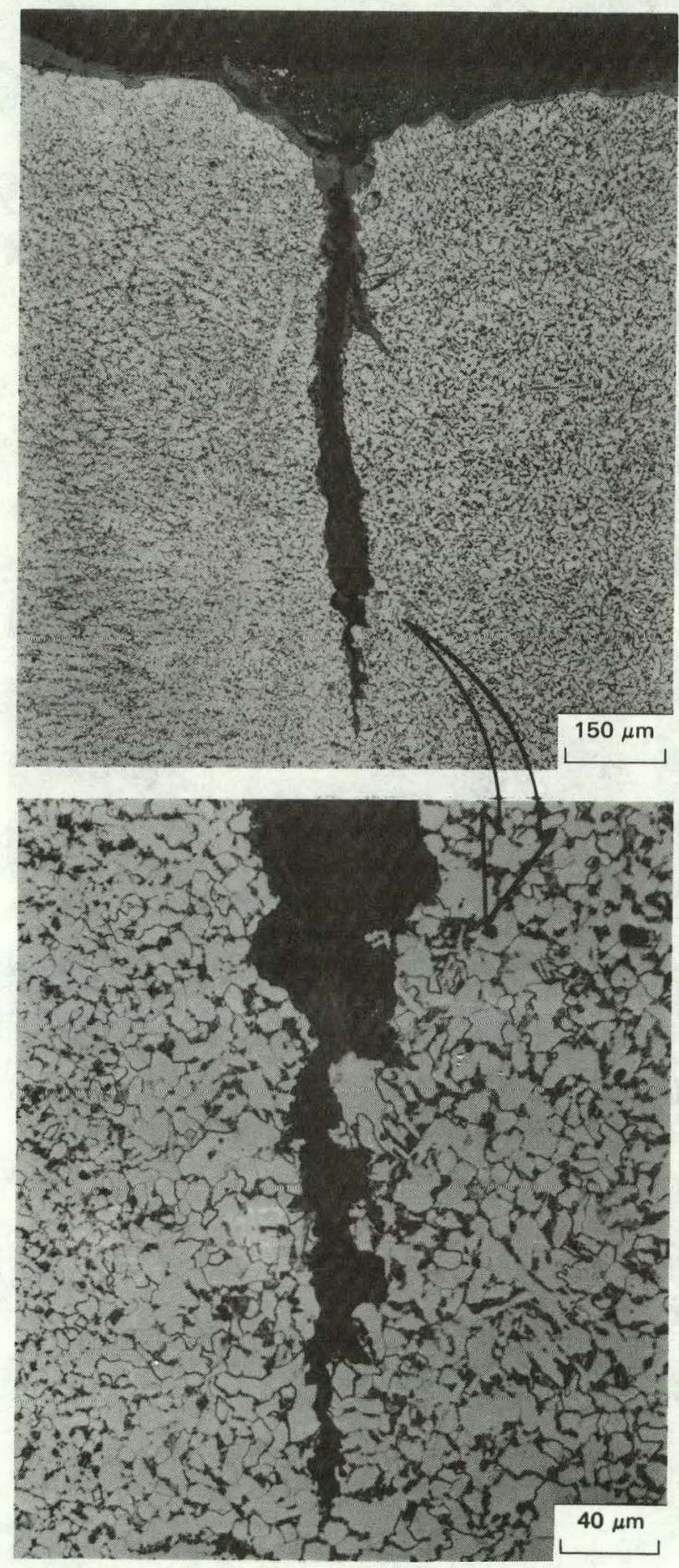

(a) Crack A

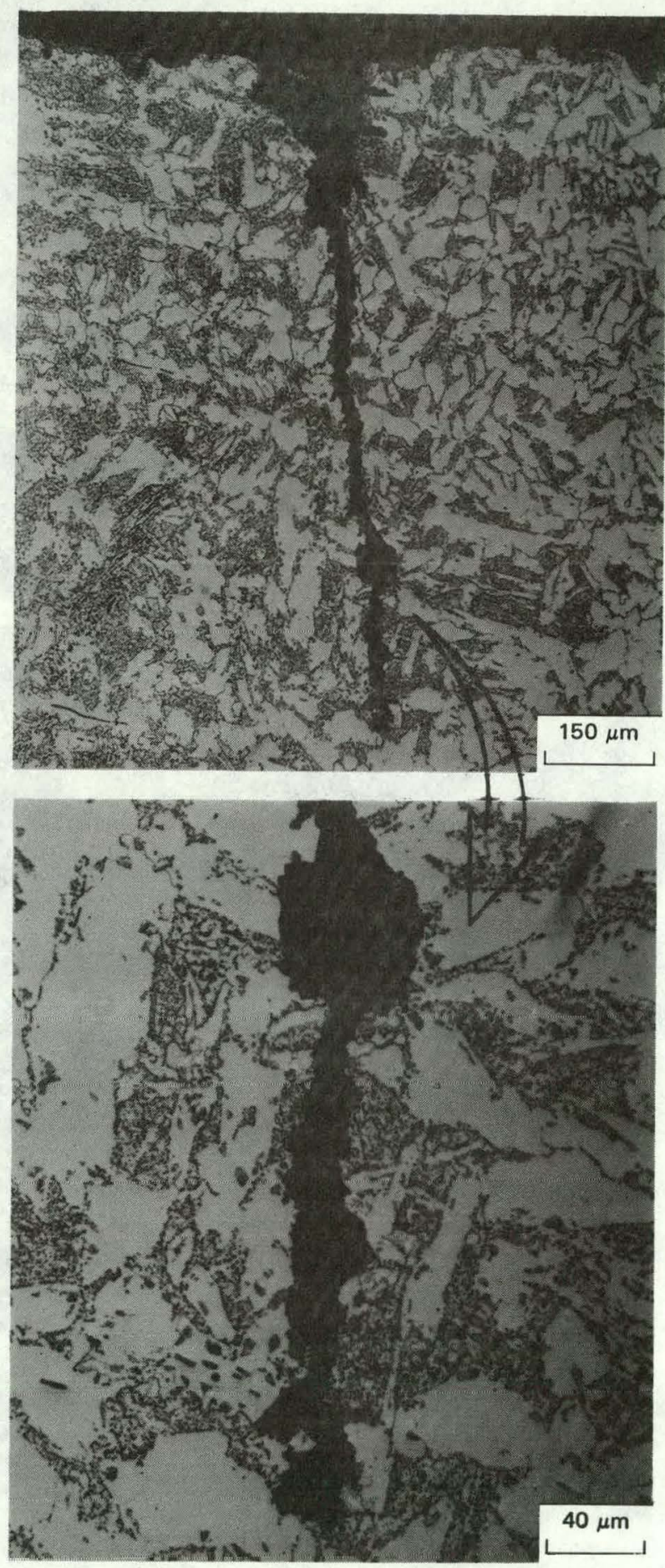

(b) Crack B

FIG. 3.14. Major crack, Crack A, initiates at pipe-to-weld interface (85X) and

Crack B initiates at discontinuity at bottom of counterbore slope (100X) in

Kewaunee section. Refer to Fig. 3.5(c). Corrosion craters and spikes are seen at craters. Note that a small sharp crack tip extends from deepest crater in both cracks, lower photographs. 


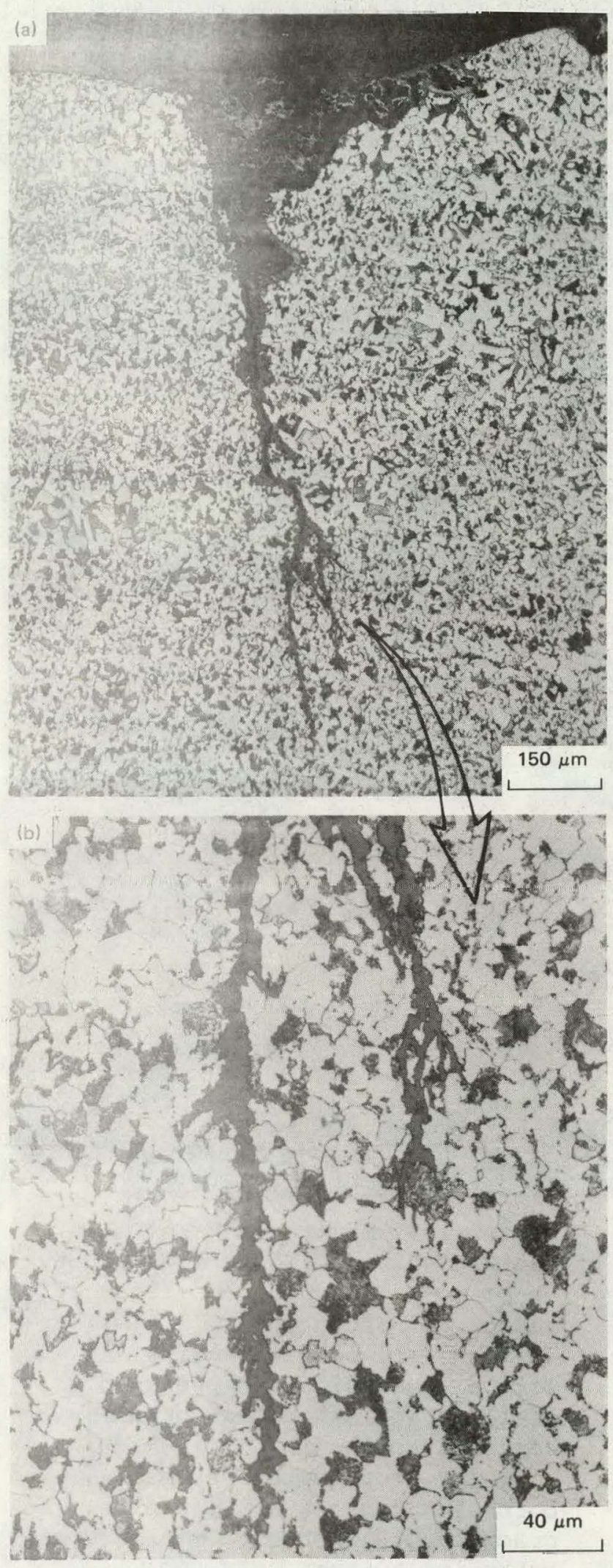

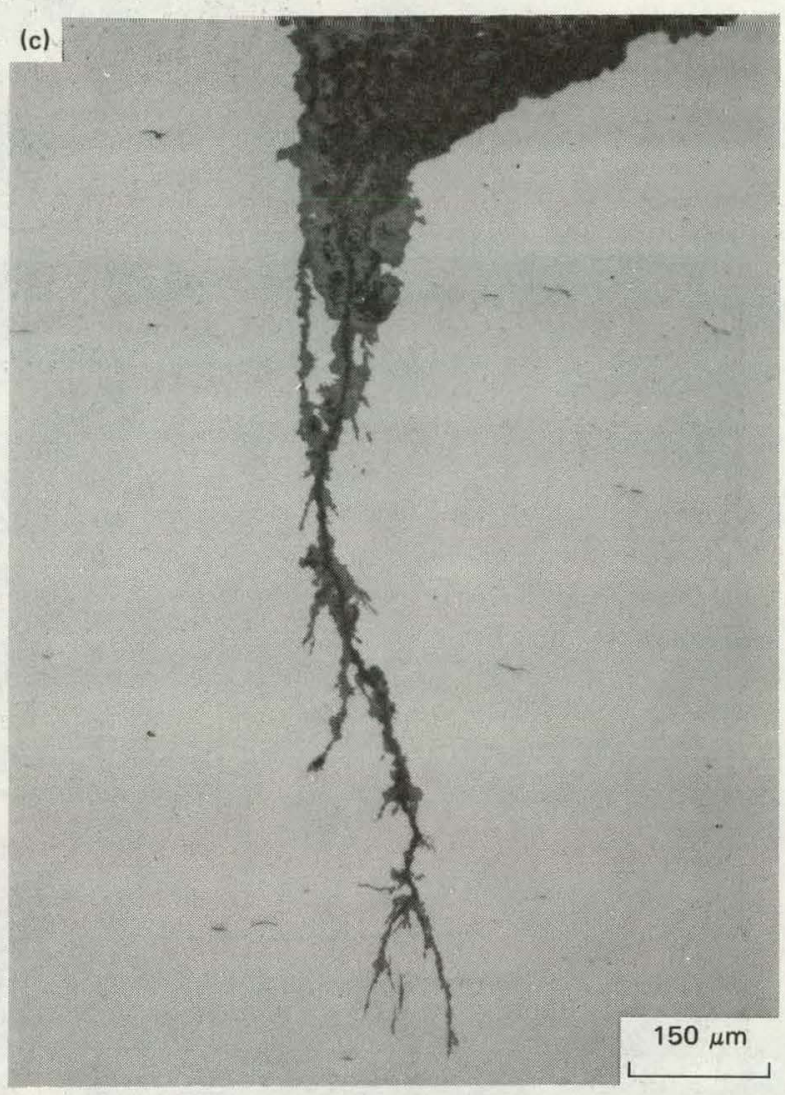

FIG. 3.15. Major crack in Beaver Valley section initiates at discontinuity at bottom of counterbore slope of elbow. Refer to Fig. 3.6(a). Note some corrosion craters. Sample shows most extensive branching of all plants. Note as-polished section. 


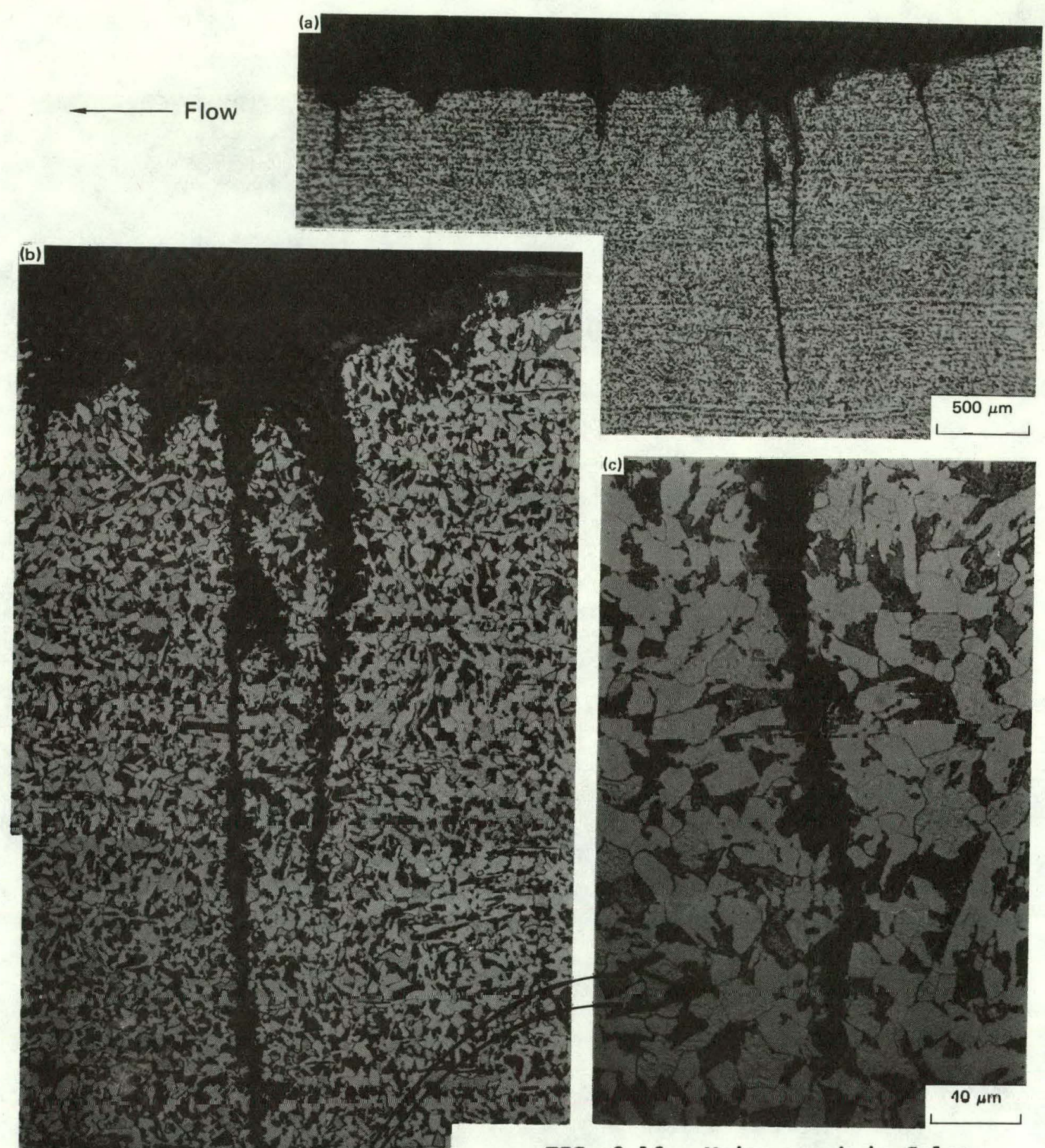



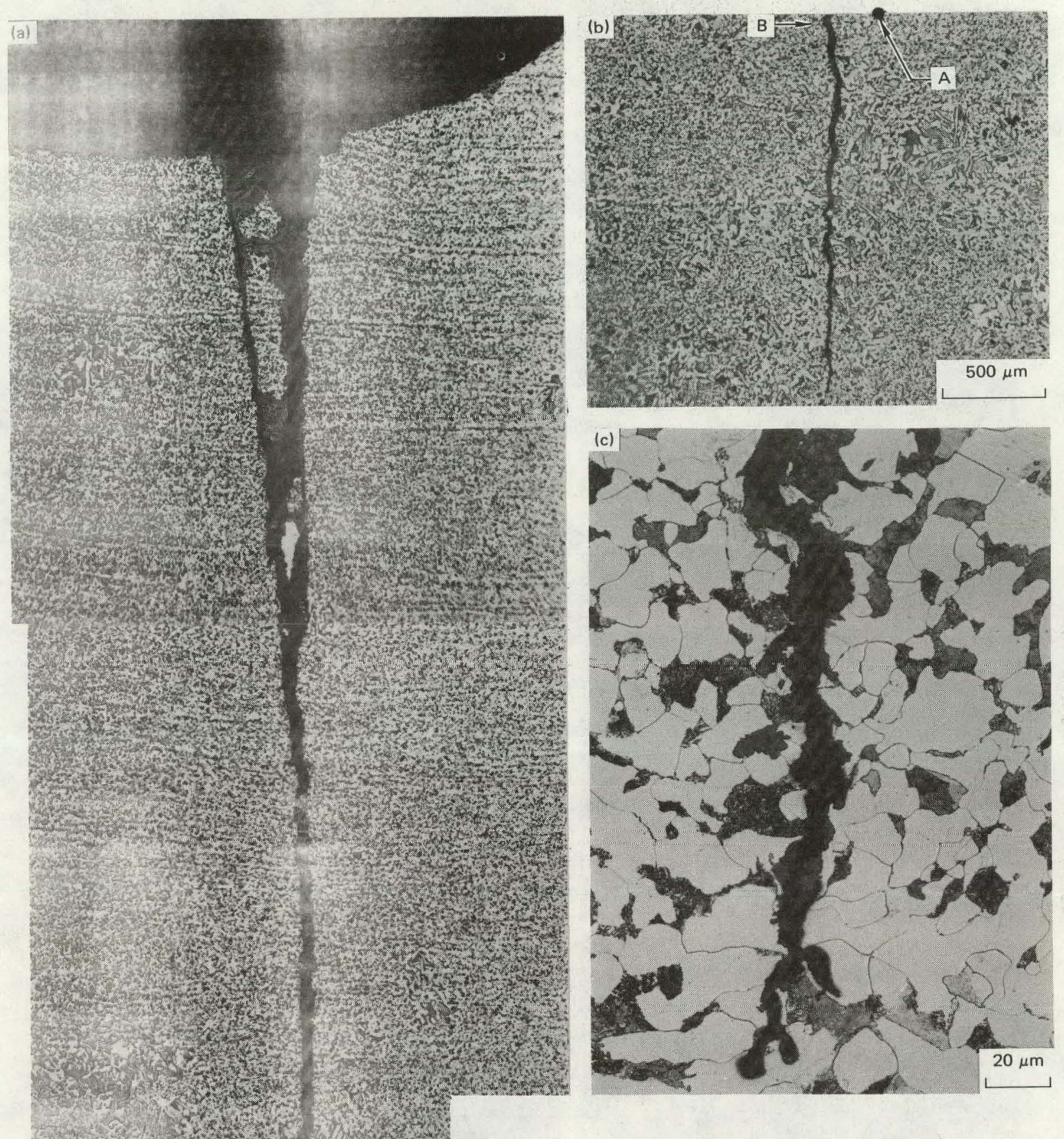

FIG. 3.17 Crack in D. C. Cook section at bottom of counterbore slope. Refer to Fig. 3.6(c). Although this crack was the only one observed in the section, it was the deepest crack and had the smallest corrosion craters in all the plants examined. See also Fig. 3.18, which shows branching at B in view (b). 


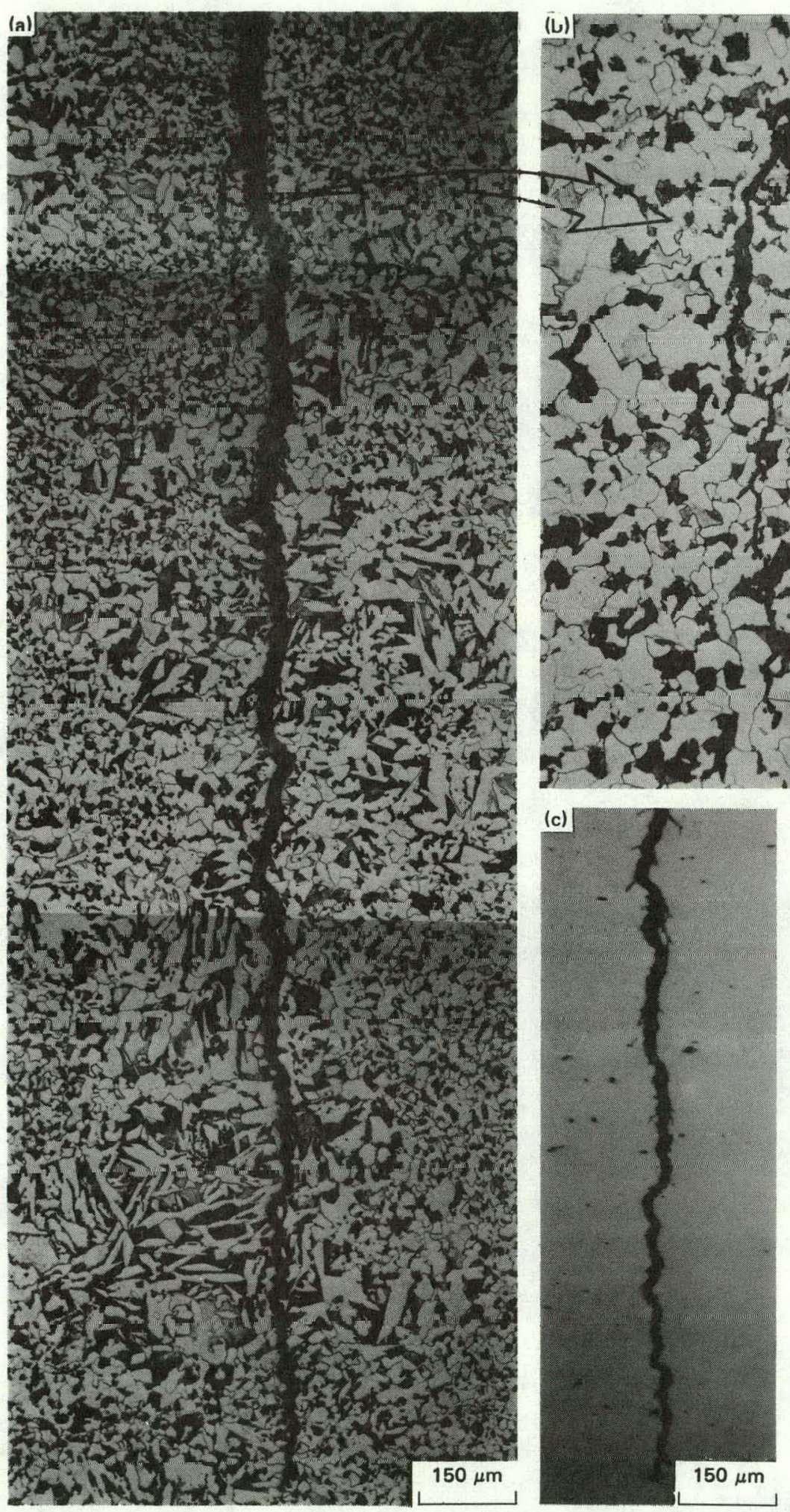

FIG. 3.18. Small branched cracks near bottom of crack at bottom of counterbore slope in D. C. Cook section. Refer to B in Fig. 3.17(b). Note very small corrosion spikes along entire crack length shown, especially in the as-polished section view (c). 

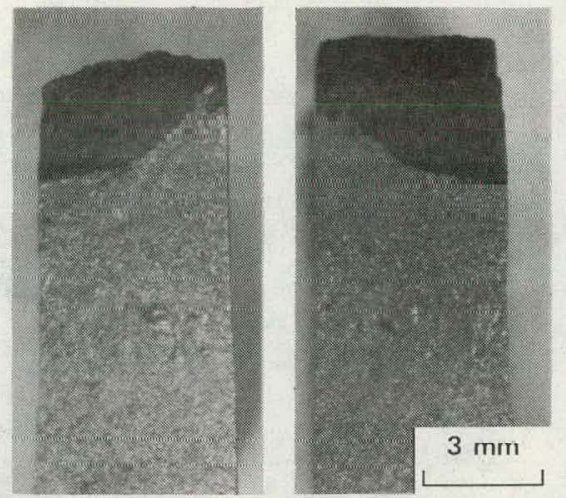

(a) San Onofre: Crack $A$ as-corroded and fractured

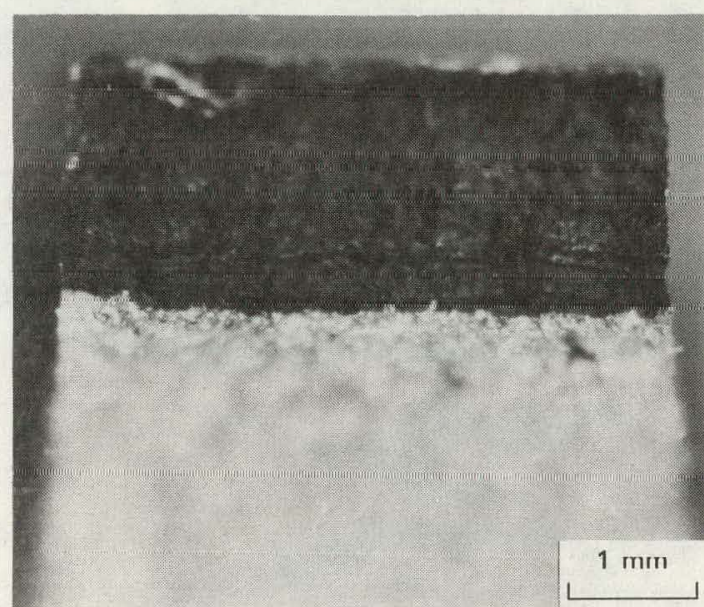

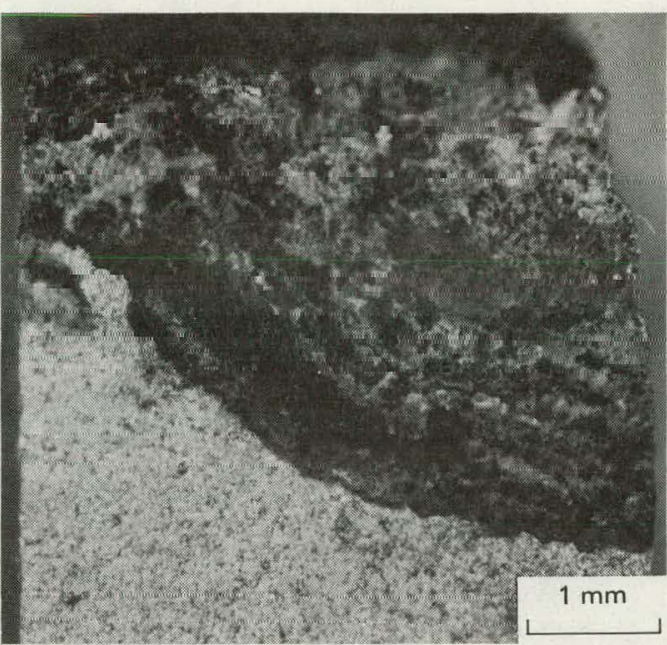

(b) San Onofre:

Crack $A$ after cathodic cleaning

(c) Ginna: Crack B

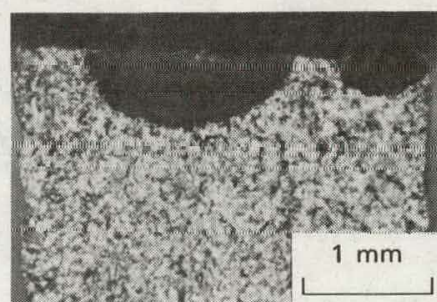

(d) H. B. Robinson: Crack B as-corroded and fractured

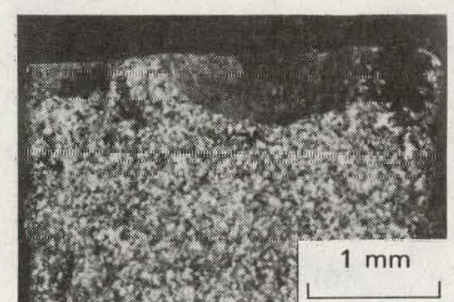

(e) H. B. Robinson: Crack B after cathodic cleaning

FIG. 3.19. Macroscopic views of crack surfaces from San Onofre, Ginna, and H. B. Robinson sections showing arrest bands. In views (a) and (b), note differences between as-corroded and after cathodic cleaning of the San Onofre crack. Upper regions are plant cracks; lower regions are laboratory fractures. Crack propagation is from top to bottom. 


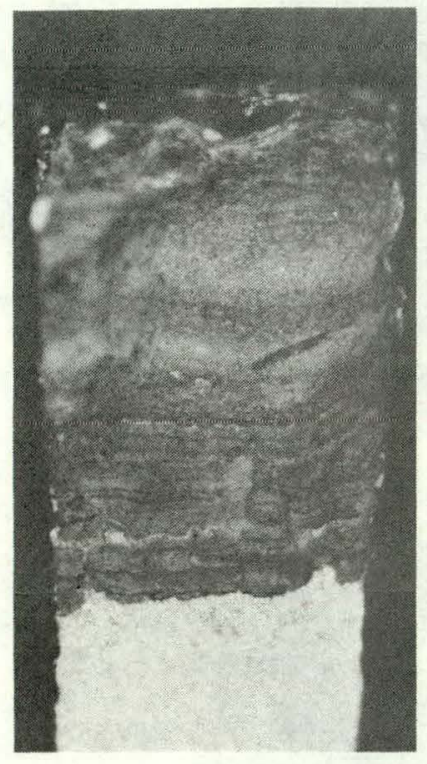

(a) $\operatorname{Crack} A$ : at pipe to weld interface

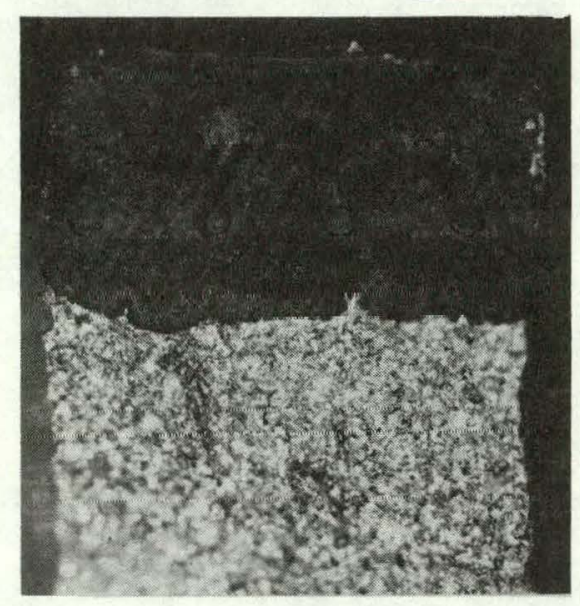

(c) Crack B:

at bottom of safe-end counterbore slope
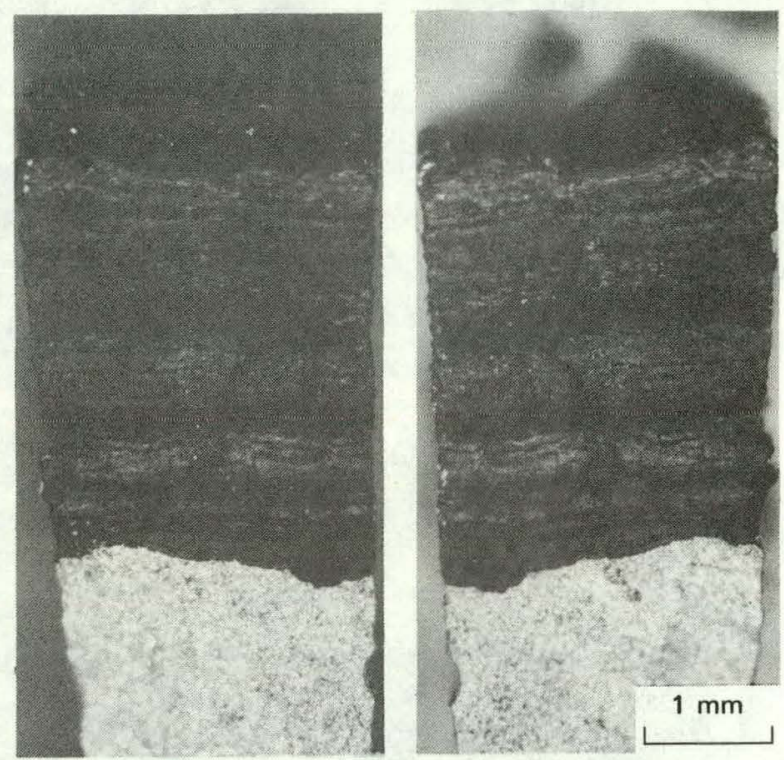

(b) Crack C: at bottom of pipe counterbore slope

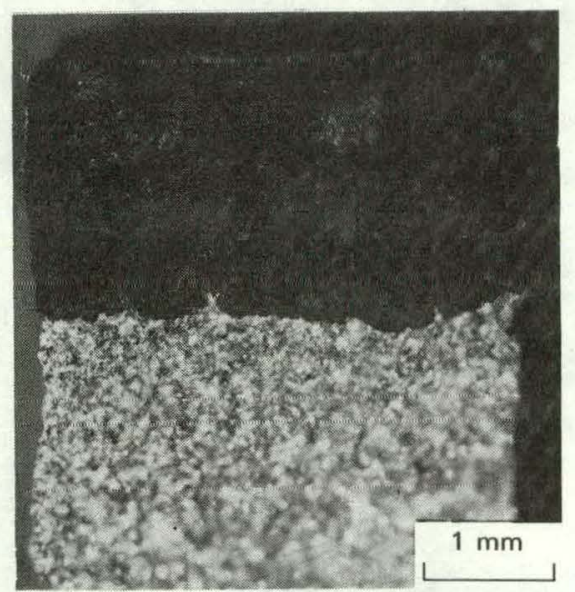

FIG. 3.20. Macroscopic views of crack surfaces of three cracks along a Palisades section. Refer to Fig. 3.5(a). Note that the arrest bands are less distinct in Crack $B$ than in Cracks $A$ and $C$. The upper regions are plant cracks; the lower regions are laboratory fractures. Crack propagation is from top to bottom. 


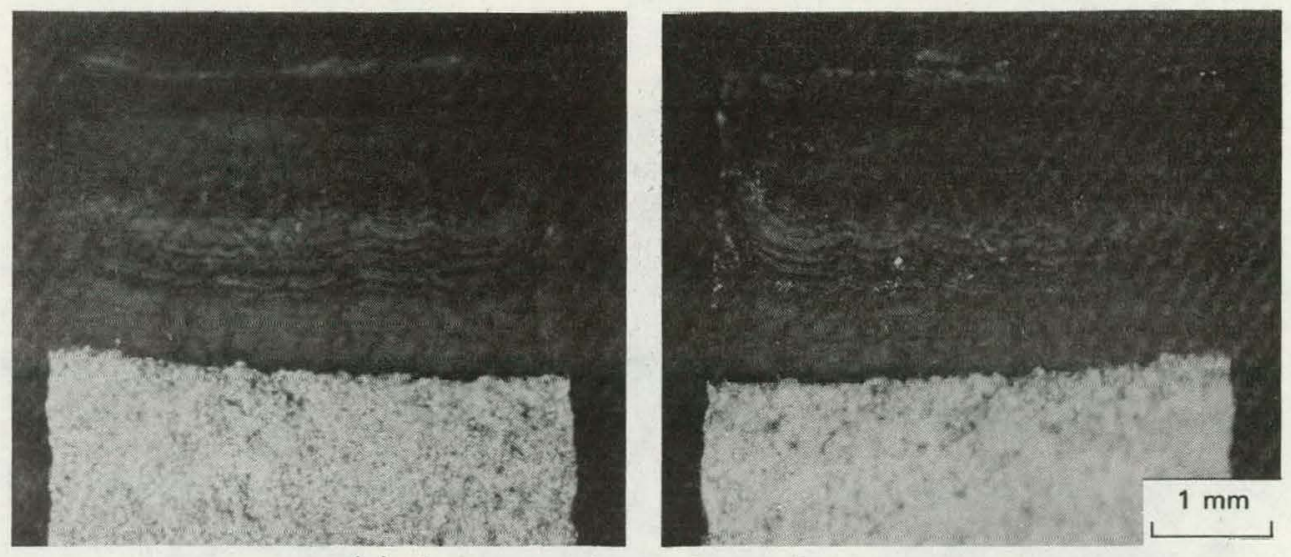

(a) At counterbore slope of safe-end

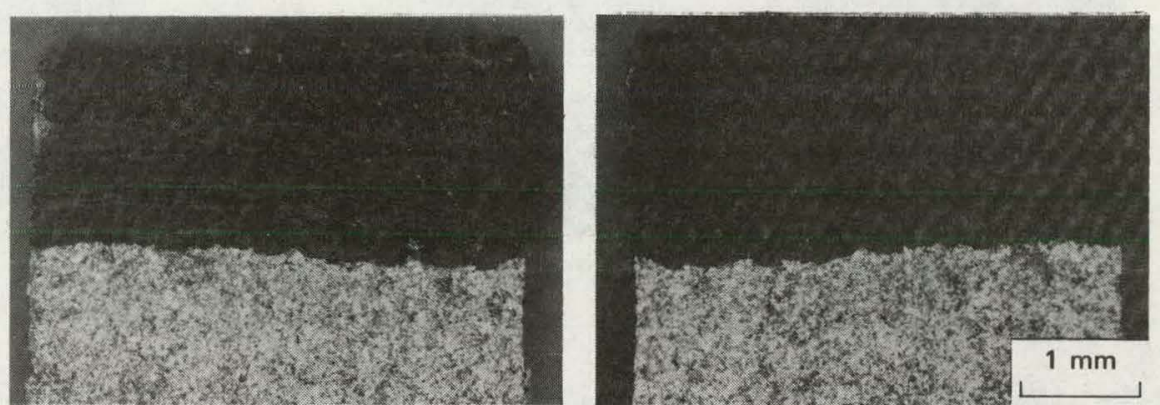

(b) At original I.D. of safe-end

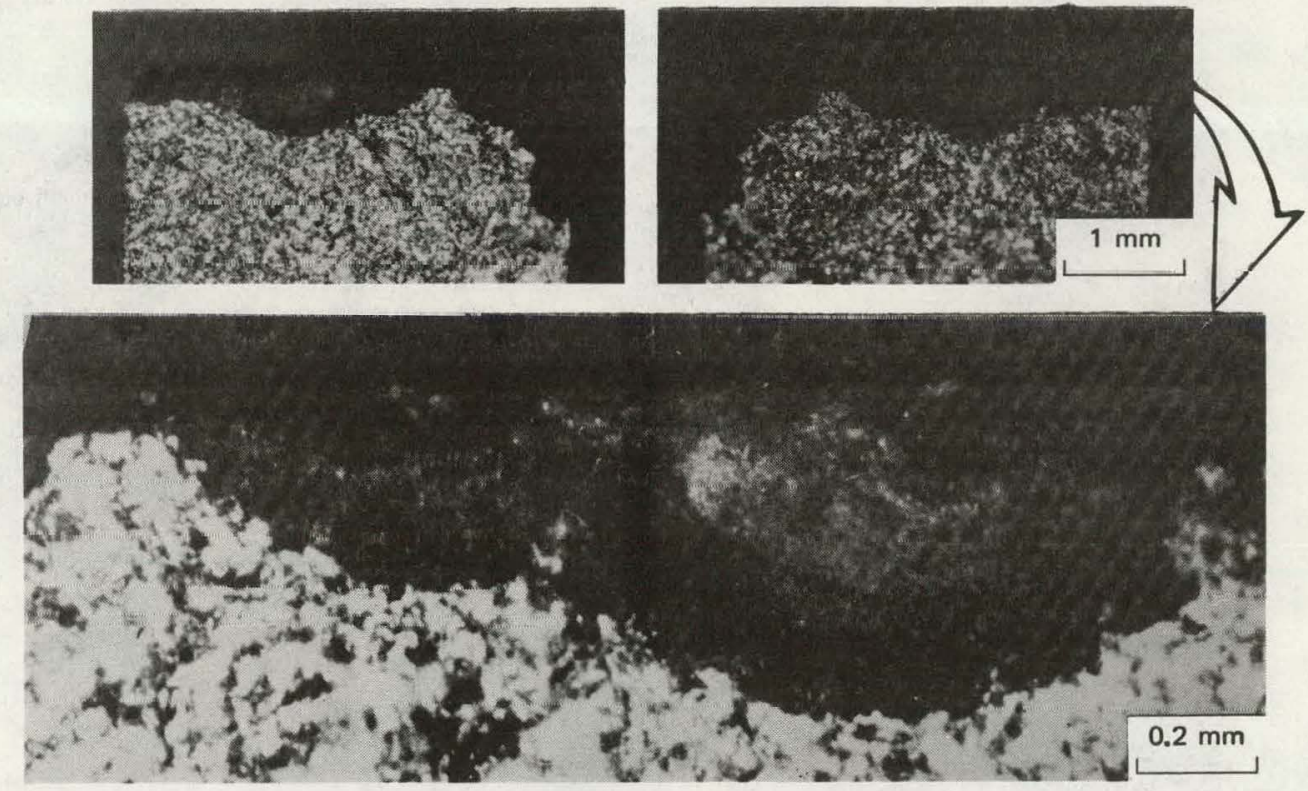

(c) At nriginal I.D. of pipe

FIG. 3.21. Macroscopic views of crack surfaces of additional cracks along a Palisades section. Refer to Fig. 3.5(a). Note that the arrest bands are less distinct in pipe cracks than in safe-end cracks. The upper regions are plant cracks; the lower regions are laboratory fractures. Crack propagation is from top to bottom. 


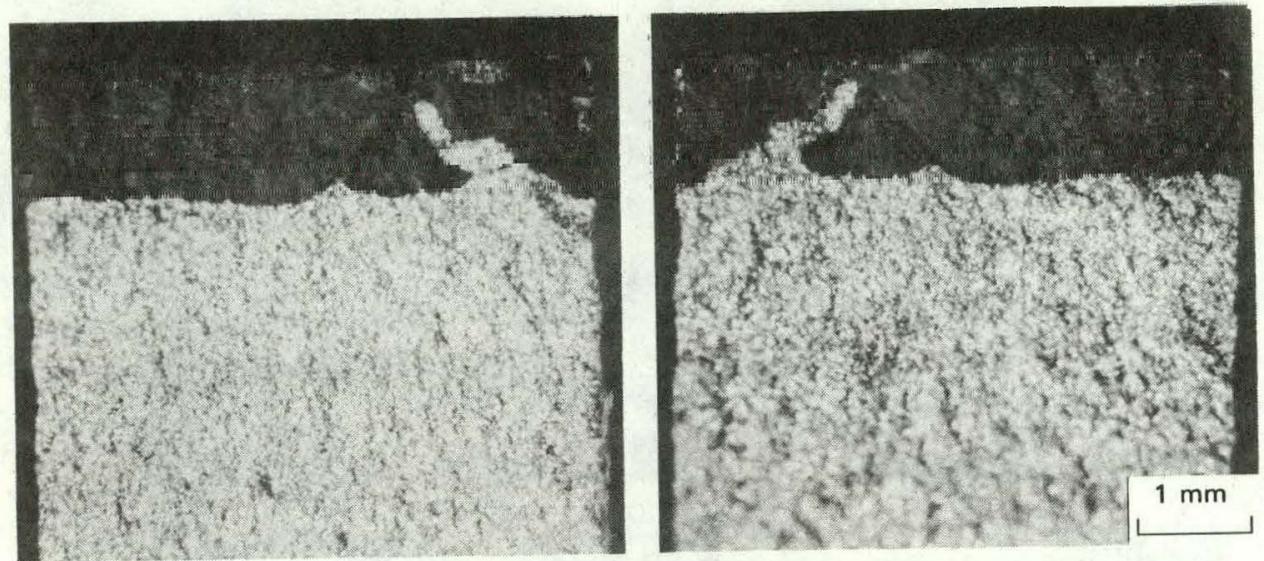

(a) Point Beach: Crack B

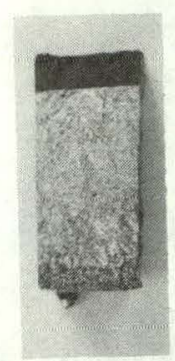

(b) Kewaunee: Crack A

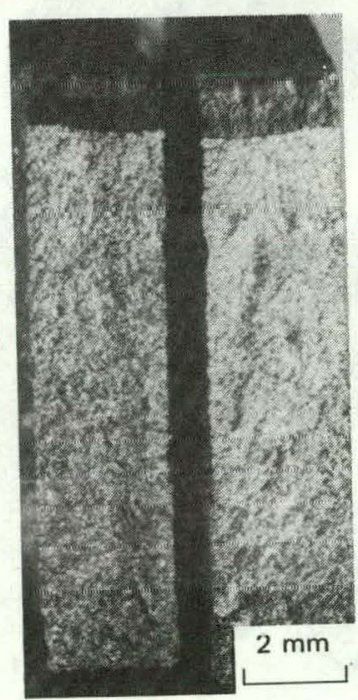

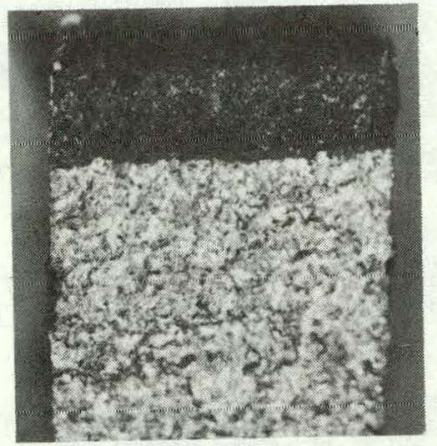

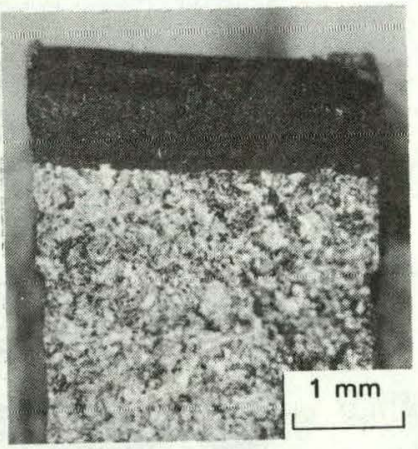

(c) Kewaunee: Crack B
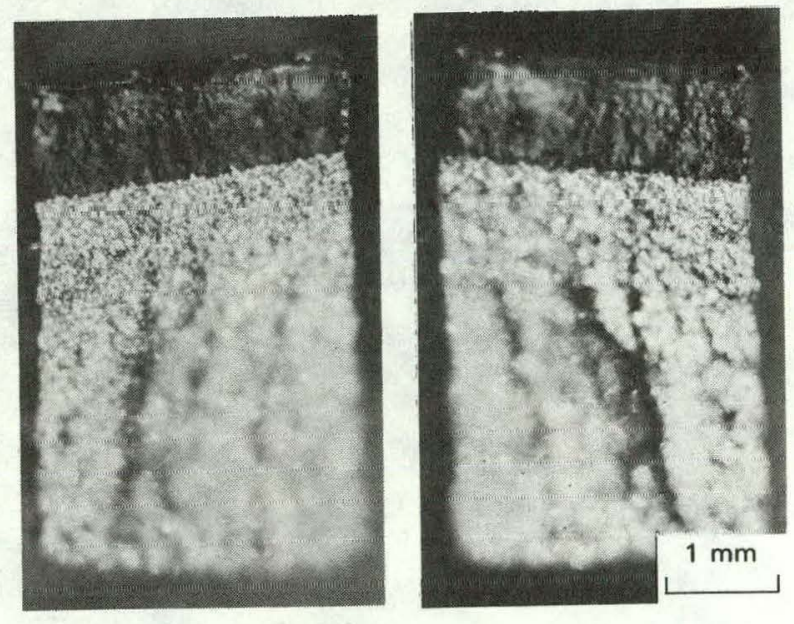

(d) Beaver Valley: Crack B

FIG. 3.22. Macroscopic views of crack surfaces from Point Beach, Kewaunee, and Beaver Valley sections showing arrest bands. Refer to Fig. 3.5(c) for Kewaunee cracks: Crack $A$ is at weld-to-pipe interface; Crack B is at discontinuity at bottom of counterbore slope. Beaver valley views are of surfaces from different sections of same crack. The upper regions are plant cracks; the lower regions are laboratory fractures. Crack propagation is from top to bottom. 

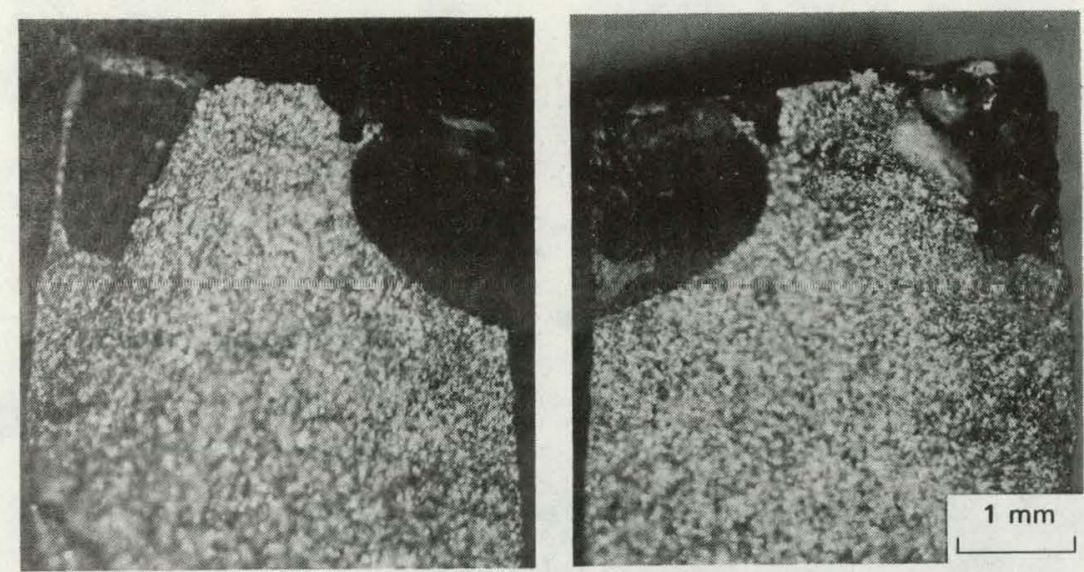

(a) Salem: Crack B
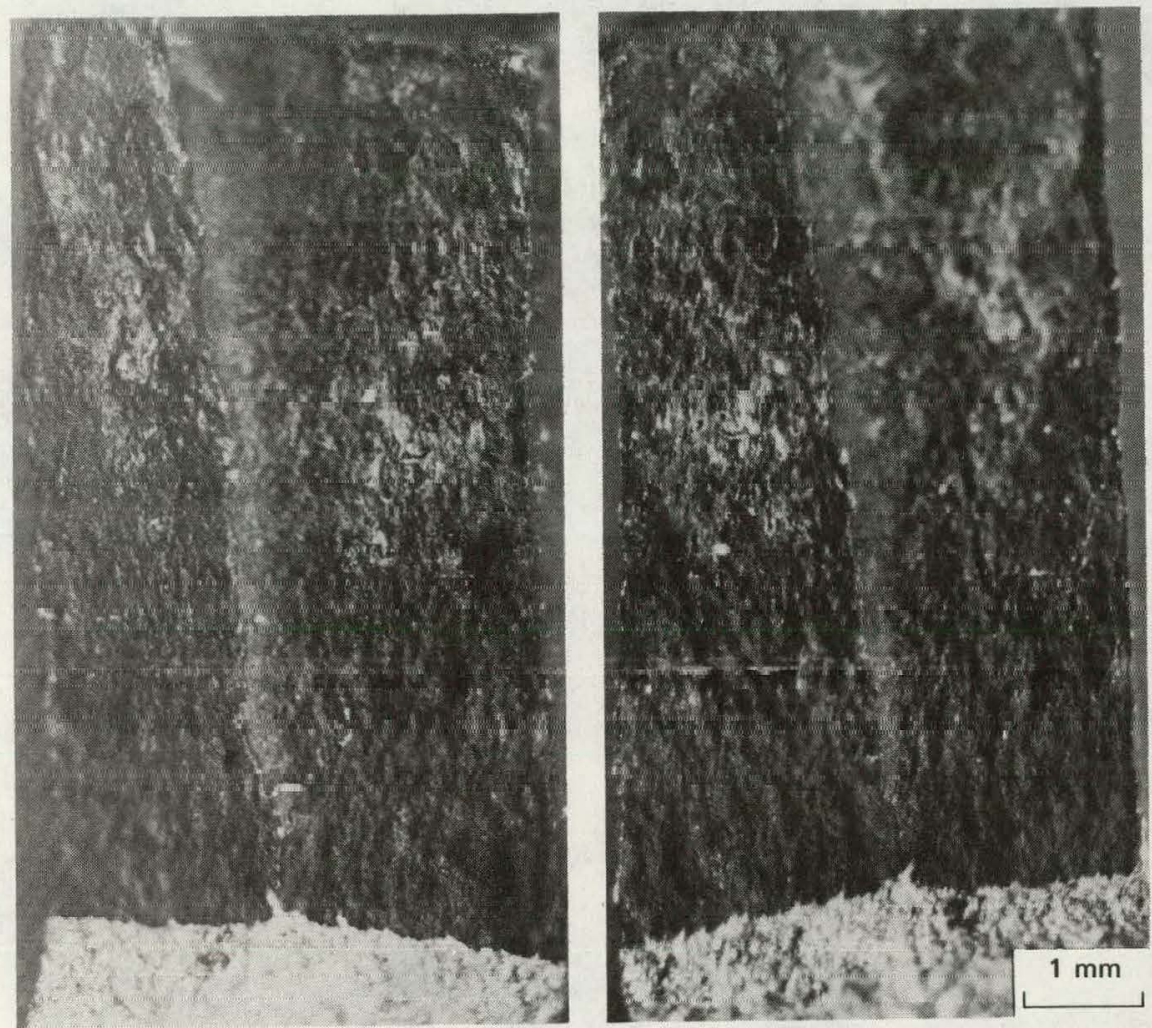

(b) D. C. Cook: Crack B as-corroded and fractured, before cathodic cleaning

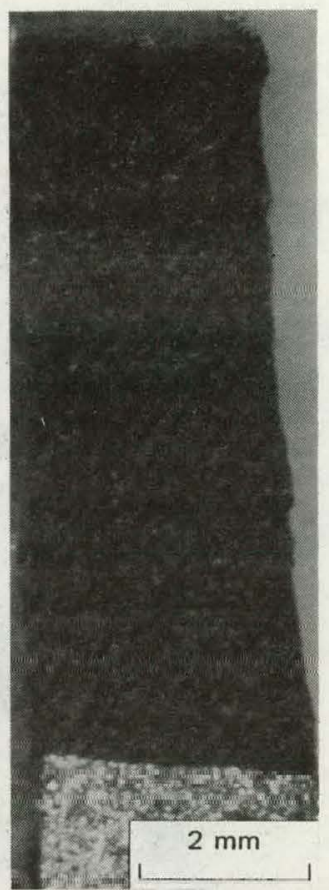

(c) D.C. Cook: before cleaning

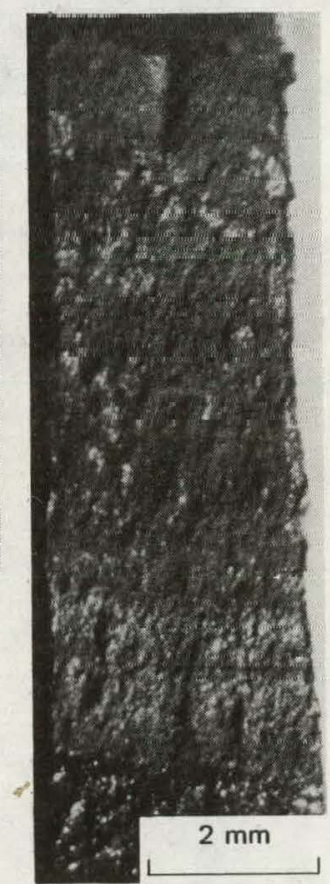

(d) D.C. Cook: after cleaning

FIG. 3.23. Macroscopic views of crack surfaces from Salem and D. C. Cook sections showing arrest bands. In view (b), note that the arrest bands are not visible on the as-corroded surface of the D. C. Cook crack. After cathodic cleaning, numerous arrest bands become visible. Compare view (c) with view (d). Views (b) and (c) are of surfaces from adjacent sections of the same crack. 


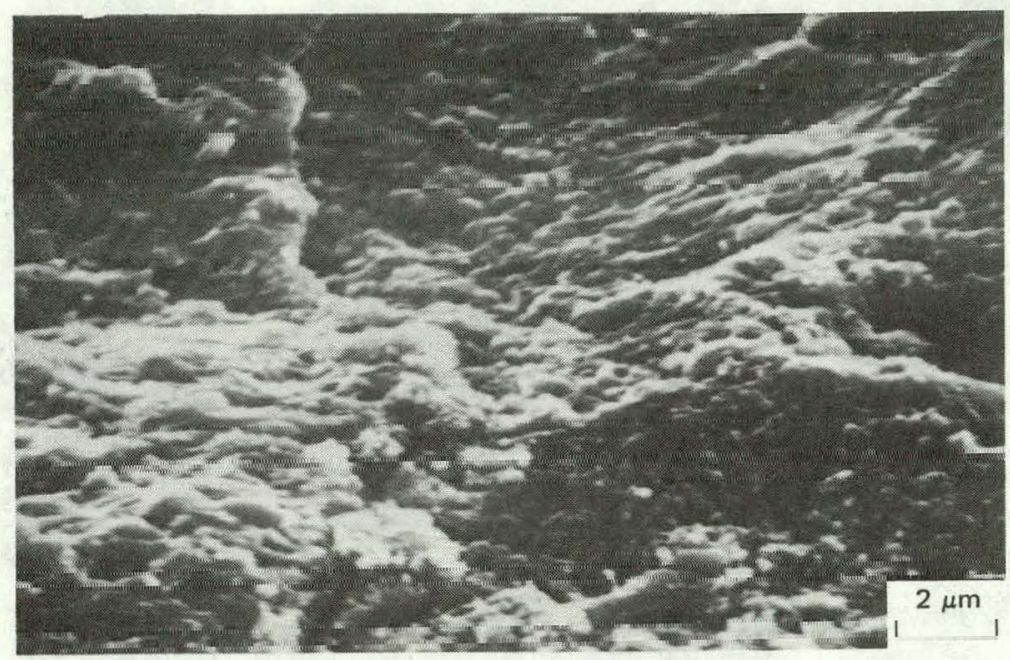

(a) H. B. Robinson

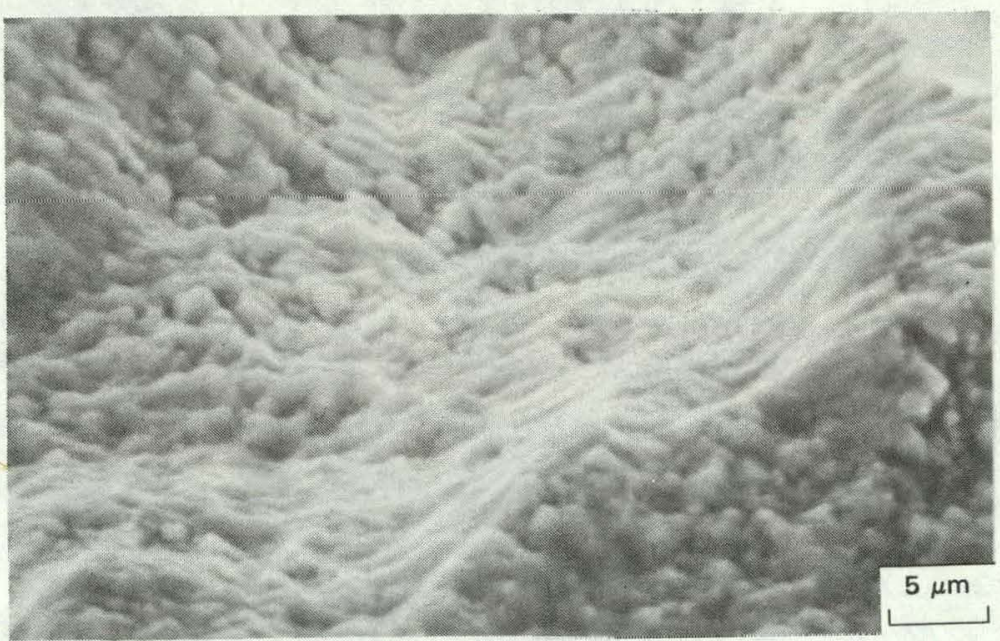

(b) Beaver Valley

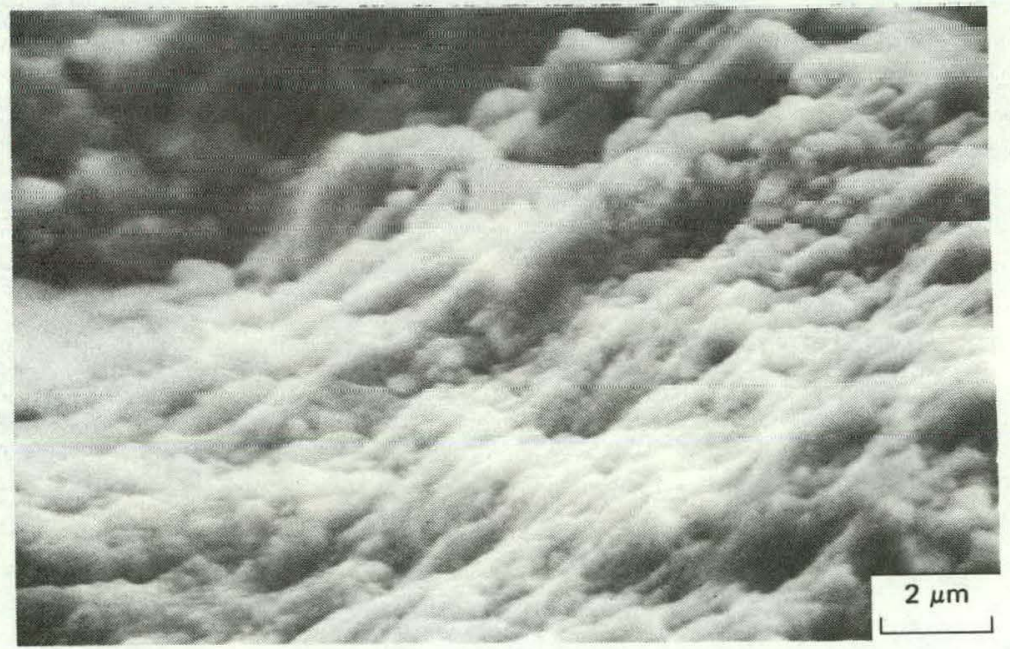

Crack

propagation

Crack

propagation

(c) D.C. Cook

(shallow crack)

Crack

propagation

FIG. 3.24. SEM fractographs of as-corroded crack surfaces from H. B. Robinson, Beaver Valley, and D. C. Cook showing wavy striations suggesting cyclic events. 


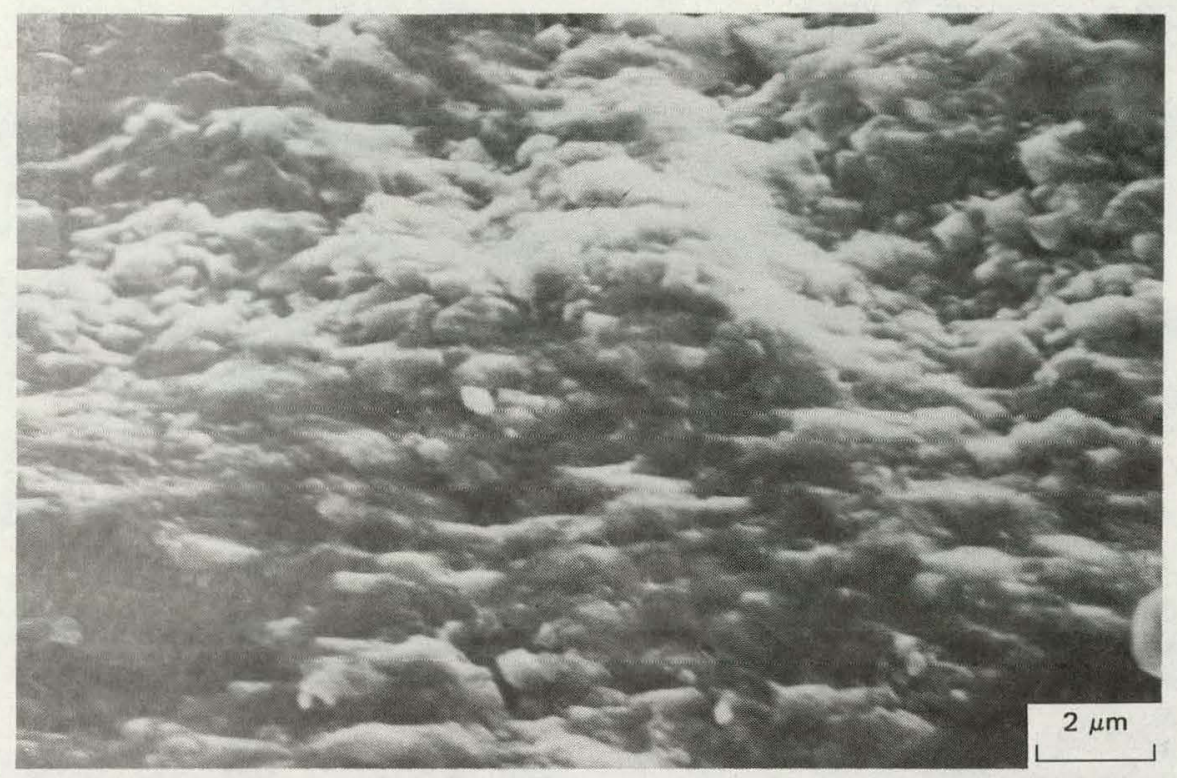

(a) Crack tip

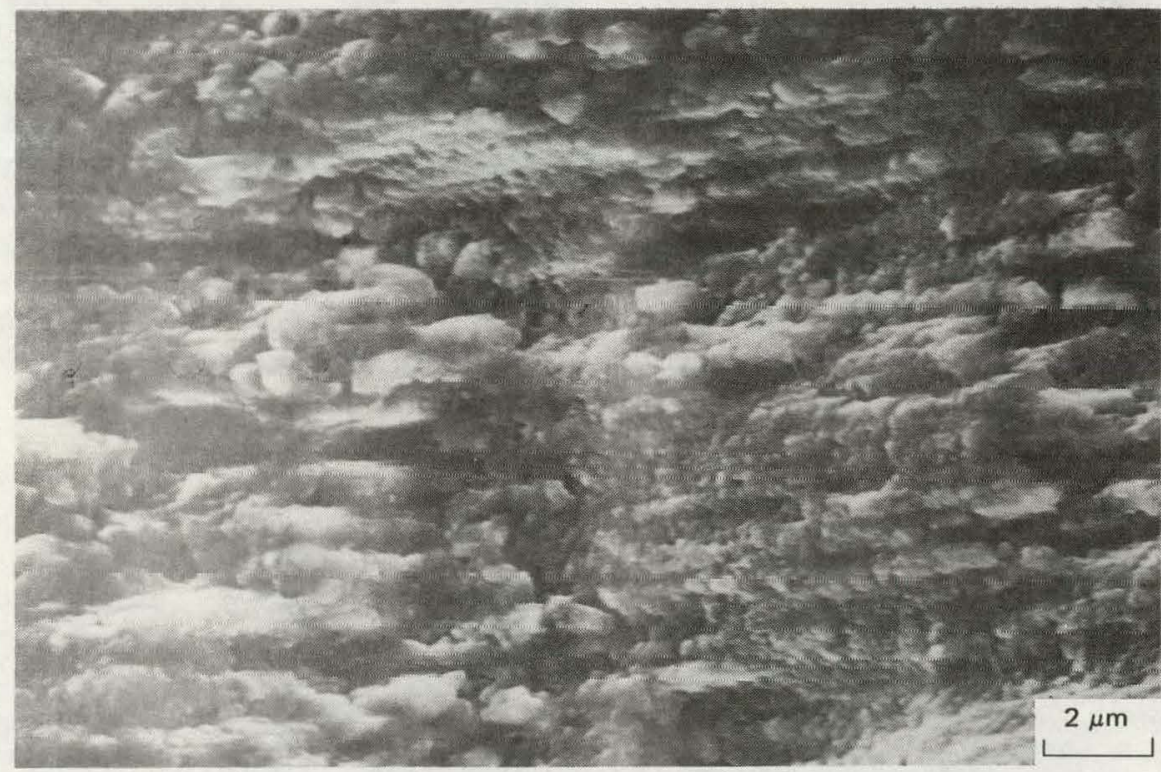

(b) Crack center Crack
propagation

Crack

propagation

FIG. 3.25. SEM fractographs of as-corroded crack surface from Beaver Valley showing crater-like, parallel ridges suggesting cyclic events. 

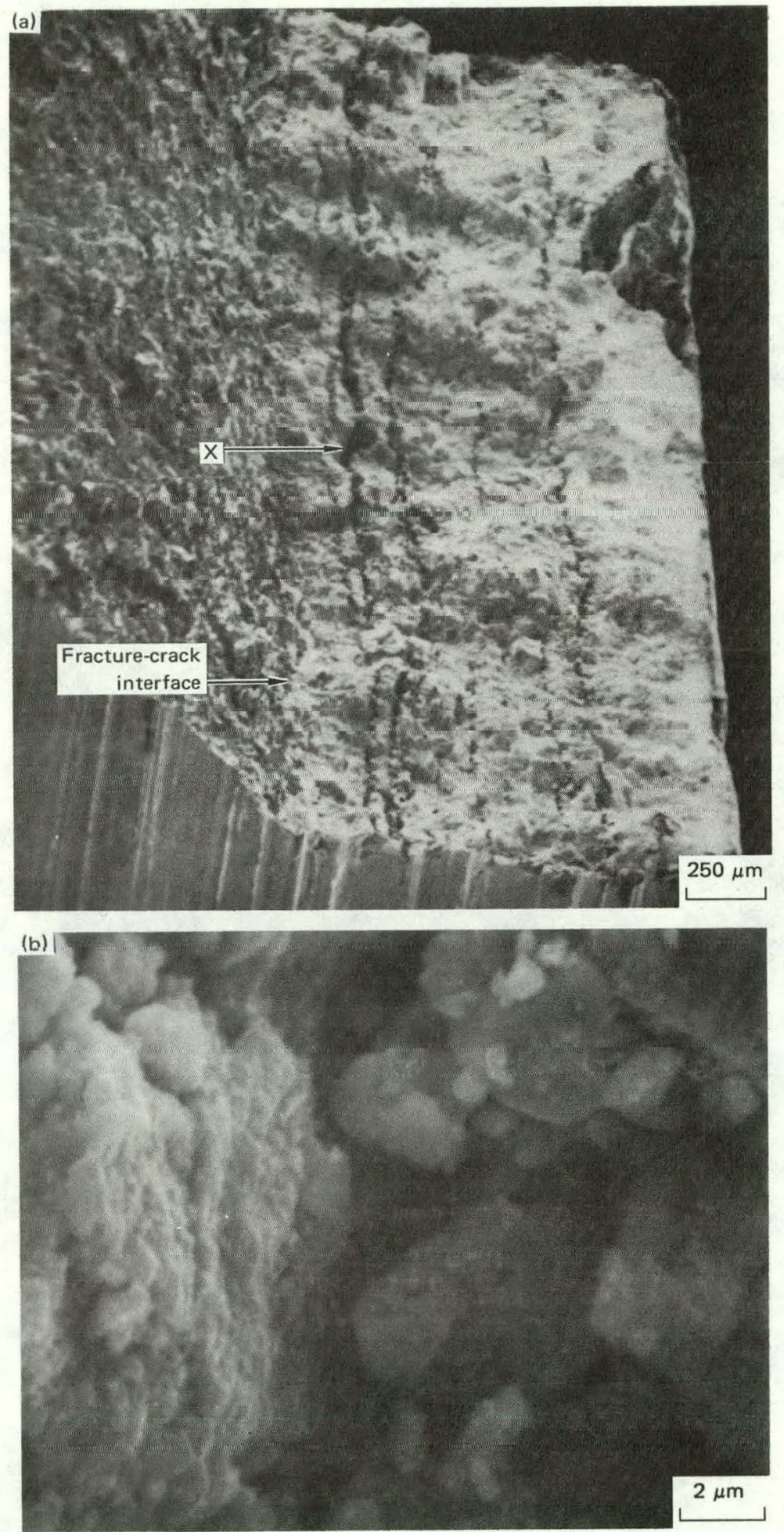

FIG. 3.26. SEM fractographs of as-corroded crack surface from Ginna. View (a) shows arrest bands along the surface. View (b) shows the relatively porous morphology of corrosion product in the arrest band indicated by $\mathrm{x}$ in view (a). 


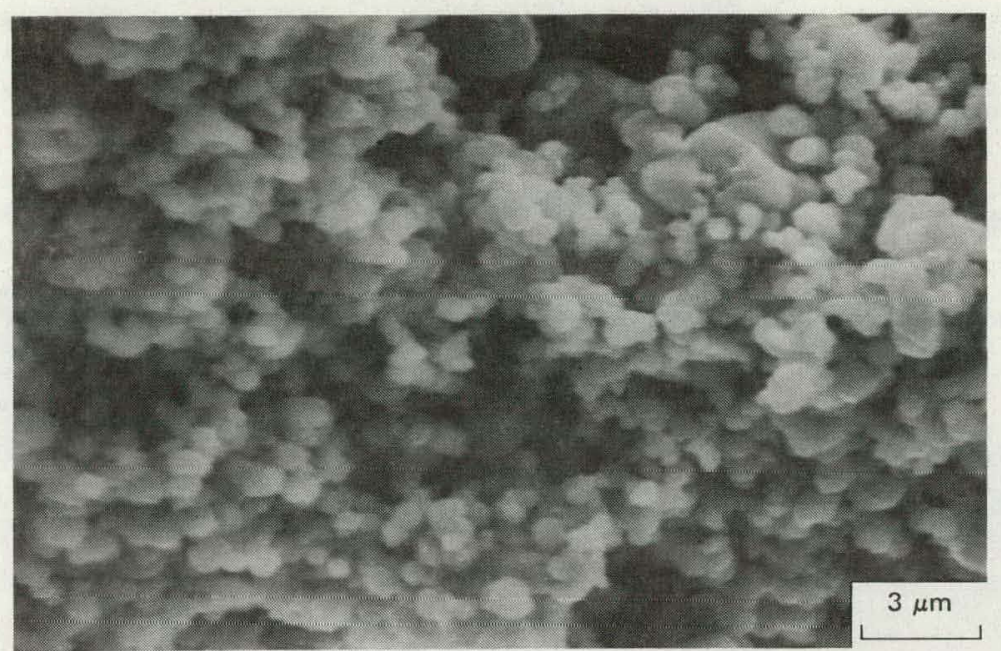

(a) San Onofre: globular

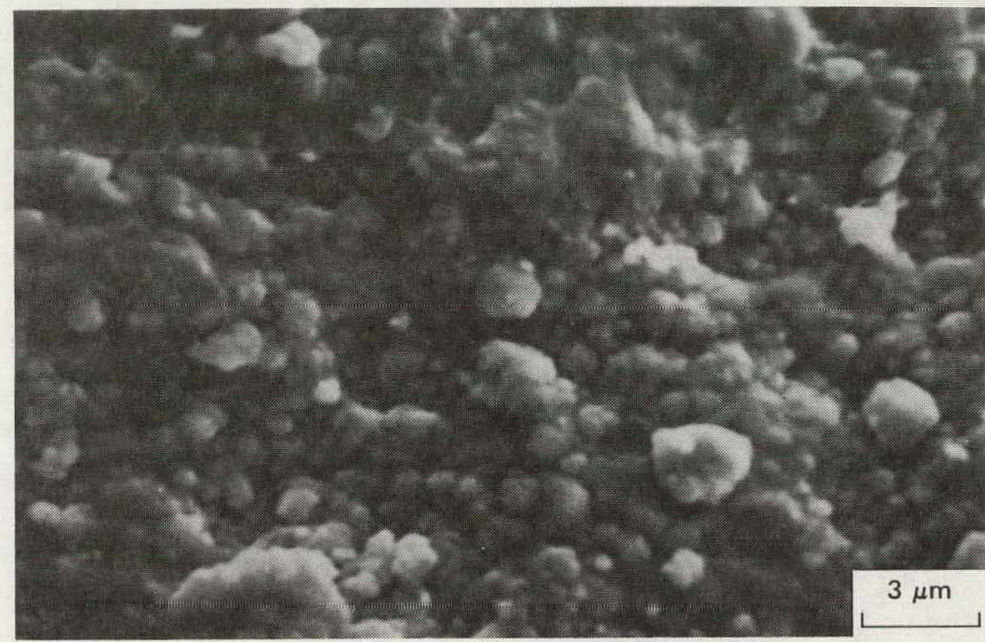

(b) H.B. Robinson: spongy

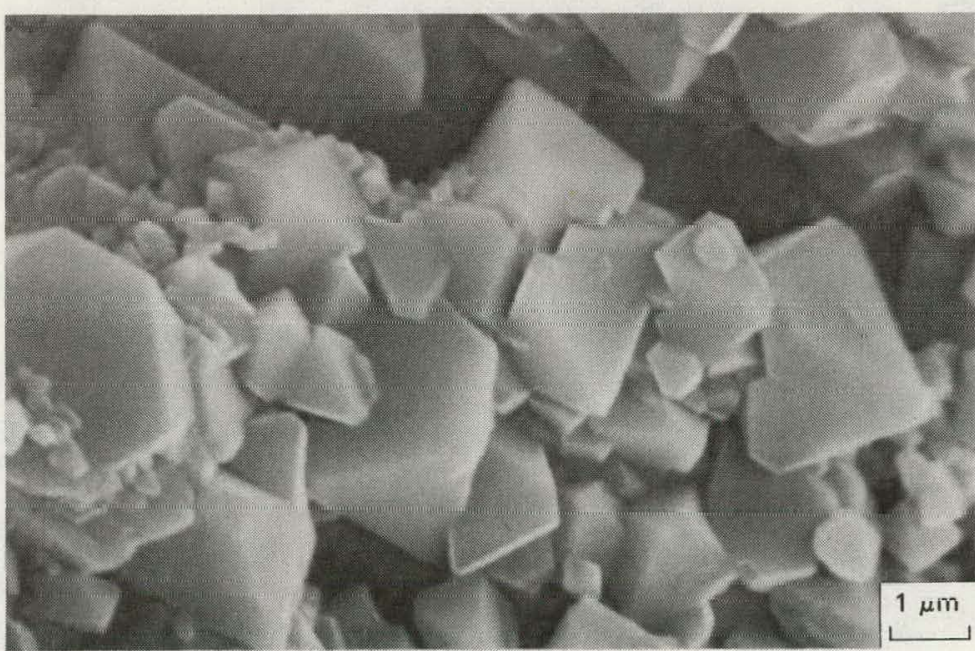

(c) D. C. Cook

(shallow crack):

faceted

FIG. 3.27. SEM views showing typical morphology of corrosion nodules on crack surfaces for sections from San Onofre, H. B. Robinson, and D. C. Cook. 


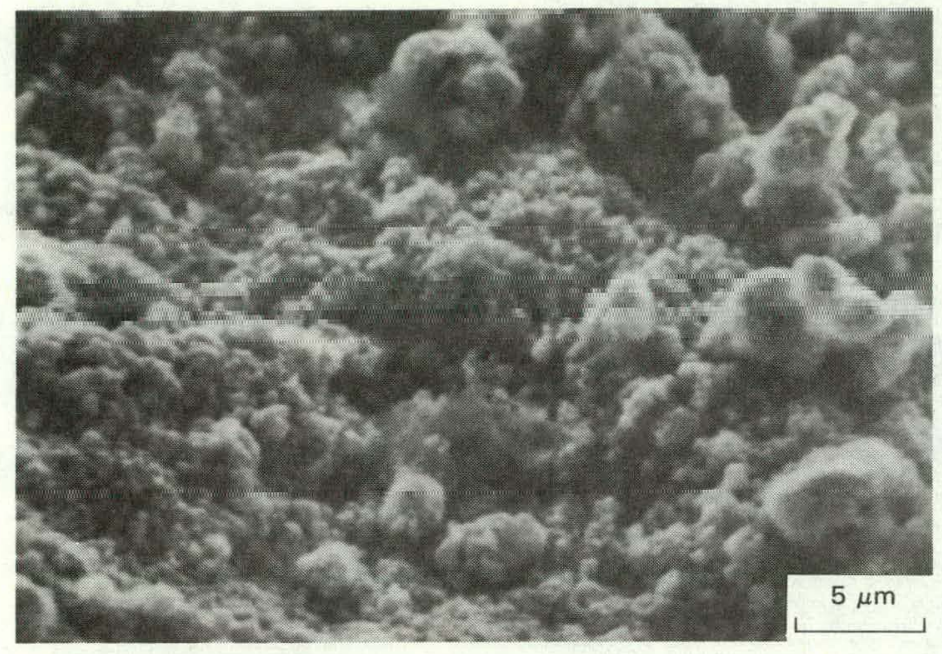

(a) Ginna: spongy

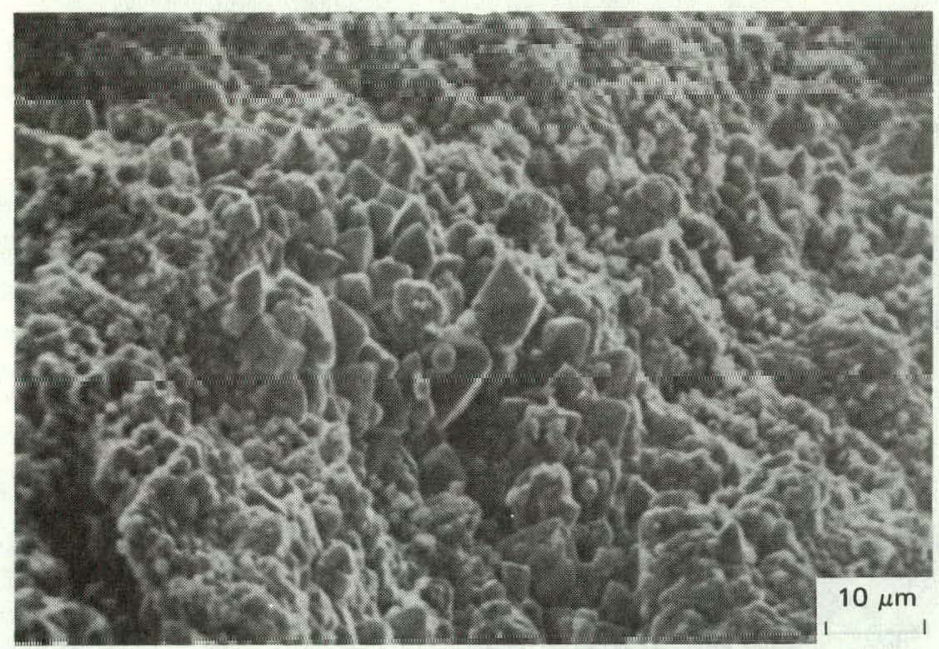

(b) Palisades: faceted, globular, and spongy

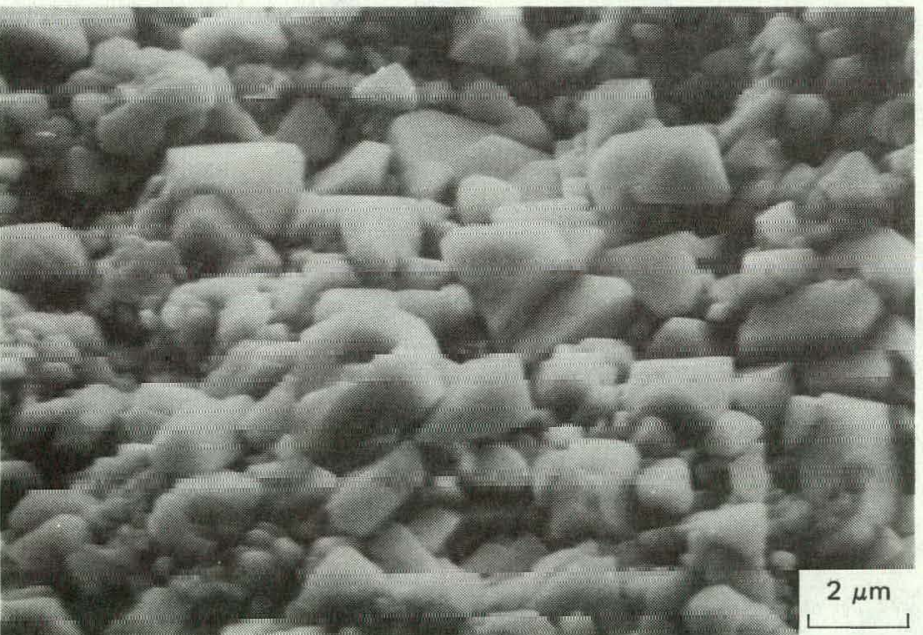

(c) Kewaunee: faceted and qlobular

FIG. 3.28. SEM views showing typical morphology of corrosion nodules on crack surfaces for sections from Ginna, Palisades, and Kewaunee. 


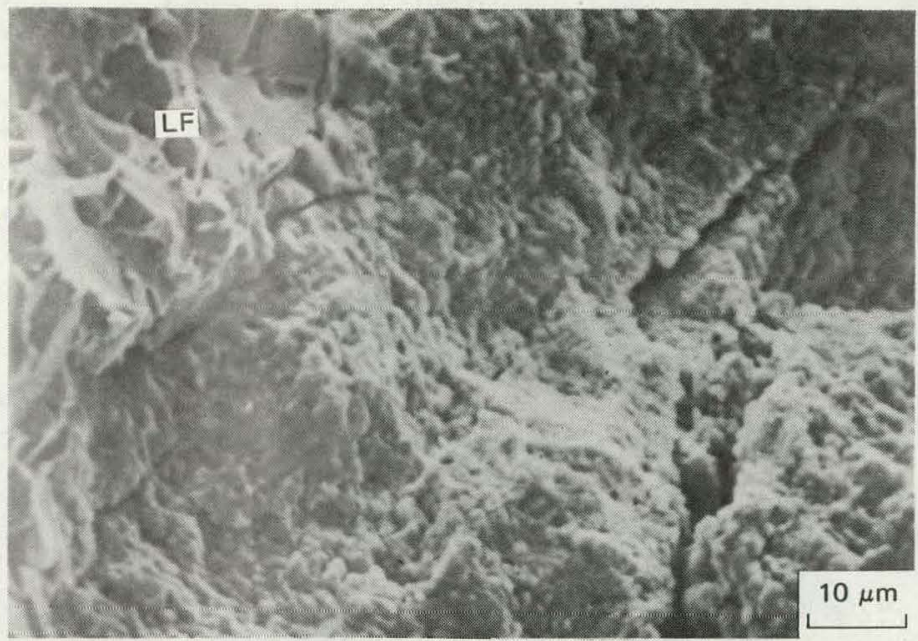

(a) Palisades

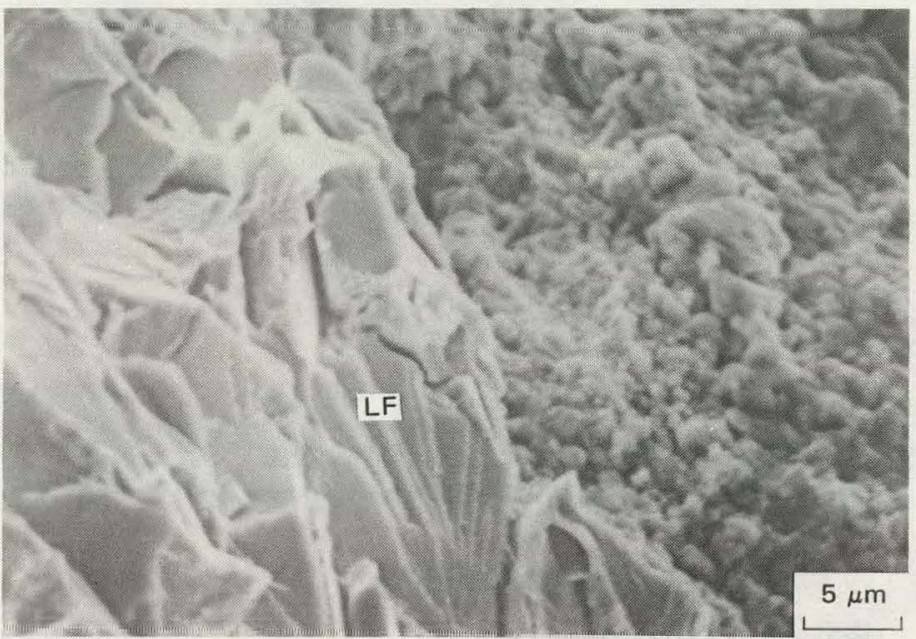

(b) Point Beach

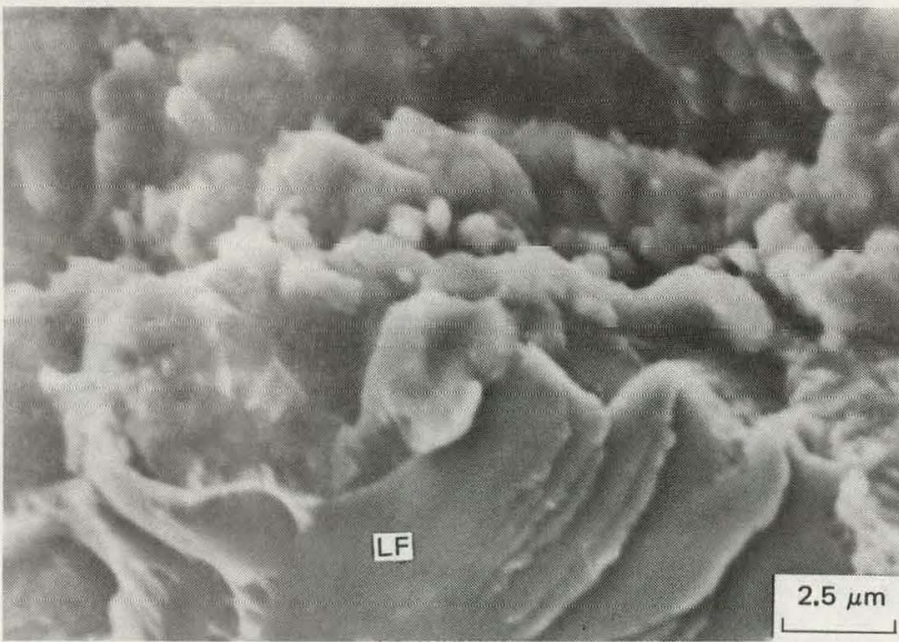

(c) D.C. Cook

(shallow crack)

$L F=$ Laboratory fracture

FIG. 3.29. SEM views taken across interface from plant crack to laboratory fracture of crack surfaces from sections from Palisades, Point Beach, and D. C. Cook. Note corrosion nodules at crack tips and crack-like appearance of corrosion product--probably an arrest band--especially at the tip in the Palisades section shown in view (a). 


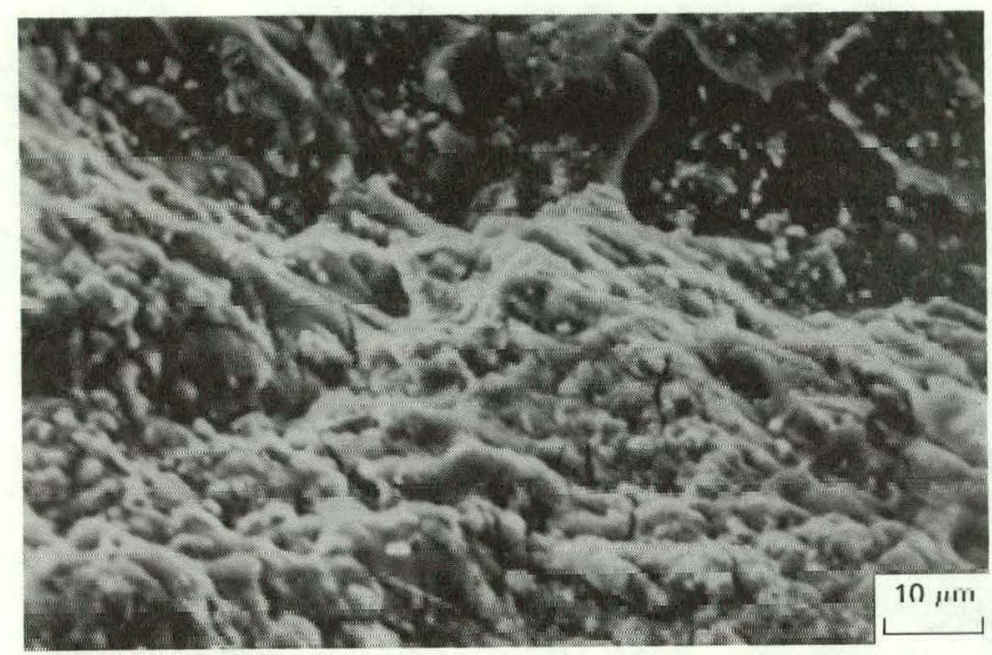

(a) Crack tip

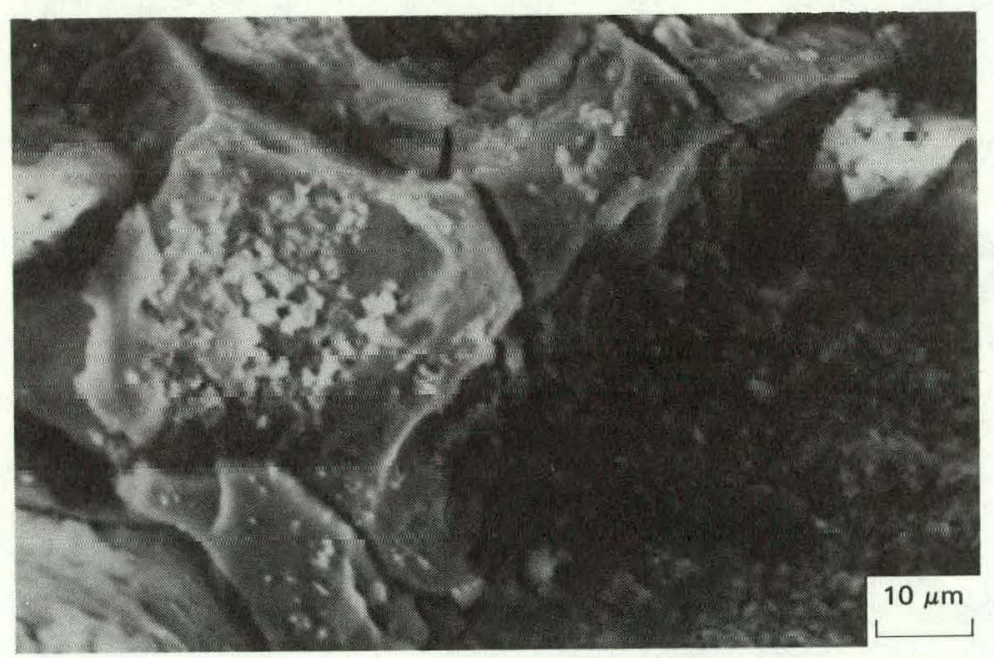

b) Crack center

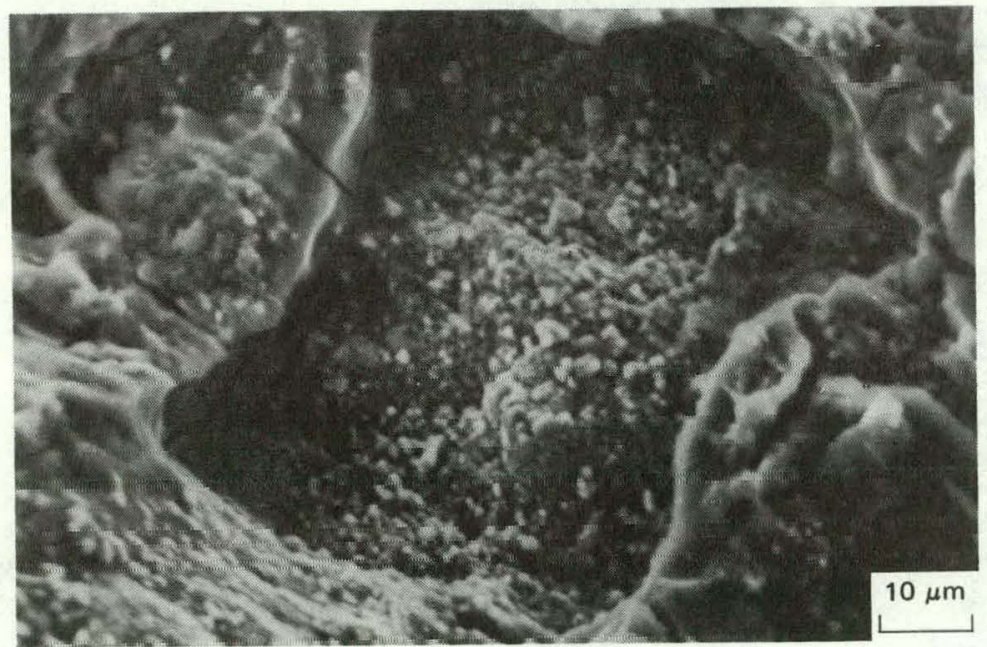

(c) Crack center

FIG. 3.30. SEM fractographs of crack surface of D. C. Cook section showing crazed surface of corrosion product at crack tip and crack center. In view (c), note increased concentration of discrete corrosion nodules where part of surface had apparently flaked-off. 

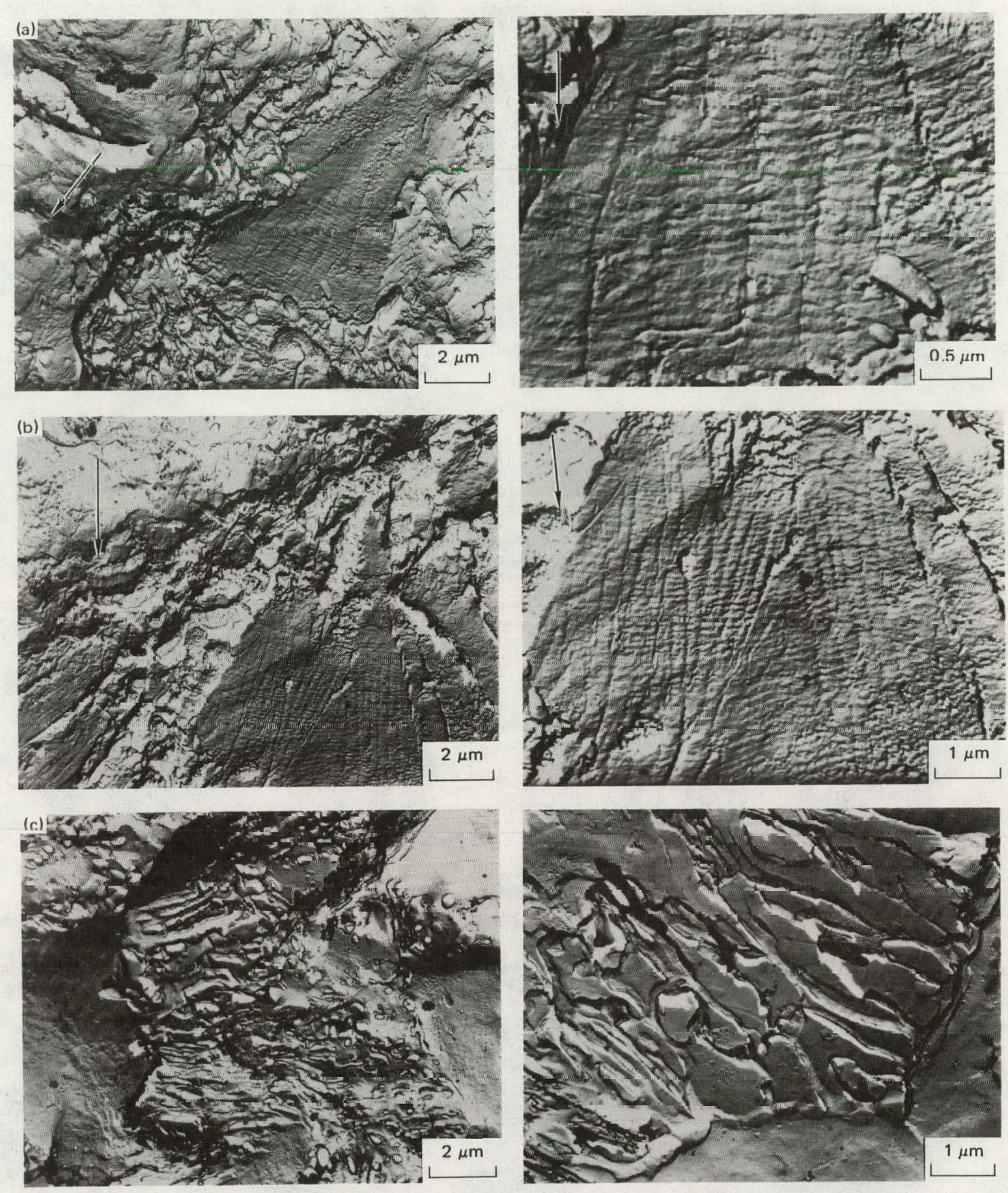

FIG. 3.31. TEM fractographs of replicas of a crack tip from the cleaned crack surface of a D. C. Cook section. Three areas, each at two magnifications, are shown. Note the classical fatigue striations and tear ridges in views (a) and (b). The arrows indicate the estimated direction of crack propagation. Note the pearlite lamellae in view (c). 

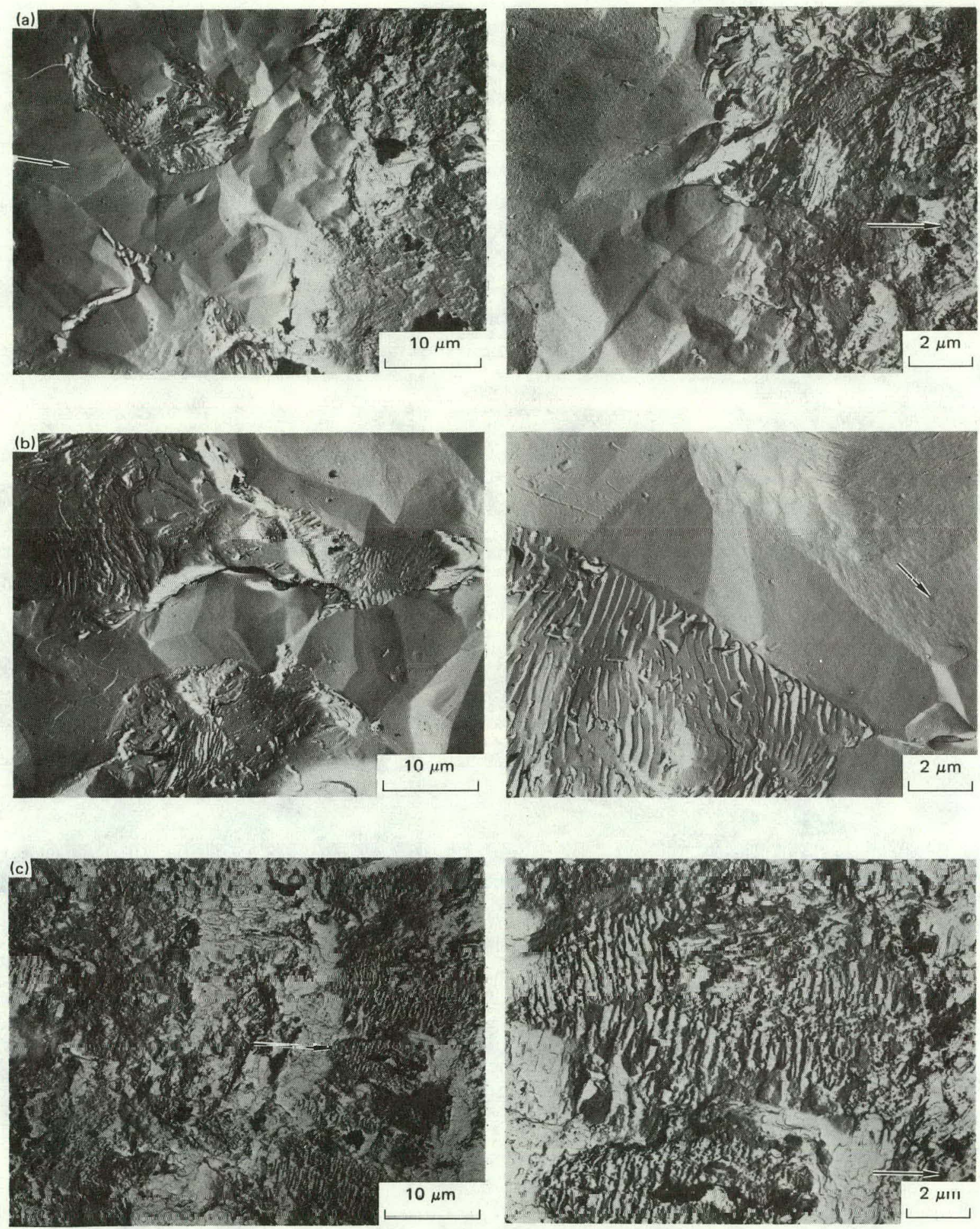

FIG. 3.32. TEM fractographs of replicas obtained near the crack origin of the cleaned crack surface of a D. C. Cook section. Three areas, each at two magnifications, are shown. Note the faceted grains between the distinct pearlite regions in views (a) and (b). Also note the corroded surface with striations and/or pearlite in views (a) and (c). Arrows indicate estimated direction of crack propagation. 

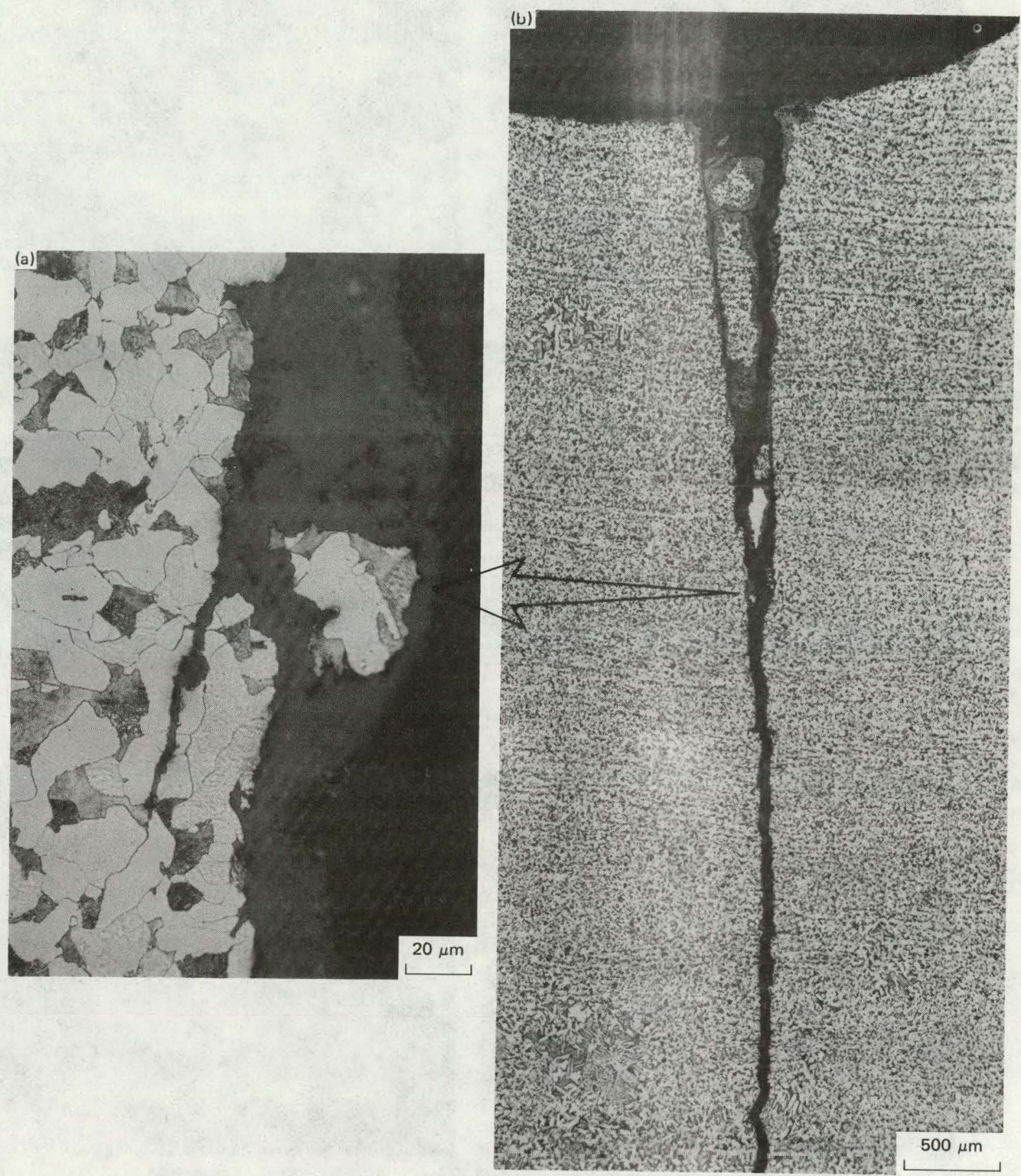

FIG. 3.33. Branched crack tip propagating at grain boundary after mostly transgranular cracking in a D. C. Cook section. The location corresponds roughly to the crack depth in Fig. 3.32. 

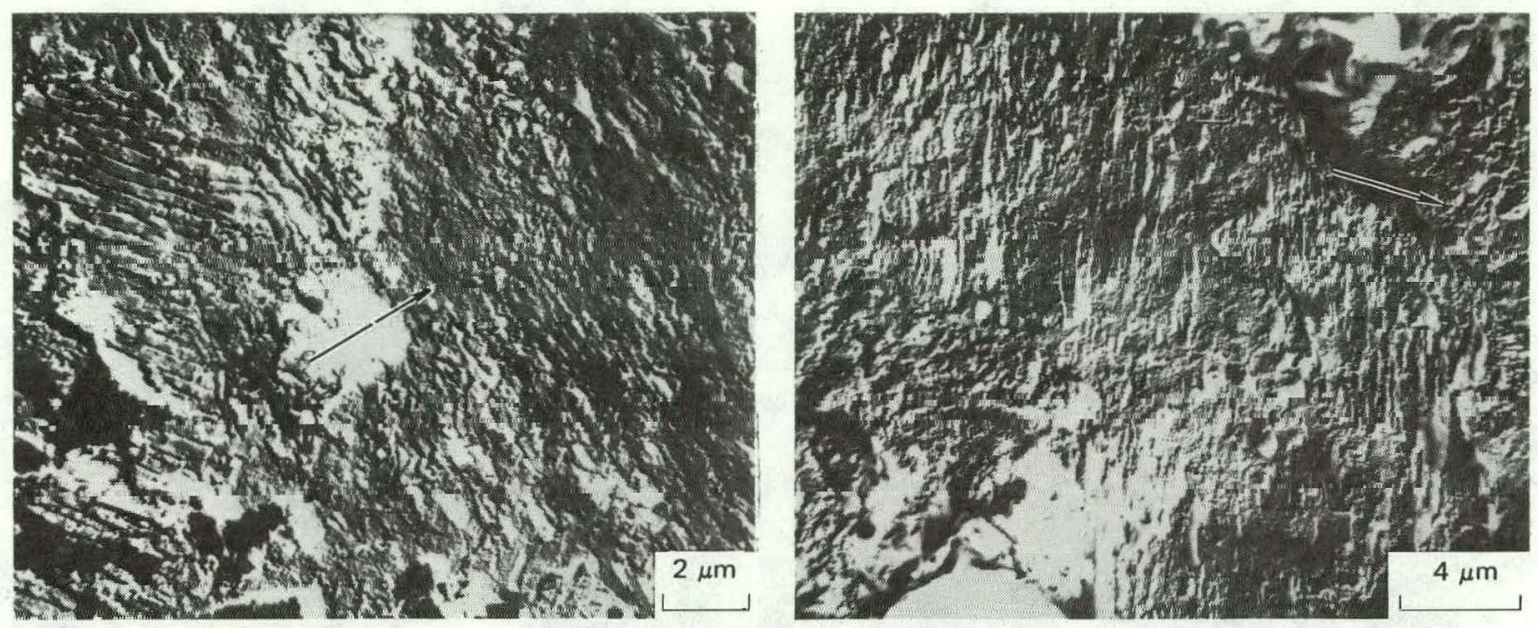

(a) H. B. Robinson
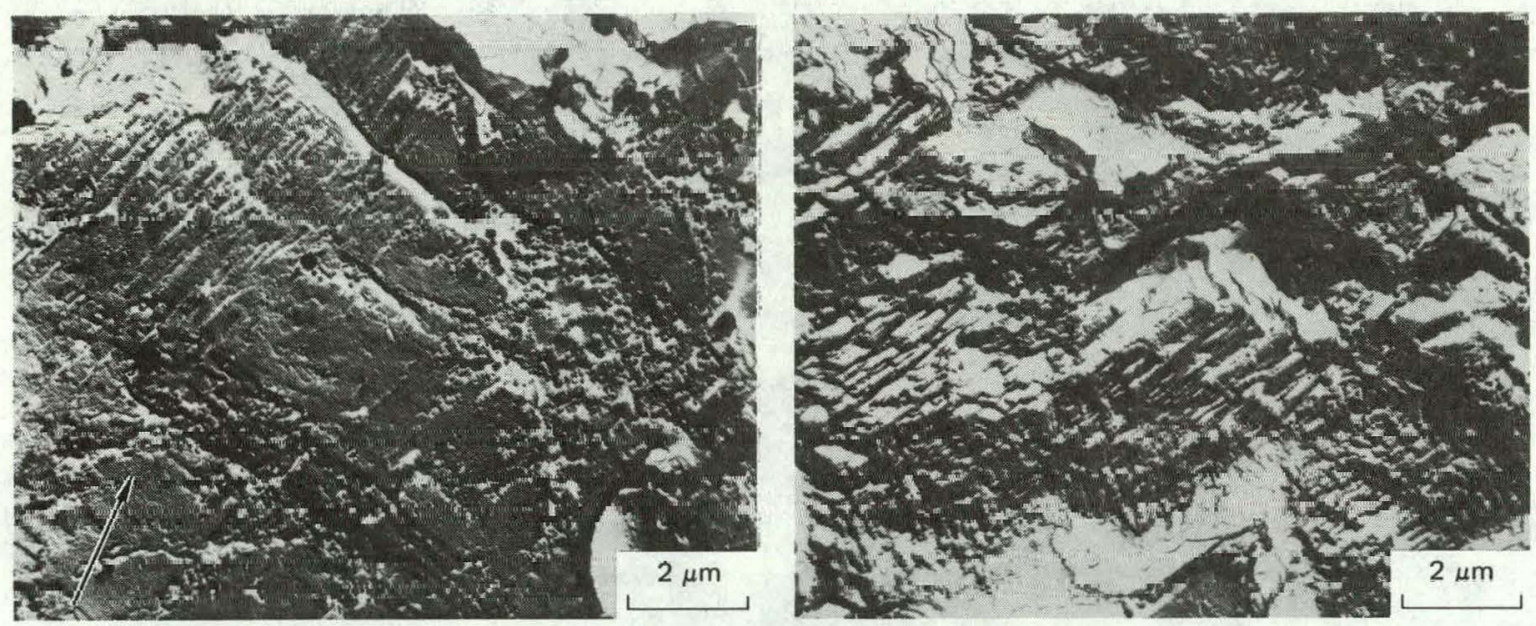

(b) Kewaunee
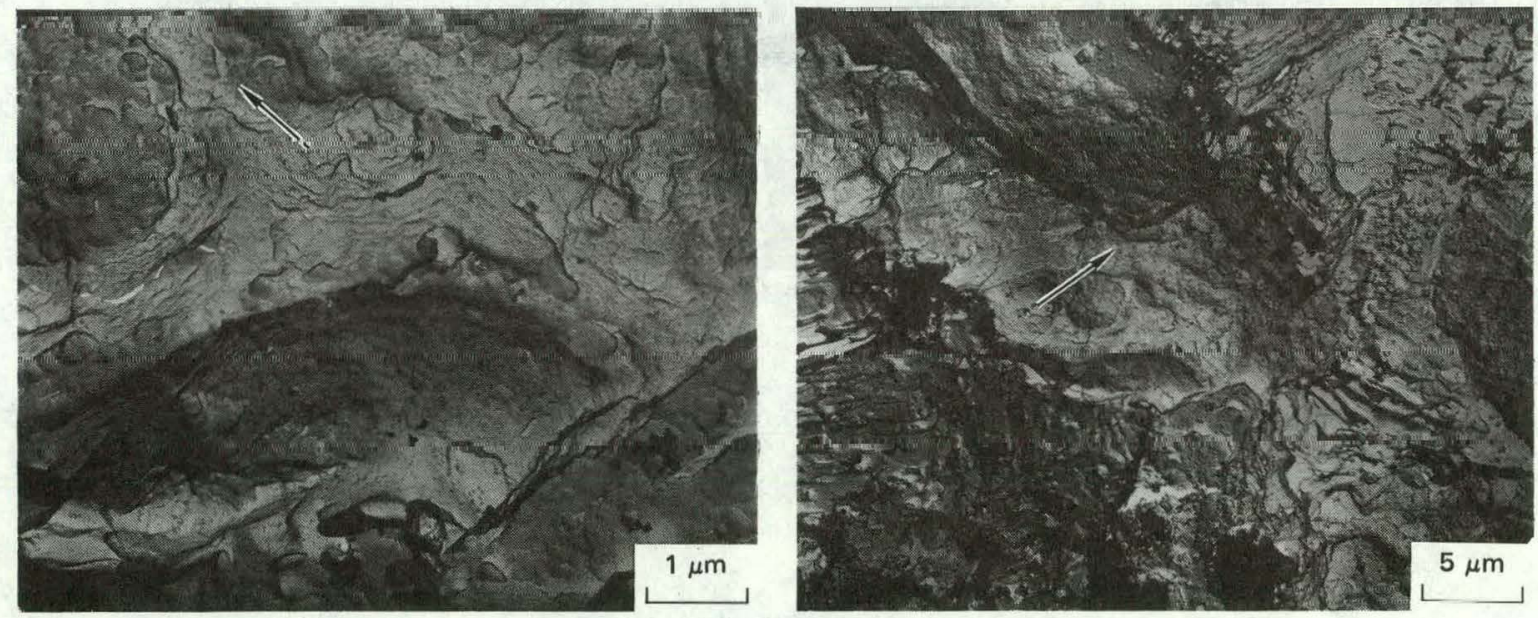

(c) Ginna

FIG. 3.34. TEM fractographs typical of replicas of crack tip of cleaned crack surfaces from H. B. Robinson, Kewaunee, and Ginna. All fractographs contain markings that could possibly be interpreted as fatigue striations. Arrows indicate estimated direction of crack propagation. 


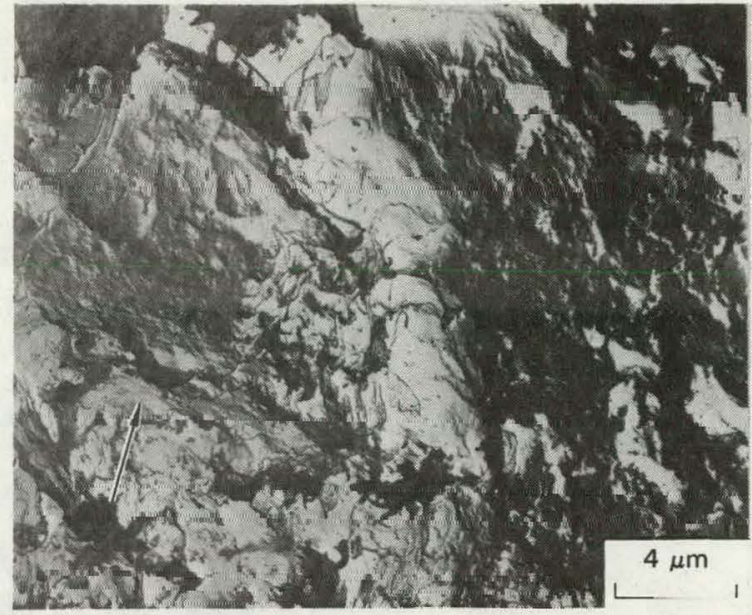

(a) San Onofre

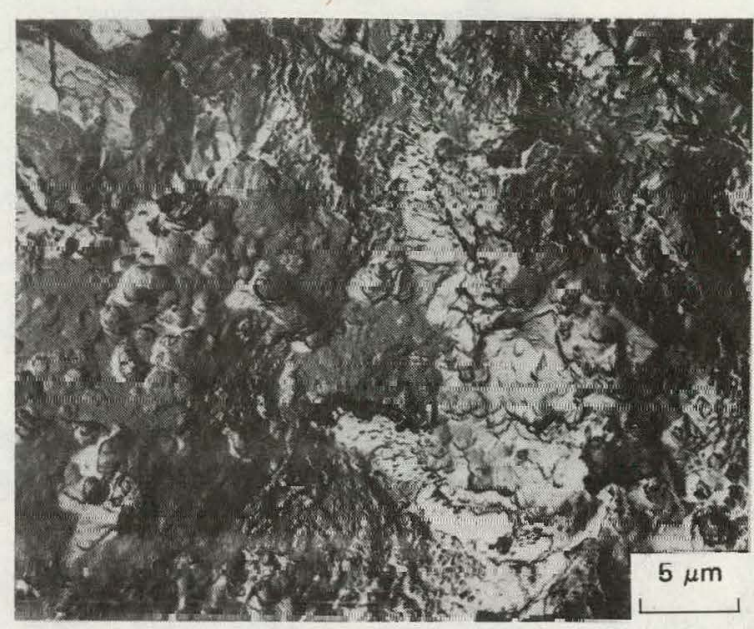

(c) Point Beach

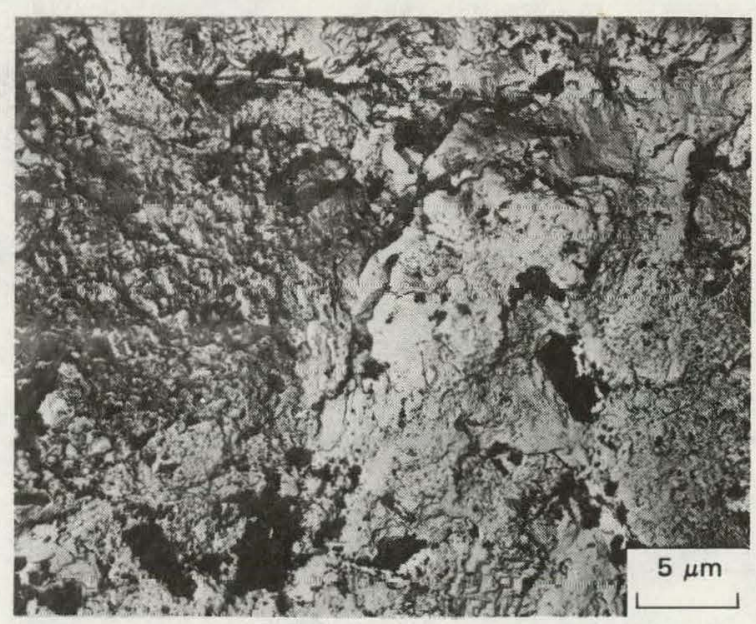

(e) Salem

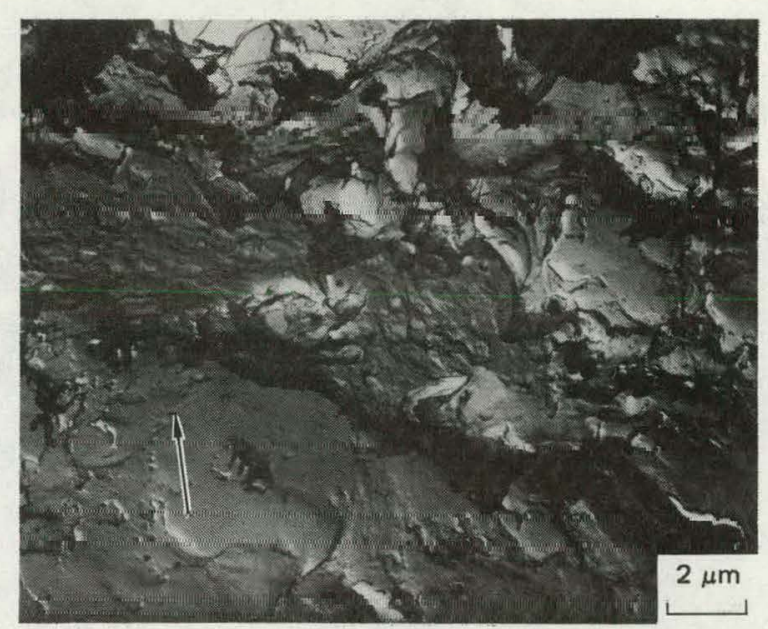

(b) Palisades

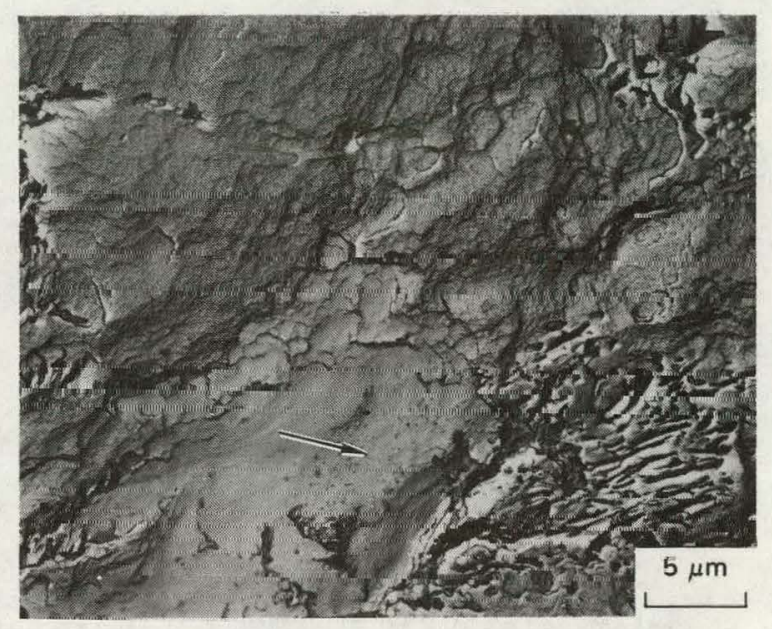

(d) Beaver Valley

FIG. 3.35. TEM fractographs typical of replicas of crack tips of cleaned crack surfaces from San Onofre, Palisades, Point Beach, Beaver Valley, and Salem. There are no indications of fatigue striations. Arrows indicate estimated direction of crack propagation. 


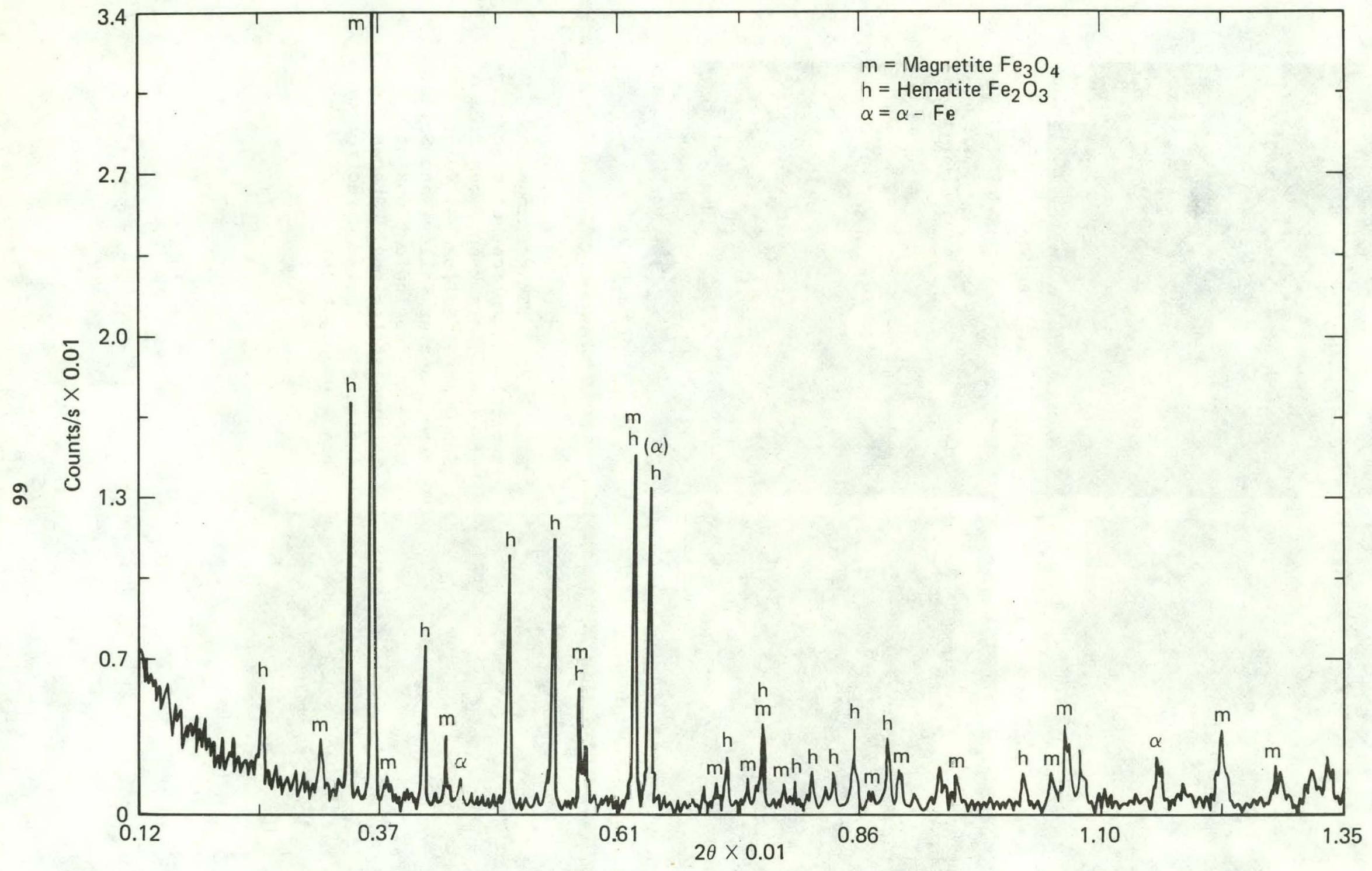

FIG. 3.36. Tracing of raw data spectrum output from the $x$-ray diffractometer (using Cu radiation) for the corroded inside diameter surface of a Beaver Valley section. 

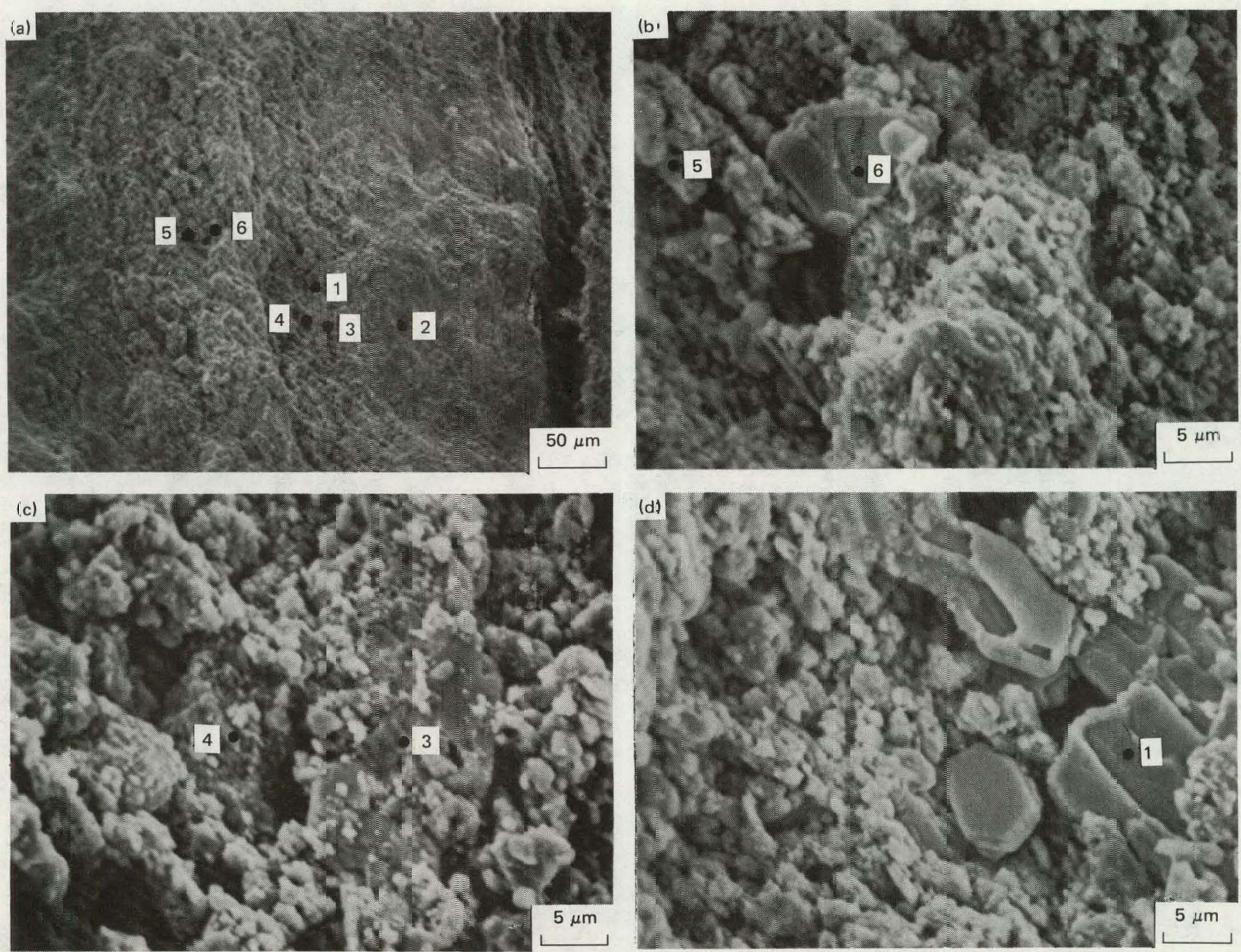

FIG. 3.37. SEM fractographs near the crack origin for a crack along the safeend of a Palisades section. The wide range of spectra obtained are independent of the type of corrosion-nodule morphology. The numbers refer to spots for spectra in Fig. 3.38 . 

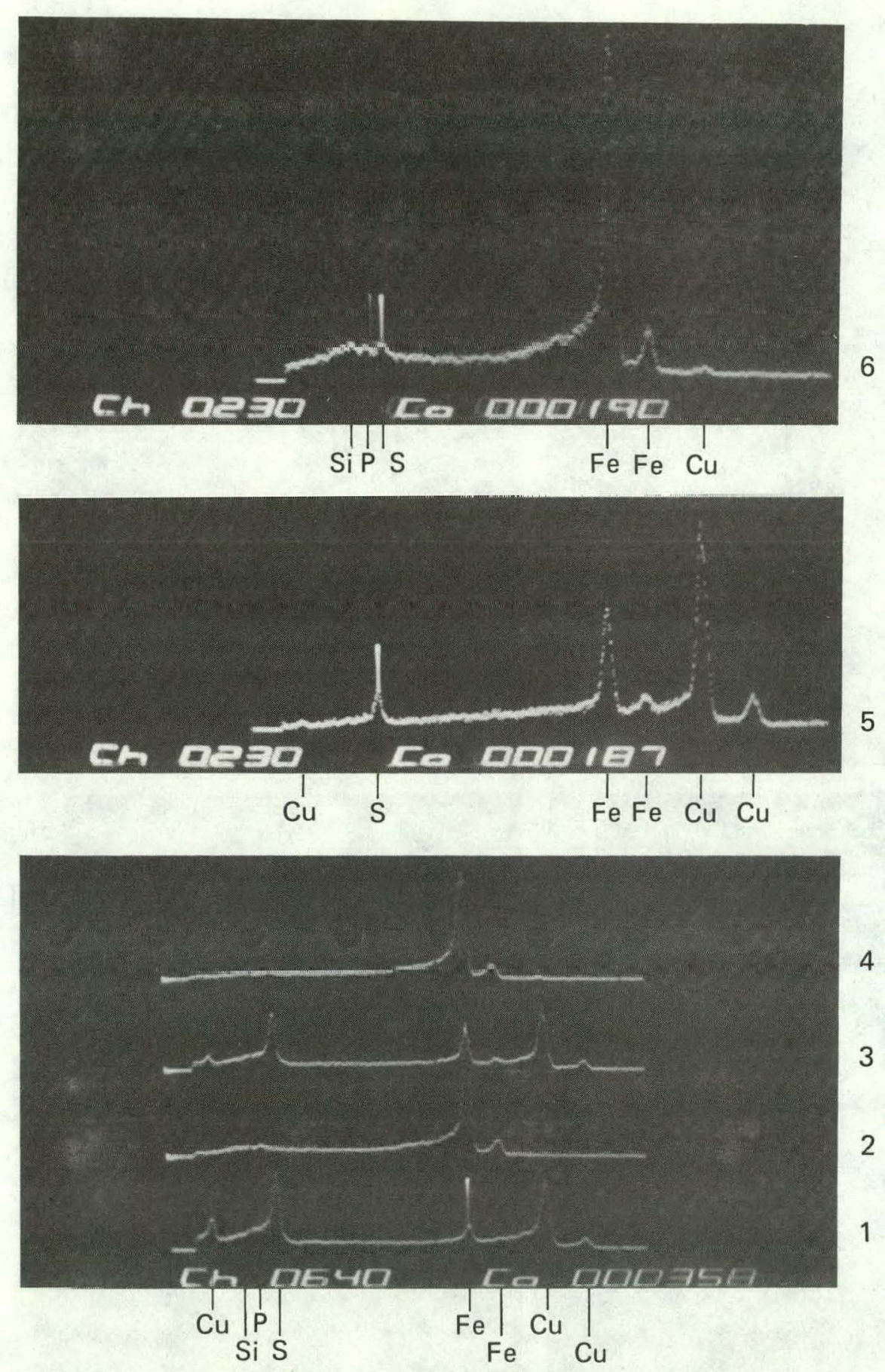

FIG. 3.38. EDS spectra of spots identified in Fig. 3.37 for a Palisades crack. 


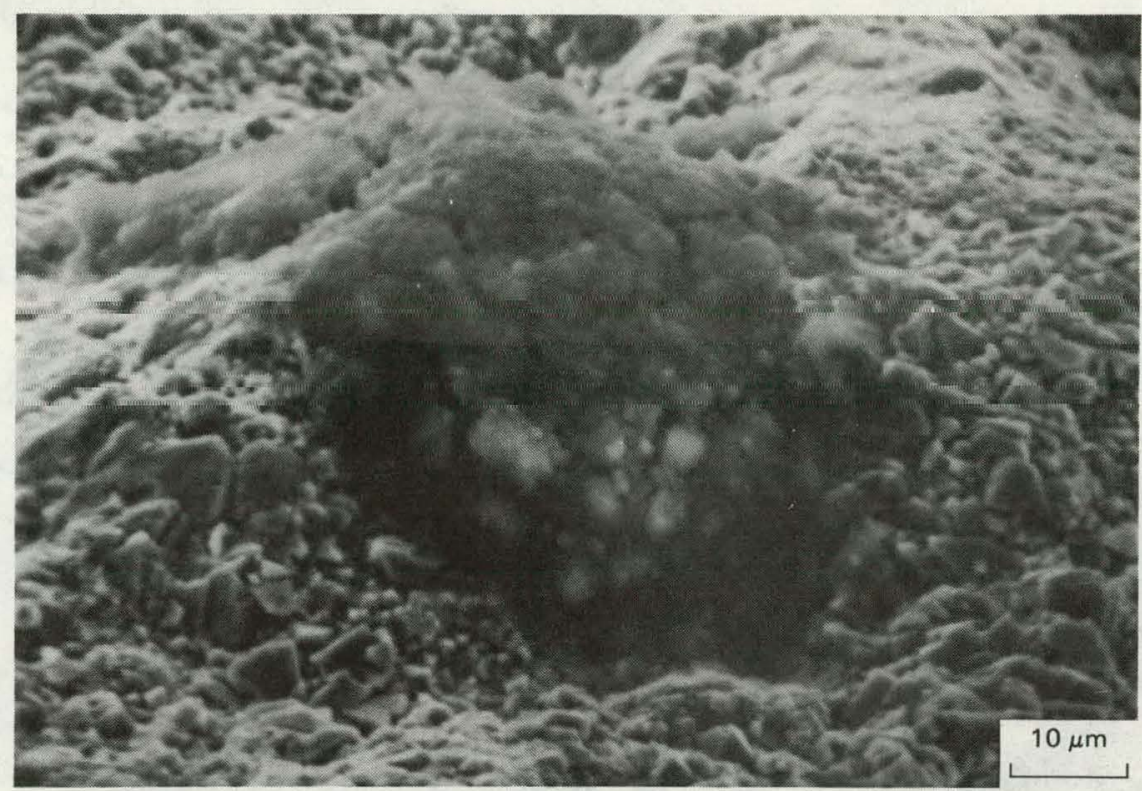

(a) SEM fractograph

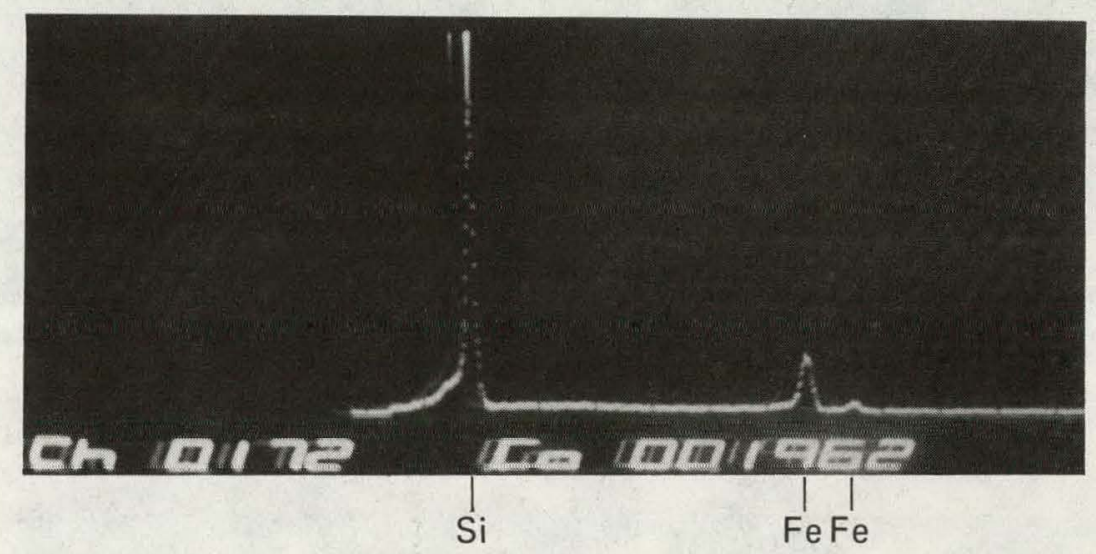

(b) Scan mode

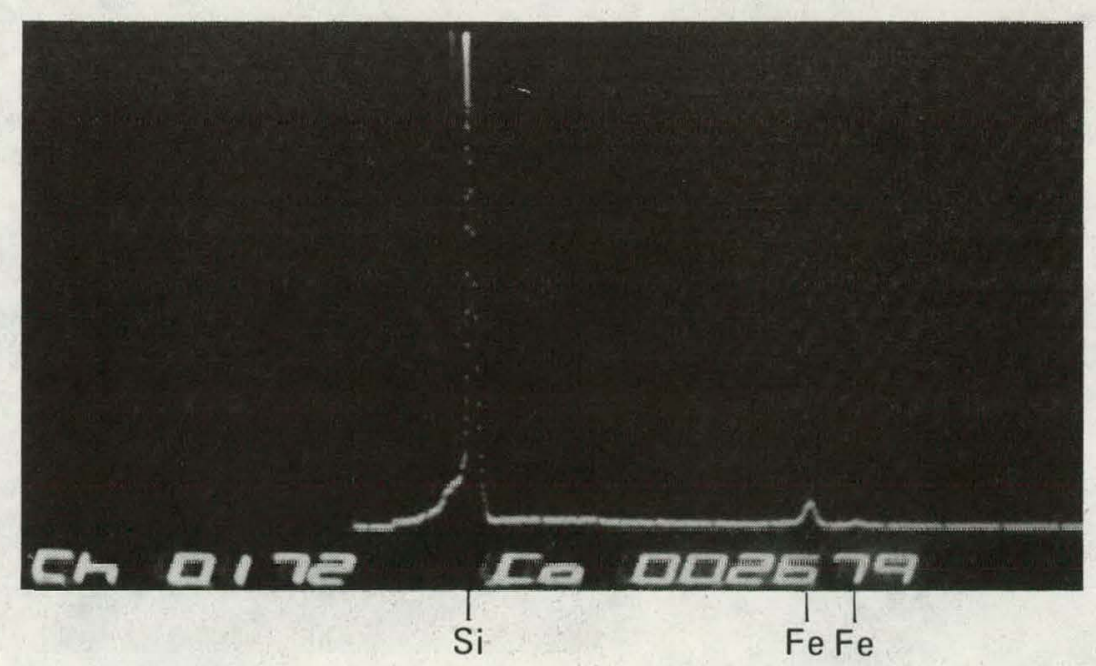

(c) Spot mode

FIG. 3.39. Large residual silicate inclusion from steel or corrosion deposit giving a strong Si line in both the scan and spot modes. 

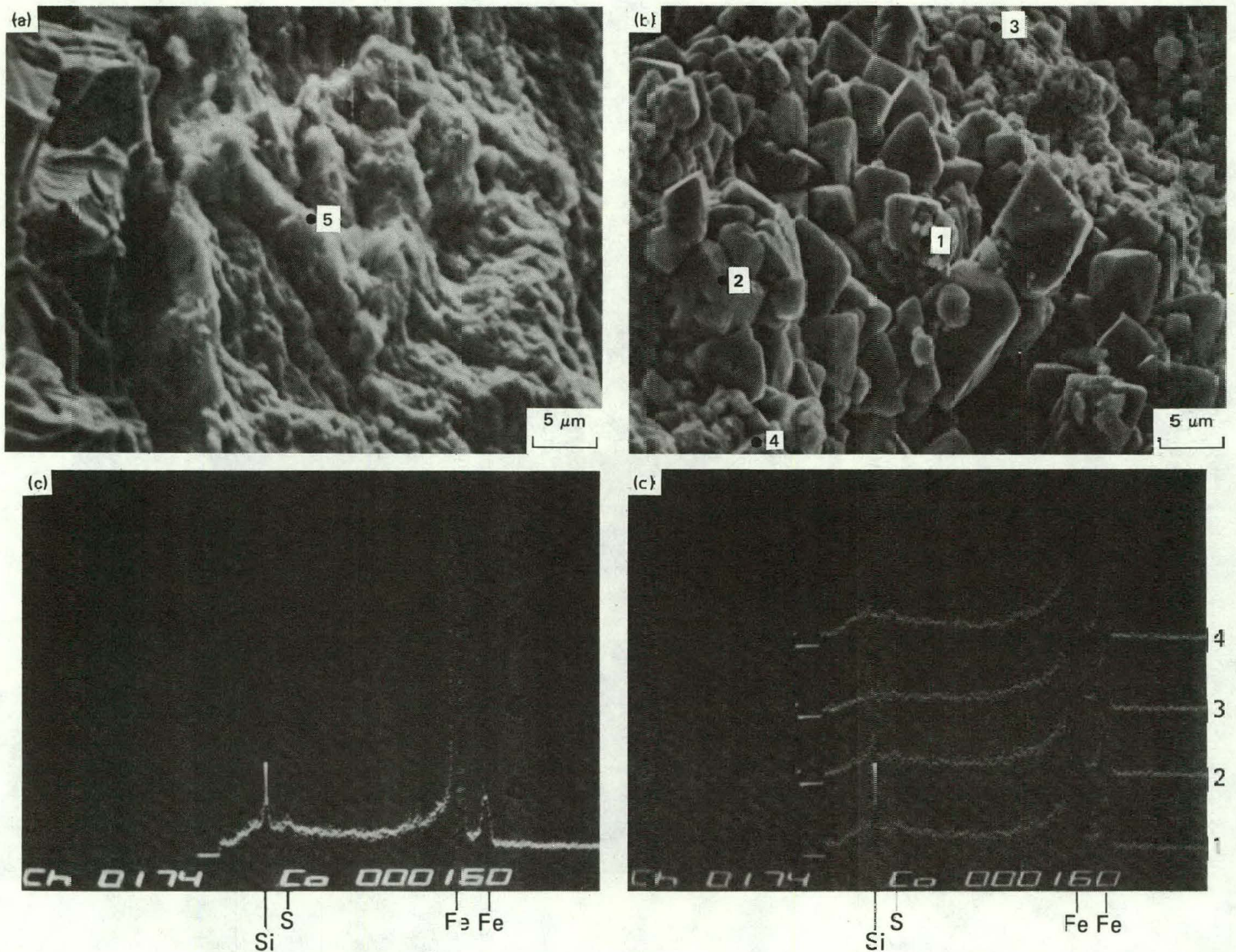

FIG. 3.40. Areas at crack tip and near crack tip that show similar EDS spot spectra of a Palisades crack. Traces of $\mathrm{S}$ and $\mathrm{Si}$ (with $\mathrm{Fe}$ and $\mathrm{Mn}$ ) are only evident. 

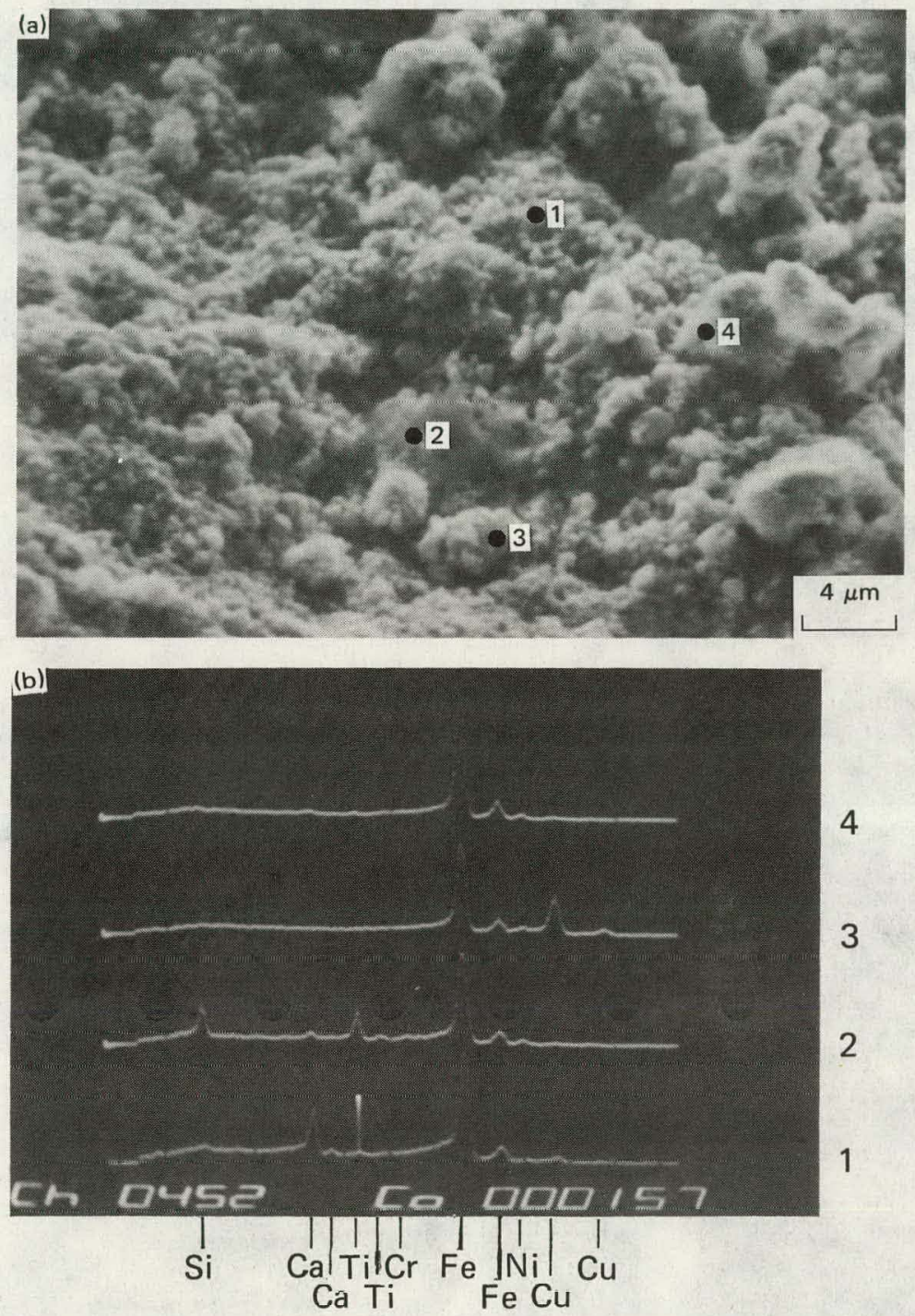

FIG. 3.41. Area near crack origin of a Ginna crack that shows a variety of EDS spectra. Note the small difference in morphology of corrosion nodules of different spots. 

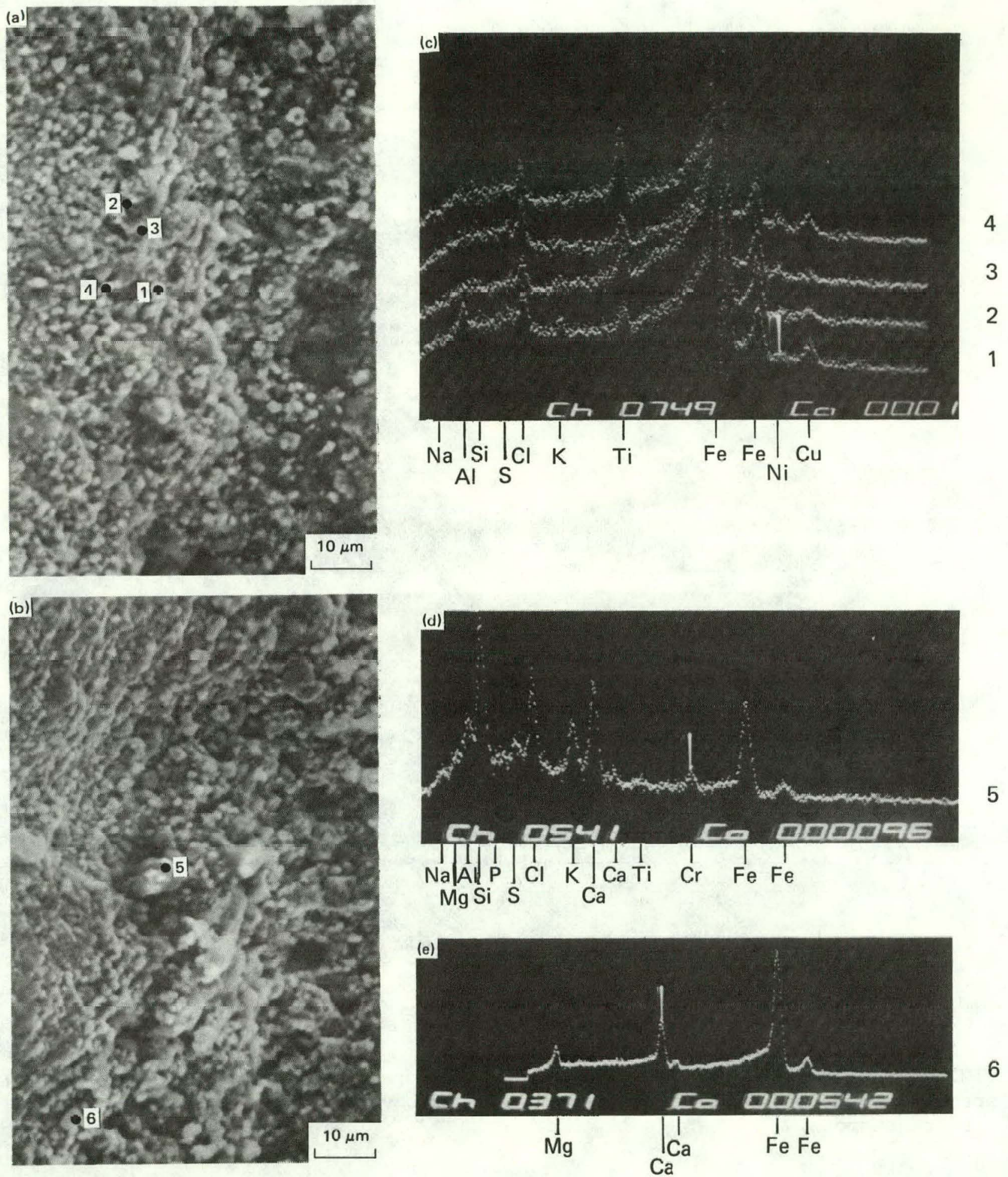

FIG. 3.42. SEM fractographs taken near the crack origin in a Beaver Valley specimen. Note the large range of elements detected in the EDS spectra. 


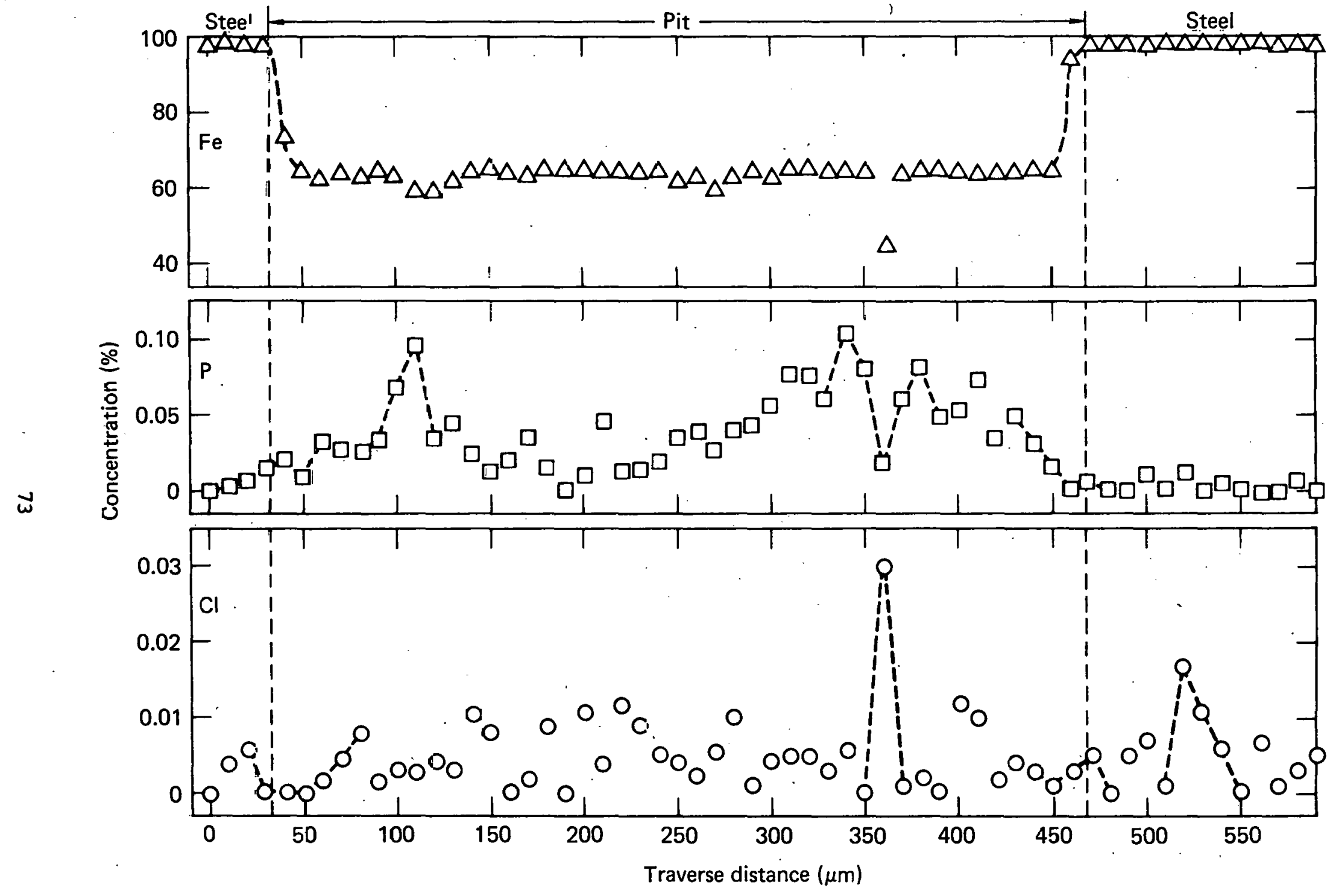

FIG. 3.43. Electron microprobe traces of $\mathrm{Cl}, \mathrm{P}_{\mathrm{f}}$ and $\mathrm{Fe}$ made across the pit near the origin of a deep crack-in the safe-end of a Palisades cross section. Traces start and terminate in steel. 


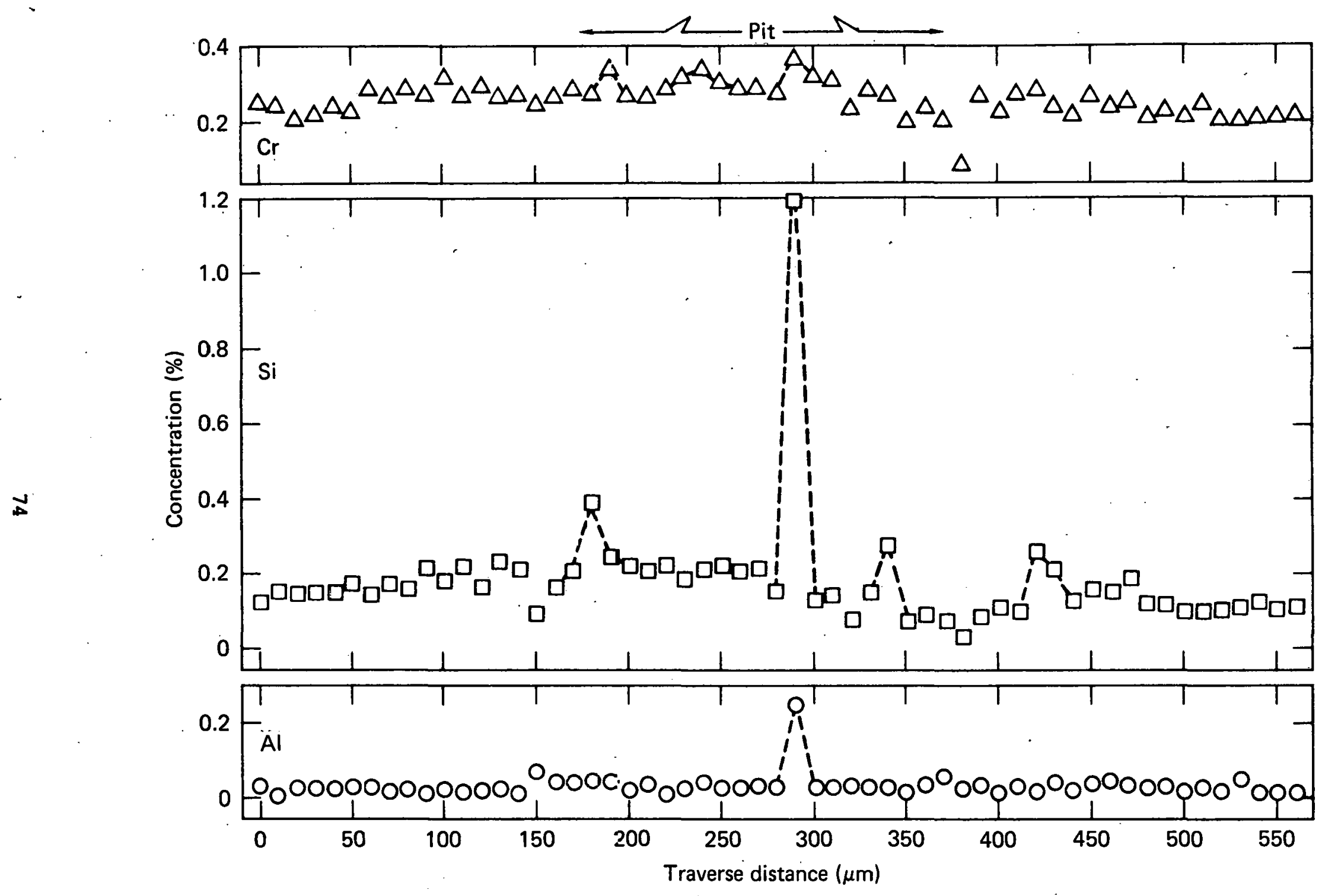

FIG. 3.44. Electron microprobe traces of $\mathrm{Al}, \mathrm{Si}$, and $\mathrm{Cr}$ made across the pit near the origin of a deep crack in the safe-end of Palisades cross section. Traces start and terminate in steel. 


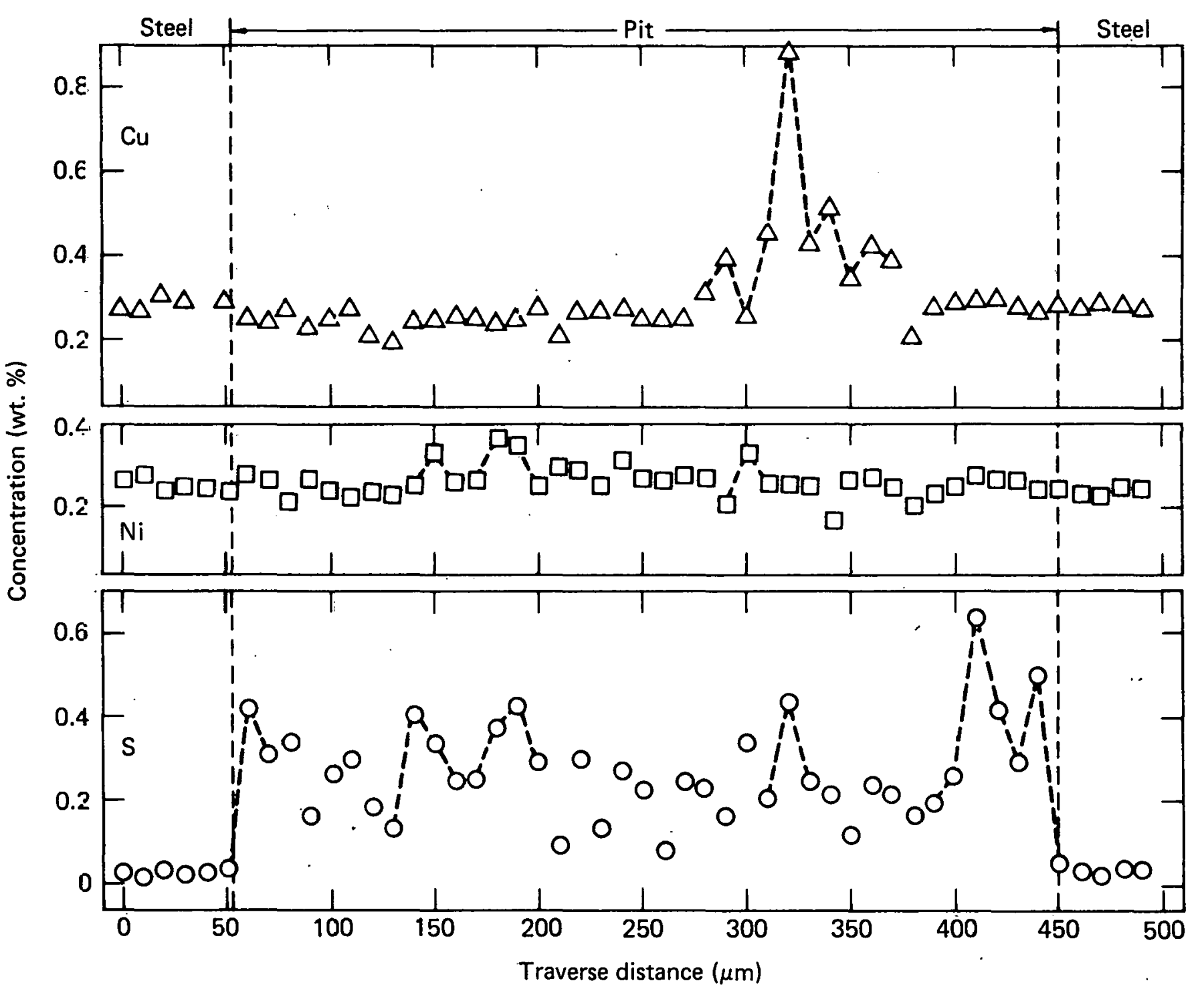

FIG. 3.45. Electron microprobe traces of $\mathrm{S}, \mathrm{Ni}$, and $\mathrm{Cu}$ made across the pit near the origin of a deep crack in the safe-end of a Palisades cross section. Traces start and terninate in steel. 


\section{MICROSTRUCTURAL CHARACTERIZATION OF STEELS}

We evaluated the microstructures of the steel phases and inclusions from sections of all nine plants. We examined the pearlite and ferrite morphology, looked for evidence of segregation as indicated by the presence of banding, measured the ferrite grain size, and classified the inclusion content. The solubility of carbon in austenite $(\gamma)$ depends on its composition, such that variations in $\gamma$ composition will cause corresponding variations in carbon. Since the amount of pearlite will depend on the carbon content, the subsequent formation of pearlite from $\gamma$ serves as a fingerprint for any segregation that existed in the steel. We examined the steels, traversing from i.d. to o.d., in sections away from the counterbore. A summary of our microstructural observations made on the piping materials is listed in Table 4.1. Although differences in microstructures exist from plant to plant, they all fall within expected limits. These steels can be made (melted, shaped, and heat-treated) by several allowable methods and correspondingly would lead to various microstructures and a corresponding range in properties all within ASTM specifications.

All the steels were relatively clean with respect to inclusions. Two examples are shown in Fig. 4.1, and we selected the dirtiest area in each case. Figure 4.1(a) is taken of the San Onofre section and is the dirtiest example for globular-type inclusions; stringers are also present. Figure 4.1(b) is from the Salem section and is the dirtiest example for stringer-type inclusions; globules are also present here to almost the same extent. All steels contained both types of inclusions. The morphologies of both the steel phases and the inclusions were different for the corresponding piping and nozzle (or safe-end). Figure 4.2 (a) illustrates this for the inclusions observed in the Palisades pipe and Fig. 4.2(b) for the Palisades safe-end. Typical stringer and globular inclusions are seen in the pipe section with the stringers parallel to the pipe axis. The safe-end, by contrast, does not contain stringers, but instead exhibits a fine dispersion of spherical or globular inclusions. Such breaking up and spheroidization of inclusions suggest the use of a significant amount of redundant deformation in its fabrication.

All the piping consisted of pearlite plus proeutectoid ferrite. The relative amounts of pearlite in all cases are reasonably consistent with the 
corresponding carbon specifications for Al06-A and Al06-B 10.25 and 0.30 percent $C)$. The pearlite was either mostly laminar, mostly spheroidal, or mixed. Banding of pearlite to various degrees was seen in six of the plants. Some widmanstätten-oriented growth of ferrite was evident for three of the plants. Medium to moderately fine ferrite grain sizes ( $7-1 / 2$ to 11$)$ were measured. These variations in pearlite and ferrite morphology result from corresponding variations in the final section reduction and heat treatment of the piping.

Examples of the microstructures of the steel phases are shown in Figs. 4.3 through 4.6. Figure $4.3(a)$ is an example of strongly banded ferrite and pearlite zones at the i.d. of the elbow from Beaver valley. The deformation at the bottom of a pit seen in Fig. $4.3(a)$, suggests that it is likely to be a machining groove. Banding decreases through the wall thickness, virtually disappearing at almost midthickness, as shown in Fig. 4.3(b). Figure 4.3(c) shows the uniform structure at the o.d. of this elbow. This general change in morphology from i.d. to o.d. is seen in all banded sections. An example showing only a trace of banding at the i.d. with an equiaxed grain structure is shown in Fig. 4.4 (a) for Salem. An example of widmanstätten foriented growth) ferrite is illustrated in Fig. 4.4(b) for Kewaunee; the structure, however, is uniform. In all cases, some decarburization can be seen; however, this decarburized layer is removed on counterboring. Examples of predominantly laminar and spheroidal pearlite are shown in Figs. $4.5(a)$ and $4.5(b)$, respectively, for $\mathrm{H}$. B. Robinson and Kewaunee. At these high magnifications, the oriented ferrite structure (widmanstätten pattern) in the Kewaunee section is more clearly revealed than at the lower magnification shown in Fig. 4.4(b). Another example of a predominantly spheroidized structure is shown in Fig. 4.5(c) for Beaver Valley which was also shown at a lower magnification in Fig. 4.3(a). The segregation is clearly evident. Figure 4.6 illustrates the contrasting morphology in the Palisades section between the pipe which contains laminar pearlite and the safe-end, which is strongly spheroidal, largely the result of different fabrication/heat treating procedures.

The banding (carbon segregation due to segregation of other elements such as $P)$ at the i.d. and its disappearance toward the o.d. can be attributed largely to the concentration of impurities at the center of the ingot. The larger reductions in the center of the piping due to piercing operations in 
forming the piping will also emphasize the banding at the i.d. Such banding would be expected to cause some reduction in transverse properties, but it should have little effect on the longitudinal properties; in fact, if the corrosion factor is minor, such banding may yield pearlite-free regions (ferrite) for crack blunting. In summary, we cannot attribute any unusual microstructural features as being a contributing cause to the cracking problem. 
TABLE 4.1. Microstructural characterization of piping.

\begin{tabular}{|c|c|c|c|c|c|c|c|}
\hline \multirow{2}{*}{$\begin{array}{l}\text { Reactor } \\
\text { plant }\end{array}$} & \multirow{2}{*}{$\begin{array}{l}\text { Piping type } \\
\text { and schedule } \mathrm{e}^{\mathrm{a}}\end{array}$} & \multicolumn{2}{|c|}{$\begin{array}{c}\text { Inclusions, } \\
\text { distribution } \\
\text { and size }\end{array}$} & \multirow{2}{*}{$\begin{array}{c}\text { Ferrite } \\
\text { grain size } \\
\text { number }\end{array}$} & \multicolumn{3}{|c|}{$\begin{array}{l}\text { steel microstructure close } \\
\text { to original i.d. surface }\end{array}$} \\
\hline & & Type A & Type $B$ & & Ferrite & Pearlite & Homogeneity \\
\hline San Onofre & Reducer 100 & $1-1 / 2-T$ & $2-1 / 2-T^{e}$ & 9 & Equiaxed & $\begin{array}{l}\text { Mostly } \\
\text { laminar }\end{array}$ & $\begin{array}{l}\text { Strongly } \\
\text { banded }\end{array}$ \\
\hline Ginna & Elbow 100 & $1-T^{f}$ & $2-T$ & $8-1 / 2$ & Equiaxed & $\begin{array}{l}\text { Mostly } \\
\text { laminar }\end{array}$ & $\begin{array}{l}\text { Strongly } \\
\text { banded }\end{array}$ \\
\hline B. B. Roblinson-2 & Reducer 140 & $2-\mathrm{H}$ & $1 / 2-T^{E}$ & $8-1 / 2$ & Equiaxed & $\begin{array}{l}\text { Essentially } \\
\text { laminar }\end{array}$ & Uniform \\
\hline Palisades & Pipe 60 & $1-1 / 2-T$ & $1 / 2-T$ & $7-1 / 2$ & $\begin{array}{l}\text { Somewhat } \\
\text { oriented }\end{array}$ & $\begin{array}{l}\text { Mostly } \\
\text { laminar }\end{array}$ & Uniform \\
\hline Point Beach-2 & Reducer 80 & $1-1 / 2-T$ & $1-T$ & 10 & Equiaxed & $\begin{array}{l}\text { Mostly } \\
\text { spheroidal }\end{array}$ & $\begin{array}{l}\text { Moder ately } \\
\text { banded }\end{array}$ \\
\hline Kewaunee-2 & Pipe 100 & $2-T$ & $1 / 2-T$ & 8 & Oriented & $\begin{array}{l}\text { Mostly } \\
\text { spheroidal }\end{array}$ & Uniform \\
\hline Beaver Valley-1 & Elbow 100 & $1-1 / 2-T$ & $1 / 2-\mathrm{T}$ & . 11 & Equiaxed & $\begin{array}{l}\text { Mostly } \\
\text { spheroidal }\end{array}$ & $\begin{array}{l}\text { Strongly } \\
\text { banded }\end{array}$ \\
\hline Salen-1 & Reducer 100 & $2-T^{e}$ & $2-T$ & 10 & Equiaxed & $\begin{array}{l}\text { Mostly } \\
\text { spheroidal }\end{array}$ & $\begin{array}{l}\text { Weakly } \\
\text { banded }\end{array}$ \\
\hline D. C. Cook-2 & Elbow 80 & $1-1 / 2-T$ & $1 / 2-T$ & $9-1 / 2$ & $\begin{array}{l}\text { Somewhat } \\
\text { oriented }\end{array}$ & $\begin{array}{l}\text { Mostly } \\
\text { laminar }\end{array}$ & $\begin{array}{l}\text { Moder ate- } \\
\text { strong } \\
\text { banded }\end{array}$ \\
\hline
\end{tabular}

asalem is ASTM Al06-C; balance is ASTM Al06-B.

bASTM-E45: refers to chart 3 for vacuum processed or other specialty steels.

Type A--primarily sulfide stringers (may include other stringers)

Type B--primarily alumina globules (may include other globular oxides)

T--thin inclusion; $\mathrm{H}-$-heavy or thick inclusion.

$C_{A 11}$ steels showed some decarburization at i.d. surface.

dBanding is related to segregation of elements that affect carbon solubility. Banding decreases from 1.d. to o.d., usually disappearing at mid-wall thickness.

Eirtiest steel.

fleanest steel.

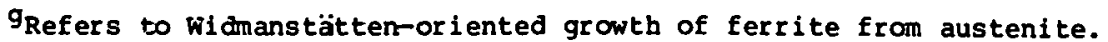




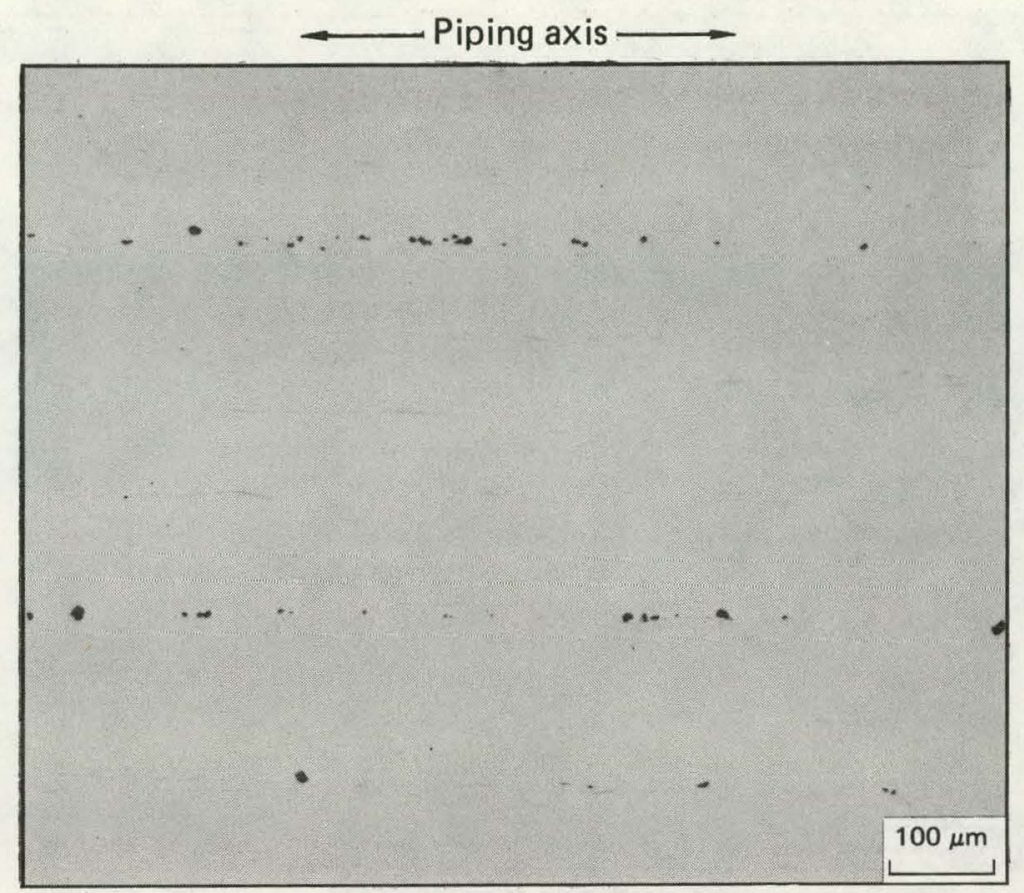

(a) San Onofre

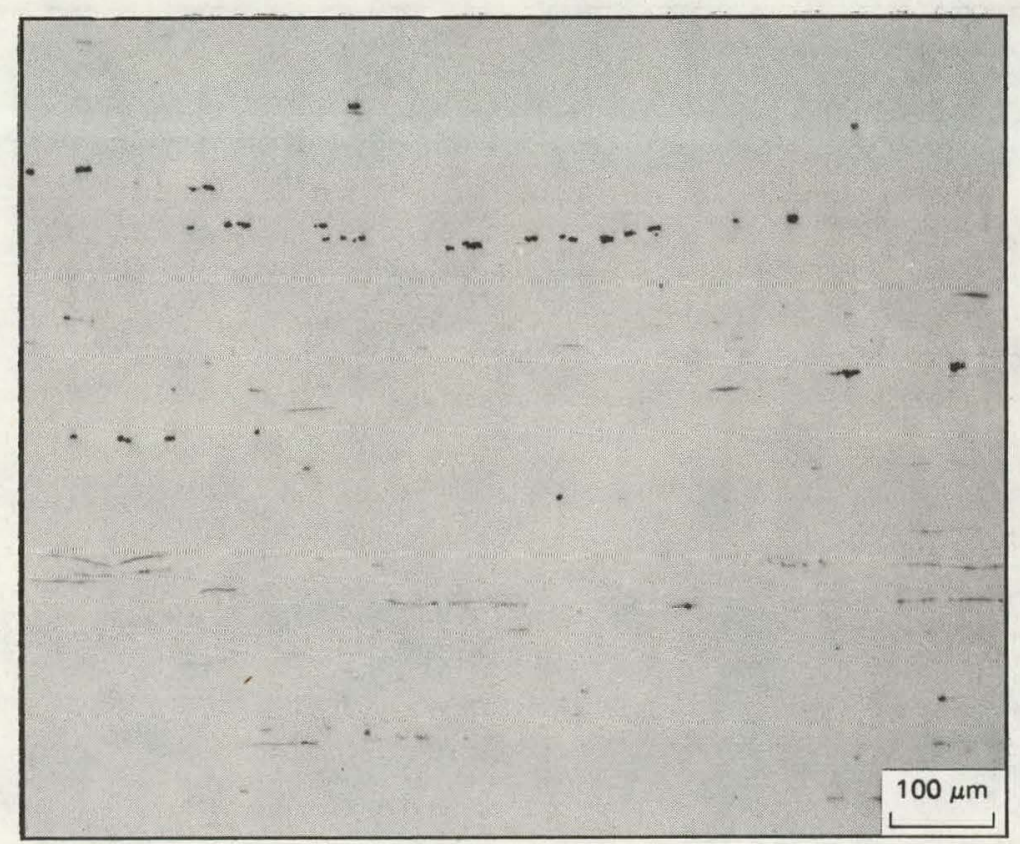

(b) Salem

FIG. 4.1. Examples of inclusions in sections from San Onofre and Salem. The dirtiest area in each material was selected. View (a) shows predominantly globular inclusions (dark) with stringers (light) in the San Onofre section. view (b) shows predominantly stringers (light) with globular inclusions (dark) in the Salem section. 


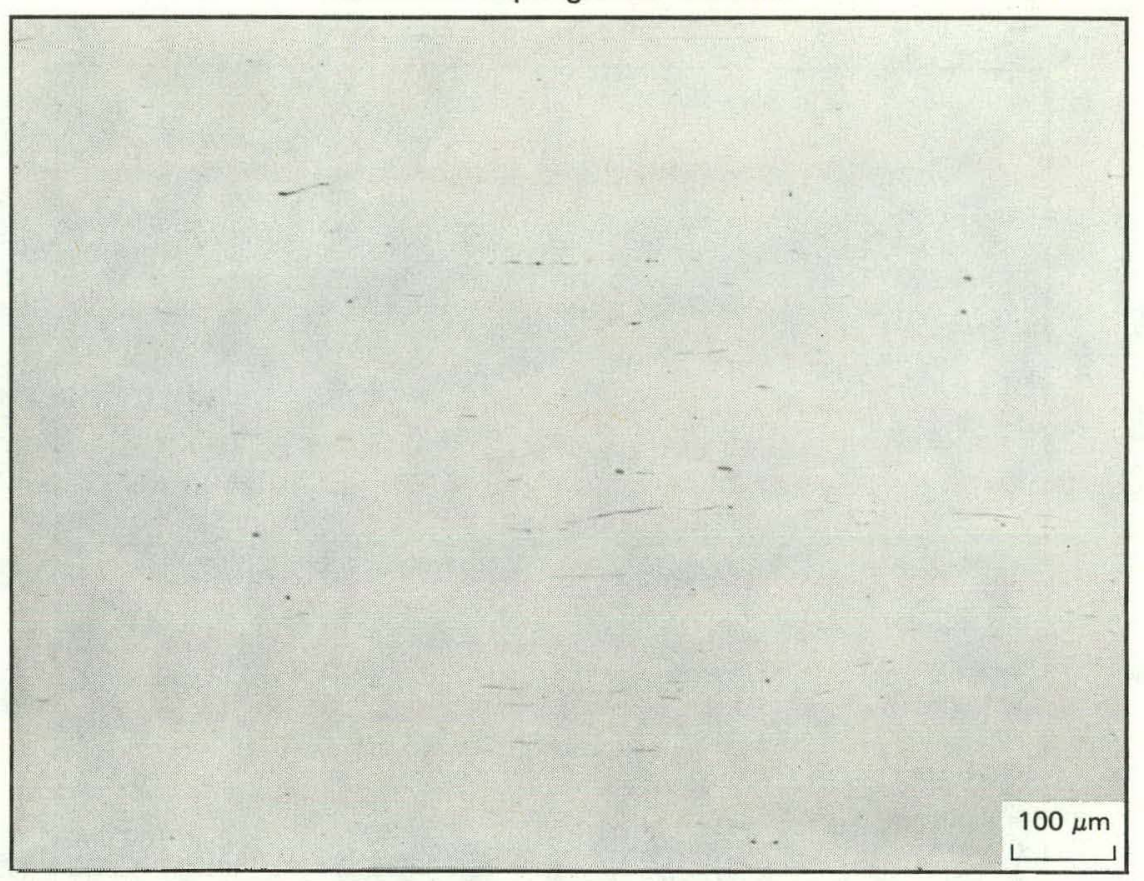

(a) Pipe

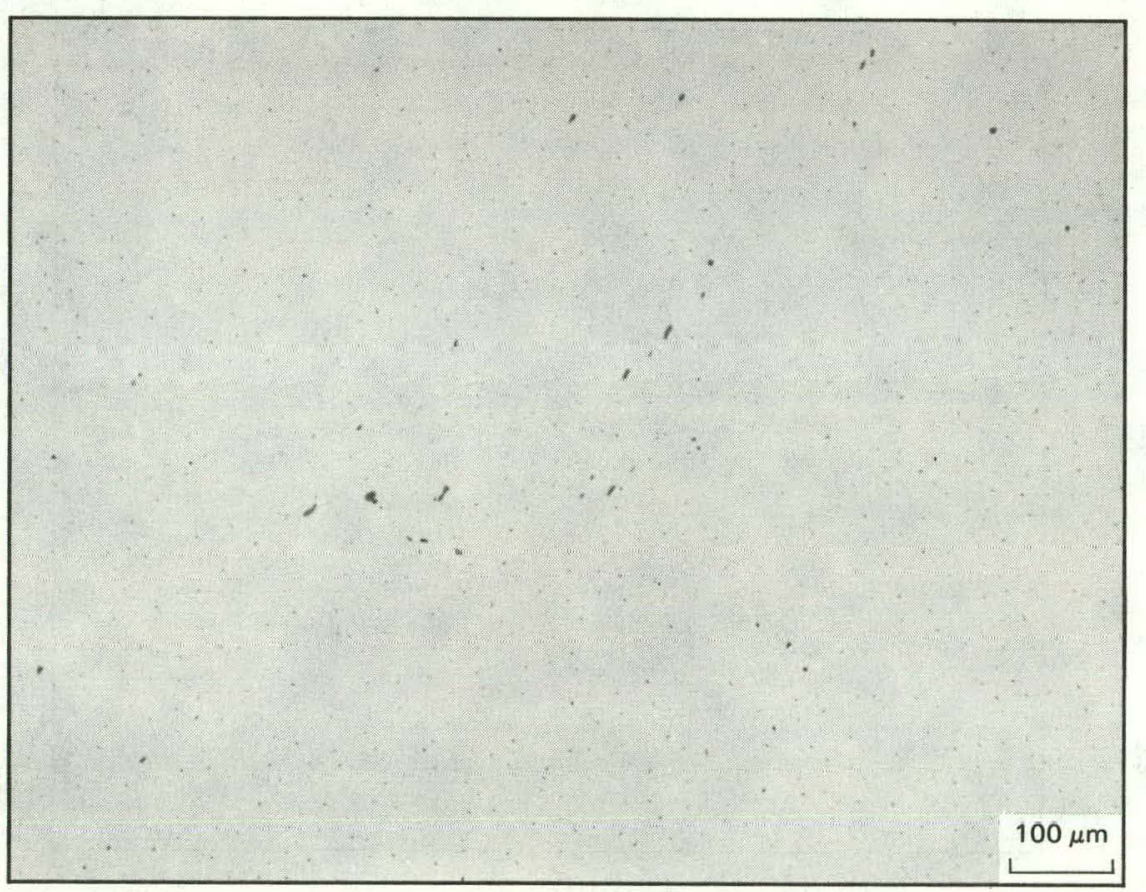

(b) Safe-end

FIG. 4.2. Photomicrographs showing differences in the morphology of inclusions in the pipe and safe-end of a Palisades section. The pipe shows mostly stringers while safe-end shows globular or spheroidal morphology; both samples are parallel to the piping axis and wall thickness. 


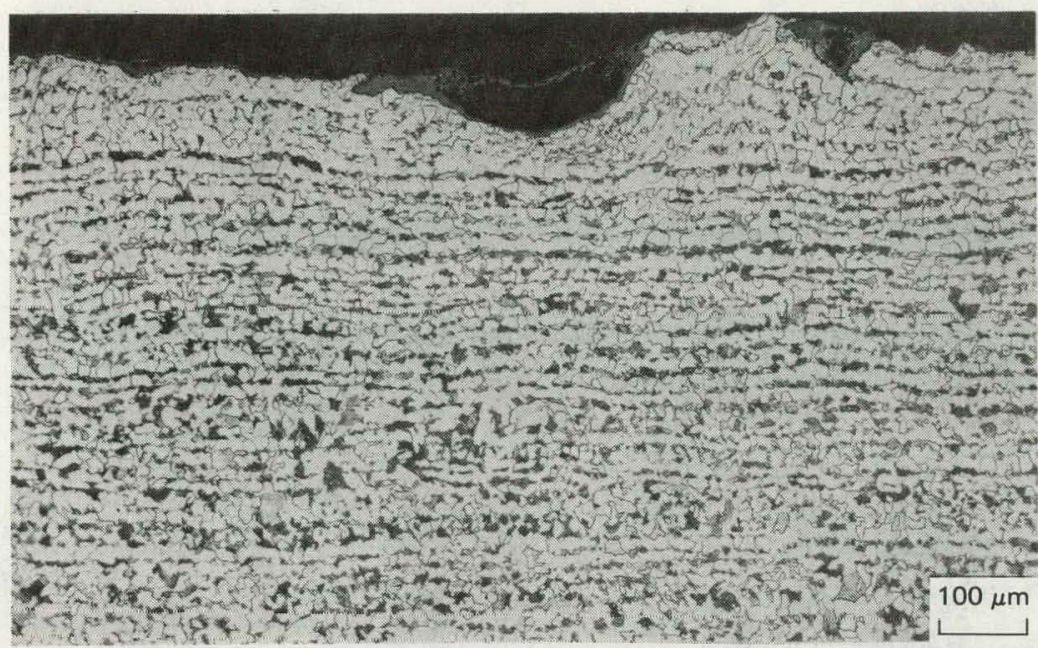

(a) Inside diameter

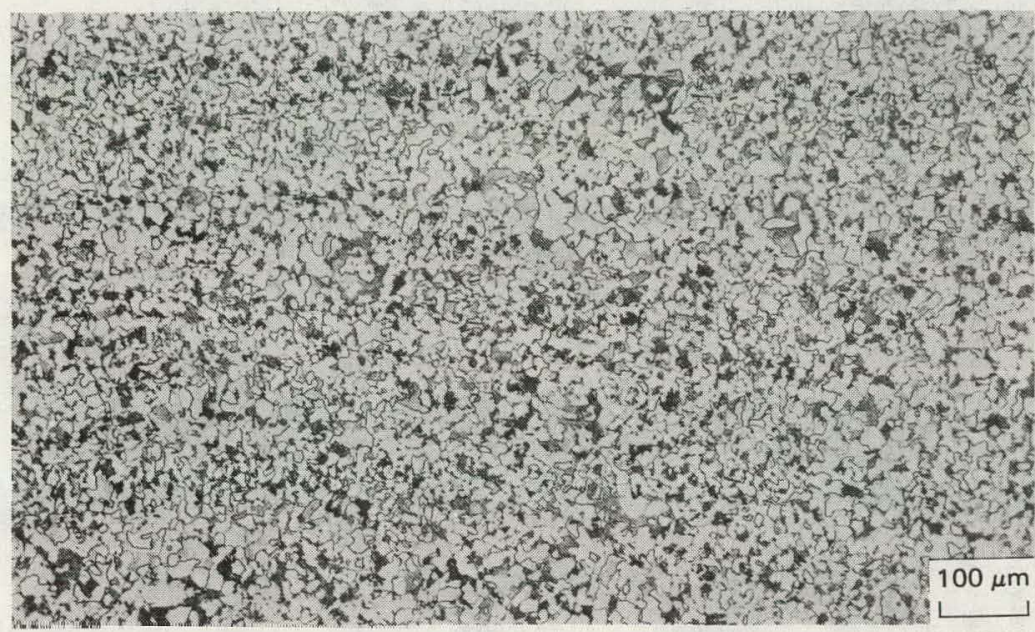

(b) Mid-thickness

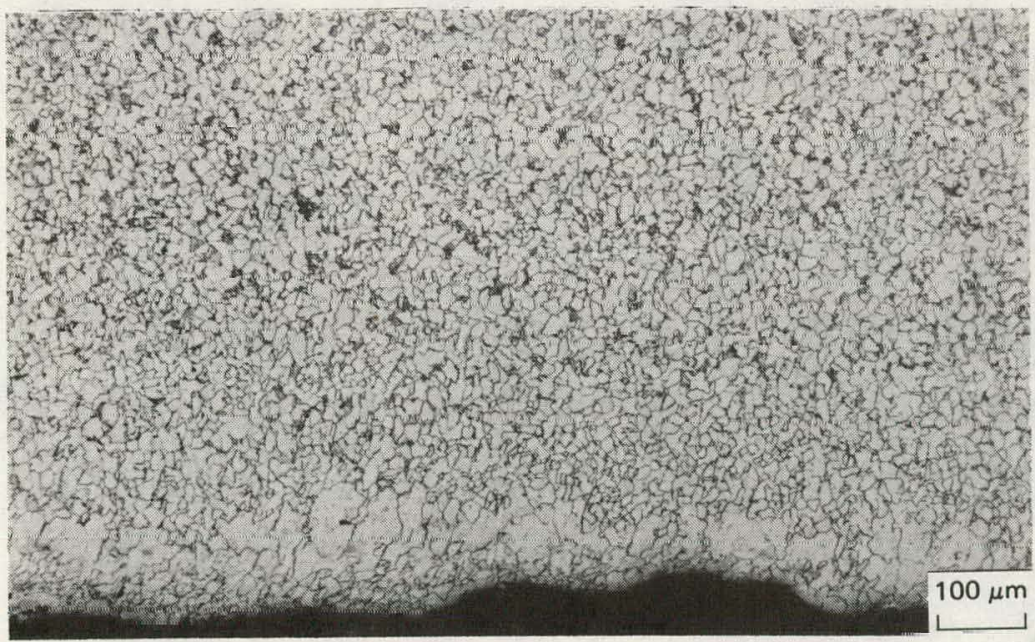

(c) Outside diameter

FIG. 4.3. Photomicrographs showing various degrees of banding across the wall thickness in a section from Beaver Valley. View (a) shows banding at the inside diameter; view (b) shows that banding virtually disappears at midthickness; and view (c) shows a uniform structure at the outside diameter. Note slight decarburization along both surfaces. 


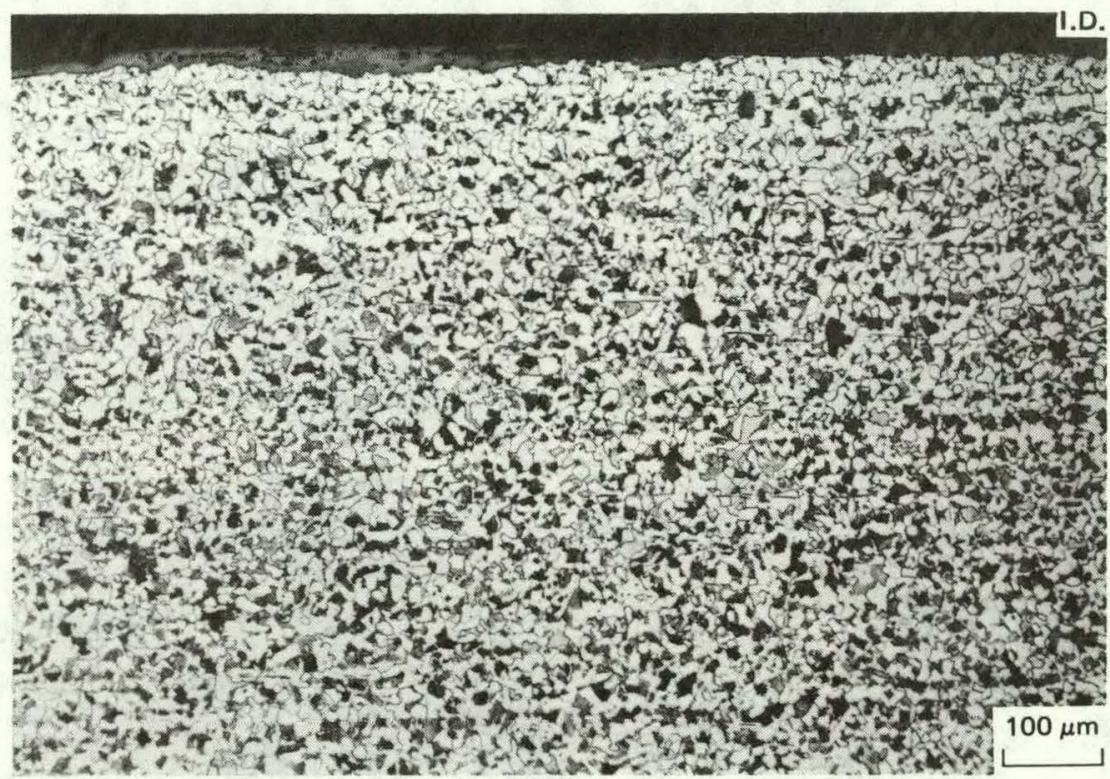

(a) Salem

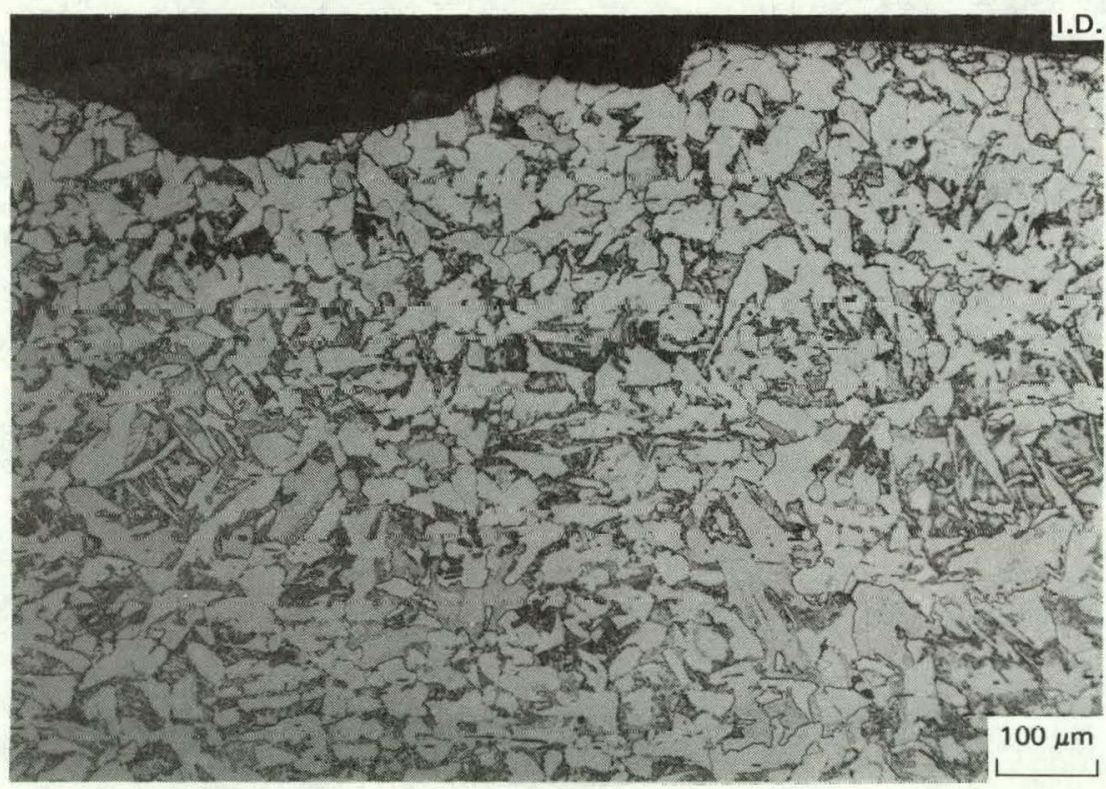

(b) Kewaunee

FIG. 4.4. Photomicrographs showing only a trace of banding near the inside diameter for a Salem section and Widmanstätten (oriented) ferrite and no banding for a corresponding Kewaunee section. Note decarburization. 


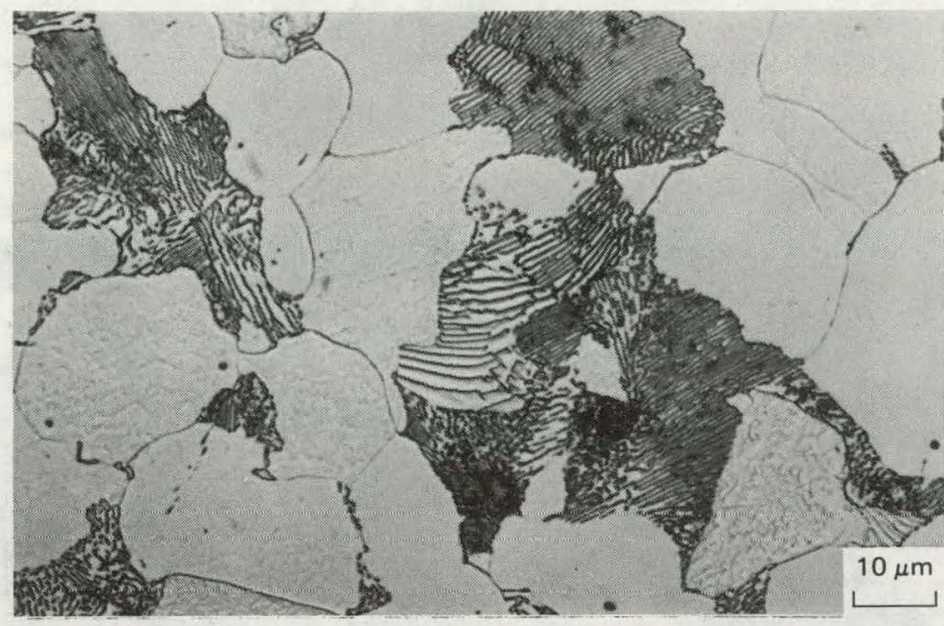

(a) H. B. Robinson

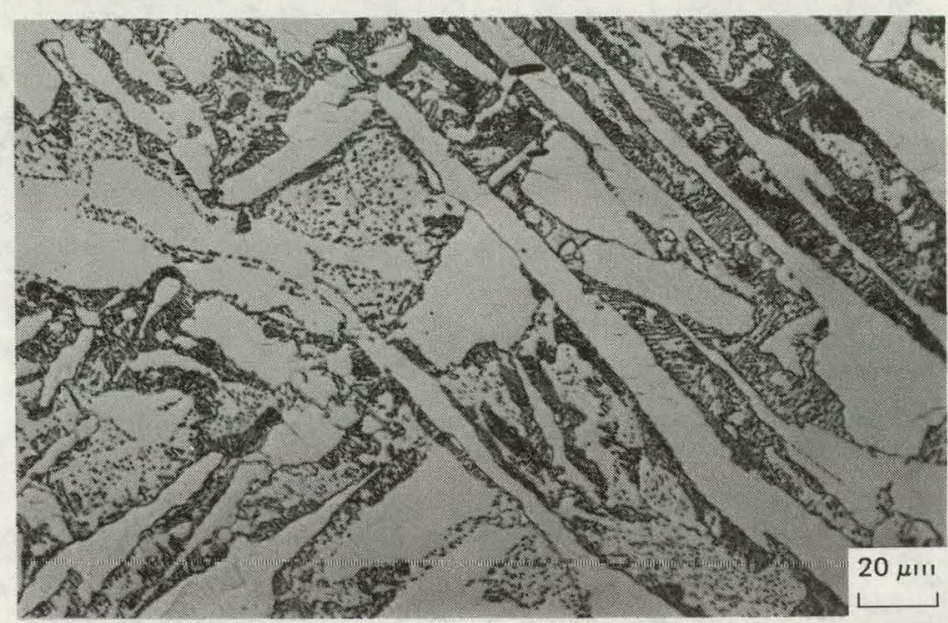

(b) Kewaunee

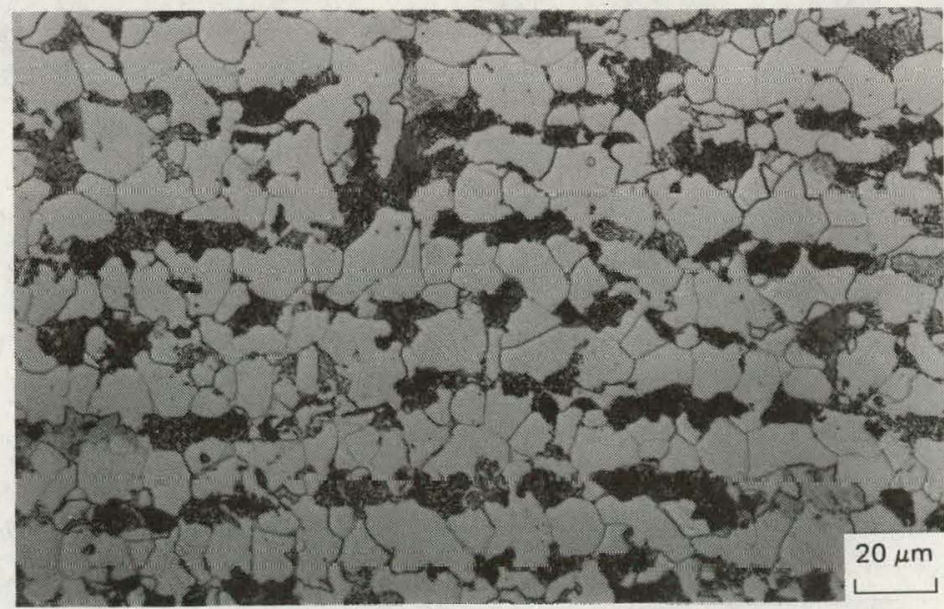

(c) Beaver Valley

FIG. 4.5. Photomicrographs of laminar and spheroidized pearlite. View (a) shows mostly laminar pearlite in an H. B. Robinson section. View (b) shows mostly spheroidal pearlite in a Kewaunee section. View (c) shows mostly spheroidal pearlite in a Beaver Valley section. Note the Widmanstätten ferrite and occasional remnants of the pearlite lamellae in view (b). Note the banding in view (c). 


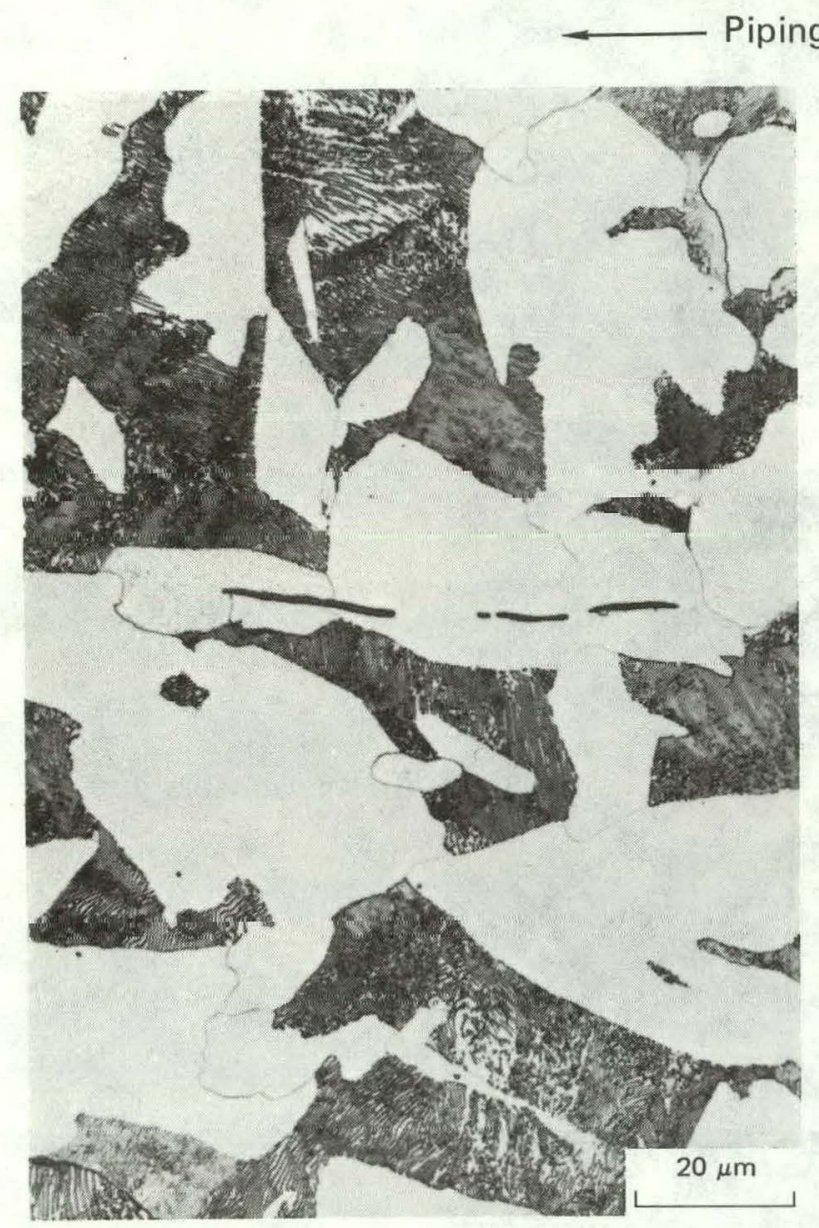

(a) Pipe

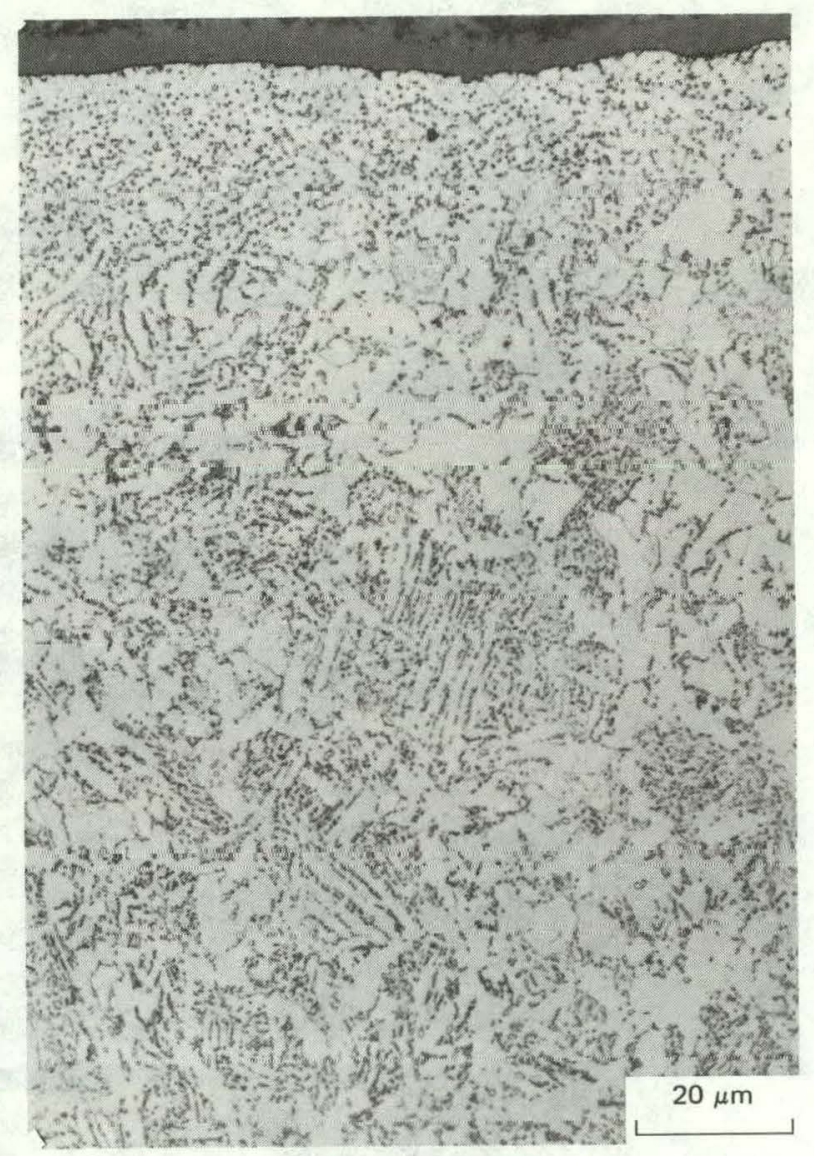

(b) Safe-end

FIG. 4.6. Photomicrographs showing differences in morphology of the steel phases in the pipe and safe-end of a Palisades section. Note the predominantly laminar pearlite in view (a) and the strongly spheroidal structure in view (b). 


\section{MATERIAL PROPERTY EVALUATION}

Tensile and fracture-toughness tests were employed to provide an independent assessment of the material properties of the feedwater piping. Tension tests provided information on the variation of strength and ductility of the feedwater materials under varying temperature and loading rate conditions. Strength values obtained at the low strain rates were compared with the corresponding values described in ASTM specification A520-72. ${ }^{8}$ The objective of the fracture toughness test was to determine the value of the crack tip characterizing parameter $J$ at the initiation of crack growth, i.e., $\mathrm{J}_{\text {IC }}{ }^{*}$ The tearing slope and tearing modulus were also evaluated using the J-test procedure. ${ }^{\dagger}$ The tearing modulus, $T$, is a measure of a materials resistance to crack tearing once crack growth is initiated. Both parameters, $\mathrm{J}_{\text {IC }}$ and $\mathrm{T}$, relate to crack growth behavior and therefore are important aspects of the cracking problem.

Tensile properties were obtained at temperatures ranging from 4 C (39 F) to $285 \mathrm{C}(545 \mathrm{~F})$ and strain rates from $10^{-3}$ to $2 \times 10^{2} / \mathrm{s}$. Due to clip gauge limitations, however, the upper temperature for fracture testing was limited to $218 \mathrm{C}(425 \mathrm{~F})$. Two stroke rates were employed: 0.03 and $100 \mathrm{~mm} / \mathrm{s}$ $(0.001$ and $4 \mathrm{in.} / \mathrm{s})$. The temperature range investigated approximates the possible extremes from cold auxiliary feedwater during standby conditions to hot main feedwater operation at full power. Loading rates tested range from normal operation to dynamic loading postulated during seismic or water-hammer events. A strain rate of $10 / \mathrm{s}$, which is roughly equivalent to a loading rate of $4.4 \mathrm{mN} / \mathrm{s}\left(1 \times 10^{6} \mathrm{lb} / \mathrm{s}\right)$ in the tensile specimens, is believed to simulate the loading in a watcr-hammer event. ${ }^{9}$

\subsection{TENSILE PROPERTIES}

The elbow from D. C. Cook was selected for the evaluation of tensile properties over an extensive matrix of temperatures and strain rates for a

\footnotetext{
*See Appendix $\mathrm{H}$ for more detail on methodology.

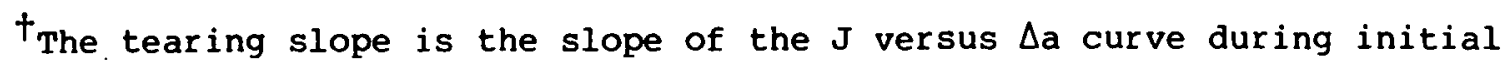
tearing, dJ/da. The tearing modulus is defined by$$
T=\left(F / \sigma_{o}^{2}\right)(d J / d a) ; \sigma_{o}=\left(\sigma_{Y}+\sigma_{u}\right) / 2 \text {. }
$$ 
material typical of Al06-B. For the remaining plants from which material was available (Beaver Valley, Ginna, H. B. Robinson, Salem, and Palisades) testing was limited to a standard strain rate of $10^{-3} / \mathrm{s}$ and temperatures from 4 to $227 \mathrm{C}(39$ to $440 \mathrm{~F})$. Details on tensile testing, the test results, and the analyses are presented in Appendix G. A summary of these analyses is presented below.

At the standard strain rate $\left(10^{-3} / \mathrm{s}\right)$, the range in values (minimum to maximum) obtained for all six reactor plants tested at the two temperatures of greatest interest are as follows:

At 22 C (72 F) :

Upper yield Lower yield UTS Elongation
251 to $344 \mathrm{MPa}$ (36 to $50 \mathrm{ksi}$ )

241 to $308 \mathrm{MPa}$ (35 to $45 \mathrm{ksi}$ ) 452 to $499 \mathrm{MPa}$ (66 to $72 \mathrm{ksi}$ ) 33.2 to 44.6 percent

At $227 \mathrm{C}(440 \mathrm{~F})$ :

Upper yield Lower yield 163 to $245 \mathrm{MPa}$ (24 to $36 \mathrm{ksi}$ ) UTS Elongation

161 to 245 . MPa (23 to $36 \mathrm{ksi}$ )

410 to $437 \mathrm{MPa}$ (59 to $63 \mathrm{ksi}$ )

24.9 to 34.6 percent

Except for the relatively low values of yield strengths obtained for Salem at $227 \mathrm{C}(440 \mathrm{~F})$, the results obtained at the standard strain rate fall within the ASTM specifications available for Al06-B. Both upper and lower yield strengths show a general decrease with an increase in temperature. The UTS shows a distinct minimum at about $149 \mathrm{C}(300 \mathrm{~F})$, with the values rising sharply with either an increase or decrease in temperature. The elongation shows a general decrease with an increase in temperature above $22 \mathrm{C}$. There is also a drop in ductility between $22 \mathrm{C}$ and $4 \mathrm{C}$ indicative of entering the ductile-to-brittle transition temperature region.

An increase in strain rate over the range of $10^{-3} / \mathrm{s}$ to $10 / \mathrm{s}$ results in a gradual increase in both upper and lower yield strengths. Only one test was made at $200 / \mathrm{s}$, and the data from this test at $22 \mathrm{C}(72 \mathrm{~F})$ show a sharp rise in the lower yield strength increasing from $330 \mathrm{MPa}(48 \mathrm{ksi})$ at $9 / \mathrm{s}$ to $472 \mathrm{MPa}$ (68 ksi). This sharp rise is consistent with strain rate effects reported in the literature. ${ }^{10}$ The variation in UTS with strain rate was found to be dependent on temperature. In the lower temperature region, the UTS increases with strain rate; at intermediate temperatures there is little change; at the highest test temperatures there is a decrease in UTS with increase in strain 
rate. These results are consistent with the corresponding effect of temperature on UTS at a given strain rate. The elongation values did not indicate any definite trends with changes in strain rate.

We attempted to relate crack length and crack-growth rate to differences in either the yield strengths or UTS, and details of this are also given in Appendix G. The yield data do not show any correlations. However, a rough trend was observed for the UTS relative to both crack depth and crack-growth rate.

We also tested several specimens of the D. C. Cook material with the tensile axis parallel to the circumferential tangent direction. These tests were at $22 \mathrm{C}(72 \mathrm{~F})$ and $10^{-3} / \mathrm{s}$. The tensile values were identical to those obtained with the longitudinal specimens. However, specimens taken from the weld-heat-affected zone show somewhat higher strengths and lower ductilities.

\subsection{FRACTURE EVALUATION}

Fracture toughness results and related tensile properties for the Al06 feedwater sections are presented in Tables 5.1 and 5.2. Details on the determination of $J_{I C}$ and $T$, as well as a more detailed discussion of the results, can be found in Appendix $\mathrm{H}$. In general, the room-temperature standard loading rate $J_{I o}$ values (average value from the five plants investigated is $254 \mathrm{~kJ} / \mathrm{m}^{2}, 1450 \mathrm{in.-1b} / \mathrm{in} .{ }^{2}$, are comparable to other available data of similar steels. ${ }^{11}$ with the exception of Ginna $(T=113)$, the corresponding tearing modulus ranged from 260 to 334--somewhat higher than reported in Ref. 11. When viewed in terms of the total resistance curve, i.e., both $\mathrm{J}_{\mathrm{Ic}}$ and $\mathrm{T}$, the differences between H. B. Robinson, Beaver Valley, Salem, and D. C. Cook appear to be minor.

The tearing modulus was virtually unaffected by a reduction in the test temperature to $3 \mathrm{C}(37 \mathrm{~F})$. However, the $\mathrm{J}_{\mathrm{IC}}$ for both Salem and D. C. Cook dropped significantly (approximately 78 and 44 percent drop, respectively), whereas the results for Beaver Valley and H. B. Robinson remained essentially unchanged from their room-temperature value.

A detailed study of temperature and loading rate effects on the fracture properties was conducted using material from D. C. Cook. The results are summarized in Table 5.2. Using the standard rate tests as baseline, J Ic was less at buth higher temperatures $(218 \mathrm{C}, 425 \mathrm{~F})$ and lower temperatures 
(3 C, $37 \mathrm{~F}$ ) than the room temperature value. While the low-temperature drop was probably a result of entering the transition temperature region, the high-temperature decrease is most likely attributed to a change in flow properties.

The high-rate tests exhibited a drop in $\mathrm{J}_{\text {Ic }}$ when compared with the standard rate test data at similar temperatures. By contrast, however, there is a significant increase in dJ/da with increasing load rate. While the increased yield has a tendency to lower the tearing modulus, the increase in $\mathrm{dJ} / \mathrm{da}$ more than offsets this decrease. Due to the steep tearing slope, the $\mathrm{J}$ values for crack extensions greater than about $0.8 \mathrm{~mm}(0.03 \mathrm{in.)}$ were greater than the corresponding $J$ values in the standard rate test. Thus, while based on $J_{I c}$ alone, the material shows a dramatic drop in toughness, the overall $J-\Delta a$ curve shows that the material will exhibit high toughness with moderate crack extension.

Although there are insufficient data (only three data points) to develop a valid $J_{\text {Ic }}$ for the high-temperature, high-rate conditions, we observe what appears to be a flattening (reduction of tearing modulus) of the resistance curve. While $J_{\text {Ic }}$ does not change dramatically from its room-temperature, standard-rate value, the corresponding tearing modulus has been reduced to almost one-third of its value. 
TABIE 5.1. Fracture toughness and tensile properties of PWR feedwater piping at room temperature and standard loading rates (related tensile properties included). ${ }^{a}$

\begin{tabular}{|c|c|c|c|c|c|c|c|c|c|c|c|c|}
\hline \multirow{2}{*}{$\begin{array}{l}\text { Reactor } \\
\text { plant }\end{array}$} & \multicolumn{2}{|c|}{$\begin{array}{c}\text { Upper yield } \\
\text { stress } \\
\end{array}$} & \multicolumn{2}{|c|}{$\begin{array}{l}\text { Lower yield } \\
\text { stress } \\
\end{array}$} & \multicolumn{2}{|c|}{$\begin{array}{c}\text { Ultimate tensile } \\
\text { strength. }\end{array}$} & \multirow{2}{*}{$\begin{array}{c}\text { Elong. } \\
\&\end{array}$} & \multicolumn{2}{|r|}{$\mathrm{J}_{\mathrm{IC},}$} & \multicolumn{2}{|c|}{$\mathrm{dJ} / \mathrm{da}$} & \multirow{2}{*}{$\begin{array}{c}\text { Tearing } \\
\text { modulus, } \\
\text { T }\end{array}$} \\
\hline & $\mathrm{MPa}$ & ksi & $\mathbf{M P a}$ & $\mathrm{ksi}$ & MFa & ksi & & $\mathrm{kJ} / \mathrm{m}^{2}$ & in. $-1 b /$ in. & $\mathrm{MJ} / \mathrm{m}^{3}$ & ksi & \\
\hline Ginna $^{b}$ & 270 & 39.1 & 261 & 37.9 & 482 & 69.9 & 34 & 231 & 1320 & 76 & 11.0 & 113 \\
\hline घ. B. Robinson & 274 & 39.7 & 258 & 37.4 & 481 & 69.8 & 34 & 245 & 1400 & 230 & 33.4 & 334 \\
\hline Beaver Valley & 331 & 48.0 & 308 & 44.7 & 473 & 68.6 & 43 & 291 & 1660 & 207 & 30.0 & 265 \\
\hline Salem & 288 & 41.8 & $25 ?$ & 37.3 & $4 \in 6$ & 67.6 & 39 & 234 & 1335 & 179 & 25.9 & 260 \\
\hline L. C. Cook & 262 & 38.0 & 246 & 35.7 & 486 & 70.5 & 36 & 268 & 1530 & 221 & 32.0 & 326 \\
\hline Average & 285 & 41.3 & 266 & 38.6 & 478 & 69.3 & 37 & 254 & 1450 & $--^{c}$ & $--^{c}$ & $-c^{c}$ \\
\hline $\begin{array}{l}\text { Variation } \\
\text { from average }\end{array}$ & & $\begin{array}{l}68 \\
88\end{array}$ & & $\begin{array}{l}68 \\
88\end{array}$ & & & $\begin{array}{r}+168 \\
-88\end{array}$ & & $\begin{array}{l}158 \\
-98\end{array}$ & & & \\
\hline
\end{tabular}

$a_{A}$ Il material is Al06-B except for Salem which is Al06-C.

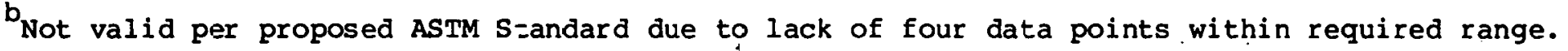

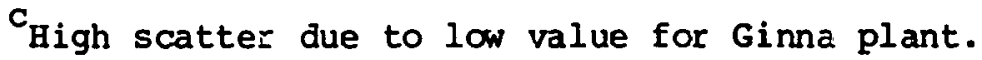


TABLE 5.2. Fracture toughness and tensile properties of D. C. Cook feedwater piping at various temperatures and loading rates (related tensile properties included).

\begin{tabular}{|c|c|c|c|c|c|c|c|c|c|c|c|c|c|c|}
\hline \multicolumn{2}{|c|}{ Temper ature } & \multirow{2}{*}{$\begin{array}{c}\text { Strain } \\
\text { rate }\end{array}$} & \multicolumn{2}{|c|}{$\begin{array}{c}\text { Upper yield } \\
\text { stress }\end{array}$} & \multicolumn{2}{|c|}{$\begin{array}{c}\text { Lower yield } \\
\text { stress } \\
\end{array}$} & \multicolumn{2}{|c|}{$\begin{array}{l}\text { Ultimate } \\
\text { tensile } \\
\text { strength }\end{array}$} & \multirow{2}{*}{$\begin{array}{c}\text { Elong. , } \\
8\end{array}$} & \multicolumn{2}{|r|}{$\mathrm{J}_{\mathrm{IC}_{1}}$} & \multicolumn{2}{|c|}{$\mathrm{dJ} / \mathrm{da}$} & \multirow{2}{*}{$\begin{array}{l}\text { Tearing } \\
\text { modulus, } \\
\text { T }\end{array}$} \\
\hline${ }^{\circ} \mathrm{C}$ & $o_{F}$ & & $\mathrm{MPa}$ & ksi & $\mathrm{MPa}$ & ksi & $\mathrm{MPa}$ & ksi & & $\mathrm{kJ} / \mathrm{M}^{2}$ & in. $-1 b /$ in. $^{2}$ & $\mathrm{MJ} / \mathrm{m}^{3}$ & ksi & \\
\hline 3 & 37 & $1 \times 10^{-3^{b}}$ & 277 & 40.2 & 261 & 37.8 & 498 & 72.2 & 36 & 149 & 851 & 221 & 32.0 & 303 \\
\hline 22 & 72 & $1 \times 10^{-3}$ & 262 & 38.0 & 246 & 35.7 & 486 & 70.5 & 36 & 268 & 1530 & 221 & 32.0 & 326 \\
\hline 218 & 425 & $1 \times 10^{-3}$ & $191^{c}$ & $27.7^{c}$ & $185^{c}$ & $26.8^{c}$ & $429^{C}$ & $62.2^{c}$ & 32 & 118 & 674 & 188 & 27.2 & 385 \\
\hline 3 & 37 & $10^{\mathrm{d}}$ & 438 & 63.5 & 352 & 51.0 & 522 & 75.7 & 35 & 111 & 634 & 360 & 52.2 & 323 \\
\hline 22 & 72 & 10 & 427 & 62.0 & 330 & 47.9 & 545 & 79.1 & 36 & 27 & 154 & 465 & 67.4 & 406 \\
\hline 218 & 425 & 10 & 277 & 40.2 & 248 & 36.0 & 434 & 63.0 & 38 & -- e & $--^{e}$ & $--^{e}$ & $--^{e}$ & -_e \\
\hline
\end{tabular}

Modulus $\mathrm{E}$ taken as $207 \mathrm{GPa}\left(30 \times 10^{6} \mathrm{psi}\right)$ at 3 and $22 \mathrm{C}(37$ and $72 \mathrm{~F})$ and $197 \mathrm{GPa}\left(28.6 \times 10^{6} \mathrm{psi}\right)$ at $218 \mathrm{C}(425 \mathrm{~F})$ for calculation of $T$.

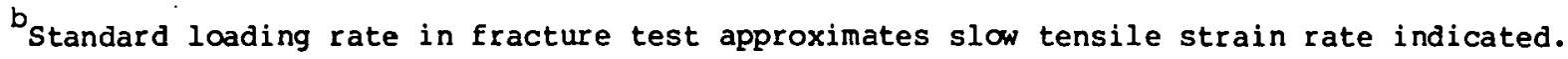

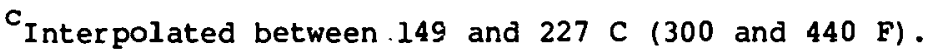

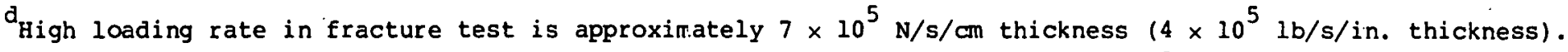

'Data exhibited high scatter; however, J Ic appears high (approximately $300 \mathrm{~kJ} / \mathrm{m}^{2}$ ) with corresponding low tearing modulus. 


\section{FATIGUE AND TEARING ANALYSES}

The inability to relate variations in maximum crack depth to either material characteristics (mechanical properties, microstructure, i.d. surface configuration), corrosion (pitting, corrosion products, corrosion morphology), cracking tendencies (depth and concentration of surface cracks), or crack morphologies (branching, corrosion spikes, corrosion craters) indicates that these factors, individually, contribute at most to only a minor extent to the cracking problem. We believe that the major cause for differences in cracking can be attributed to differences in undocumented, unforeseen cyclic loadings. These loads would result in either fatigue, CF or SCC. It is clear that cracks are initiated at surface irregularities--generally geometric changes for the major cracks and machining grooves and pit sites for most of the minor cracks. However, it is not clear as to what extent corrosion contributed to the propagation of the cracks, and in fact, it is likely that cracking would have occurred in at least some of the plants in the absence of any concomitant corrosion.

\subsection{FAtigue anALYSis}

Results from recently instrumental plants and simulated flow studies ${ }^{1}$ indicate that fluctuations during auxiliary feedwater operations can give rise to relatively high cyclic stresses. The presence of fatigue striations on a number of the TEM replicas, especially those taken at the crack tip from D. C. cook, confirms that fatigue played a role in the cracking. Unfortunately, much of the evidence for fatigue was probably destroyed by corrosion.

Using measurements made on the TEM replicas taken from the crack tip of the D. C. Cook crack, we calculated the cyclic stress range that should give rise to the observed striation spacings. A typical fatigue crack-growth relationship for ferritic-pearlitic steels such as Al06-B is given by the Paris equation:

$$
\frac{d a}{d N} \simeq 3.6 \times 10^{-10}(\Delta K)^{3.0}
$$


where the crack growth rate da/dN is in (inch/cycle) and the stress intensity $\mathrm{r}$ ange $\Delta \mathrm{K}$ is in (ksi-in. ${ }^{1 / 2}$ ). Although a complete fatigue study is beyond the project scope, this relationship was shown to correlate with data obtained during fatigue precracking of the fracture specimens. If we assume that the observed striation spacing corresponds to the crack growth per cycle, then with an average observed spacing of about $0.10 \mu_{\mathrm{m}}\left(3.9 \times 10^{-6}\right.$ in.) a cyclic stress intensity of $24 \mathrm{MPa} \cdot \mathrm{m}^{1 / 2}\left(22 \mathrm{ksi} \cdot \mathrm{in}^{1 / 2}\right)$ is calculated. Employing the stress intensity solution for a long thumbnail crack,

$$
\Delta R=c \Delta \sigma \sqrt{\pi a}
$$

where $\mathrm{a}=$ crack depth and $\mathrm{c}$ is a geometry-dependent constant that has a value approximately equal to one, we can evaluate the corresponding stress range. The striations were observed at a crack depth of about $8.3 \mathrm{~mm}(0.33 \mathrm{in.})$. Thus, using this value for the crack length and the estimated cyclic stress intensity of $24 \mathrm{MPa} \cdot \mathrm{m}^{1 / 2}$, the resulting cyclic stress range is about $150 \mathrm{MPa}$ $(22 \mathrm{ksi})$. Stresses of this order can be reached if cold auxiliary feedwater is brought into contact with hot feedwater pipe.

The spacings of the wavy striations seen with the SEM range from 0.2 to $1.5 \mu \mathrm{m}\left(7.9 \times 10^{-6}\right.$ to $59 \times 10^{-6}$ in. $)$. Using the Paris equation, this corresponds to a range of cyclic stress intensities from 31 to $60 \mathrm{MPa} \cdot \mathrm{m}^{1 / 2}$ ( 28 to $55 \mathrm{ksi} \cdot \mathrm{in} \cdot{ }^{1 / 2}$ ). The wavy striations were observed on a number of crack surfaces usually at a depth of approximately $2 \mathrm{~mm}(0.08 \mathrm{in.})$. The resulting cyclic stresses are within the range of 386 to $758 \mathrm{MPa}$ (56 to $110 \mathrm{ksi})$. These stresses are unreal, and they suggest that the wavy striations generally cannot be related on a $1: 1$ basis to fatigue stresses.

\subsection{APPLICATION OF J-INTEGRAL AND TEARING CONCEPTS}

The J-integral can be related to the design of piping systems to assess its safety against crack initiation and unstable tearing. The behavior of real or postulated cracks are evaluated with respect to growth initiation and stability by comparing the applied $J$ to $J_{I c}$ and the applied $T$ to $T$ material; i.e.,

$$
\begin{aligned}
& \mathrm{J}_{\text {Appl }} \geq \mathrm{J}_{\text {IC }}: \text { crack initiation } \\
& \mathrm{T}_{\text {Appl }}>\mathrm{T}_{\text {Matl }}:
\end{aligned}
$$


Unfortunately, however, the analyses of $\mathrm{J}_{\mathrm{Appl}}$ and $\mathrm{T}_{\mathrm{Appl}}$ generally require a detailed elastic-plastic computer evaluation. Often the required input relating to the loading conditions (i.e., load versus displacement control) must be postulated. In Appendix I, some approximate upper bound analysis methods are employed to estimate $J$ and $T$ under maximum design load conditions and plastic limit moment. The Millstone-2, steam generator-1, feedwater system was analyzed because the NRC was interested in evaluating a utility company request to continue its operation with possible cracks in the feedwater piping. The results for a postulated 152-mm (6-in.) through-wall crack indicate that while crack initiation may be possible under design basis earthquake (DBE) conditions, tearing should be stable and therefore the crack is likely to arrest. 


\section{SUMMARY}

We evaluated cracking in sections removed from the feedwater piping adjacent to the steam generators from nine PWR plants. The evaluation is based on the following:

1. Conditions of the i.d. piping surfaces;

2. Relative operating life of the plants;

3. Examination of corrosion, pitting, and crack morphologies in longitudinal cross sections;

4. Fractography of fractured crack surfaces;

5. Corrosion-product chemistry and crystallography;

6. Characterization of the steel microstructure, tensile properties, and fracture toughness properties of the piping material.

We used light microscopy, SEM, TEM, EDS, x-ray diffraction, and electron microprobe techniques.

Tensile properties at several temperatures, 4 to $440 \mathrm{C}$ (39 to $227 \mathrm{~F}$ ), and at a strain rate of $10^{-3} / \mathrm{s}$ were obtained for six of the piping materials with a more extensive test matrix being used for one of these materials, D. C. Cook, namely, temperatures from 4 to. $285 \mathrm{C}(545 \mathrm{~F})$ and strain rates from $10^{-3} / \mathrm{s}$ to $10 / \mathrm{s}$. Fracture toughness data ( $\mathrm{J}_{\text {IC }}$ and tearing modulus) were obtained for five of these six materials, mostly at $22 \mathrm{C}(72 \mathrm{~F})$ and at a loading rate of about $210 \mathrm{~N} / \mathrm{s} / \mathrm{cm}$ thickness $\left(120 \mathrm{lb} / \mathrm{s} / 1 \mathrm{n}_{\text {. }}\right)$. The D. C. Cook material was also tested at a high loading rate of about $7 \times 10^{5} \mathrm{~N} / \mathrm{s} / \mathrm{cm}$ $\left(4 \times 10^{5} \mathrm{lb} / \mathrm{s} / \mathrm{in.}\right)$ and at 3,22 , and $218 \mathrm{C}(37,72$, and $425 \mathrm{~F})$.

The following observations were made:

1. The major rrarks initiated along the discontinuous section change at the bottom of the counterbore slope and/or at discontinuities along the weld-to-piping or weld-to-nozzle interfaces and along weld surfaces.

2. Cracks extended circumferentially along the i.d. and propagated relatively straight in a direction that closely bisected the angle formed by the intersection of the two contiguous surfaces at the corresponding discontinuity.

3. In addition to the main crack, piping from some plants contained many shallow cracks or corrosion spikes, $\leq 0.25 \mathrm{~mm}(0.010 \mathrm{in}$.) deep (San Onofre, Ginna, Palisades, and Kewaunee). Some plants contained a 
number of intermediate size cracks, 0.25 to $1.0 \mathrm{~mm} 10.010$ to 0.039 in.) deep (San Onofre, Salem, Palisades, Ginna, and Point Beach) and two plants contained a number of relatively deep cracks, $>1 \mathrm{~mm}$ (0.039 in.) deep (Palisades and San Onofre). Three plants had either no cracks (D. C. Cook) or very few cracks (Beaver Valley and H. B. Robinson) in addition to the major crack.

4. Laboratory-fractured crack surfaces contained arrest bands; their presence was consistent with the presence of corrosion craters viewed in cross section.

5. The predominant cracking mode was transgranular; some minor or very minor branching was evident in four plants. All cracks contained corrosion spikes, mostly at corrosion craters, and these are small arrested cracks. Occasionally, a corrosion spike extended normal to the crack propagation direction, and this could be related to the steel microstructure.

6. The corrosion product exhibited a variety of morphologies that were present on essentially all crack surfaces except on those from the deep D. C. Cook crack. A number of impurity elements were detected but $x$-ray diffraction revealed the presence of only the $\mathrm{Fe}_{3} \mathrm{O}_{4}$ and $\mathrm{Fe}_{2} \mathrm{O}_{3}$ lattices.

7. Wavy striation-like structures, which we at first attributed to fatigue, were seen on many as-corroded crack surfaces. However, their association with fatigue stresses was shown to be questionable since their spacings frequently coincided with the observed steel pearlite spacings.

8. Using TEM on replicas of cleaned crack surfaces, classical fatigue striations and tear ridges were observed at the tip of the deep D. C. Cook crack. Evidence, but to a lesser degree of clarity, of fine fatigue markings were similarly observed on crack tips from three other plants.

9. With but one distinct exception and one possible exception, correlations showing any significant trends were not obtained between surface conditions, various aspects of corrosion and pitting, reactor plant operating life, assumed crack-growth rate, section thickness, general cracking tendency, and major crack depths. We did observe a general trend between major crack depth and the number of arrest 
bands on the corresponding crack surface. The average crack length per cyclic event (arrest band) did not vary by more than about a factor of two. There appears to be a general trend for most of the plants between crack depth (or estimated crack-growth rate) and surface defect at the major crack.

10. The steels were relatively clean with respect to inclusions. Various pearlitic-ferritic-spheroidal microstructures were obtained; all can be obtained with the manufacturing practices allowed for ASTM Al06. No trends between microstructure and either cracking, corrosion, or mechanical properties could be found.

11. The tensile properties for the six materials tested were within the room-temperature specifications for ASTM Al06-B; however, the yield strength of Salem material at elevated temperatures falls slightly below that for ASTM Al06-B.

12. The yield strengths decrease with an increase in temperature. This trend holds for D. C. Cook material at all strain rates tested. The ultimate tensile strengths all show a minimum value at an intermediate temperature of $149 \mathrm{C}(300 \mathrm{~F})$. This is consistent with a reversal of the strain-rate effect on UTS as the temperature is raised for the D. C. Cook material.

13. Fracture toughness data, considering both $J_{I C}$ and tearing modulus, show adequate toughness at room temperature and standard loading rates for the five materials tested. Also, adequate toughness was measured at high loading rates and over a range of temperatures for the D. C. Cook material. A drop in toughness at $3 \mathrm{C}(37 \mathrm{~F})$ is consistent with entering into the ductile-to-brittle transition region. Variations in $\mathrm{J}_{\mathrm{Ic}}$ or tearing modulus as a result of changes in temperature or loading rate are attributed to changes in flow characteristics seen on the corresponding tensile curves.

14. Correlations showing significant trends between mechanical properties and cracking behavior could not be obtained.

We applied J-integral and tearing concepts to the feedwater system in Millstone-2 and showed for a postulated 152-mm (6-in.) through-wall crack that although the crack may initiate under DBE conditions, the tearing should be stable and the crack is likely to arrest. 


\section{CONCLUSIONS}

Surface geometric defects from fabrication practices provided sites for stress concentration and crack initiation.

Corrosion pitting, especially at the root of machining grooves, probably accelerated the initiation of cracking at these sites.

Cracking or corrosion could not be related to differences in either. material microstructure or mechanical properties.

The role of corrosion as being an important factor in continuing to drive the crack is somewhat unclear. The inability to obtain trends that relate corrosion activity either to crack length or to reactor-plant life suggests that for most of these plants the overriding factor was the presence of unforeseen, undocumented overloads. Corrosion, or at least any excessive corrosion, was likely only a minor contributor to the cracking problem.

Analysis of the crack cross-section morphologies, the appearance of fatigue striations on replicas of cleaned crack surfaces, and the presence of arrest bands on as-corroded crack surfaces all indicate that cyclic overloads with both short- and long-time intervals are probably major contributors to the cracking problems.

The presence of corrosion craters, possibly formed during periods of lowamplitude cyclic loading does indicate extensive corrosive activity, especially for the Palisades and San Onofre cracks. Such cratering, however, is not indicative of corrosion helping to drive the crack, and in fact it may ald, instead, in blunting the crack during periods of lower loads.

Various elements were present in the corrosion product as impurities in the predominantly $\mathrm{Fe}_{2} \mathrm{O}_{3}$ or $\mathrm{Fe}_{3} \mathrm{O}_{4}$ lattice. These elements may have originated from the steel, condensers, or heat exchangers. Some of these elements likely contribute to the corrosion activity by changing the effective potential of the feedwater; however, their added contribution to the cracking problem is likely to be minor. A detailed analysis of corrosion product as related to its circumferential position around the piping may provide a better answer to this question. The high $\mathrm{Fe}_{2} \mathrm{O}_{3} / \mathrm{Fe}_{3} \mathrm{O}_{4}$ ratio obtained only from the D. C. Cook plant material should also be clarifed.

With the exception of a low yield stress value for Salem at elevated temperatures and the relatively low toughness values for Ginna, the mechanical properties all fall within acceptable limits. However, the cracking behavior 
for these two plants was not especially unique; and, we conclude that any differences in the mechanical properties are not pertinent to the cracking problem.

The direction of continued crack propagation, normal to the i.d. surface or along the bisecting angle of the normals to the two contiguous surfaces at the crack origin, indicates that the net tensile stresses driving the crack are essentially parallel to the corresponding i.d. surface region and not to the piping axis. This is consistent with the suggestion of the presence of thermally induced surface stresses such as may be caused by striping or stratification of the feedwater. 
REFERENCES

1. Westinghouse Users' Group--NRC Meetings at Bethesda, MD, 1979-1980.

2. Hertzberg, R. W. and Mills, W. J., "Character of Fatigue Fracture Surface Micromorphology in the Ultra-Low Growth Rate Region," in Fractography-Microscopic Cracking Processes, STP 600, Eds. C. D. Beachem and W. R. Warke, ASTM, Philadelphia, 1976, p. 220.

3. Yuzawich, P. M. and Hughes, C. W., "An Improved Technique for Removal of Oxide Scale from Fractured Surfaces of Ferrous Materials," Practical Metallurgy, vol. 15, 1978, p. 184 .

4. IITRI Fracture Handbook, Eds. S. Bhattachargya, V. E. Johnson, S. Agarwal, and M. A. H. Howes, published by IIT Research Institute, Chicago, Jan. 1979 , p. $1-143$.

5. Ibid, p. 1-180.

6. Staehle, R. W. and Payer, J. H., "Dissolution Behavior of Carbides in Aqueous Environments," in Localized Corrosion, NACE 3, Eds. R. W. Staehle, B. F. Brown, J. Kruger, and A. Agarwal, 1974, p. 482.

7. Potter, E. C. and Mann, G. M. W., "The Fast Linear Growth of Magnetite on Mild Steel in High Temperature Aqueous Conditions," Brit. Corrosion $J .$, Vol. 1, 1963, p. 26 .

8. 1979 ASTM Annual Book of Standards, Part 1, ANSI/ASTM A520-72, American Soriety for Testing and Materials, Philadelphia, 1979.

9. Sutton, S. B., "An Investigation of Pressure Transient Propagation in Pressurized Water Reactor. Feedwater Lines," UCRL-52265, Lawrence Livermore National Laboratory, Livermore, CA, July 22, 1977.

10. Edington, J. W., "Effect of Strain Rate on the Dislocation Substructure in Deformed Niobium Single Crystals," in Mechanical Behavior of Materials Under Dynamic Loads, Ed. U. S. Lindholm, 1968, p. 191.

11. Memorandum on "Millstone Nuclear Power Station, Unit 2 Feedwater Lines," from Northeast Utilities to NRC, August 22, 1979, Docket 50-336. 
APPENDIX A

AS-RECEIVED SECTIONS

Photographs of as-received sections are given in Figs. A.1, A.2, and A.3. The figures do not include sections from Palisades and Ginna since they are included and discussed in the report. Also, the figures do not include additional reducer section received direct from Public Service Electric and Gas Company, Newark, NJ (Salem) or additional pipe section received direct from Consumers Power Company, Jackson, MI (Palisades). 


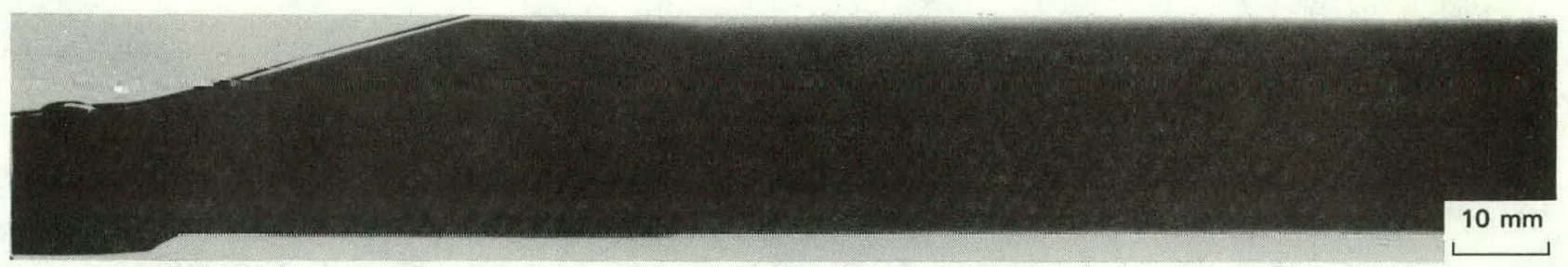

(a) Kewaunee: radiograph

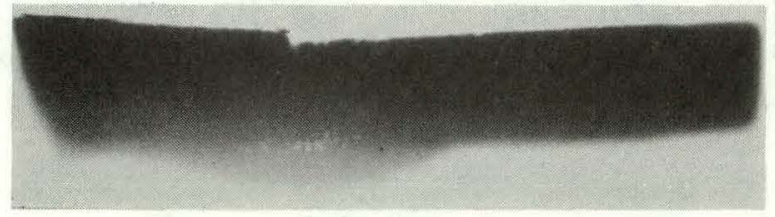

(b) San Onofre: radiograph

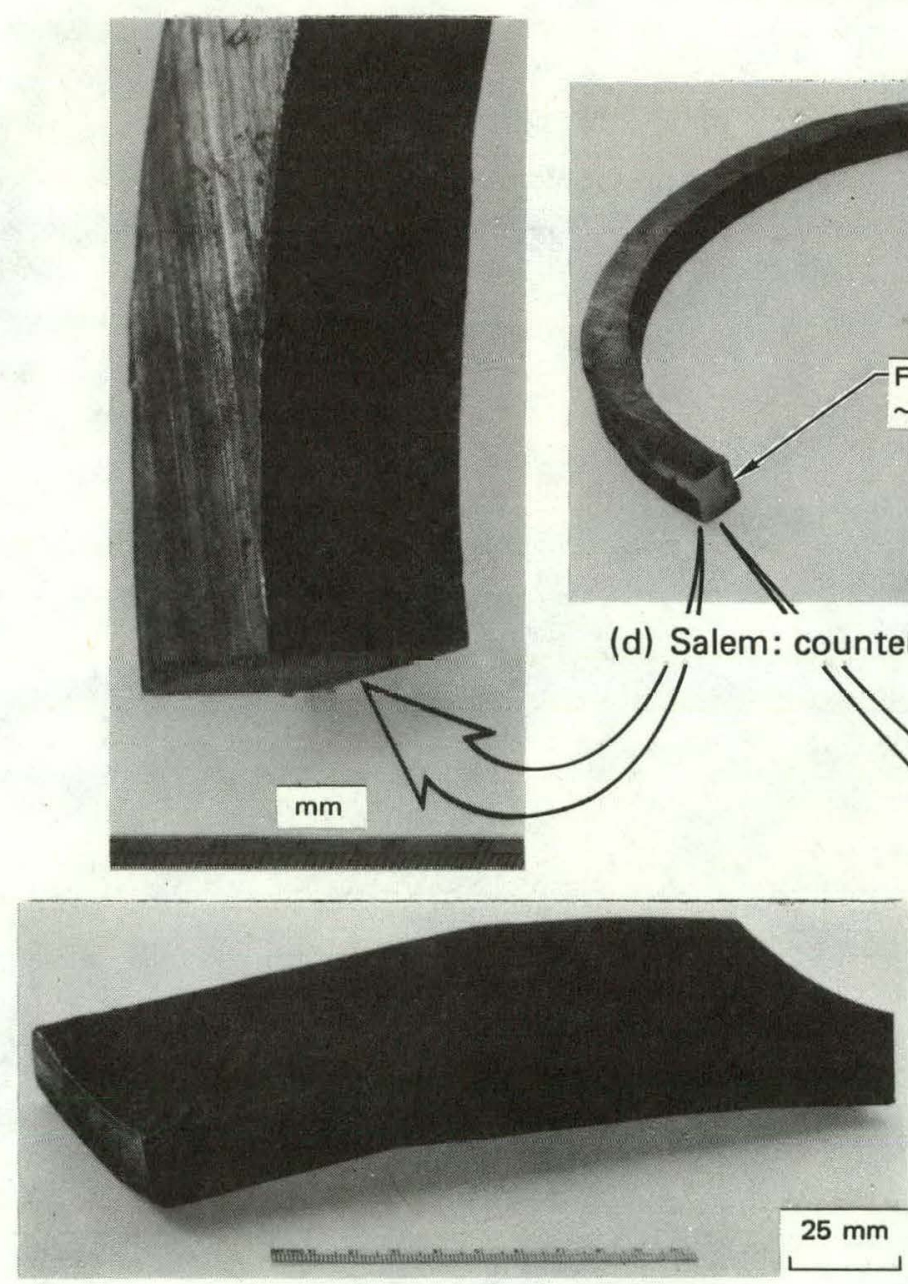

(e) Salem: reducer section

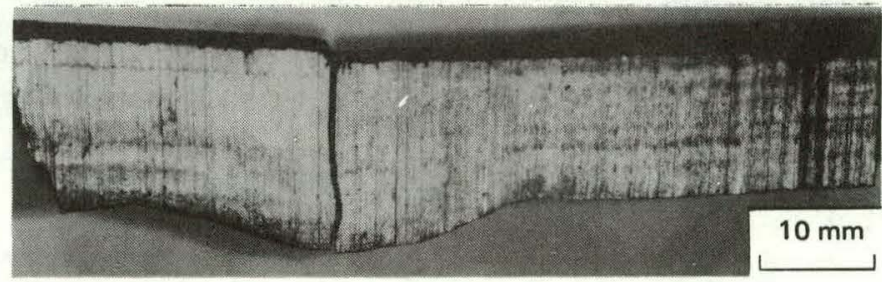

(c) San Onofre

FIG. A.1. Kewaunee, San Onofre, and Salem counterbore sections used for crack evaluation and Salem reducer section used for mechanical properties testing. Note: The Kewaunee and San Onof re as-received sections were about $8 \mathrm{~mm}$ ( 0.3 in.) wide. 


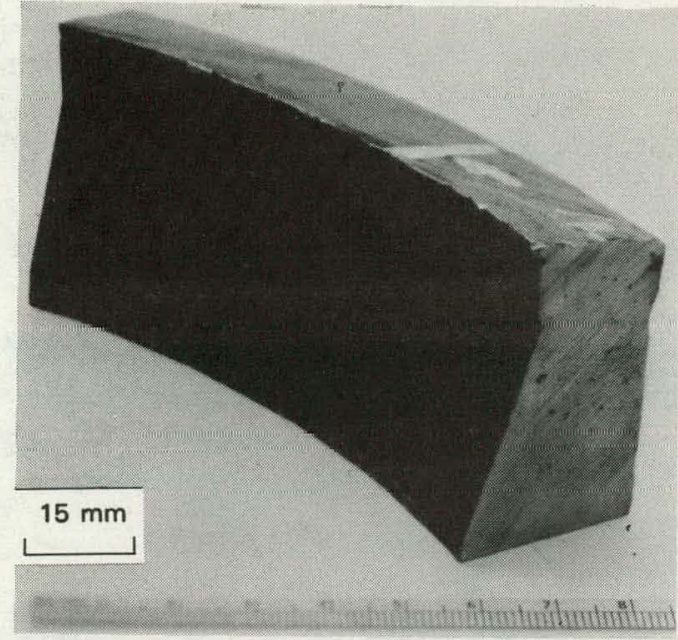

(a) Point Beach from Section 43

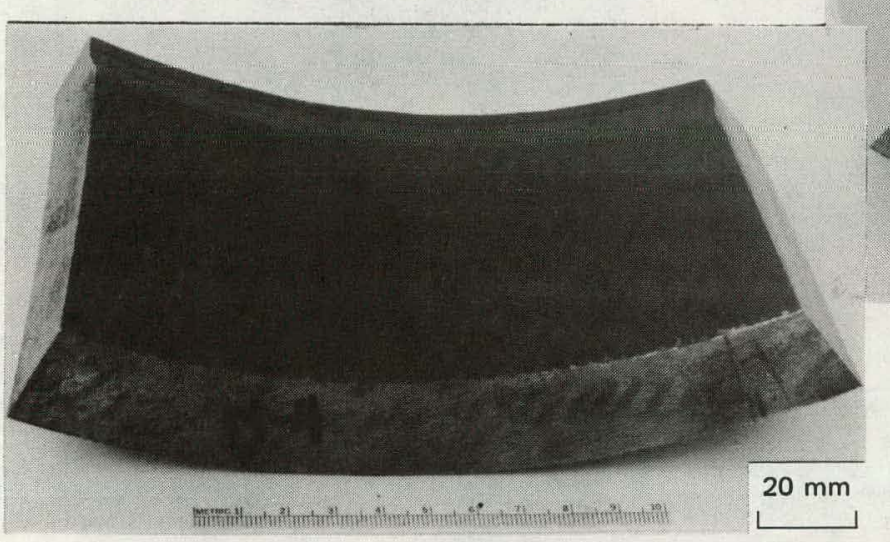

(c) Beaver Valley from Section 6-7

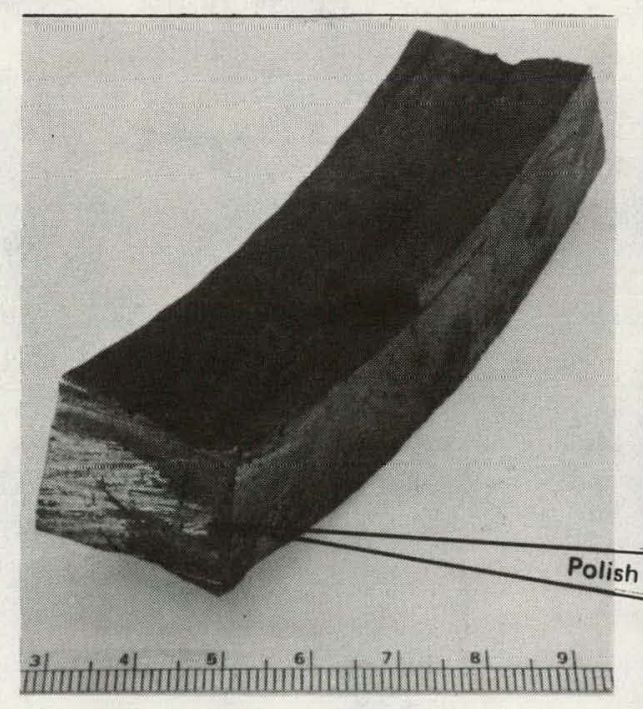

(e) D. C. Cook from Section 1 before and after polishing (d) Beaver Valley from Section 4-5

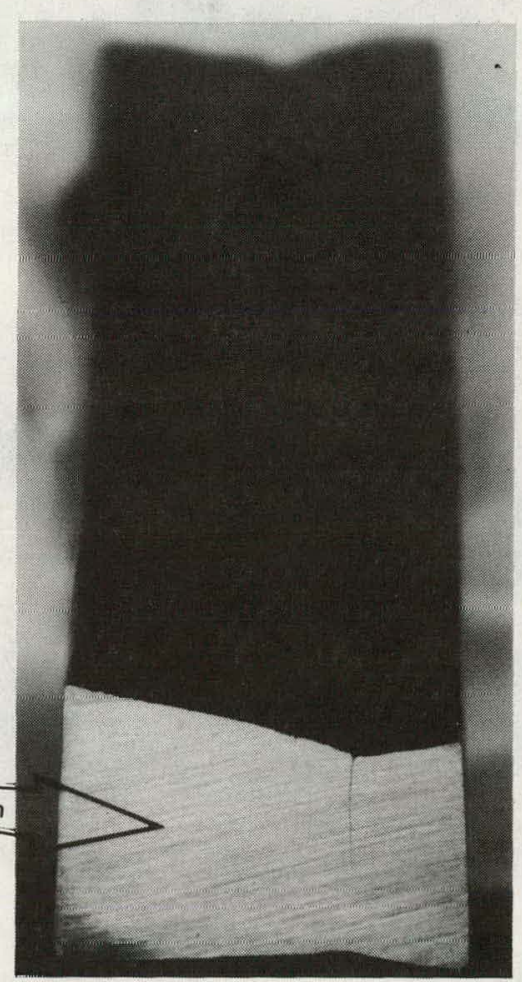

(b) H. B. Robinson from Section B

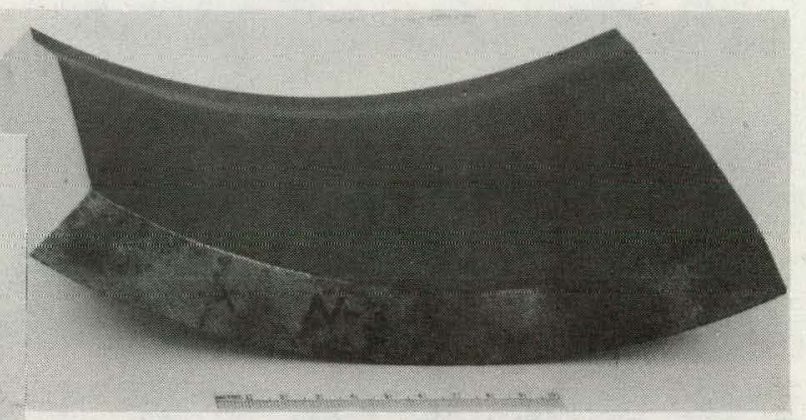

$10 \mathrm{~mm}$

FIG. A.2. Point Beach and D. C. Cook sections used for crack evaluation; and Beaver Valley and H. B. Robinson sections used for crack evaluation and mechanical properties testing. 


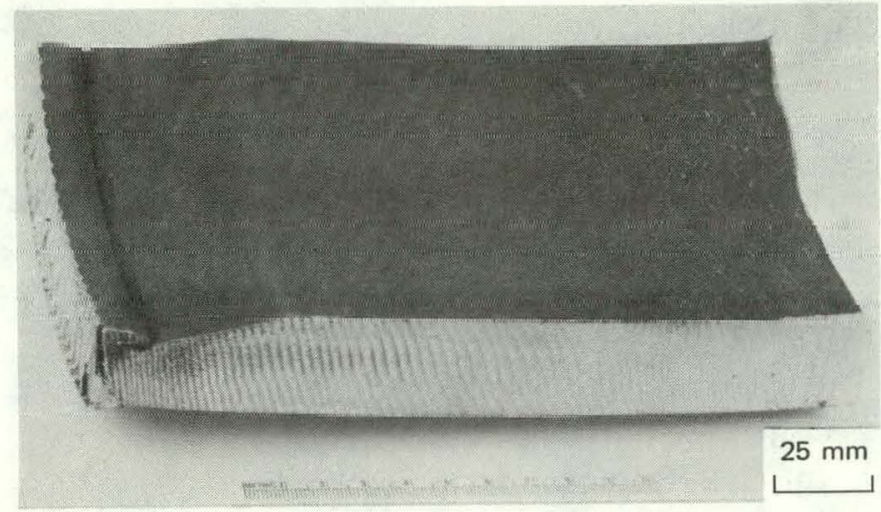

(a) Section 6-7

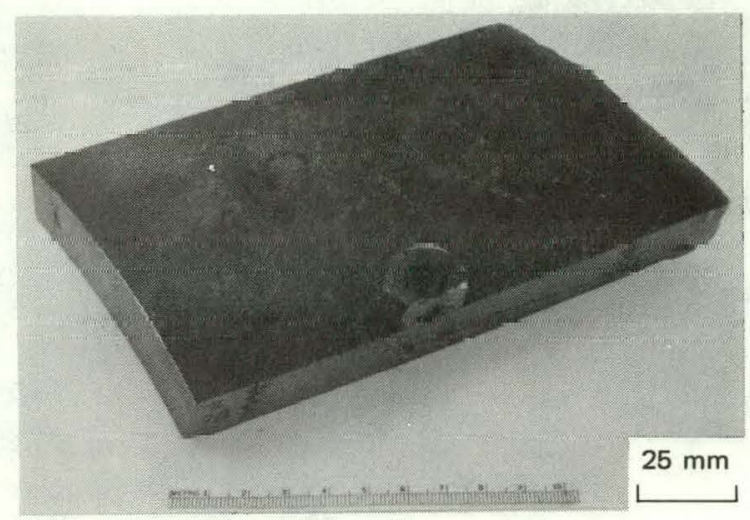

(b) Section 3

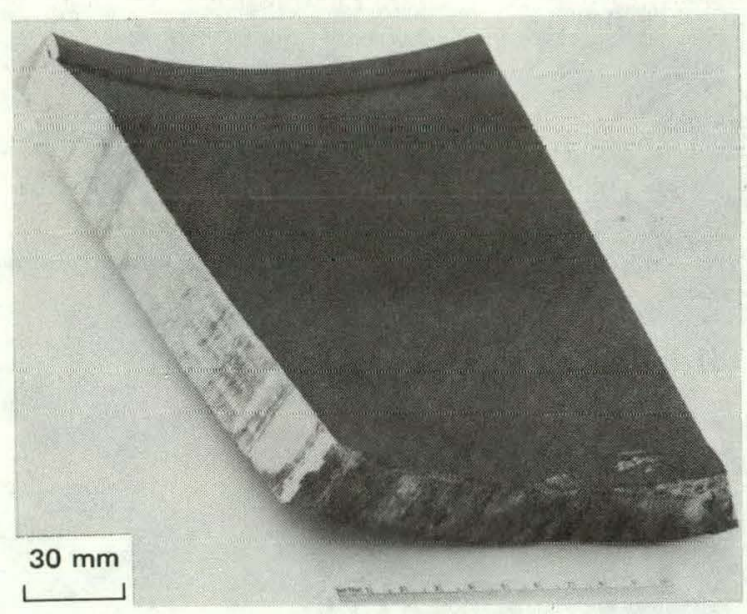

(c) Section 1-2

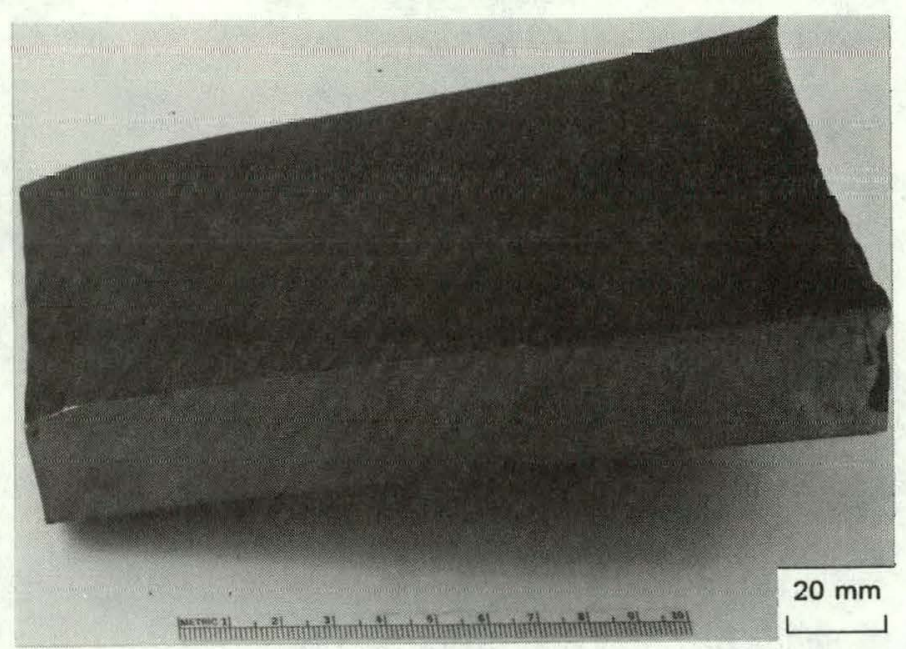

(d) Section 2

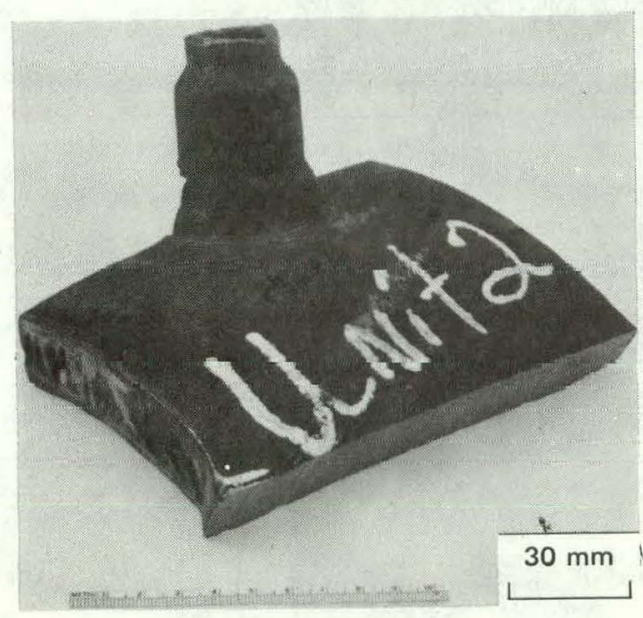

(e) Section 1

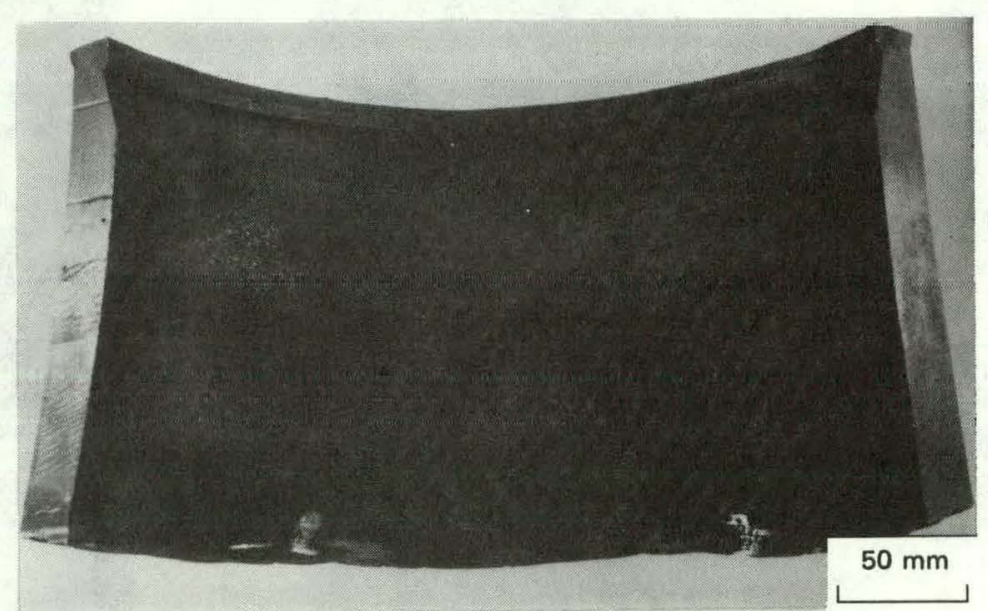

(f) Section 2-3-4-5

FIG. A.3. Sections from D. C. Cook used for mechanical properties testing. The specimens referenced in the text as containing shallow crack were taken from section 6-7. 
APPENDIX B

SURFACES

Photomacrographs of i.d. surfaces of as-received sections are given in Figs. B.1 through B.4. The figures do not include surfaces from Ginna since they are included and discussed in the report. 

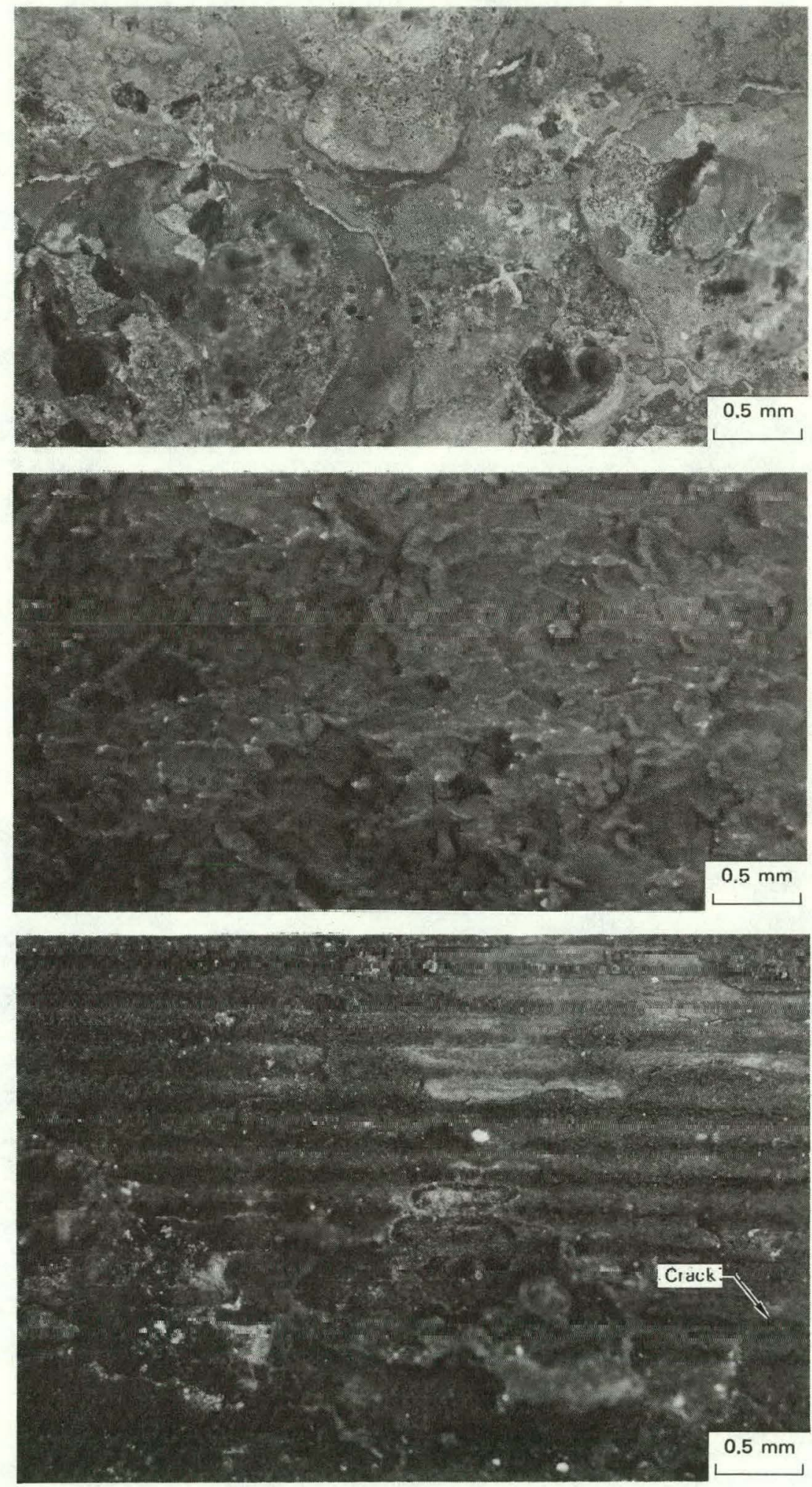

(a) San Onofre: at original I.D. surface (unmachined)

(h) Kewanten: at original I.D. surface (unmachined)

(c) Palisades: at counterbore safe-end

FIG. B.1. Photomacrographs (25X) showing the surface condition of as-received sections from San Onofre, Kewaunee, and Palisades. The areas along the counterbore were unavailable from the San Onofre and Kewaunee sections because the entire crack sections had been used for other analyses. 

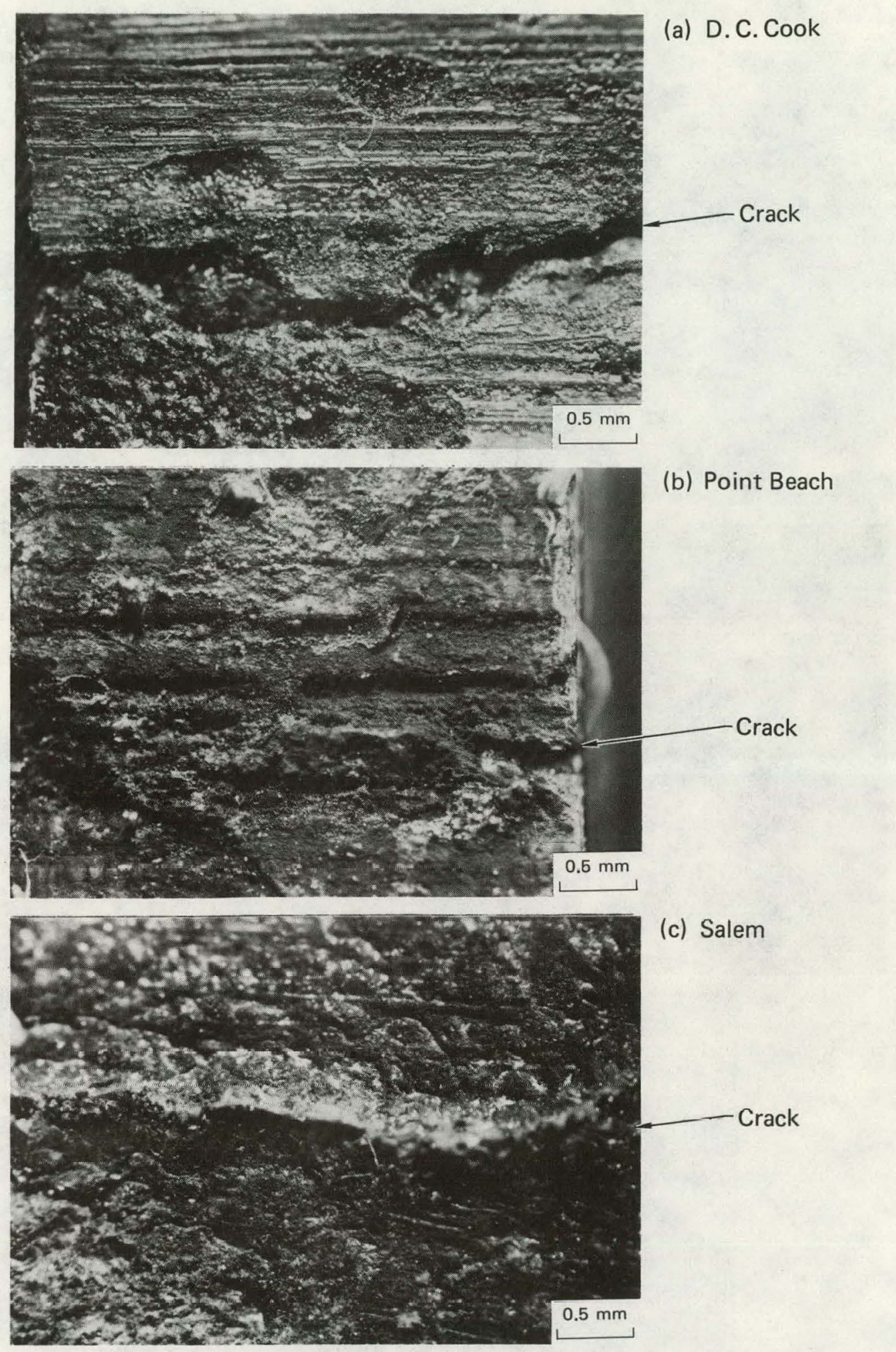

FIG. B.2. Photomacrographs (25X) showing the condition of the counterbore surface in the vicinity of a major crack in as-received sections from D. C. Cook, Point Beach, and Salem. 

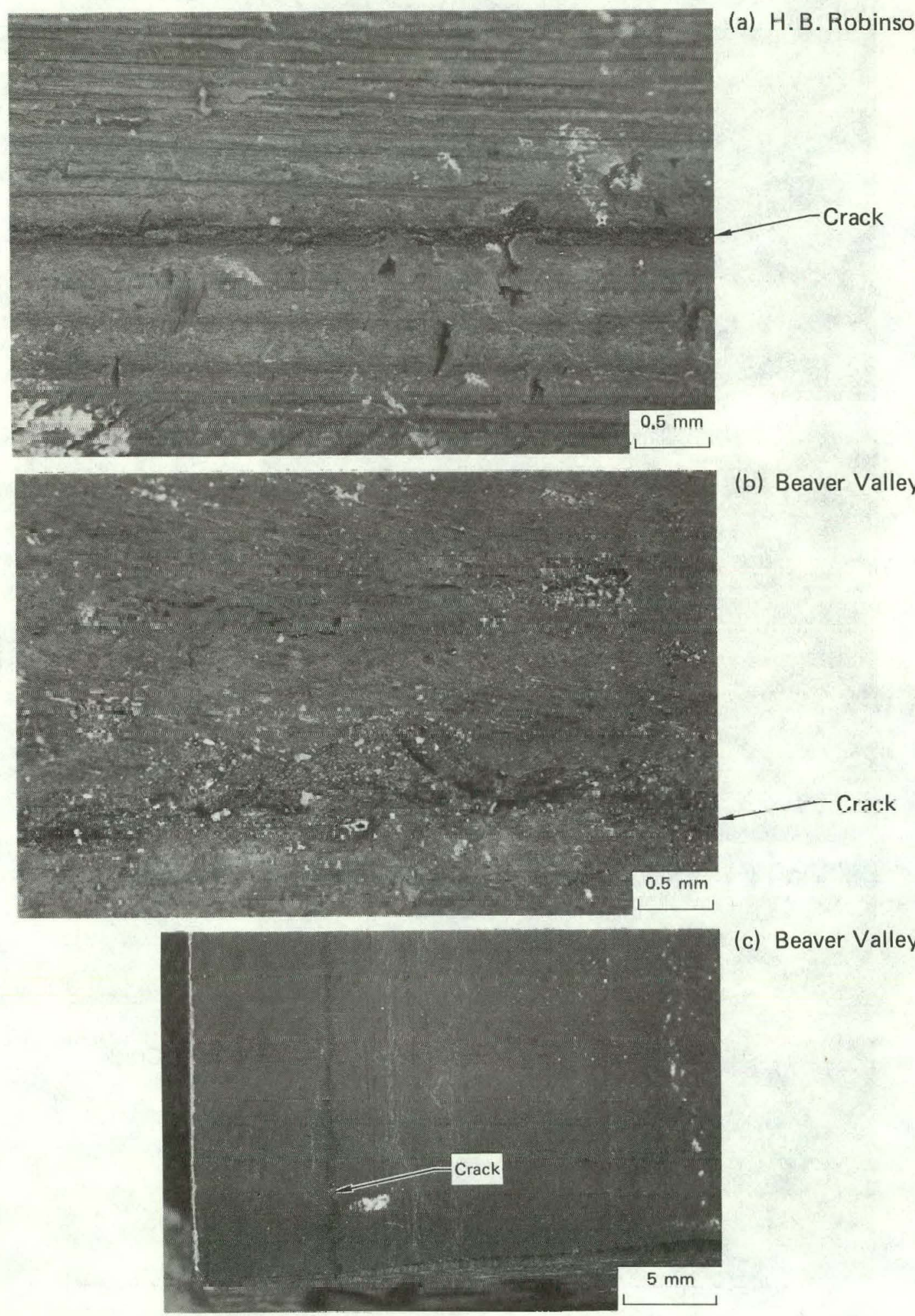

(c) Beaver Valley

FIG. B.3. Photomacrographs showing the condition of the counterbore surface in the vicinity of a major crack in as-received sections from H. B. Robinson and Beaver Valley. 


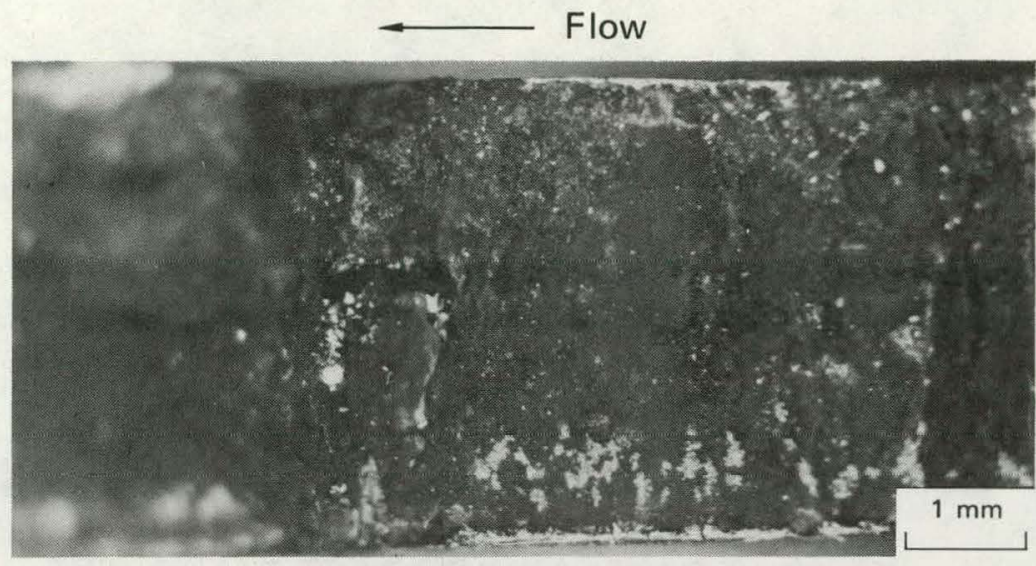

(a) Palisades: at Crack A;

piping-to-weld

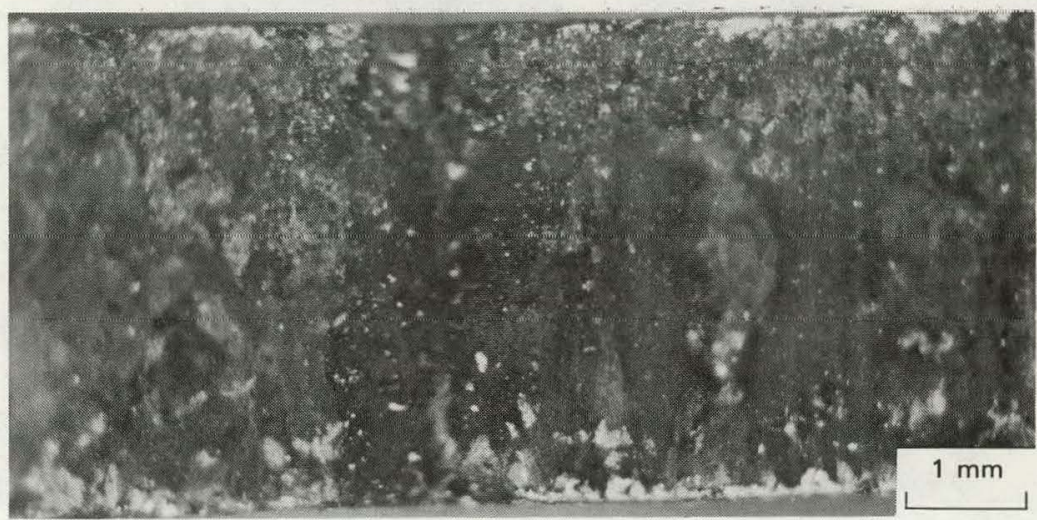

(b) Palisades: at Crack C; safe-end counterbore

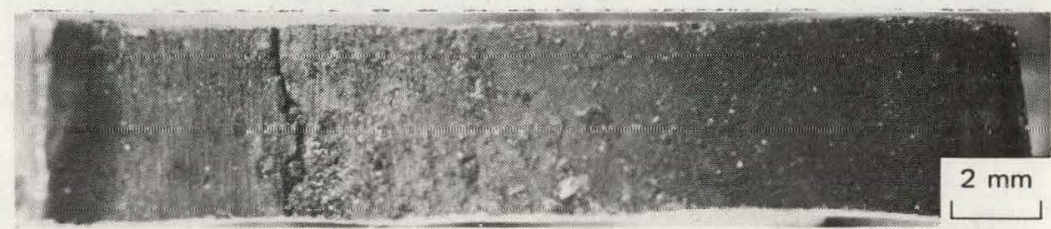

(c) D.C. Cook

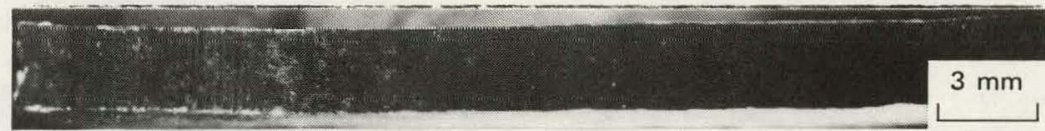

(d) Point Beach

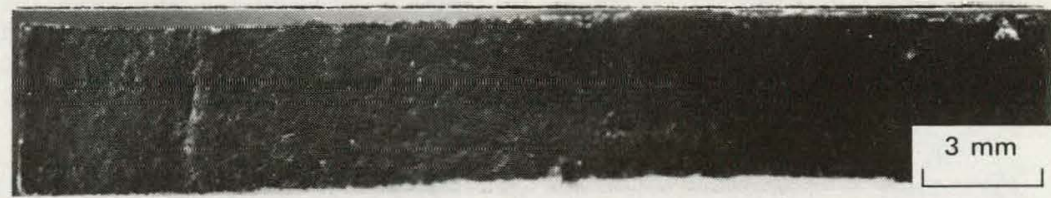

(e) Salem

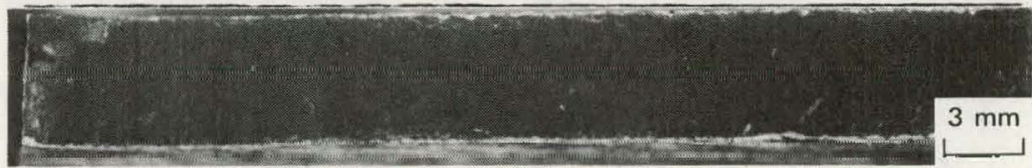

(f) H. B. Robinson

FIG. B.4. Photomacrographs showing typical original inside diameter surfaces of cut section slices used for analyses. 
APPENDIX C

DETAILS ON ATTEMPTED CORRELATIONS

Tables C.I to C.4 list and rank various factors that were evaluated along the i.d. surfaces and cross sections that might be related to the cracking problem. The plants are listed in chronological order with the oldest plant at the top. In what follows we describe the methods used to arrive at the rankings listed for these factors as well as discuss any difficulties encountered. Finally, we attempted to determine if any trends can be detected between these factors. The analyses also include the data previously listed in Tables 3.1, 3.2, and 3.5. We use the same ranking system, namely, the higher the ranking number the more likely should the material be susceptible to cracking or the greater is the degradation.

The angle formed at the intersection of the two contiguous i.d. surfaces at the crack origin (Table C.1) was made by rotation of a calibrated microscope stage; it may not necessarily correspond to the average macroscopic measurement. For example, in H. B. Robinson there is a change in the counterbore slope just before the crack from about 168 to 174 degrees. The smaller the angle listed, the greater the discontinuity across the crack, e.g., 180 degrees indicates no discontinuity. Although we observe the crack origin for D. C. Cook as being off by $0.5 \mathrm{~mm}(0.02 \mathrm{in.})$ from the counterbore discontinuity, it is likely that either the crack or machining groove was deflected in the section we examined. In fact we would expect variations to occur in all the sections if measurements were to be made on successive longitudinal slices.

We have also ranked the potential notch effect due to machining grooves, pitting and general surface roughness. Ranking of pitting considers both the depth and extent of pits observed microscopically in cross section. Several examples of pits are shown in Fig. C.1. Corrosion spikes (small corrosionfilled cracks) are seen at the bottom of many of the pits in Figs. C.I(a) and C.l(b). We noted that some of these small cracks or spikes were relatively sharp while others were blunted or corrosion craters had formed along their length. Figure C.l(c) is an example of small pits along a counterbore slope. Small cracks initiating from a uniformly corroded surface apparently in the absence of any surface irregularity are shown in Fig. C.l(d). These occur halfway up a rounterbore slope; some pitting is seen at the origin of one of 
the spikes. In a number of cases, there was some question as to whether we were looking at corrosion pits or at a cross section of a machining groove. An example of the latter can be seen in Fig. C.2 on a surface that contained relatively shallow pits. Usually these machining grooves could be identified by an undercut or by the presence of deformed metal; these occurrences are seen in the "pits" shown in Fig. C.2(b) and C.2(c). Deformed regions along the i.d. were observed in sections from seven of the plants. San Onofre and Palisades sections, in which surface deformation was not detected, exhibited extensive corrosion and pitting, and it is likely that any deformed surface region in these two plants had corroded away. Although the deformed metal may have been sites for accelerated corrosive attack, we believe that its contribution to the cracking problem is, at most, insignificant. Ranking of surface appearance in Table C. 2 considers corrosion, roughness, and pitting as viewed both macroscopically and by naked eye.

Table C.2 shows the relative magnitude of pitting that developed at the crack origins by comparing the pitted areas above the respective cracks. The bottom of the pit was considered to be where there was a discontinuous change between the "crack" and "pit" widths. Details of these pits are described in the main body of the report. Table c. 3 gives an estimated operating time. Not having access to the dates when the sections were removed from the reactor plants, we assumed that operations for all plants were discontinued in August, 1979, and used, as the start-up, the date of initial criticality listed in Table 2.1. Using crack depth and the estimated operating time, we calculated what we consider are best-guess, relative, crack-growth rates. These are listed in Table C.3. These values were then normalized for the wall thickness (Table C.1) at the respective cracks. As seen in Table C.3, the relative ranking based on crack growth rate does not change significantly by adjusting for the thickness.

The morphology and analysis of corrosion products are discussed in detail in various sections in the main body of the report. However, we will refer here to observations that can be readily ranked relative to degradation. The $x$-ray diffraction spectra taken of surfaces selected from each of the plants indicated that the corrosion product consisted almost entirely of the crystal structures represented by $\mathrm{Fe}_{3} \mathrm{O}_{4}, \mathrm{Fe}_{2} \mathrm{O}_{3}$, or a combination of both. The magnitude of the ratios of $\mathrm{Fe}_{2} \mathrm{O}_{3} / \mathrm{Fe}_{3} \mathrm{O}_{4}$ should be a relative indication of the oxide potentials of the feedwater and the protective nature 
of the corrosion product. The relative intensities of the strongest peak for each oxide were used to obtain these ratios, and these are listed in Table C.2. Point Beach was almost entirely $\mathrm{Fe}_{3} \mathrm{O}_{4}$; on the other extreme D. C. Cook showed only a trace of this oxide. We have also included in the table information reported* on the relative times of exposure of $25 \mathrm{ppb}$ of $\mathrm{O}_{2}$ to the feedwater lines during operation.

We attempted to see if any trends could be detected between crack length and the various factors listed in Tables C.I to C.4. In Figs. C.3 and C.4, we plotted the ranking of crack growth rates for the major crack along the total section and along the piping, respectively, versus various factors reflecting surface conditions: the intersection angle of the contiguous $i . d$. surfaces at the crack origin, the extent of surface damage by machining grooves, the general surface appearance, and the $\mathrm{Fe}_{2} \mathrm{O}_{3} / \mathrm{Fe}_{3} \mathrm{O}_{4}$ ratio. The solid lines indicate a 1 to 1 relationship in each case. For both the total section and piping section alone there is a limited trend with intersection angle. In both cases, D. C. Cook presents a strong exception. There is an indication of a limited trend for oxide ratio with reference to the total section cracks. Taking into account the different operating periods, one can also see from Table C.2 some trend between oxide ratio and oxygen exposure, which in turn reflects a slight correlation between crack length and feedwater oxygen content. The data in the remaining plots are essentially random, although limited trends can be seen by isolating the plants into groups; however, such groupings are not always consistent either within these plots or with additional plots described below.

In Figs. C.5, C.6, and C.7, we plotted the ranking of crack length versus the ranking of a number of those factors or characteristics that could be ranked and, in general, may be expected to vary with crack length. Plots in most cases are made for both the total section and for the piping alone. The only definite trend that is obtained is that crack length increases with the number of arrest bands, Fig. C.5(e). The presence of arrest bands on crack surfaces is discussed in detail in the main body of the report. Again we note some limited trends: general pitting, general cracking tendency, and crack-pit area (Fig. C.5) for the total section, and possibly general pitting and general

*West1nghuuse Users Group -NRC meetings at Bethesda, MD, 1979-1980. 
cracking tendency (Fig. C.6) for the piping. The data from D. C. Cook are invariably out of line for these factors.

Figure C.7 contains plots of crack depth ranking versus ranking of observations on corrosion along cracks. The data are essentially all random, although limited trends can be detected in plots Figs. C.7(a), C.7(b), and C.7(c) between Beaver Valley, Point Beach, Ginna, and Palisades. The sharpness of the crack tip, Fig. C.7(d), should indicate whether corrosion or stresses were the predominant factor in the final stages of exposure of the pipe, i.e., whether the "cracking" was active at that time. Assuming that stress is the major factor in the cracking problem, we ranked the crack tips on the basis of their sharpness with the most blunt crack tip as 1 (San Onofre) and the sharpest crack tip as 9 (Beaver Valley). We considered, generally, the most advanced region of a crack. In some cases the relatively sharper tips have only propagated a short distance from the final corrosion crater, e.g., the Kewaunee crack, Fig. 3.14(d). In the case of the most blunted crack tips, Figs. $3.7(b)$ and $3.7(d)$, it is apparent that aggressive corrosion had played a major role in the degradation of the steel. However, the blunting may have actually delayed the propagation of the crack.

In Fig. C. 8 are plotted the ranking of various factors that are related to corrosive attack versus ranking indicating relative operating life. We have also included crack depth ranking which shows high randomness relative to operating life. The plots for surface appearance and crack-pit area are also quite random; the former can be attributed to the added contribution of the initial conditions of the piping surfaces, the latter to the uncertainty as to when in the operation of the plant the cracks started to propagate. However, in contradiction to the uncertainty of crack initiation time, we do see a definite trend between the severity of corrosion craters and operating life. But, as indicated in Table C.4, there are only slight differences in the severity of these craters for six of the plants with greatly different operating periods. The plot for pitting corrosion, and possibly for surface cracks and spikes, shows some limited trends, and these factors do reflect the relative total operating times of the plants. 
TABLE C.1. Cracking related to surface conditions.

\begin{tabular}{|c|c|c|c|c|c|c|c|}
\hline \multirow[b]{3}{*}{ Reactor plant } & \multicolumn{4}{|c|}{$\begin{array}{l}\text { Angle at intersection of i.d. } \\
\text { surfaces at major crack }\end{array}$} & \multirow{3}{*}{$\begin{array}{l}\text { Indication } \\
\text { of machining } \\
\text { grooves } \\
\text { ranking }\end{array}$} & \multirow{2}{*}{\multicolumn{2}{|c|}{$\begin{array}{l}\text { Section thickness } \\
\text { at deepest crack }\end{array}$}} \\
\hline & \multicolumn{2}{|c|}{ Total section } & \multicolumn{2}{|c|}{ Piping section } & & & \\
\hline & Degrees & Rank & Degrees & Rank & & $\operatorname{man}$ & in. \\
\hline San Onofre & 120 & 9 & 180 & 1 & $?$ & $\begin{array}{l}20.0 \\
(15.0)^{c}\end{array}$ & $\begin{array}{c}0.79 \\
(0.59)^{a}\end{array}$ \\
\hline Ginna & 125 & 8 & 125 & 9 & 7 & 19.8 & 0.78 \\
\hline H. B. Robinson-2 & 174 & $\stackrel{2}{(1)} b$ & 174 & $\stackrel{3}{(2) b}$ & 3 & 30.7 & 1.21 \\
\hline Palisades & 156 & 7 & 164 & 5 & 5 & $\begin{array}{c}20.0 \\
(17.5)\end{array}$ & $\begin{array}{c}0.79 \\
(0.69)\end{array}$ \\
\hline Point Beach-2 & 158 & 5 & 158 & 7 & 6 & 18.8 & 0.74 \\
\hline Kewaunee-2 & 160 & 4 & 172 & ${ }_{(3)}^{4} b$ & $?$ & $\begin{array}{c}17.5 \\
(16.4)\end{array}$ & $\begin{array}{c}0.69 \\
(0.65)\end{array}$ \\
\hline Beaver Valley-1 & 157 & 6 & 157 & 8 & 1 & 18.1 & 0.71 \\
\hline Salem-1 & 161 & 3 & 161 & 6 & 2 & 22.5 & 0.87 \\
\hline D. C. Cook-2 & $\begin{array}{l}180^{C} \\
(165)\end{array}$ & $\frac{1}{2} b$ & $\begin{array}{l}180^{C} \\
(165)\end{array}$ & $4^{2} b$ & 4 & 14.3 & 0.56 \\
\hline
\end{tabular}

avalues in parentheses consider major crack in piping only; they exclude weld and inlet.

b Assumes crack of D. C. Cook at an angle of $165^{\circ}$.

$C_{\text {Located }} 0.5 \mathrm{~mm}(0.02 \mathrm{in.})$ distance from intersection angle of $165^{\circ}$. 
TABLE C.2. Crackir.g selated to pitting and corrosion.

\begin{tabular}{|c|c|c|c|c|c|c|c|c|c|c|}
\hline \multirow[b]{2}{*}{ Reactor plant } & \multirow{2}{*}{$\begin{array}{l}\text { Surface } \\
\text { appearance } \\
\text { ranking }^{a}\end{array}$} & \multicolumn{3}{|c|}{ Pitting corrosion } & \multicolumn{3}{|c|}{$\begin{array}{c}\text { Pit area at } \\
\text { crack origin }\end{array}$} & \multicolumn{2}{|c|}{$\mathrm{Fe}_{2} \mathrm{O}_{3} / \mathrm{Fe}_{3} \mathrm{O}_{4}{ }^{\mathrm{e}}$} & \multirow{2}{*}{$\begin{array}{l}\text { Exposure to } \\
\text { oxygen }^{f}\end{array}$} \\
\hline & & $\mathrm{mn}$ & in. & Ranking ${ }^{c}$ & $\mathrm{~mm}$ & in., $10^{-4}$ & Ranking & Ratio & Ranking & \\
\hline San Onofre & 9 & 0.40 & 0.016 & 9 & $\begin{array}{c}0.32 \\
(0.29)\end{array}$ & $\begin{array}{c}5.0 \\
(4.5)\end{array}$ & ${ }_{(9)}^{8} g$ & 1.1 & 8 & Light \\
\hline Ginna & 5 & 0.05 & 0.002 & 6 & 0.053 & 0.8 & 4 & 0.023 & 2 & Moderate \\
\hline H. B. Robinson-2 & 3 & 0.08 & 0.003 & 5 & 0.0085 & 0.1 & 1 & 0.027 & 3 & Light \\
\hline Palisades & 8 & 0.50 & 0.020 & 8 & $\begin{array}{c}1.01 \\
(0.27)\end{array}$ & $\begin{array}{c}1.6 \\
(4.2)\end{array}$ & $\begin{array}{c}9 \\
(8)\end{array}$ & 0.067 & 4 & -- \\
\hline Point Beach-2 & 1 & 0.10 & 0.004 & 3 & 0.12 & 1.9 & 6 & 0.012 & 1 & -- \\
\hline Kewaunee-2 & 6 & 0.09 & 0.004 & 2 & $\begin{array}{l}0.23 \\
(0.034)\end{array}$ & $\begin{array}{c}3.6 \\
(0.5)\end{array}$ & $\begin{array}{c}7 \\
(6)\end{array}$ & 0.12 & 5 & Light \\
\hline Beaver Valley-1 & 2 & 0.08 & 0.003 & 1 & 0.063 & 1.0 & 5 & 0.48 & 6 & Moderate \\
\hline Salem-1 & 7 & 0.20 & 0.008 & 7 & $0.015^{\mathrm{h}}$ & 0.2 & 2 & 0.83 & 7 & $\mathrm{High}$ \\
\hline D. C. Cook-2 & 4 & 0.20 & 0.008 & 4 & $0.048^{h}$ & 0.7 & 3 & 17 & 9 & High \\
\hline
\end{tabular}

\footnotetext{
${ }^{a}$ Based on observations made with stereo-nicroscope and naked eye; surface roughness associated with corrosion/pitting.

$b_{\text {Depth }}$ of deepest pit excluding pits at najor crasks

Considers both number and size of pits.

dArea down to discontinuous change between "pit" and "crack" regions.

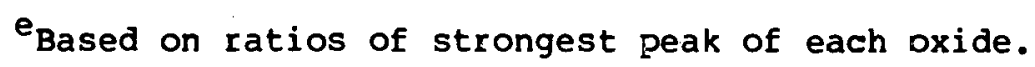

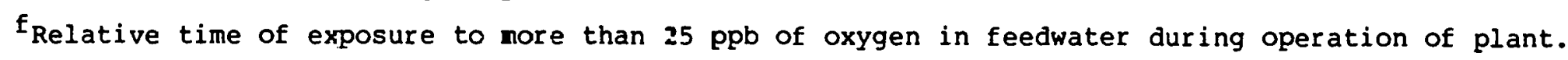

9 Values in parentheses consider major crack in piping only; they exclude weld and inlet.

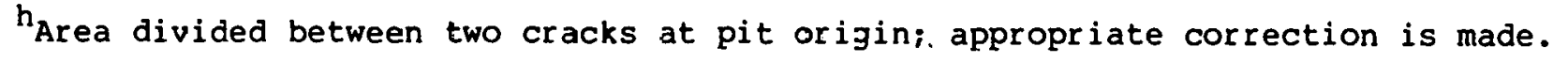


TABLE C.3. Ranking based on estimated crack-growth rate.

\begin{tabular}{|c|c|c|c|c|c|c|}
\hline \multirow[b]{2}{*}{$\begin{array}{c}\text { Reactor } \\
\text { plant }\end{array}$} & \multicolumn{4}{|c|}{ Estimated crack growth per month } & \multirow{2}{*}{\multicolumn{2}{|c|}{$\begin{array}{l}\text { Crack growth per month } \\
\frac{\text { per section thickness }}{\text { mon }^{-1}}\end{array}$}} \\
\hline & $\begin{array}{l}\text { Length of } \\
\text { operation, } \\
\text { mon }\end{array}$ & $\begin{array}{c}\mathrm{mm} / \mathrm{mon} \\
10^{-3}\end{array}$ & $\begin{array}{c}\text { in./mon, } \\
10^{-4}\end{array}$ & Ranking & & \\
\hline San Onofre & 146 & $\begin{array}{l}11.9 \\
(6.9)^{c}\end{array}$ & $\begin{array}{c}4.7 \\
(2.7)\end{array}$ & 2 & $\begin{array}{c}6.0 \\
(4.6)\end{array}$ & 2 \\
\hline Ginna & 117 & 18.8 & 7.4 & 5 & 9.5 & 5 \\
\hline H. B. Robinson-2 & 107 & 6.6 & 2.6 & 1 & 2.2 & 1 \\
\hline Palisades & 99 & $\begin{array}{c}43.2 \\
(23.9)\end{array}$ & $\begin{array}{l}17 \\
(9.4)\end{array}$ & ${ }_{(6)}^{7} \mathrm{c}$ & $\begin{array}{l}22 \\
(14)\end{array}$ & ${ }_{(6)}^{7} \mathrm{c}$ \\
\hline Point Beach-2 & 87 & 16.0 & 6.3 & 4 & 8.5 & 3 \\
\hline Kewaunee-2 & 65 & $\begin{array}{c}15.2 \\
(13.7)\end{array}$ & $\begin{array}{c}6.0 \\
(5.4)\end{array}$ & 3 & $\begin{array}{c}8.7 \\
(8.4)\end{array}$ & 4 \\
\hline Beaver Valley-l & 39 & 27.9 & 11 & $\begin{array}{c}6 \\
(7)\end{array}$ & 15 & $\begin{array}{c}6 \\
(7)\end{array}$ \\
\hline Salem-1 & 32 & 73.7 & 29 & 8 & 33 & 8 \\
\hline D. C. Cook-2 & 17 & 518 & 204 & 9 & 403 & 9 \\
\hline \multicolumn{7}{|c|}{$\begin{array}{l}\text { a Time calculated from date of initial criticality; we assume all plants } \\
\text { discontinued in. August } 1979 \text {. } \\
b_{\text {Refers to thickness of section at crack origin; see Table c.l. }} \\
{ }_{\text {c }} \text { alues in parentheses consider major crack in piping only; they exclude } \\
\text { weld and inlet. }\end{array}$} \\
\hline
\end{tabular}


TABLE C.4. Evaluation and ranking relative to cross-section morphology of major cracks.

\begin{tabular}{|c|c|c|c|c|c|c|c|c|}
\hline & \multirow{2}{*}{$\begin{array}{c}\text { Reactor } \\
\text { plant }\end{array}$} & \multicolumn{2}{|c|}{$\begin{array}{c}\text { Corrosion } \\
\text { craters }\end{array}$} & \multicolumn{2}{|c|}{$\begin{array}{c}\begin{array}{c}\text { Corrosion } \\
\text { spikes }\end{array} \\
\end{array}$} & \multirow{2}{*}{$\begin{array}{l}\text { Horizontal spikes } \\
\text { related to } \\
\text { steel morphology }\end{array}$} & \multirow[b]{2}{*}{ Branching } & \multirow{2}{*}{$\begin{array}{c}\text { Crack-tip } \\
\text { sharpness } \\
\text { ranking }\end{array}$} \\
\hline & & Degree & Rank & Degree & Rank & & & \\
\hline \multirow{9}{*}{ N } & San Onofre & Extensive & 9 & Minor & 1 & None & None & 1 \\
\hline & Ginna & Minor & 7 & Medium & 8 & $\begin{array}{l}\text { Moderate, at } \\
\text { banding or } \\
\text { inclusions }\end{array}$ & $\begin{array}{l}\text { Some, mostly } \\
\text { near tip }\end{array}$ & 4 \\
\hline & $\begin{array}{l}\text { H. B. } \\
\text { Robinson-2 }\end{array}$ & Minor & 2 & Medium & 6 & None & $\begin{array}{l}\text { Very minor } \\
\text { near tip }\end{array}$ & 7 \\
\hline & Palisades & Extensive & 8 & $\begin{array}{l}\text { Many } \\
\text { large }\end{array}$ & 9 & $\begin{array}{l}\text { Very minor, } \\
\text { at inclusions }\end{array}$ & $\begin{array}{l}\text { (Corrosion } \\
\text { spikes) }\end{array}$ & 3 \\
\hline & $\begin{array}{l}\text { Point } \\
\text { Beach-2 }\end{array}$ & Minor & 6 & Medium & 7 & None & None & 2 \\
\hline & Kewaunee-2 & Minor & 5 & Medium & 4 & None & None & 8 \\
\hline & $\begin{array}{l}\text { Beaver } \\
\text { Valley-1 }\end{array}$ & Minor & 4 & Medium & 5 & None & $\begin{array}{l}\text { Extensive } \\
\text { near tip }\end{array}$ & 9 \\
\hline & Salem-1 & Minor & 3 & Minor & 3 & $\begin{array}{l}\text { Minor, at } \\
\text { banding }\end{array}$ & None & 6 \\
\hline & $\begin{array}{lll} & & \text { D. C. } \\
\because \quad & \text { Cook-2 }\end{array}$ & Minimal & 1 & $\begin{array}{l}\text { Many, } \\
\text { very } \\
\text { small }\end{array}$ & 2 & $\begin{array}{l}\text { Very minor, } \\
\text { unrelated }\end{array}$ & Some, fine & 5 \\
\hline
\end{tabular}




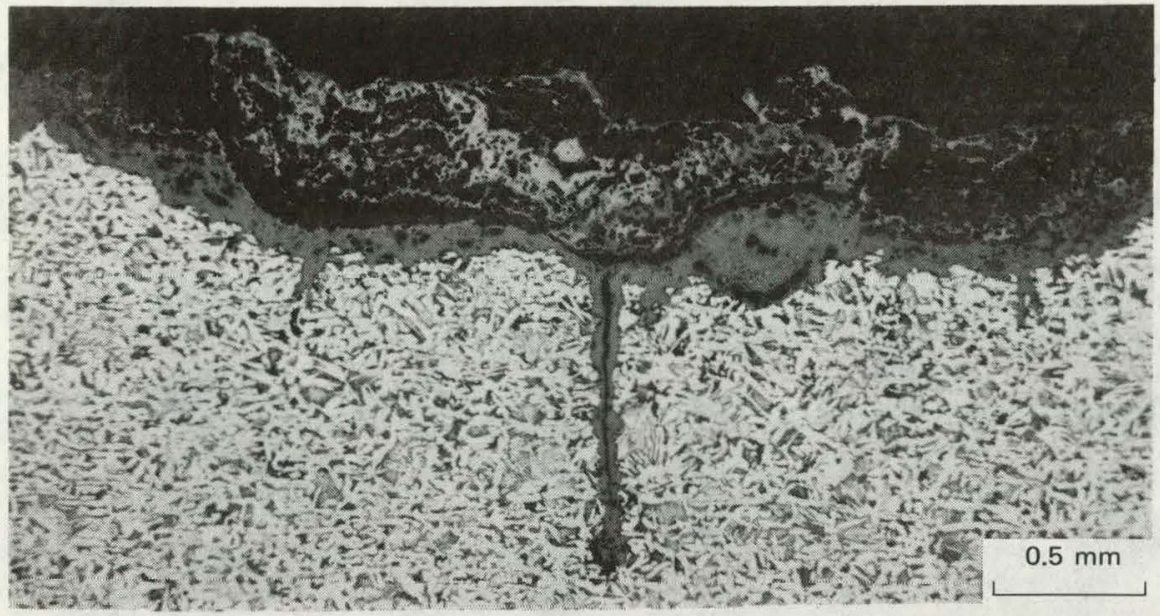

(a) Palisades

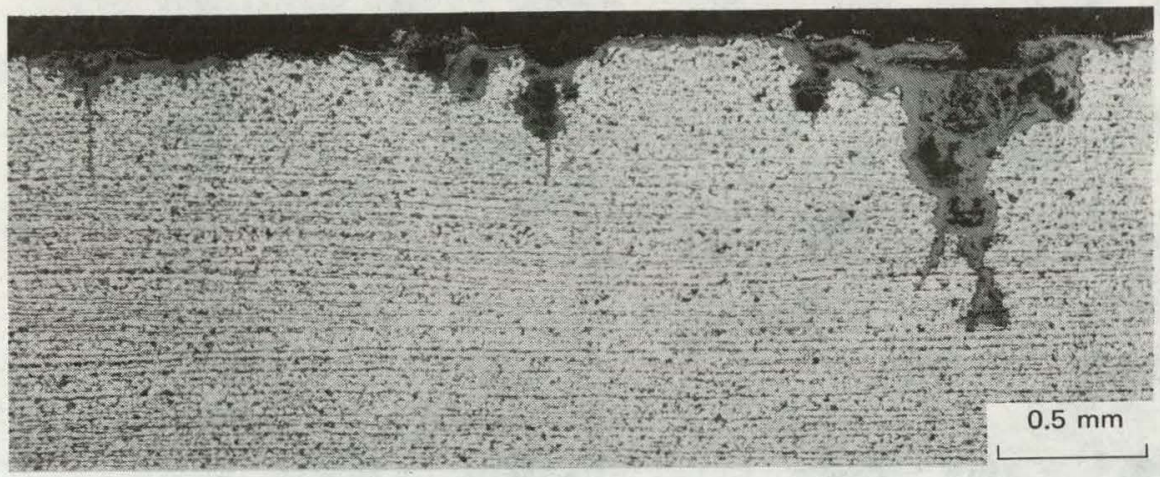

(b) San Onofre

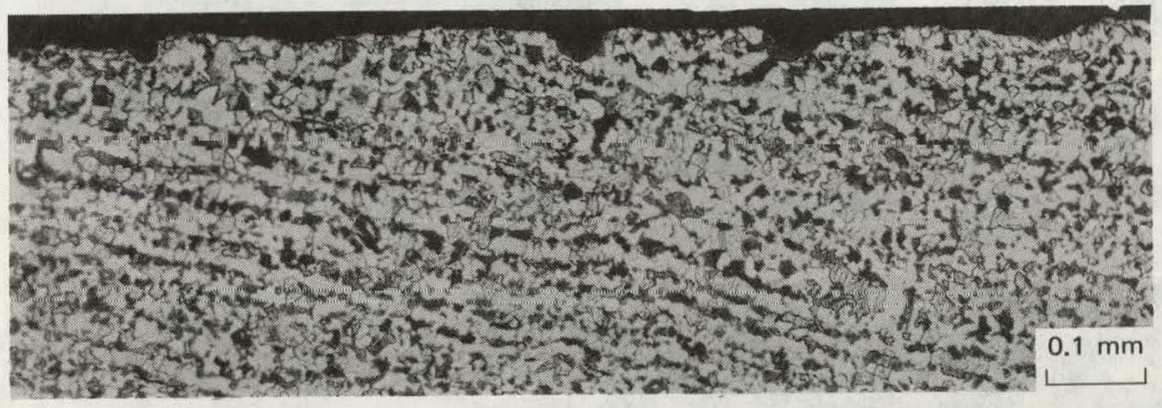

(c) Beaver Valley

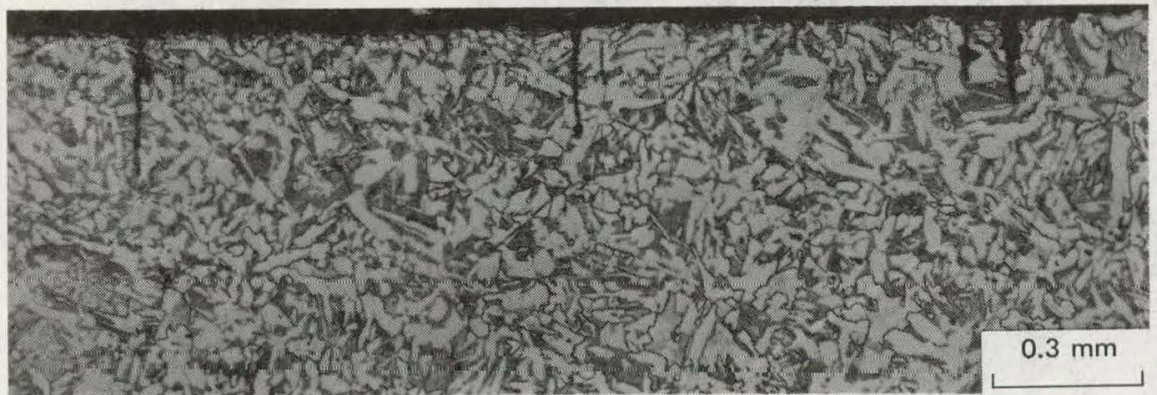

(d) Kewaunee

FIG. C.1. Examples of corrosion pits and corrosion spikes (most likely small corrosion-filled cracks) in Palisades, San Onofre, Beaver Valley, and Kewaunee sections. Views (a) and (b) show spikes (cracks) extending from the bottom of large pits. View (c) shows an example of small pits (and possibly machining grooves). View (d) shows spikes extending down directly from a uniformly corroding surface region. 


\section{Flow}
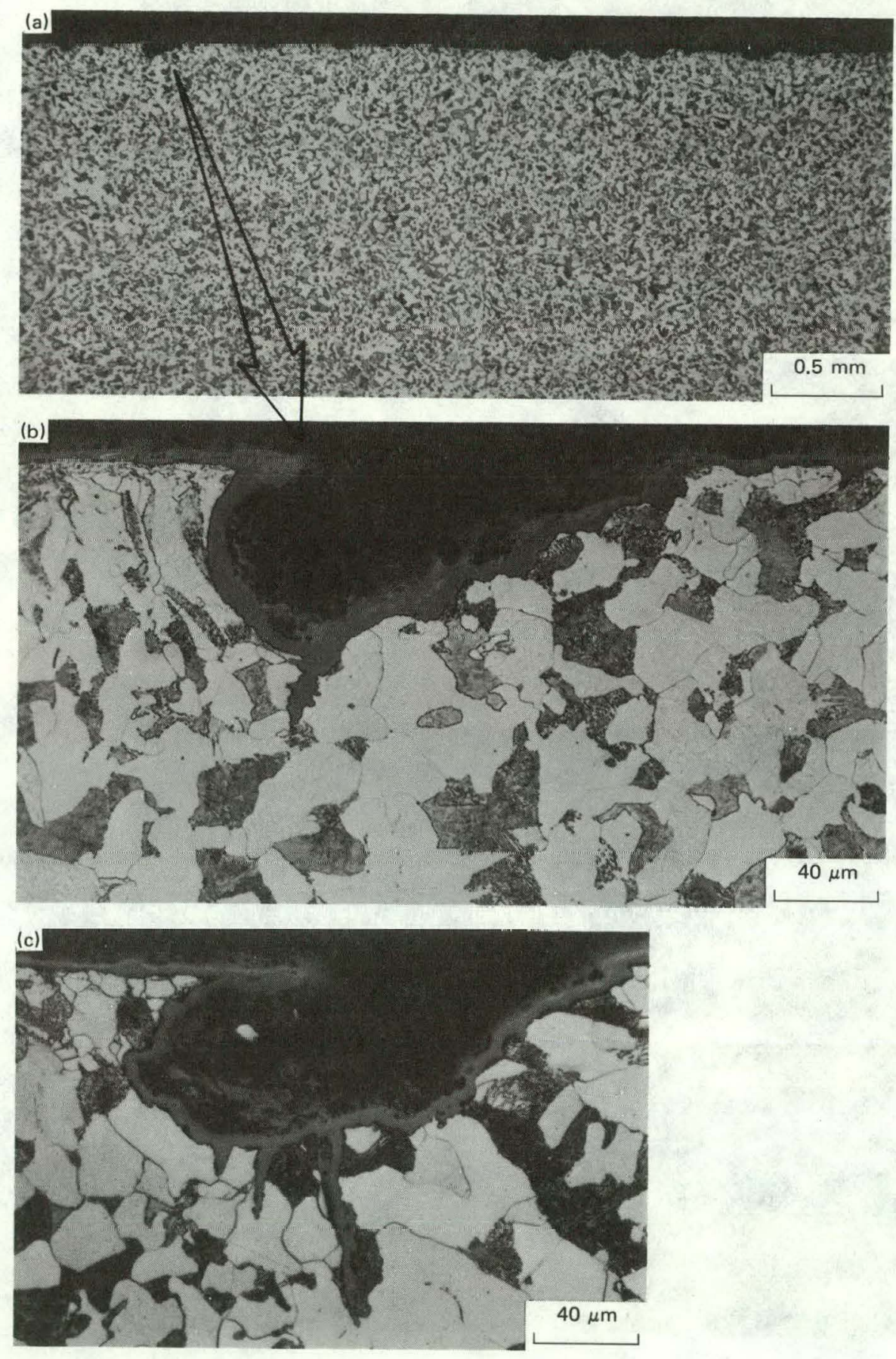

FIG. C.2. Corrosion pits identified as cross sections of machining grooves from an H. B. Robinson section. View (a) shows the pits at low magnification and views (b) and (c) show them at high magnification. Note the deformed region adjacent to both undercuts. Also note the spikes at the root of the grooves. 


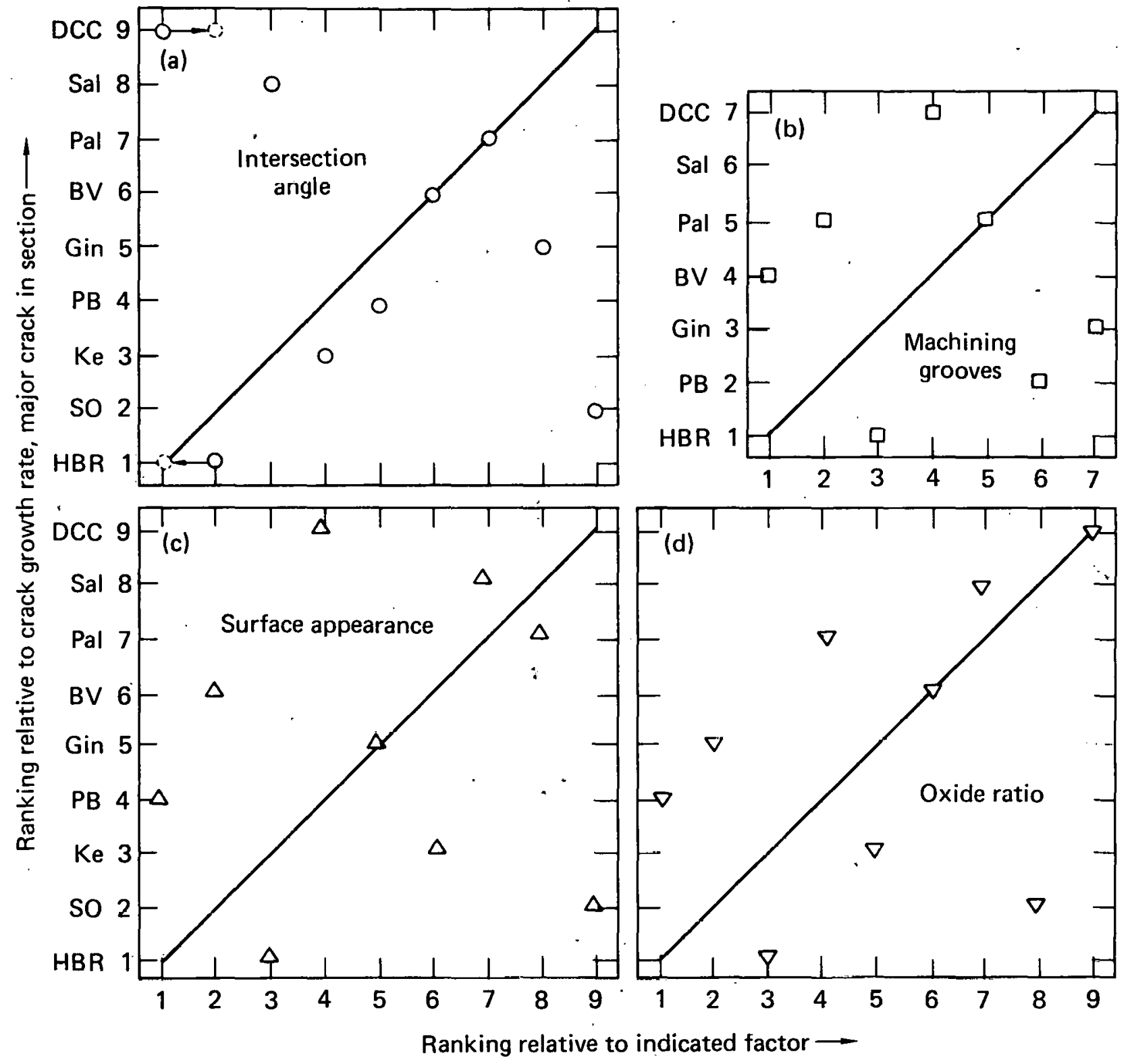

FIG. C.3. Ranking relative to (estimated) crack-growth rate of major crack in section versus ranking of various inside diameter surface observations ( 1 is best, 9 is worst). Note that only seven plants were used to rank machining grooves. The dashed data points in (a) refer to alternative ranking. See Table C.l. 


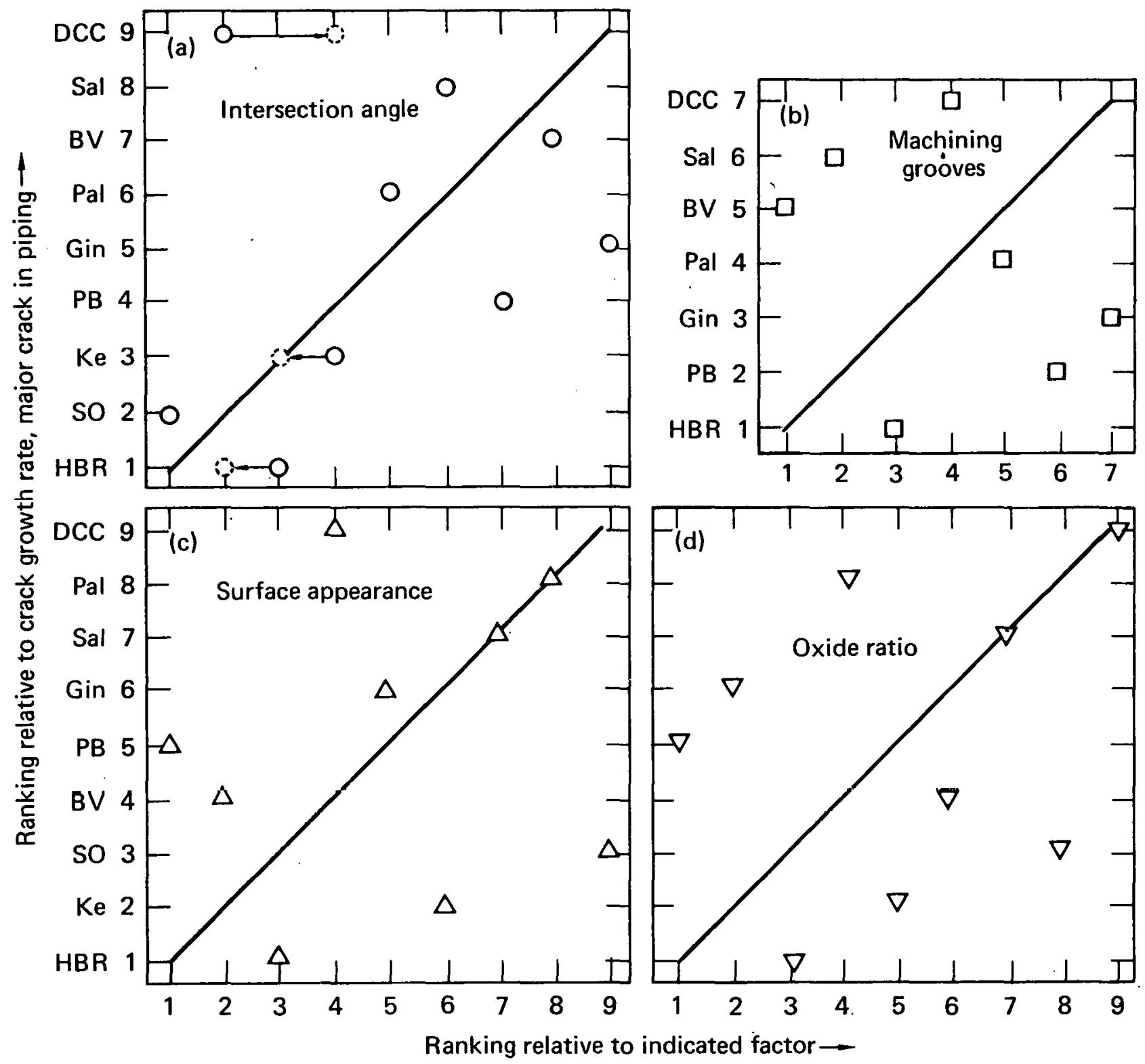

FIG. C.4. Ranking relative to (estimated) crack-growth rate of major crack in piping versus ranking of various inside diameter surface observations ( 1 is best, 9 is worst). Note that only seven plants were used to rank machining grooves. The dashed data points in (a) refer to alternative ranking. See Table C.I. 


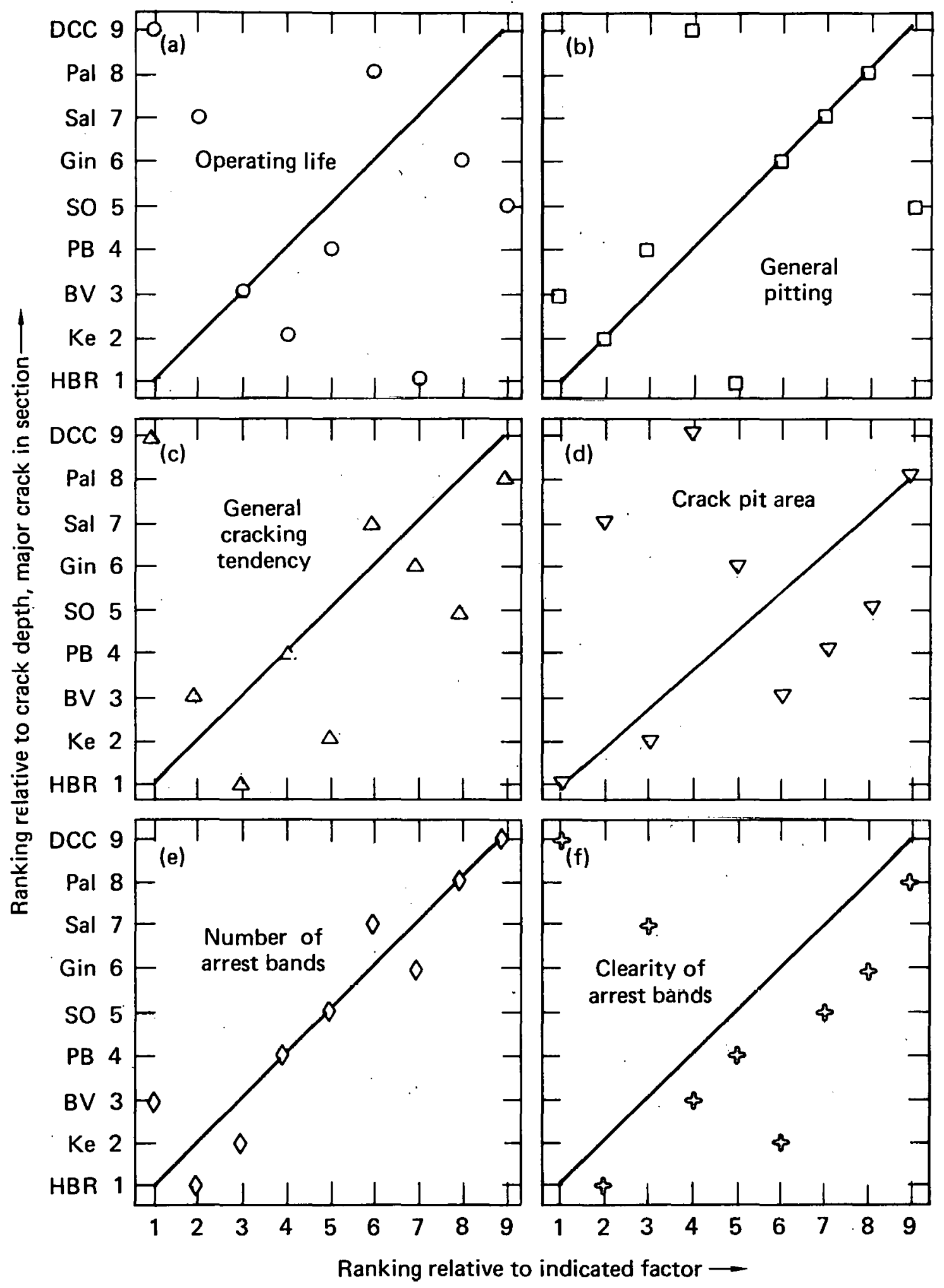

FIG. C.5. Ranking relative to crack depth of major crack in section versus ranking of various factors that should relate to corrosion/cracking degradation ( 1 is best, 9 is worst). 


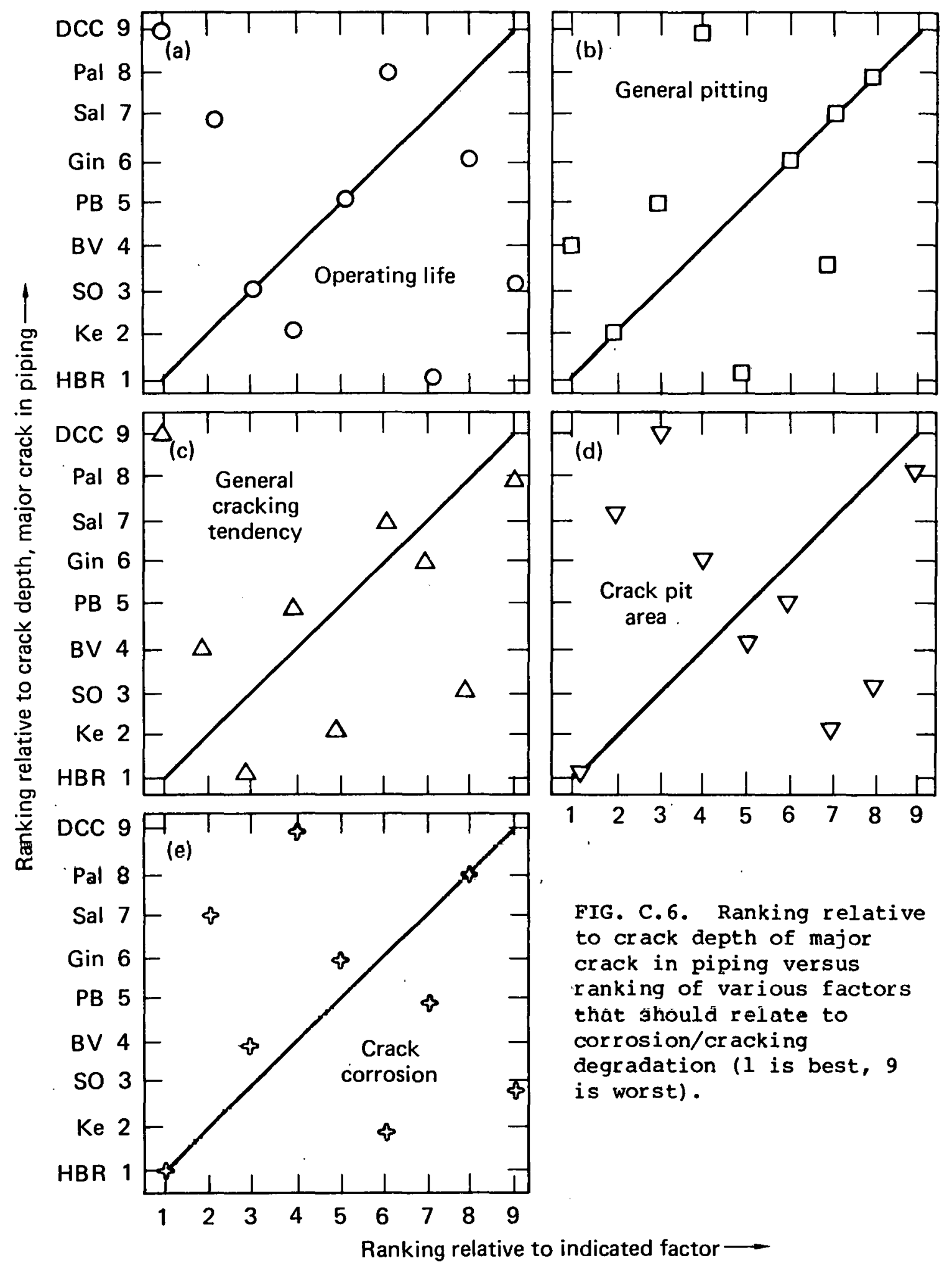




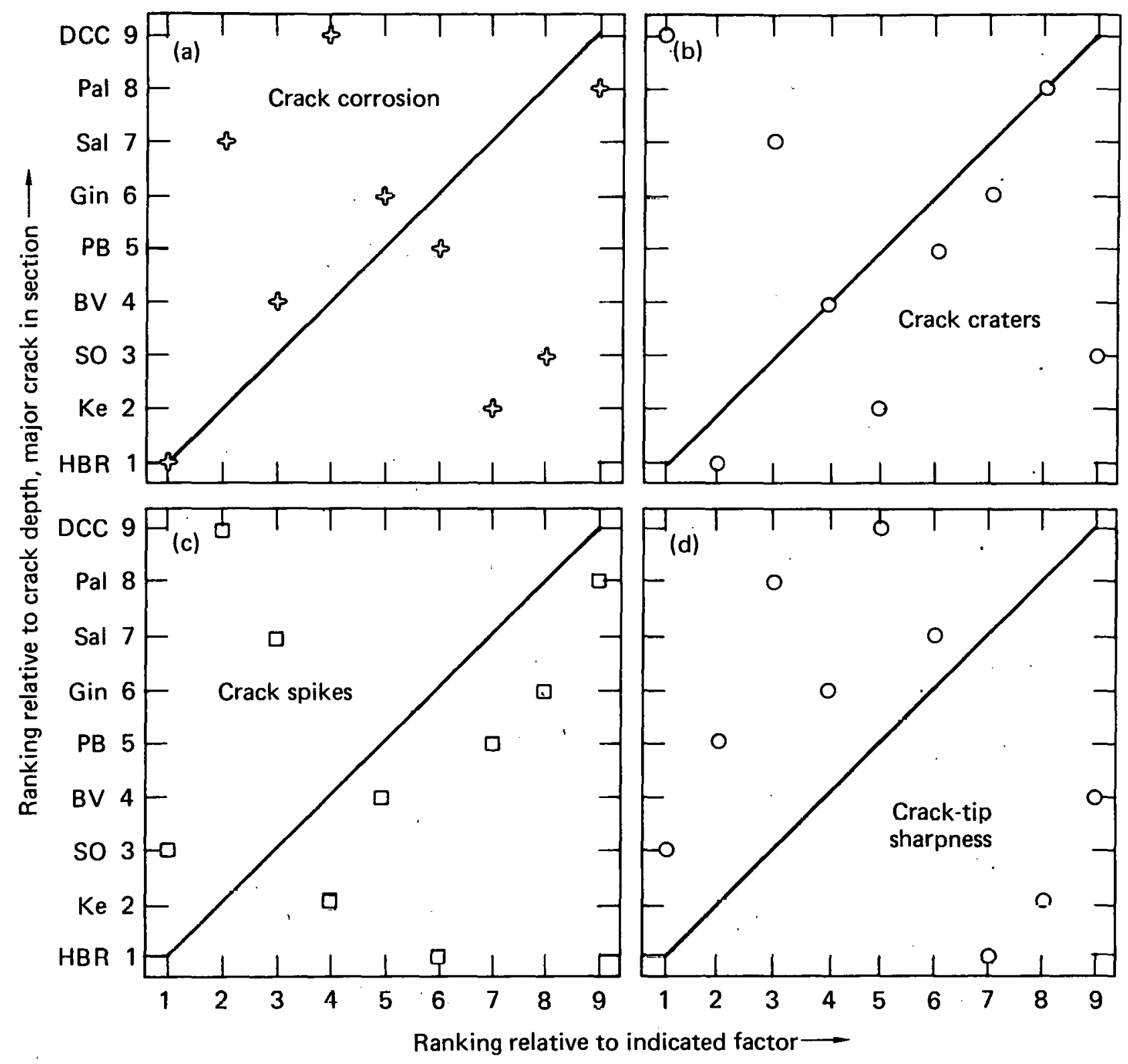

FIG. C.7. Ranking relative to crack depth of major crack in section versus ranking of various observations made along corresponding crack $(1$ is best, 9 is worst). 


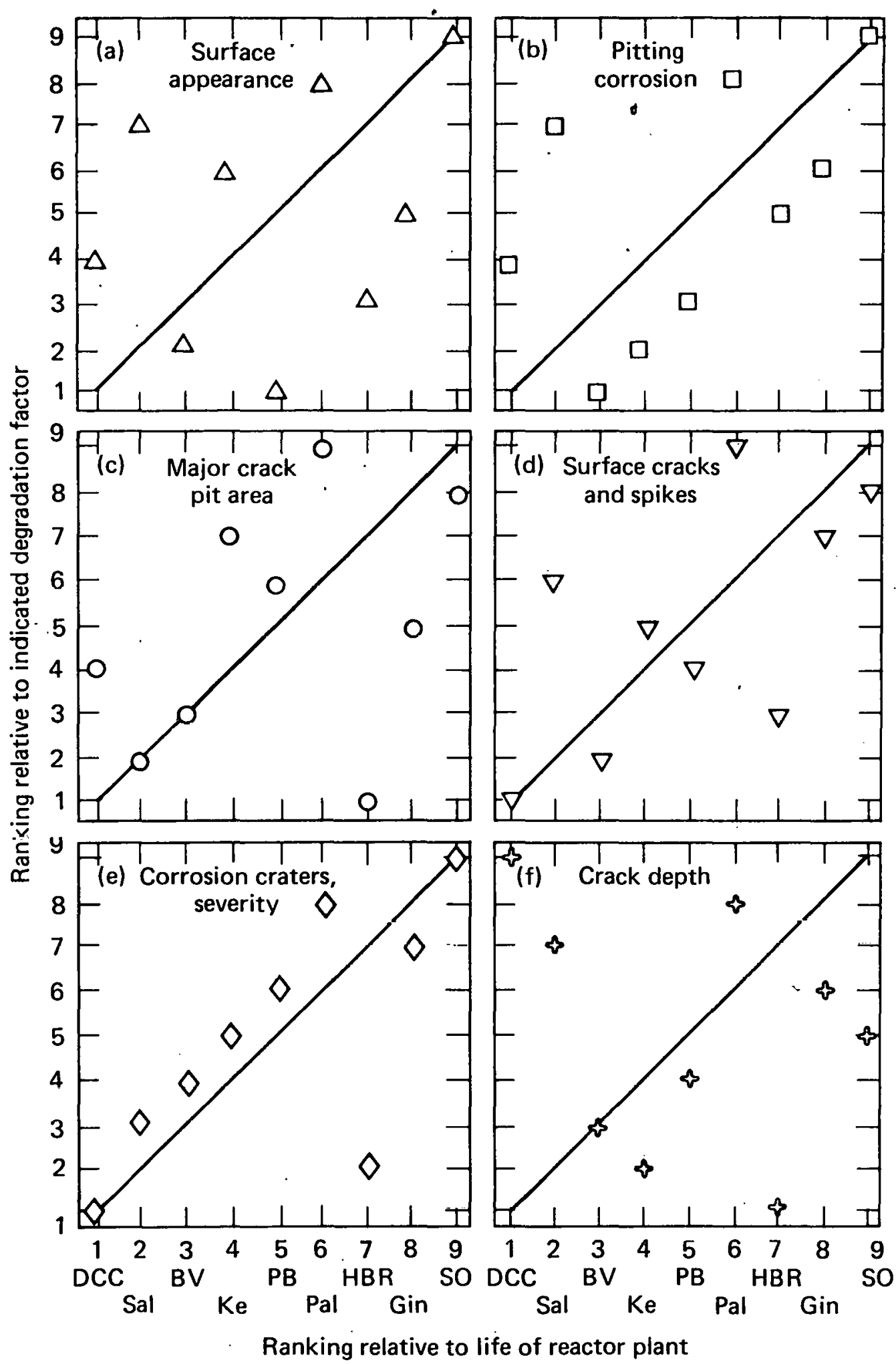

FIG. C.8. Ranking relative to extent of degradation seen on inside diameter surface along crack versus ranking relative to estimated corresponding reactor plant life ( 1 is best, 9 is worst). 


\section{APPENDIX D \\ CROSS-SECTION MORPHOLOGIES}

Figures D.1 through D.8 show the appearance of corrosion, pits, and cracks along various surface regions, extending the scope on such information described in the main body of the report. 


\section{Flow}

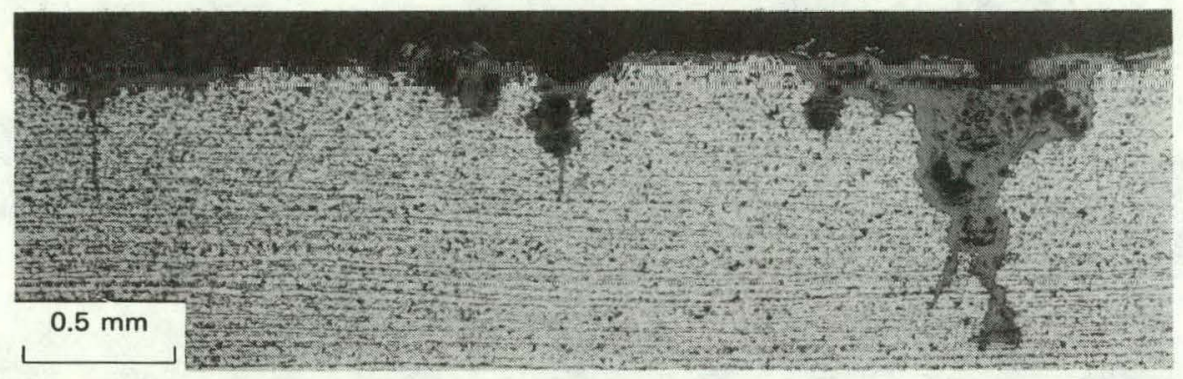

(a) Original reducer structure

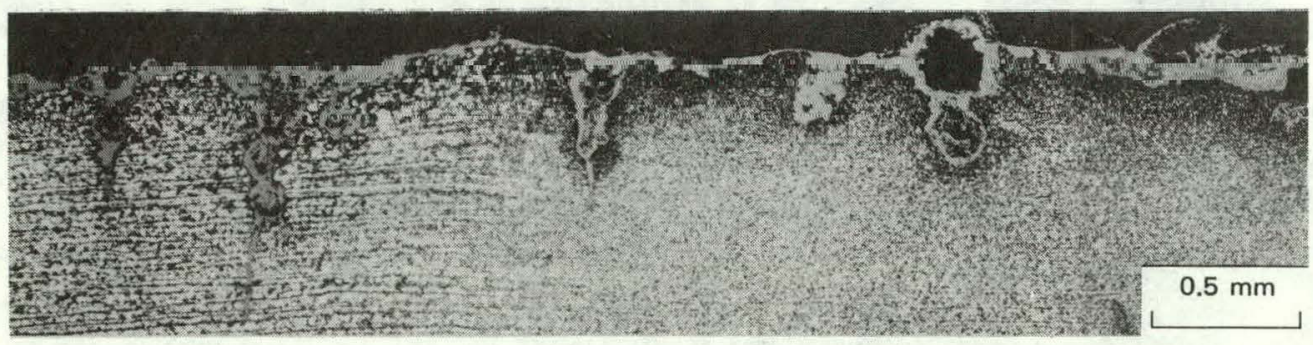

(b) HAZ-reducer
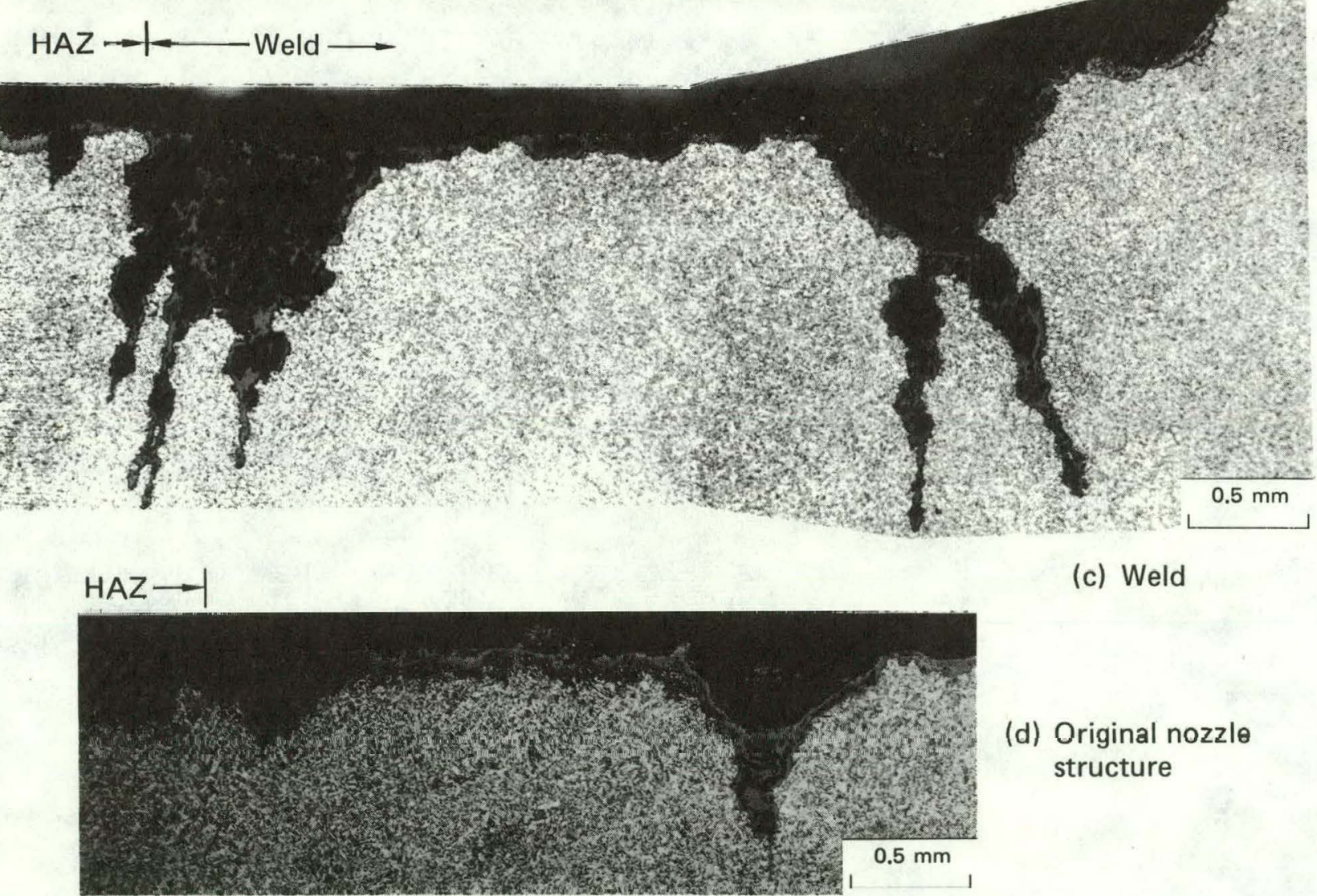

(c) Weld

(d) Original nozzle structure

FIG. D.1. Photomicrographs showing corrosion, pits, and cracks along the inside diameter surface of a San Onofre section. 
Flow
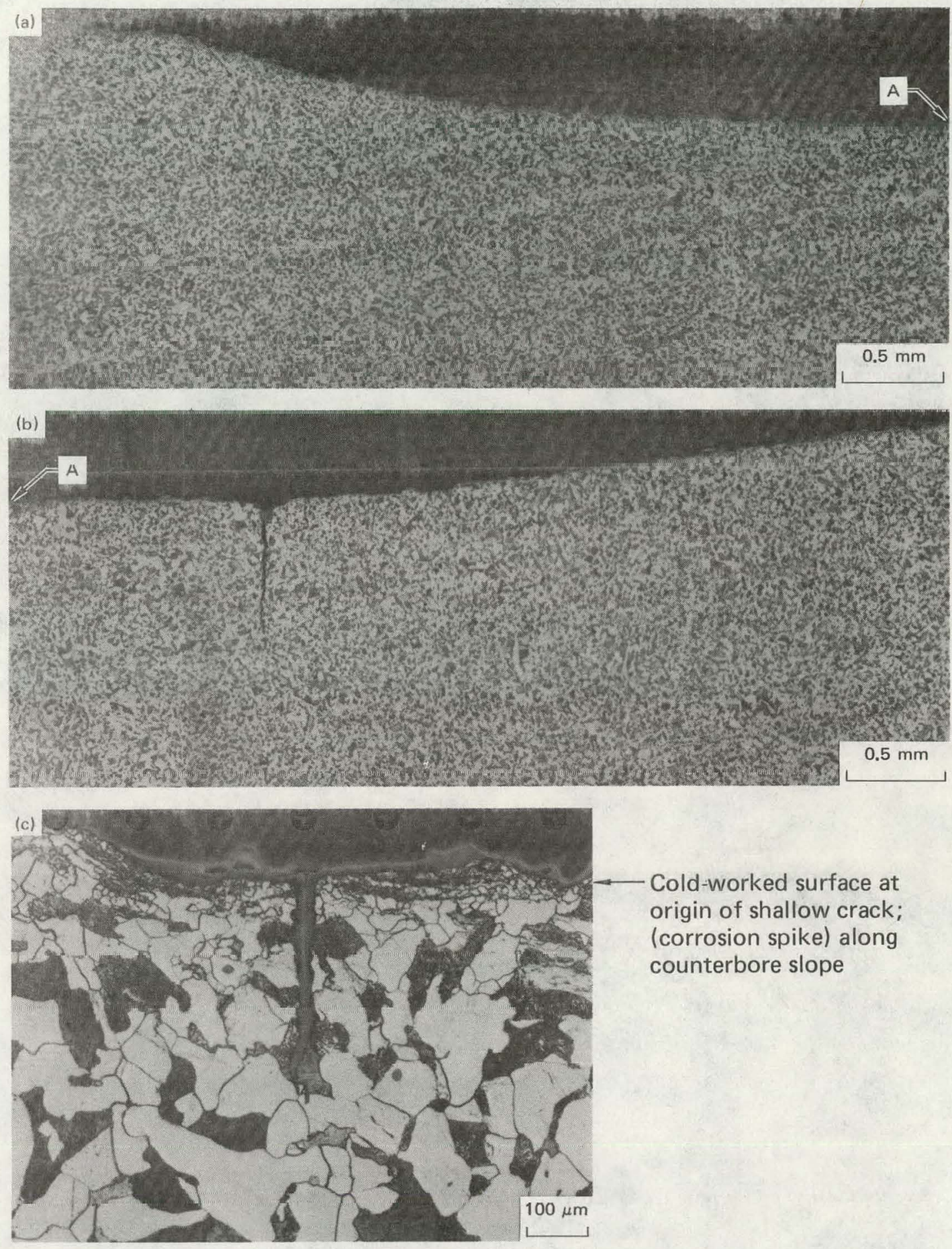

Cold-worked surface at origin of shallow crack; (corrosion spike) along counterbore slope

FIG. D.2. Photomicrographs of an H. B. Robinson section showing surface and major crack along counterbore. Views (a) and (b) match up at $A$ and show a crack initiating at the bottom of the counterbore slope. The approximate flow directions for views (a) and (b) are indicated by an arrow. 
Flow
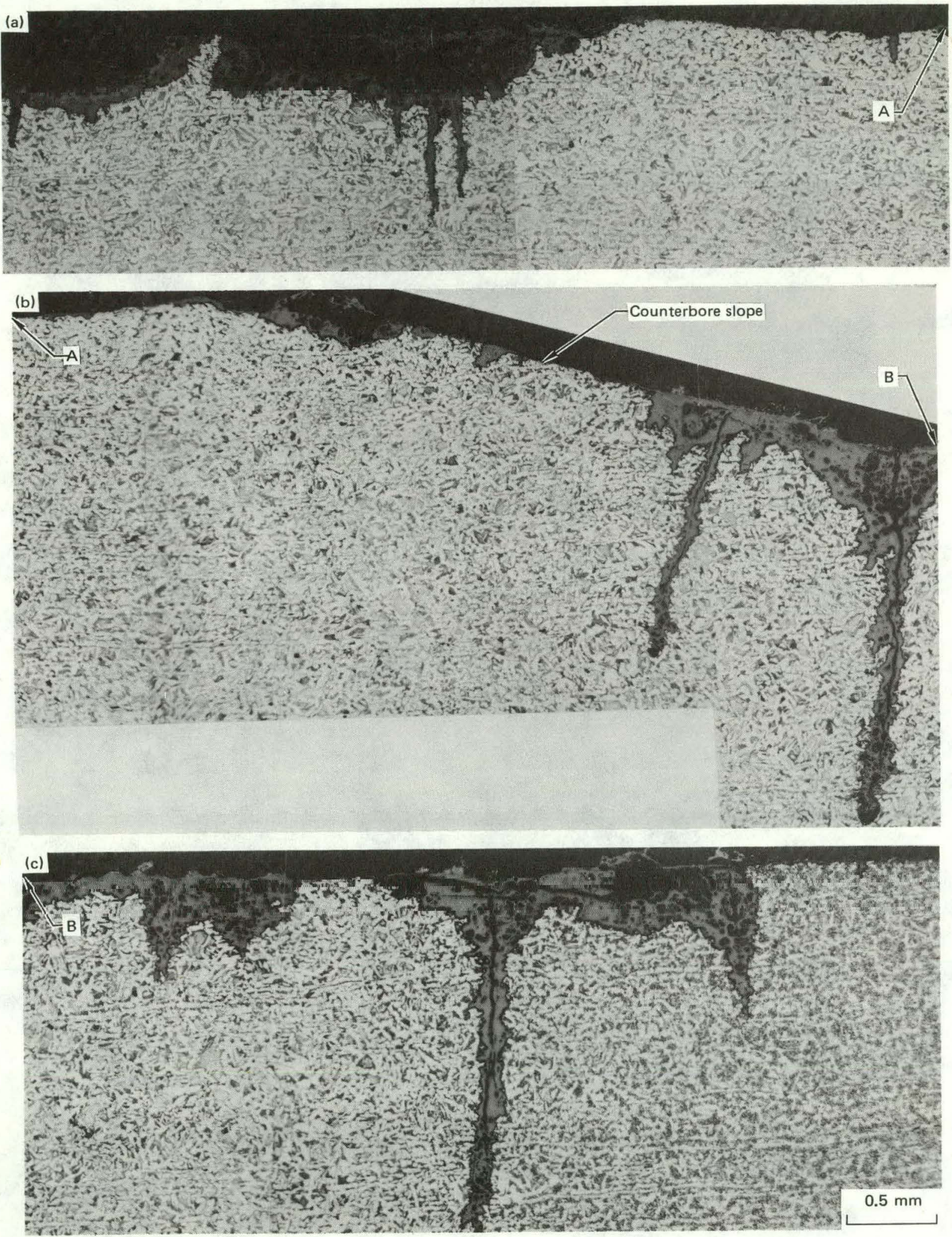

FIG. D.3. Photomicrographs of a Palisades section showing the appearance of corrosion, pits, and cracks. View (a) shows the area along the inside diameter surface above the counterbore slope; view (b), along the counterbore slope; and view (c), at the bottom of the counterbore for the pipe section. Note that views (a) and (b) match up at A, and (b) and (c) at B. 


\section{Flow}

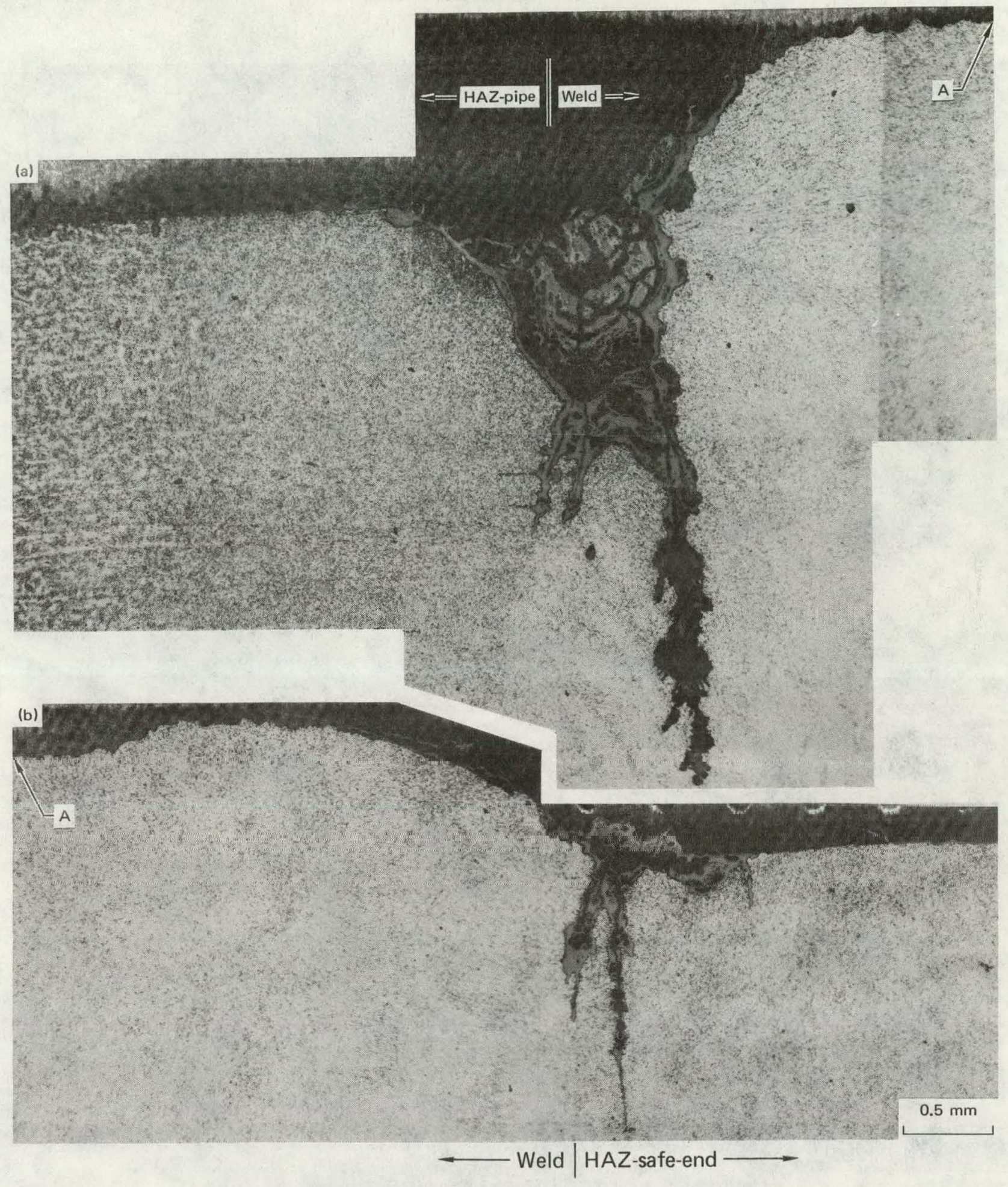

FIG. D.4. Photomicrographs showing cracks initiating at weld-HAz interfaces corresponding to points of discontinuous changes in a Palisades section. Note that views (a) and (b) match up at A. 
Flow

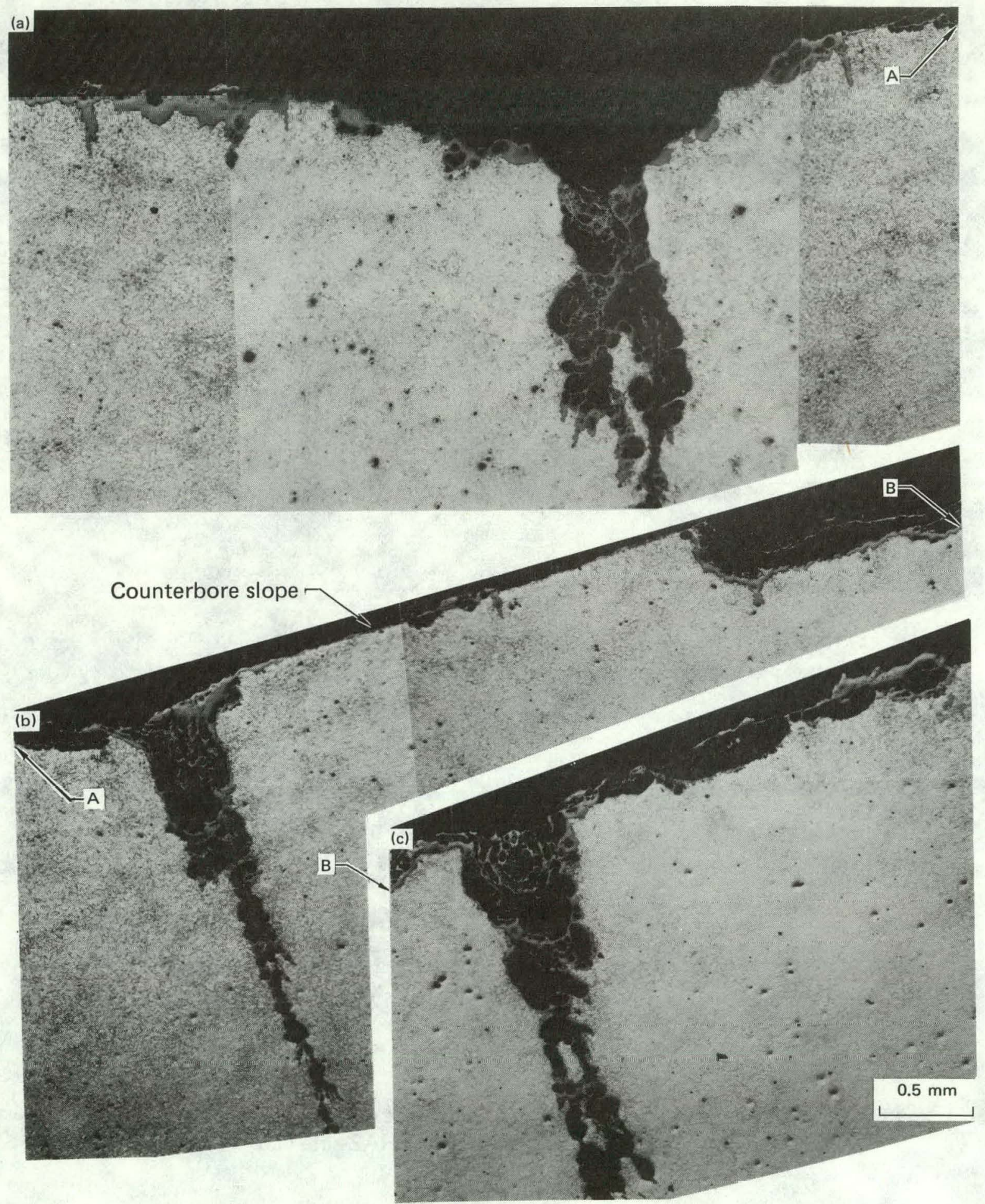

FIG. D.5. Photomicrographs of a Palisades section showing corrosion, pits, and cracks along the counterbore of the safe-end. In views (b) and (c), note the orientation of cracks along counterbore slope. Note that views (a) and (b) match up at $A$ and views (b) and (c) at B. 


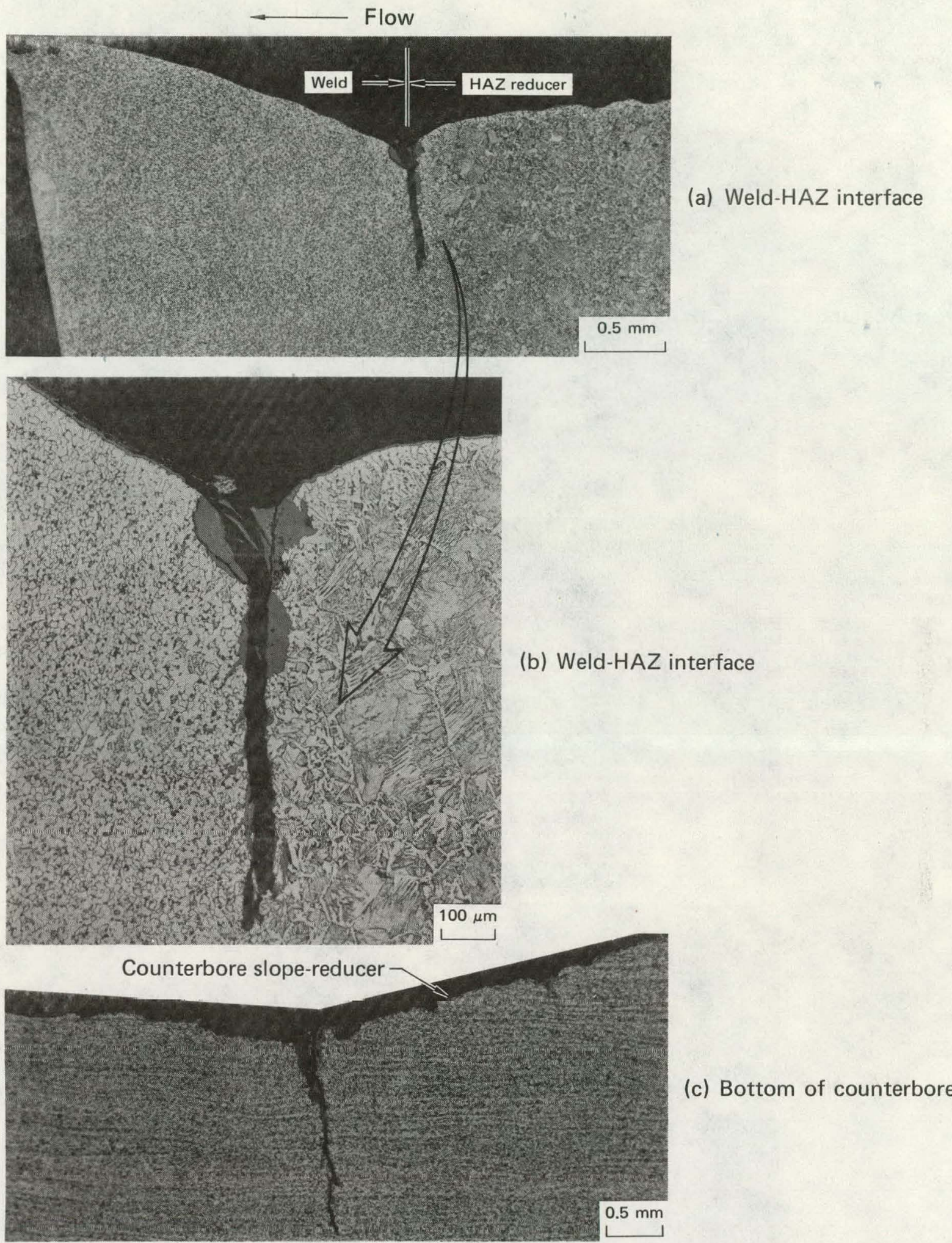

FIG. D.6. Photomicrographs showing cracks at discontinuous cross-sectional changes in a Point Beach section. Views (a) and (b) show the weld-HAz interface, and view (c) shows the critical region of the counterbore. 

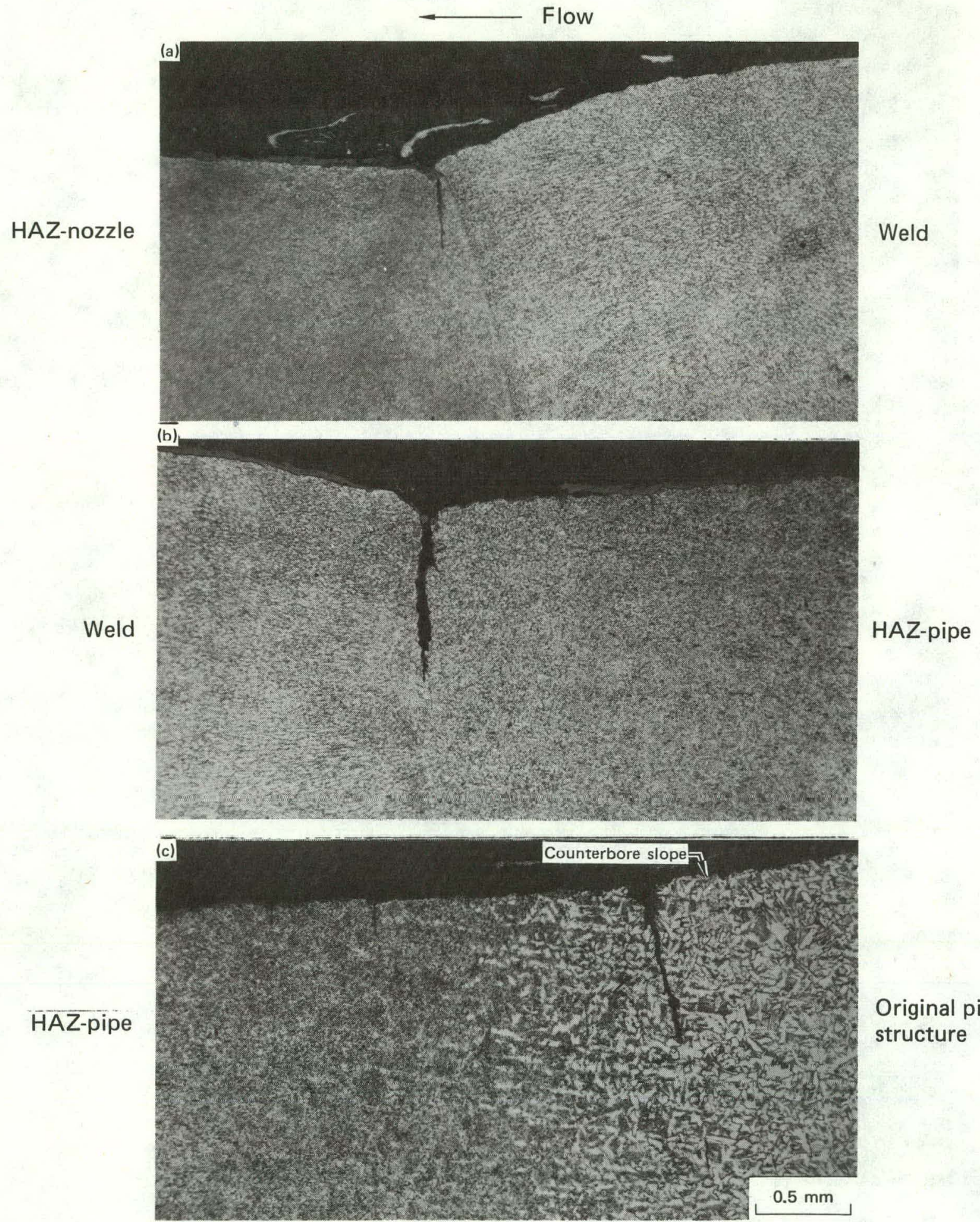

Original pipe structure

FIG. D.7. Photomicrographs showing cracks at discontinuous changes in a Kewaunee section. Views (a) and (b) show the weld-HAz interfaces. View (c) shows the bottom of the counterbore slope. 


\section{Flow}

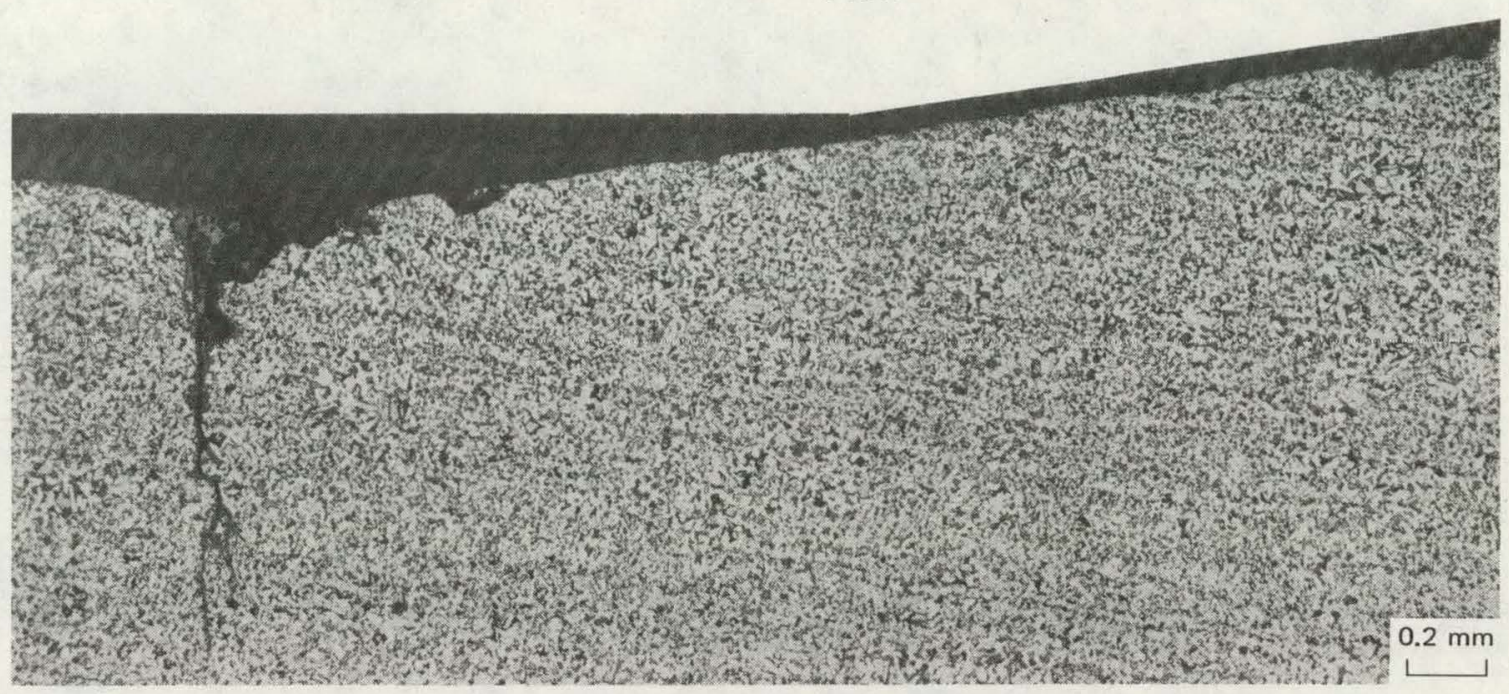

(a) Section 4-5

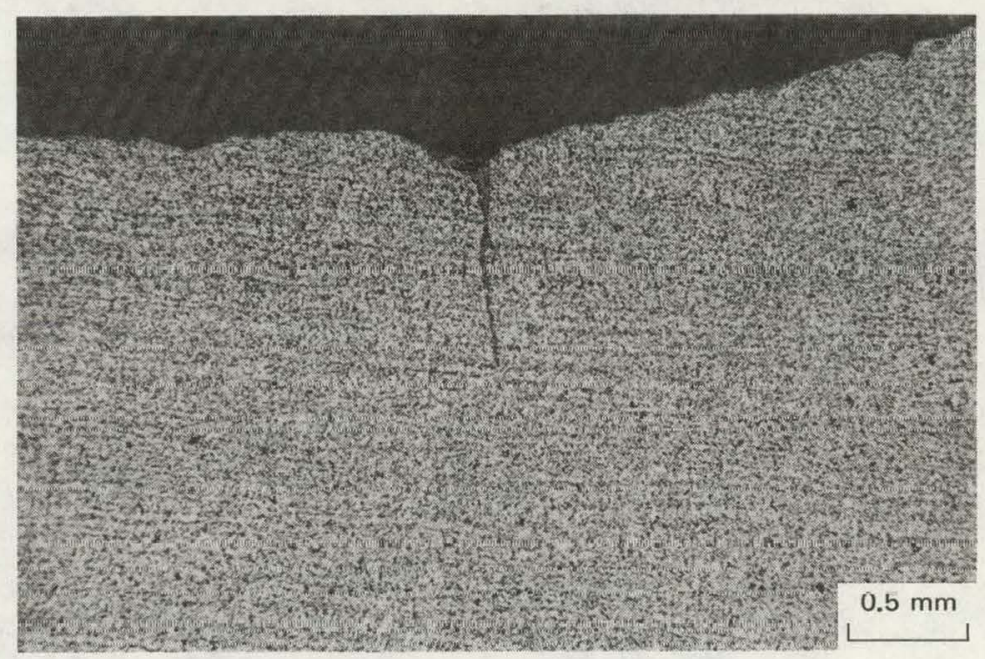

(b) Section 6-7

FIG. D.8. Photomicrographs showing a crack at the bottom of the counterbore slope in two longitudinal sections taken from two different regions along the circumference of the elbow from Beaver valley. 
It is to be expected that the craters and arrest bands are at the same locations along a crack; but, they are viewed along surfaces differently prepared, normal to each other, and on different longitudinal slices taken from the same section. The ease with which the bands are detected follow closely the severity of the craters (Table C.4). Furthermore, we attempted with reasonable success to show a 1 to 1 correlation between the distances from the crack origin of the craters seen in cross section and the arrest bands on the crack surfaces for cracks $A$ and $C$ in the Palisades section. Figure E.l illustrates this for crack A. Although there is a definite trend between crack depth and the number of crater events (arrest bands), there is much less of a trend between crack depth and the severity of the craters. Compare Fig. C.5(e) with Fig. C.7(b). If one assumes that each cyclic event is due to a stress activity, then this suggests that corrosion-assisted stress cracking (CF or SCC) is of greater consequence than stress-assisted corrosion in causing the observed degradations. 

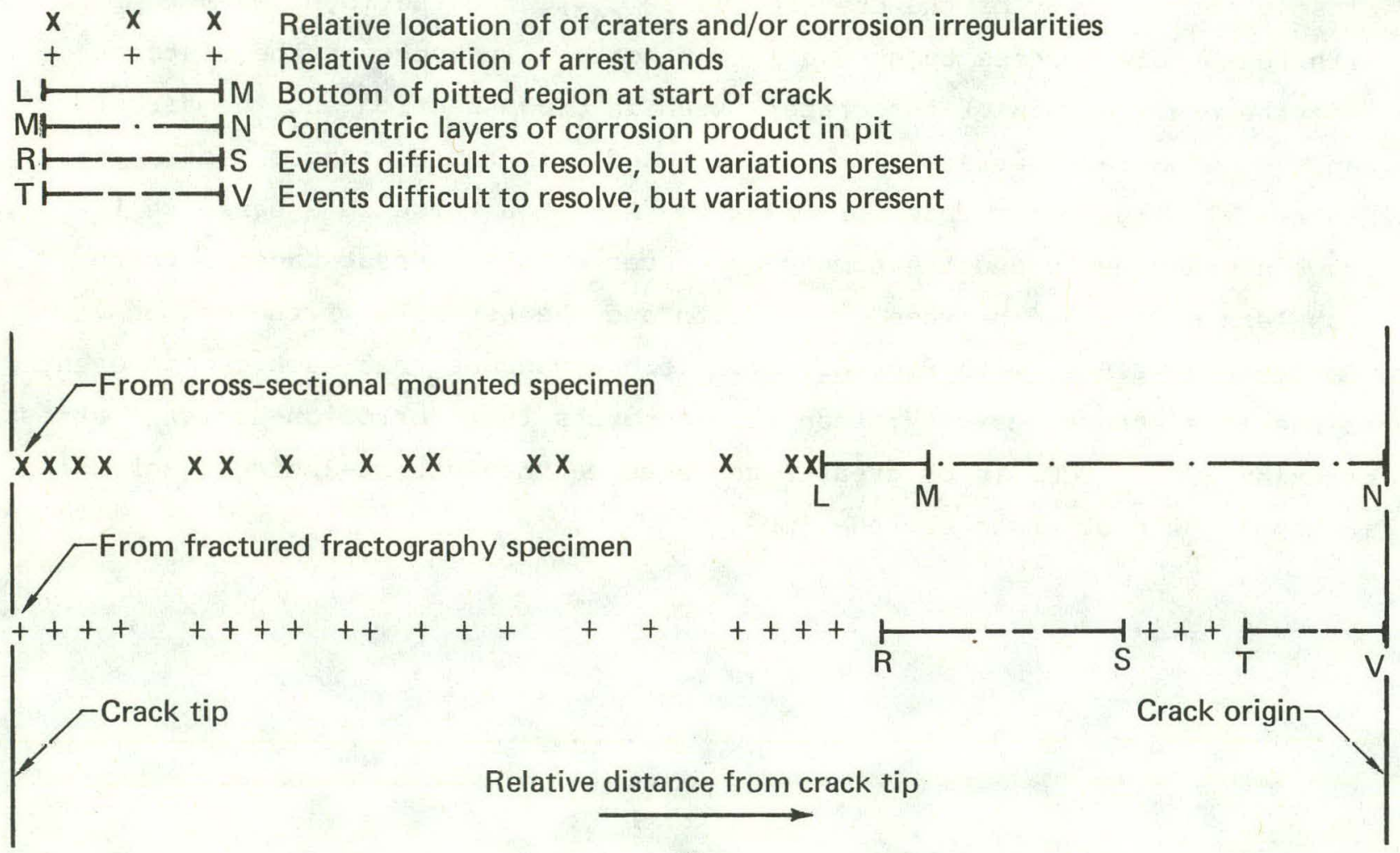

FIG. E.1. Correlations between distribution of craters and corrosion irregularities in a polished-and-etched specimen and of arrest bands in a fractured fractography specimen for Crack A of Palisades section. Refer to Fig. 3.10. 


\section{APPENDIX F \\ EVALUATION OF SEM STRIATIONS}

Using the solution recommended for removal of iron-oxide scales by cathodic cleaning,* we evaluated the use of SEM for evidence of fatigue striations on cleaned crack surfaces. Figure F.I shows SEM views of the cleaned crack surface from H. B. Robinson at the crack tip and crack center at approximately 5000x. Most of the striations seen in Figs. F.1(a) and F.l(c) could possibly be interpreted as resulting from a fatigue process. The center region in Fig. F.l(b) suggests pearlite. However, at higher magnifications of approximately $20,000 x$, as shown in Fig. F.2, the pearlite morphology is obvious for all three areas.

Figure F.3 shows SEM views of a specimen that was removed from a region just below the crack tip from the H. B. Robinson section. It was then polished and cathodically cleaned. A portion of the specimen was masked; the exposed surface was then anodically cleaned. Figures F.3(a) and F.3(b) reveal pearlite on the anodically attacked surface; Fig. F.3(c) is a transition region at the edge of the masking, and Fig. F.3(d) is the cathodically cleaned surface. The fact that the cathodic cleaning did not attack the steel surface indicates that the morphology of the cleaned steel surface is indeed that caused by the corrosive attack of the environment. This is further illustrated in Fig. F.4(a) for the interface region between the laboratory fracture and plant crack from H. B. Robinson. Figure F.4(b) shows the unattacked laboratory fracture, while Fig. F.4(c) shows the corrosive attack of the steel which is revealed by the removal of the oxide had been removed by the cathodic cleaning. Again, we see here a periodic-type pattern, but we question as to whether these markings are actually due to a cyclic event or due to selective attack of the pearlite phases. Furthermore, are the wavy striations on the as-corroded surfaces the result of retention of the pearlite-developed corrosion pattern throughout the growth of the corrosion deposits? The observations indicated to us that the use of SEM to detect evidence of fatigue in our samples is very limited and, in fact, may lead to erroneous conclusions.

*Yuzawich, P. M. and Hughes, C. W., "An Improved Technique for Removal of Oxide Scale from Fractured Surfaces of Ferrous Materials," Practical Metallurgy, vol. 15, 1978, p. 184. 


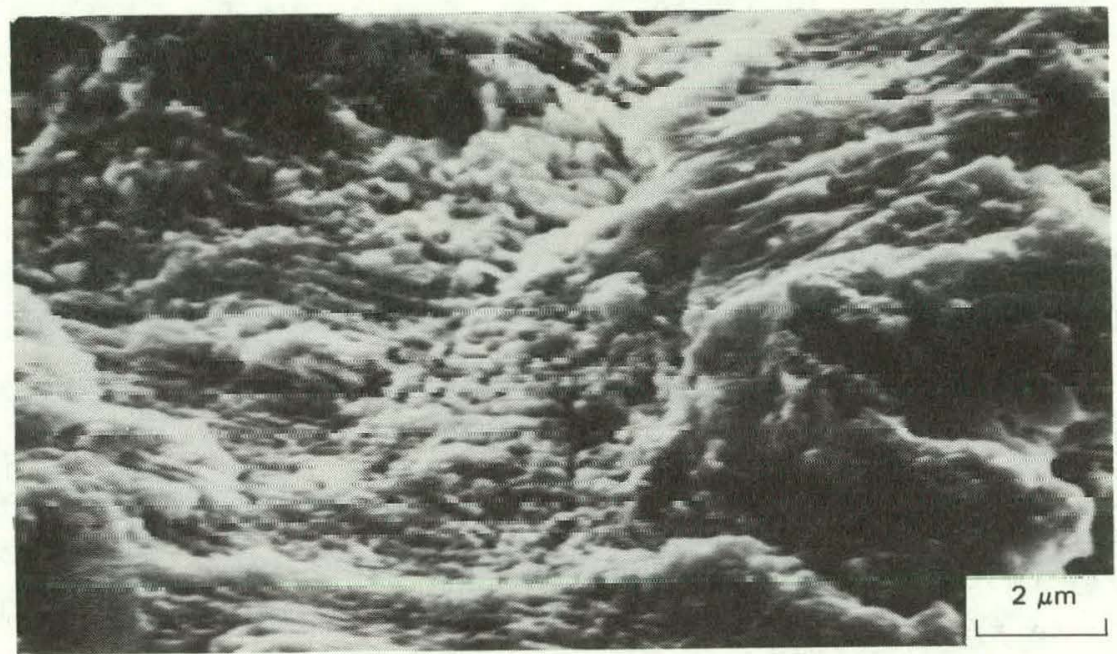

(a) Crack tip

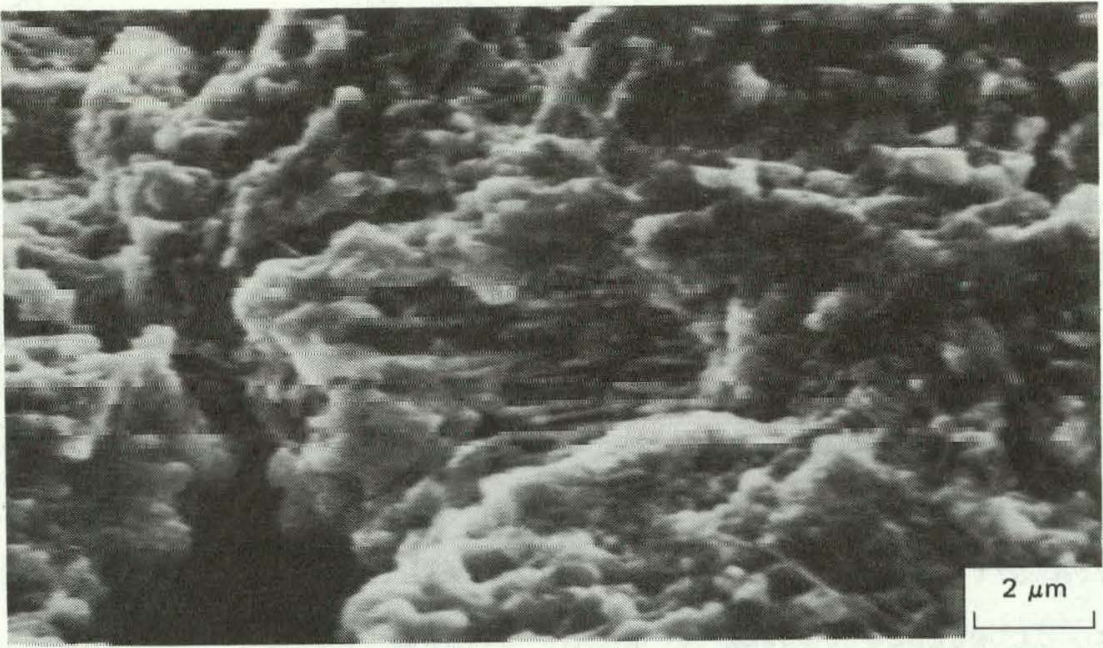

(b) Crack center

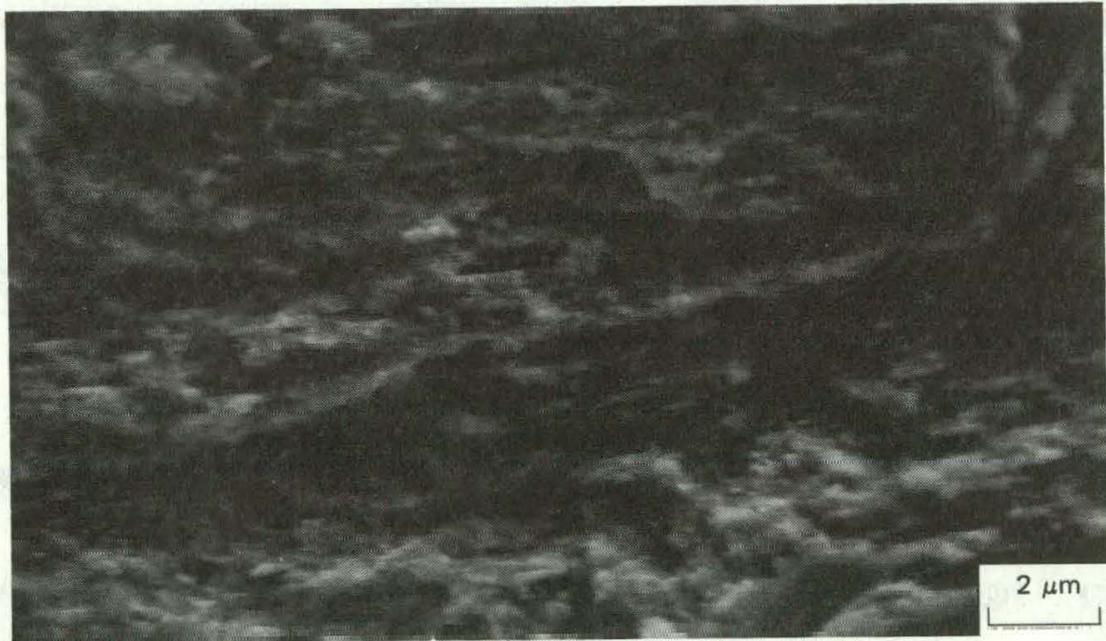

(c) Crack center

FIG. F.1. SEM fractographs of a cathodically cleaned crack surface of an H. B. Robinson section. In view (a) and possibly (c), note the parallel markings that suggest fatigue striations. Note the pearlite in view (b). Compare view (a) with Fig. 3.24(a). 


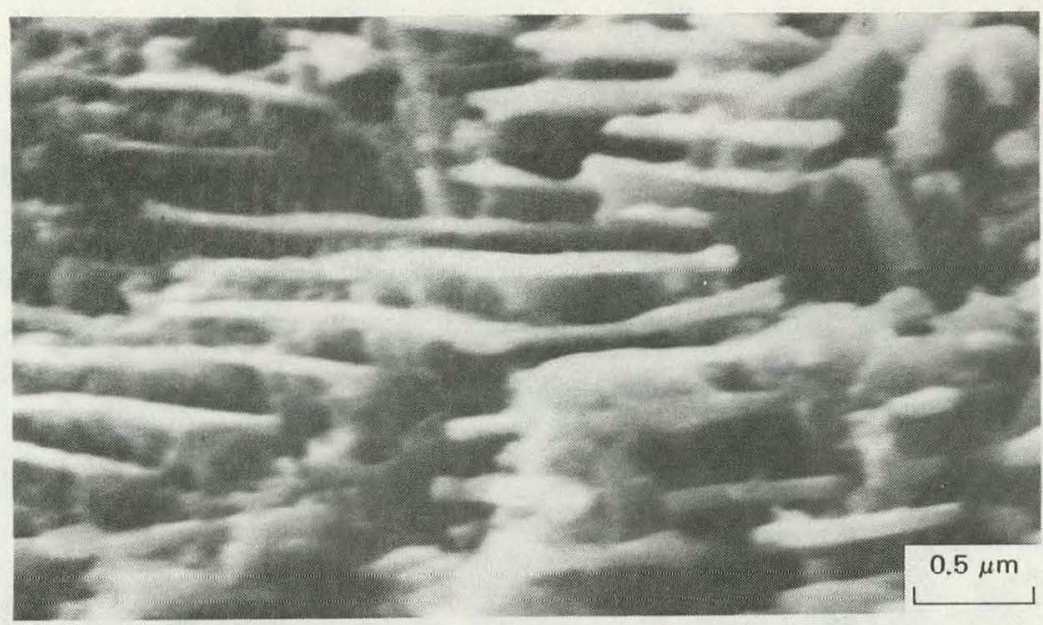

(a) Crack tip

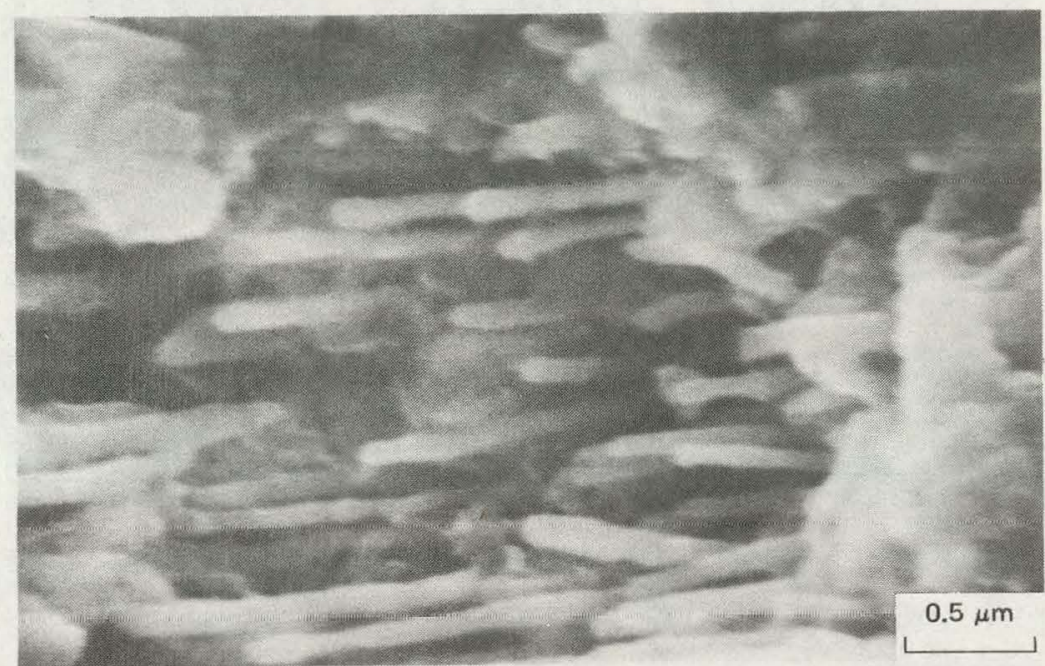

(b) Crack center

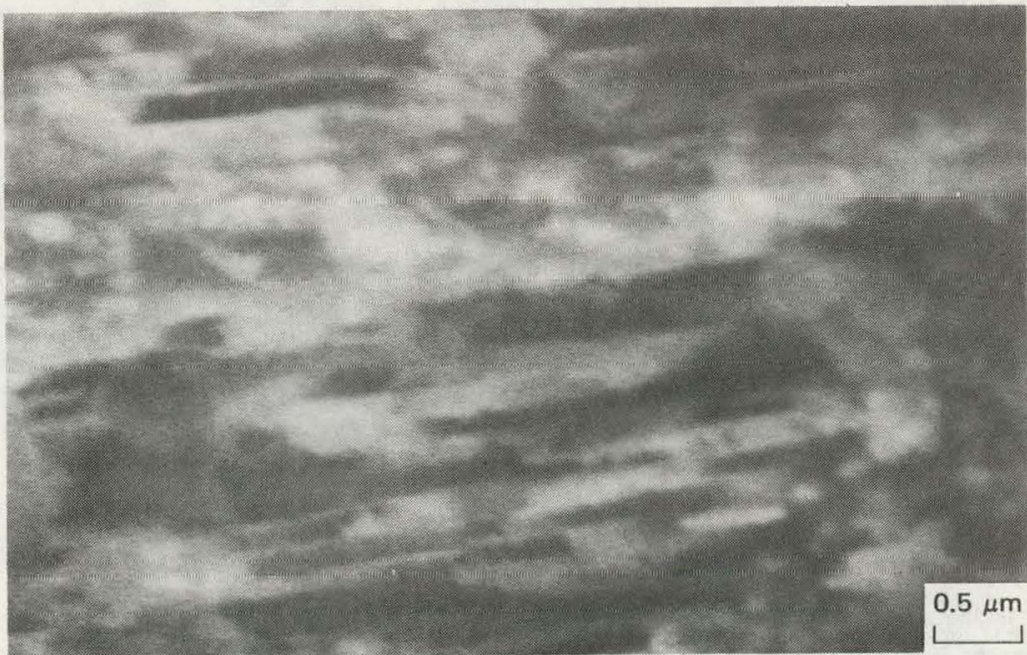

(c) Crack center

FIG. F.2. SEM fractographs of areas in Fig. F.l showing distinct pearlite at higher magnifications in an $\mathrm{H}$. B. Robinson section. 

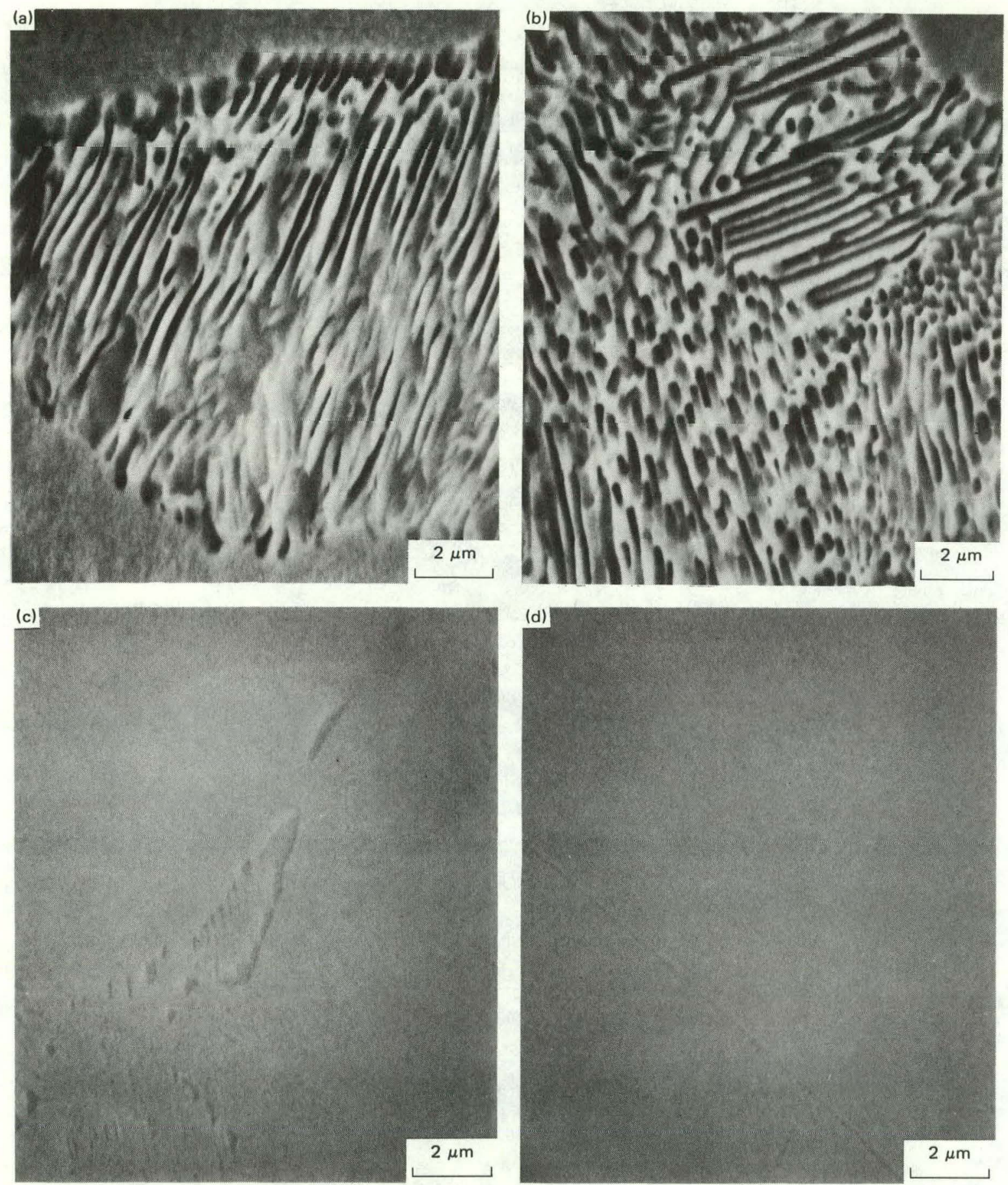

FIG. F.3. SEM fractographs of a polished-and-cleaned surface of an H. B. Robinson section. In views (a) and (b), note the pearlite etched by anodic cleaning. View (d) shows the surface unattacked by cathodic cleaning. The transition region is shown in view (c). 

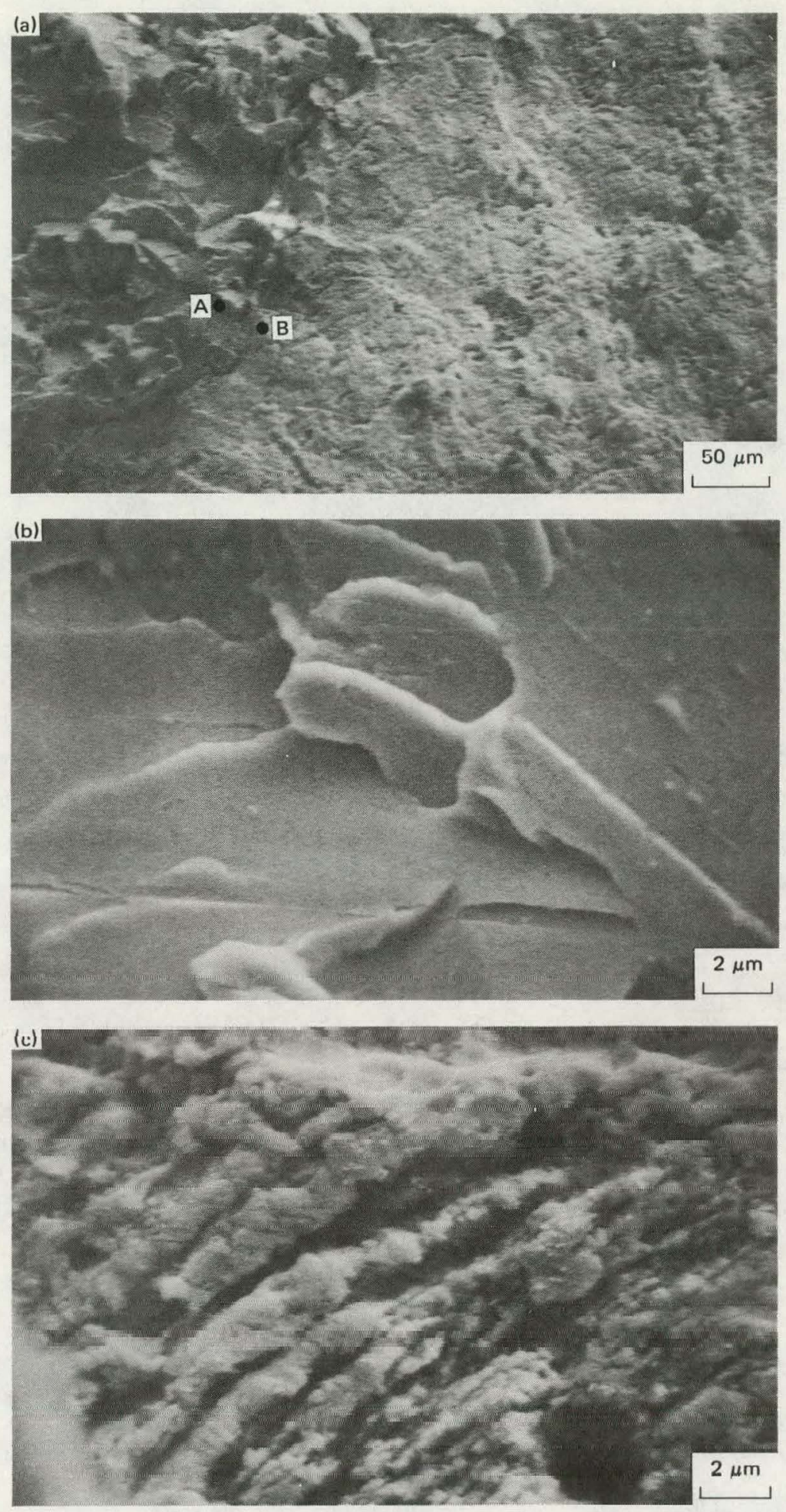

FIG. F.4. SEM fractographs across the interface from a plant crack to the laboratory fracture of a cathodically cleaned crack surface from an H. B. Robinson section. In view (b), note that the laboratory fracture was unattacked while the corrosion product was removed (attacked) revealing, in view (c), a series of ridges on the exposed steel surface suggestive of cyclic events. Views (b) and (c), respectively, are taken at A and B in view (a).

$$
147 / / 46
$$




\section{APPENDIX G}

TENSILE TESTING

\section{G.1 SELECTION OF STRAIN RATES}

We initially selected three strain rates for our study on tensile properties of the D. C. Cook material: (1) a standard slow rate of $10^{-3} / \mathrm{s}$, (2) an intermediate rate of $1 / 5$ which was calculated to give a loading rate of approximately $4.4 \mathrm{MN} / \mathrm{s}\left(1 \times 10^{6} \mathrm{lb} / \mathrm{s}\right)$, and (3) a rate of $200 / \mathrm{s}$, the 1 imit for our MTS machine. Due to the long load train through the environmental chamber, the intermediate strain rate, however, proved to be ten times slower than that necessary to achieve the desired load rate. The corrected rate of $10 / \mathrm{s}$ was then used for the intermediate rate.

At the high strain rate, $200 / \mathrm{s}$, the data were somewhat obscured by the load-train, natural-frequency excitation. This signal is transmitted to the piezo-electric force transducer as a high amplitude wave and must be removed prior to evaluating the true material behavior. This was performed with some success for the ambient-temperature data. However, the resonant effect becomes a particular problem when an environmental chamber is used (i.e., for the temperature test-matrix), as this requires an increase in the length of the load train. The resonant problem and its solution can be understood by examining the natural frequency of a small dlameter rod, which is given by

$$
f(c p s)=K_{n}(C / \ell)
$$

where $K_{n}$ - constant depending on the mundary conditions,

$\mathrm{n}=$ resonant frequency mode number (we assume 1),

$\mathrm{C}=$ speed of sound in the material, and

$\ell=$ length of rod.

This indicates that high strain-rate tests are necessarily limited by the type. and length of material. used between the specimen and load cell. In using steel for both the initial and added-on segments of the load train, we were limited in the ability to obtain yield-profile data at very high rates. This is because the equivalent frequency of the rise time to the yield point always 
exceeded the natural frequency of the total load-train connecting rods required with the environmental chamber. The test data reported at the $200 / \mathrm{s}$ strain rate were obtained prior to the installation of the environmental chamber with the specimen mounted directly to the force-cell assembly. The data still displayed considerable ringing, however, since the natural frequency of the system was close to that of the frequency of the loading rise time and required processing by an LSI-11 supported data acquisition system. We estimate that the yield and ultimate strengths are accurate to \pm 10 and \pm 5 percent, respectively, at these very high strain rates.

The speed of sound, $C$, is given by

$$
C=\sqrt{E / \rho}
$$

where $\mathrm{E}=$ modulus and

$\rho=$ density.

We therefore planned to substitute most of the load-train components with those made from a material having a low density and high modulus, namely, Lockalloy (62 wt. percent Be--38 wt. percent Al) which has a density of $2.086 \mathrm{Mg} / \mathrm{m}^{3}$ compared to roughly 8.4 for steel, and a modulus of $193 \mathrm{GPa}\left(28 \times 10^{6} \mathrm{psi}\right)$ close to that of steel. This will result in an increase in the frequency (f) by a factor of 2. Modifications decreasing the length of the load train will result in a further increase in the natural frequency. Also, the reduced mass will decrease the overshoot inherent in the force-transducer assembly at extremely high-loading rates. Components of Lockalloy have been machined for this purpose, and the system is currently being evaluated.

The strain and strain rates at low strain rates were obtained directly from the extensometer transducer outputs; however, at high strain rates, this information was obtained by converting the output from the crosshead displacement transducer.

\section{G.2 TEST SPECIMENS}

Figure G.l shows a cross section of the elbow and the locations from which tensile as well as fracture specimens were taken. An example of the layout of individual specimens is shown in Fig. G.2 for section 2-3-4-5 of Fig. G.1. All specimens were machined from midthickness. Reduced-size, round-tensile specimens with a 6.35-mm (0.25-in.) diameter and a 25.4-mm (1-in.) gauge length were used throughout the tensile test series. These specimens conform to the 
ASTM specifications $A-370 *$ and E-8.* Except for five specimens taken in the transverse direction from the D. C. Cook material, the tensile axis of all specimens was parallel to the piping axis. Wherever applicable, testing methods and procedures conformed to the ASTM Designations A370, E-8 and E-21. ${ }^{\dagger}$

\section{G.3 TEST RESULTS AND EVALUATION}

The tensile results for each specimen, from all six plants, tested at the slow strain rate, aproximately $10^{-3} / \mathrm{s}$, are listed in Table G.1. The additional results for D. C. Cook at other strain rates are listed in Table G.2. All the above data were obtained for longitudinal specimens. Table G.3 contains the results for the D. C. Cook transverse tensile specimens (axis parallel to the circumferential tangent). These specimens were tested at $22 \mathrm{C}$ $(72 \mathrm{~F})$ and $10^{-3} / \mathrm{s}$. The circumferential tensile values were virtually identical to the corresponding longitudinal values. However, specimens taken from the weld heat-affected zone show somewhat higher strengths and lower ductilities. In what follows are the analyses of the longitudinal tensile properties as affected by temperature and strain rate.

The changes in upper and lower yield strengths with temperature for all plants are shown in the plots of Figs. G.3 and G.4, respectively. Most data points represent an average of two specimens. In several cases, discontinuous yield was not obtained, and here the 0.2 percent offset values are used for both yield strengths. We have also plotted the minimum ASTM yield strengths for Al06-B at $22 \mathrm{C}(72 \mathrm{~F}), 250 \mathrm{C}(480 \mathrm{~F}), 275 \mathrm{C}(525 \mathrm{~F})$, and $300 \mathrm{C}$ (570 F). We note that the yield strengths for Salem at the higher temperatures fall below the minimum specified for Al06-B. Yet, this material is listed as A.106-C which has specified minimum values of nearly $5 \mathrm{ksi}$ (34.5 MPa) greater than those for Al06-B. The values for Salem, however, fall within specifications of $\mathrm{Al06}-\mathrm{C}$ at the lower temperatures.

*1979 ASTM Annual Book of Standards, Part 10, American Society for Testing Materials, Philadelphia, 1979.

$\dagger_{1979}$ ASTM Annual Book of Standards, Part 1, American Society for Testing Materials, Philadelphia, 1979. 
Both upper and lower yield strengths show a general decrease with an increase in temperature. However, a positive deviation from this trend can be seen at $88 \mathrm{C}(190 \mathrm{~F})$. Specimens from only D. C. Cook and Beaver valley were tested at this temperature. We should point out that, except for D. C. Cook, we had a very limited amount of material. Therefore, we were usually restricted to a choice of either testing at some new temperature or duplicating a test at an originally selected temperature. For example, Fig. G.3 shows that the lowest upper yield strength at $22 \mathrm{C}(72 \mathrm{~F})$ was obtained for Palisades; by contrast this material had the highest value at $227 \mathrm{C}(440 \mathrm{~F})$. This extreme reversal in relative values between the six plants is surprising, but we were unable to examine this further. In the tensile plots, solid lines indicate likely trends between data points whereas dashed lines suggest uncertainties between points.

Changes in ultimate tensile strengths (UTS) with temperature are plotted in Fig. G.5. All the data fall well within the ASTM limits specified for Al06-B at $22 \mathrm{C}(72 \mathrm{~F})$. A distinct minimum in UTS is observed at about $149 \mathrm{C}$ $(300 \mathrm{~F})$ for the four plants tested at this temperature. The increase in UTS (and work hardening) at temperatures above this minimum is likely due to solute-dislocation interactions or carbon-vacancy interactions. Similar trends were not obtained for any of the other tensile properties. The corresponding elongation data are shown in Fig. G.6. We note a drop in ductility from $22 \mathrm{C}$ to $4 \mathrm{C}(39 \mathrm{~F})$ in several cases, especially for Beaver valley, and this is probably indicative of being within the ductile-to-brittle transition temperature region. The data show a general drop in elongation with increase in temperature. It should be noted that the elongation axis is a greatly expanded scale, and with the exception of three points, all the data fall between 30 and 39 percent elongation. The rapid drop off from nearly 43 percent at $22 \mathrm{C}$ to 30 percent at $149 \mathrm{C}$ for Beaver valley is unusual. It is also the only plant that shows an elongation minimum corresponding with the UTS minimum. Of the six plants investigated, Ginna exhibited the lowest elongation to failure: 34 percent at $22 \mathrm{C}(72 \mathrm{~F})$ and 25 percent at $227 \mathrm{C}$ $(440 \mathrm{~F})$.

The effects of strain rates on the D. C. Cook material are illustrated in the semilog plots of Figs. G.7, G.8, and G.9. There is a general increase in the yield strengths at all temperatures with increasing strain rate from about $10^{-3} / \mathrm{s}$ to $10 / \mathrm{s}$. We only report results for one of the specimens tested at 
the highest strain rate of $200 / \mathrm{s}$. As we noted earlier, we encountered interference from the frequency response of the load train at the highest loading rate. This has now been corrected. The rapid increase in lower yield (i.e., decrease been upper and lower yield) at strain rates above about 100/s has been reported for a number of materials.*

The effect of strain rate on the UTS shown in Fig. G.9 is consistent with the corresponding effect of temperature. For temperatures up to $149 \mathrm{C}(300 \mathrm{~F})$, there is a definite increase in UTS with an increase in strain rate. At $227 \mathrm{C}$ $(440 \mathrm{~F})$, there is very little effect. At the highest temperature of $285 \mathrm{C}$ ( $545 \mathrm{~F})$, the UTS drops by nearly $8 \mathrm{ksi}$ (55 MPa) in going from a strain rate of $10^{-3} / \mathrm{s}$ to nearly $10 / \mathrm{s}$. For temperature-activated phenomena, a decrease in temperature has a similar effect as an increase in strain rate, suggesting here a diffusion mechanism as being a rate controlling factor of the flow stress. The elongation values were random with strain rate and are not plotted.

We attempted to relate the yield strengths and UTS to either crack length or crack growth rate with and without corrections for section thickness at the major cracks. Figures G.10(a), G.10(b), and G.10(c) are plots of crack growth versus upper and lower yield strengths and UTS at 4 C (39 F), 22 C (72 F), and $227 \mathrm{C}(440 \mathrm{~F})$, respectively. The crack growth rates are divided by the corresponding section thicknesses. Figures G.1l(a), G.11(b), and G.1l(c) are corresponding plots of crack length versus the same strength values. Correction for section thickness has a negligible effect on the results. As expected, the D. C. Cook data are greatly displaced from the remaining data. The yield data are quite random. However, a rough trend can be detected for the UTS relative to both crack length and crack propagation rate at all three temperatures, in that an increase in UTS roughly results in an apparent increase in resistance to cracking. We question the significance of this trend with UTS as one normally would expect instead a trend with yield strength for either SCC, CF, or fatigue.

*Edington, J. W., "Effect of Strain Rate on the Dislocation Substructure in Deformed Niobium Single Crystals," in Mechanical Behavior of Materials Under Dynamic Loads, Ed. U. S. Lindholm, 1968, p. 191. 
TABLE G.1. Tensile properties of feedwater piping materials ${ }^{a}$ from six nuclear power plants. Tensile axis parallel to piping axis. Tested at strain rate of approximately $10^{-3} \mathrm{~s}^{-1}$ at several temperatures.

\begin{tabular}{|c|c|c|c|c|c|c|c|c|c|c|}
\hline \multirow{2}{*}{$\begin{array}{c}\text { Reactor } \\
\text { plant }\end{array}$} & \multirow{2}{*}{$\begin{array}{l}\text { Spec. } \\
\text { no. }\end{array}$} & \multicolumn{2}{|c|}{ Temper ature } & \multicolumn{2}{|c|}{ Upper yield stress } & \multicolumn{2}{|c|}{ Lower yield stress } & \multicolumn{2}{|c|}{$\begin{array}{c}\text { Ultimate } \\
\text { tensile strength } \\
\end{array}$} & \multirow{2}{*}{$\begin{array}{c}\text { Elong. } \\
8\end{array}$} \\
\hline & & ${ }^{\circ} \mathrm{C}$ & $o_{F}$ & $\mathbf{M P a}$ & ksi & $\mathrm{MPa}$ & ksi & $\mathrm{MPa}$ & ksi & \\
\hline Ginna & $N-10-5$ & 4 & 39 & 324.8 & 47.10 & 281.1 & 40.77 & 483.3 & 70.10 & 33.2 \\
\hline Ginna & $N-10-9$ & 4 & 39 & 259.9 & 37.70 & 252.7 & 36.65 & 494.4 & 71.70 & 35.0 . \\
\hline H. B. Robinson & $N-5-6$ & 4 & 39 & 298.2 & 43.25 & 279.9 & 40.60 & 502.0 & 72.80 & 34.1 \\
\hline Palisades & $N-17-3^{b}$ & 4 & 39 & 282.0 & 40.90 & 282.0 & 40.90 & 470.1 & 68.30 & 35.4 \\
\hline Beaver Valley & $N-3-5$ & 4 & 39 & 351.3 & 52.40 & 320.6 & 46.50 & 486.4 & 70.54 & 37.5 \\
\hline Salem & $\mathrm{N}-12-3$ & 4 & 39 & $3 \div 7.2$ & 46.00 & 301.7 & 43.75 & 479.2 & 69.50 & 37.9 \\
\hline D. C. Cook & 27 & 4 & 39 & 282.0 & 40.90 & 253.7 & 36.80 & 494.0 & 71.65 & 36.3 \\
\hline D. C. Cook & 41 & 4 & 39 & 272.4 & 39.50 & 267.9 & 38.85 & 502.5 & 72.88 & 38.6 \\
\hline Ginna & $N-10-6$ & 22 & 72 & 280.0 & 40.60 & 262.0 & 38.00 & 479.3 & 69.52 & 33.2 \\
\hline Ginna & $\mathrm{N}-10-10$ & 22 & 72 & 261.0 & 37.85 & 259.6 & 37.65 & 484.3 & 70.24 & 34.7 \\
\hline H. B. Robinson & $N-5-5$ & 22 & 72 & 251.0 & 36.40 & 251.0 & 36.40 & 477.1 & 69.20 & 35.1 \\
\hline H. B. Robinson & $N-5-7$ & 22 & 72 & 297.9 & 43.20 & 265.8 & 39.36 & 484.7 & 70.30 & 33.5 \\
\hline Palisades & $N-17-1^{b}$ & 22 & 72 & 257.1 & 37.30 & 257.1 & 37.30 & 451.6 & 65.50 & 36.3 \\
\hline Palisades & $N-17-5^{b}$ & 22 & 72 & 256.3 & 37.17 & 256.3 & 37.17 & 452.7 & 65.65 & 35.4 \\
\hline Beaver Valley & $N-3-3$ & 22 & 72 & $3 i 9.1$ & 46.28 & 308.0 & 44.67 & 470.9 & 68.30 & 40.4 \\
\hline Beaver Valley & $N-3-6$ & 22 & 72 & 343.7 & 49.80 & 308.2 & 44.70 & 473.7 & 68.70 & 44.6 \\
\hline Salem & $N-12-5$ & 22 & 72 & 300.6 & 43.60 & 261.7 & 37.95 & 465.4 & 67.50 & 38.8 \\
\hline Salem & $\mathrm{N}-12-7$ & 22 & 72 & $2 ? 4.1$ & 39.76 & 253.0 & 36.70 & 466.0 & 67.60 & 39.1 \\
\hline D. C. Cook & 16 & 22 & 72 & 259.8 & 37.68 & 241.3 & 35.00 & 474.7 & 68.84 & 34.4 \\
\hline D. C. Cook & 40 & 22 & 72 & 264.8 & 38.40 & 250.6 & 36.35 & 498.7 & 72.33 & 38.7 \\
\hline
\end{tabular}


TABLE G.I. (Continued.)

\begin{tabular}{|c|c|c|c|c|c|c|c|c|c|c|}
\hline \multirow{3}{*}{$\begin{array}{c}\text { Reactor } \\
\text { plant }\end{array}$} & \multirow{3}{*}{$\begin{array}{c}\text { Spec. } \\
\text { no. }\end{array}$} & \multirow{2}{*}{\multicolumn{2}{|c|}{ Temper ature }} & \multirow[b]{2}{*}{ Upper vield } & \multirow[b]{2}{*}{ stress } & \multirow[b]{2}{*}{ Lower yield } & \multirow[b]{2}{*}{ stress } & \multicolumn{2}{|c|}{ Ultimate } & \multirow{3}{*}{$\begin{array}{c}\text { Elong. } \\
\text { \& }\end{array}$} \\
\hline & & & & & & & & tensile & strength & \\
\hline & & ${ }^{\circ} \mathrm{C}$ & $o_{F}$ & $\mathrm{MPa}$ & $\mathrm{ksi}$ & $\mathrm{MPa}$ & ksi & $\mathrm{MPa}$ & kși & \\
\hline Beaver Valley & $N-3-8$ & 88 & 190 & 332.3 & 48.20 & 289.6 & 42.00 & 440.6 & 63.90 & 34.9 \\
\hline D. C. Cook & 44 & 88 & 190 & 299.2 & 43.40 & 256.8 & 37.25 & 448.9 & 65.10 & 37.3 \\
\hline D. C. Cook & $46^{\mathrm{b}}$ & 88 & 190 & 251.3 & 36.44 & 251.3 & 36.44 & 450.9 & 65.39 & 36.6 \\
\hline H. B. Robinson & $N-5-9$ & 149 & 300 & 221.5 & 32.13 & 221.5 & 32.13 & 424.0 & 61.50 & 30.7 \\
\hline Beaver Valley & $N-3-7$ & 149 & 300 & 293.0 & 42.50 & 251.3 & 36.45 & 417.1 & 60.50 & 30.2 \\
\hline Salem & $\mathrm{N}-12-8$ & 149 & 300 & 228.9 & 33.20 & 201.3 & 29.20 & 409.6 & 59.40 & 34.6 \\
\hline D. C. Cook & 20 & 149 & 300 & 206.6 & 29.96 & 202.4 & $29: 35$ & 420.6 & 61.00 & 33.0 \\
\hline D. C. Cook & 26 & 149 & 300 & 213.7 & 31.00 & 198.2 & 28.75 & 420.6 & 61.00 & 34.5 \\
\hline D. C. Cook & 45 & 182 & 360 & 232.4 & 33.70 & 193.1 & 28.00 & 426.8 & 61.90 & 35.9 \\
\hline Ginna & $N-10-8^{b}$ & 227 & 440 & 182.5 & 26.46 & 182.5 & 26.46 & 433.0 & 62.80 & 24.9 \\
\hline H. B. Robinson & $N-5-8^{b}$ & 227 & 440 & 202.0 & 29.30 & 202.0 & 29.30 & 437.4 & 63.43 & 26.5 \\
\hline Palisades & $N-17-4^{b}$ & 227 & 440 & 244.8 & 35.50 & 244.8 & 35.50 & 431.1 & 62.50 & 30.6 \\
\hline Beaver Valley & $N-3-4$ & 227 & 440 & 215.9 & 31.30 & 202.0 & 29.30 & 431.8 & 62.63 & 33.5 \\
\hline Salem & $\mathrm{N}-12-4$ & 227 & 440 & 163.4 & 23.70 & 160.6 & 23.30 & 415.8 & 60.30 & 34.2 \\
\hline Salem & $N-12-6^{b}$ & 227 & 440 & 174.8 & 25.35 & 174.8 & 25.35 & 409.6 & 59.40 & 34.6 \\
\hline D. C. Cook & $31^{b}$ & 227 & 440 & 181.1 & 26.26 & 181.1 & 26.26 & 434.4 & 63.00 & 29.9 \\
\hline D. C. Cook & 39 & 227 & 440 & 189.6 & 27.50 & 181.3 & 26.30 & 427.7 & 61.61 & 33.9 \\
\hline D. C. Cook & $30^{b}$ & 285 & 545 & 164.1 & 23.80 & 164.1 & 23.80 & 444.7 & 64.80 & 31.6 \\
\hline D. C. Cook & $43^{b}$ & 285 & 545 & 195.4 & 28.30 & 195.4 & 28.34 & 457.1 & 66.30 & 34.1 \\
\hline
\end{tabular}

$a_{A 11}$ ASTM A-106B, except A-106C for Salem.

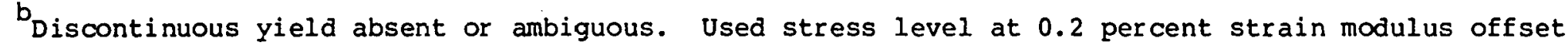

for yield values. 
TABLE G.2. Tensile properties of D. C. Cook elbow material at various strain rates and temperatures. Tensile axis parallel to elbow axis (normal to circumferential direction).

Ultimate

Spec. Strain Temperature Upper yield stress Lower yield stress tensile strength Elong.,

\begin{tabular}{|c|c|c|c|c|c|c|c|c|c|c|c|c|}
\hline \multirow{2}{*}{ no. } & \multirow{2}{*}{\multicolumn{3}{|c|}{ rate, $s^{-1}$}} & \multirow{2}{*}{\multicolumn{2}{|c|}{${ }^{o_{C}} \quad o_{F}$}} & \multirow{2}{*}{\multicolumn{2}{|c|}{ MPa $\quad k s i$}} & & & \multirow{2}{*}{8} \\
\hline & & & & & & & & $\mathrm{MPa}$ & ksi & MPa & ksi & \\
\hline 41 & 0.8 & $x$ & $10^{-3}$ & 4 & 39 & 272.4 & 39.50 & 267.9 & 38.85 & 502.5 & 72.88 & 38.6 \\
\hline 47 & 1 & $x$ & $10^{-3}$ & 4 & 39 & 232.0 & 40.90 & 253.7 & 36.80 & 494.0 & 71.65 & 36.3 \\
\hline 16 & 0.5 & $x$ & $10^{-3}$ & 22 & 72 & 259.8 & 37.68 & 241.3 & 35.00 & 474.7 & 68.84 & 34.4 \\
\hline 40 & 0.7 & $x$ & $10^{-3}$ & 22 & 72 & 254.8 & 38.40 & 250.6 & 36.35 & 498.7 & 72.33 & 38.7 \\
\hline 44 & 0.8 & $x$ & $10^{-3}$ & 88 & 190 & 279.2 & 43.40 & 256.8 & 37.25 & 448.9 & 65.10 & 37.3 \\
\hline 26 & 0.8 & $x$ & $10^{-3}$ & 149 & 300 & 213.7 & 31.00 & 198.2 & 28.75 & 420.6 & 61.00 & 34.5 \\
\hline 20 & 0.9 & $x$ & $10^{-3}$ & 149 & 300 & 206.6 & 29.96 & 202.4 & 29.35 & 420.6 & 61.00 & 33.0 \\
\hline 45 & 0.9 & $x$ & $10^{-3}$ & 182 & 360 & 232.4 & 33.70 & 193.1 & 28.00 & 426.8 & 61.90 & 35.9 \\
\hline $31^{a}$ & 0.9 & $x$ & $10^{-3}$ & 227 & 440 & 131.1 & 26.26 & 181.1 & 26.26 & 434.4 & 63.00 & 29.9 \\
\hline 39 & 0.9 & $x$ & $10^{-3}$ & 227 & 440 & 139.6 & 27.50 & 181.3 & 26.30 & 427.7 & 61.61 & 33.9 \\
\hline $30^{a}$ & 0.9 & $x$ & $10^{-3}$ & 285 & 545 & 154.1 & 23.80 & 164.1 & 23.80 & 444.7 & 64.80 & 31.6 \\
\hline $43^{a}$ & 0.9 & $x$ & $10^{-3}$ & 285 & 545 & 195.4 & 28.34 & 195.4 & 28.30 & 457.1 & 66.30 & 34.1 \\
\hline 18 & 0.7 & $x$ & $10^{0}$ & 22 & 72 & 356.8 & 53.20 & 310.3 & 45.00 & 513.7 & 74.50 & 35.6 \\
\hline 19 & 0.8 & $x$ & $10^{\circ}$ & 149 & 300 & 248.2 & 36.00 & 237.9 & 34.50 & 428.9 & 62.60 & 34.9 \\
\hline 28 & 0.6 & $x$ & $10^{1}$ & 4 & 39 & 437.8 & 63.50 & 351.6 & 51.00 & 522.3 & 75.75 & 34.7 \\
\hline 24 & 0.9 & $x$ & $10^{1}$ & 22 & 72 & 427.5 & 62.00 & 330.3 & 47.90 & 545.4 & 79.10 & 35.6 \\
\hline 23 & 0.9 & $x$ & $10^{1}$ & 149 & 300 & 299.9 & 43.50 & 241.3 & 35.20 & 458.5 & 66.50 & 36.2 \\
\hline 25 & 0.9 & $x$ & $10^{1}$ & 149 & 300 & 308.9 & 44.80 & 243.0 & 35.25 & 460.6 & 66.80 & 34.5 \\
\hline 42 & 0.9 & $x$ & $10^{1}$ & 218 & 425 & 277.2 & 40.20 & 248.2 & 36.00 & 434.4 & 63.00 & 37.6 \\
\hline 21 & 0.8 & $x$ & $10^{1}$ & 285 & 545 & 206.9 & 30.00 & 196.5 & 28.50 & 399.2 & 57.90 & 32.6 \\
\hline 22 & 0.8 & $x$ & $10^{1}$ & 285 & 545 & $2 \Xi 6.5$ & 31.40 & 196.5 & 28.50 & 399.9 & 58.00 & 36.0 \\
\hline 29 & 0.7 & $x$ & $10^{1}$ & 285 & 545 & 231.0 & 33.50 & 186.2 & 27.00 & 403.4 & 58.50 & 33.2 \\
\hline 17 & 2.0 & $x$ & $10^{2}$ & 22 & 72 & 482.7 & 70.00 & 472.3 & 68.50 & 565.4 & 82.00 & 35.4 \\
\hline
\end{tabular}

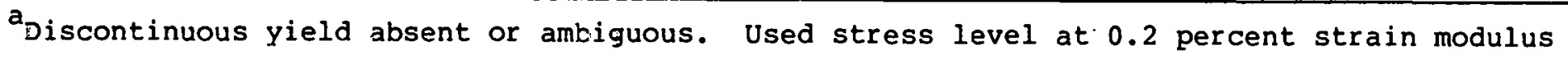
offset for yield values. 
TABLE G.3. Transverse tensile properties of D. C. Cook elbow material; tensile axis normal to elbow axis (parallel to circumferential tangent).

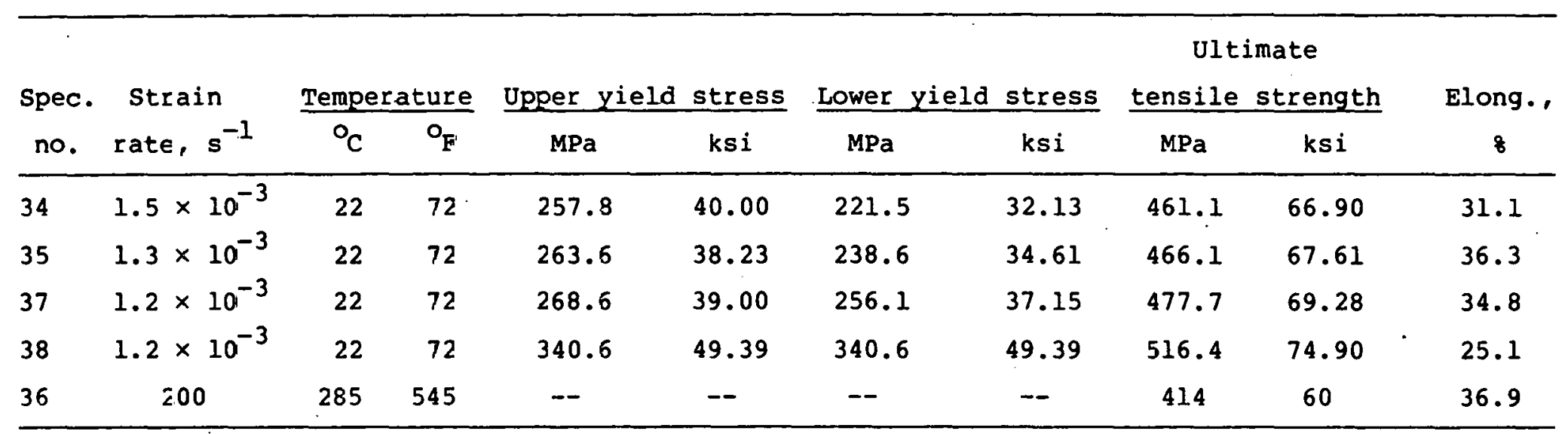




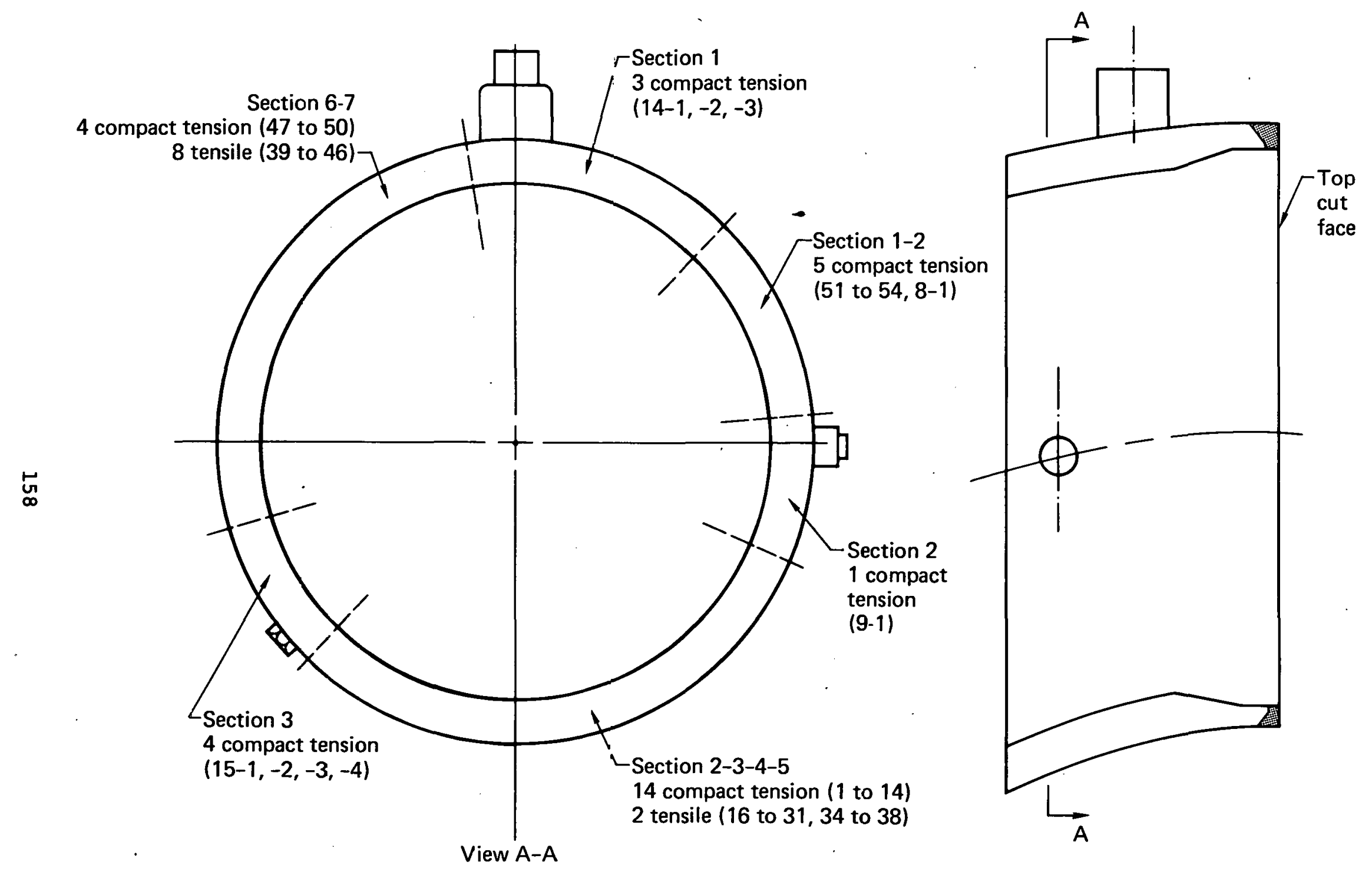

FIG. G.1. D. C. Cook feedwater piping elbow section indicating the general location of compact-tension fracture toughness specimens and tensile specimens. 


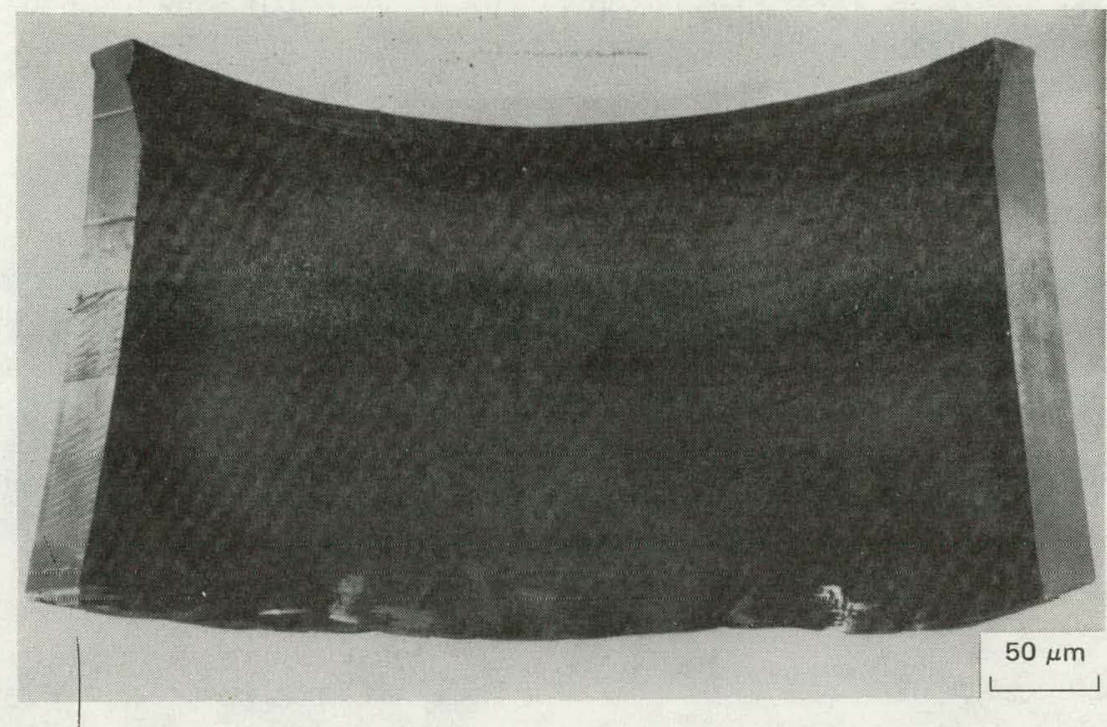

(a) Section 2-3-4-5 (113 to $\left.225^{\circ}\right)$; as-received

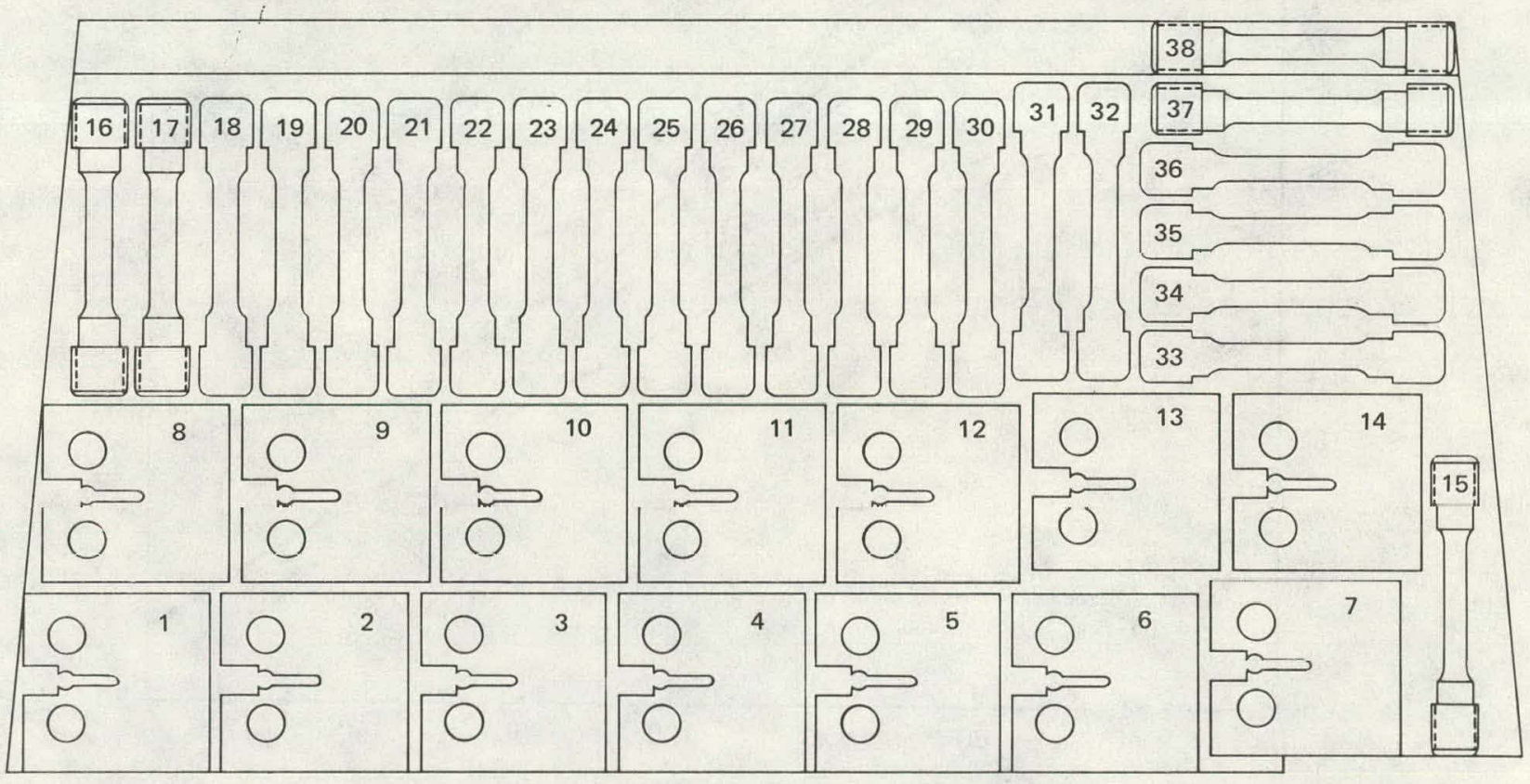

FIG. G.2. Photograph of as-received D. C. Cook elbow section $(2-3-4-5$ of Fig. G.1) and drawing of layout of specimens for mechanical properties characterization. Specimens 15, 32, and 33 were not machined. Note that the circumferential direction of the elbow is normal to the tensile axis for all specimens except 33 through 38. 
Temperature $\left({ }^{\circ} \mathrm{F}\right)$

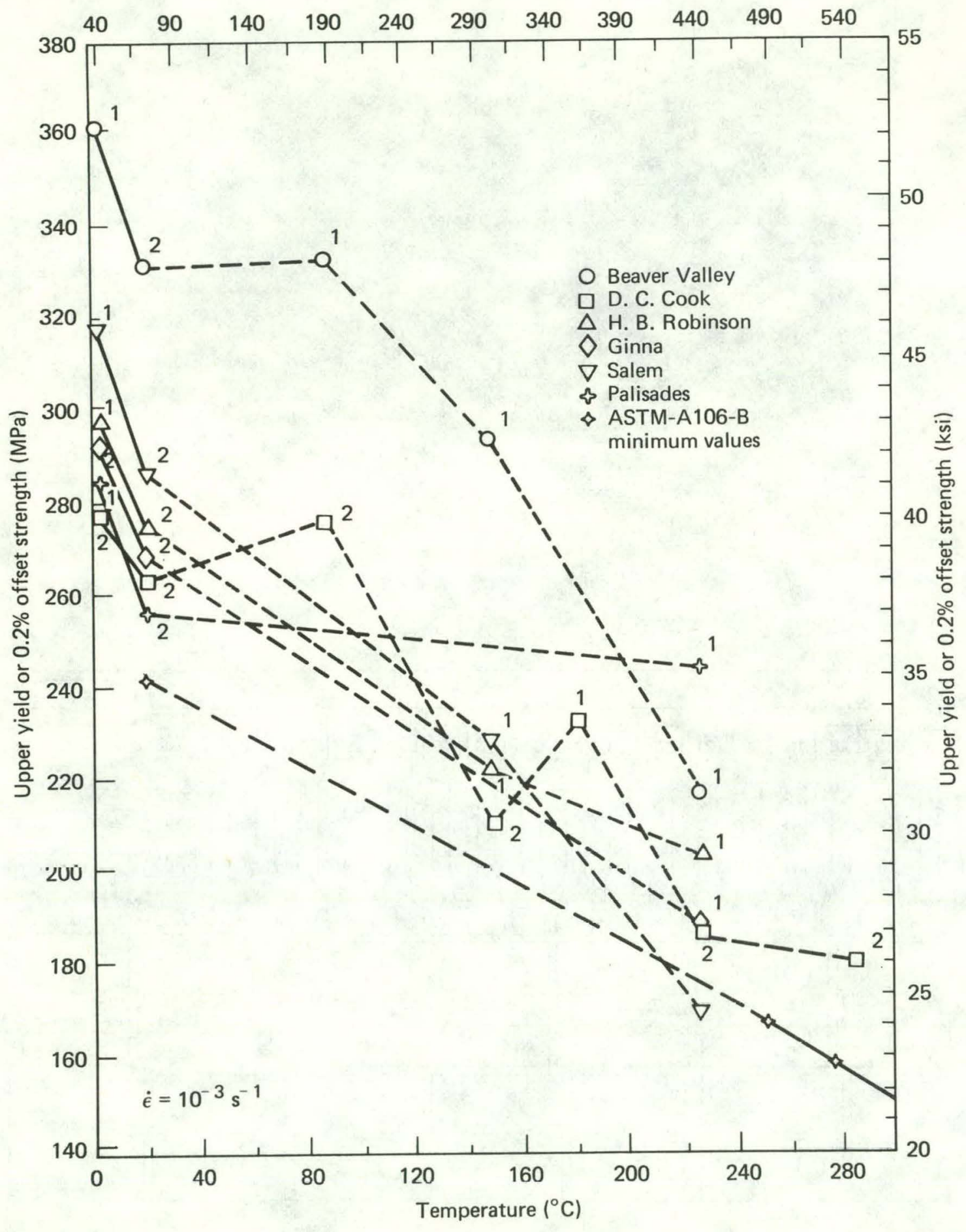

FIG. G.3. Upper yield strength (or 0.2 percent offset strength) as a function of temperature for piping material from six plants tested at the standard strain rate. Materials are Al06-B except Al06-C for Salem. A general decrease in strength is obtained with an increase in temperature, but some anomalous points do appear. All data fall above minimum Al06-B except those at $227 \mathrm{C}$ $(440 \mathrm{~F})$ for Salem. If more than one test was conducted, average values are plotted. Numbers indicate tests. 


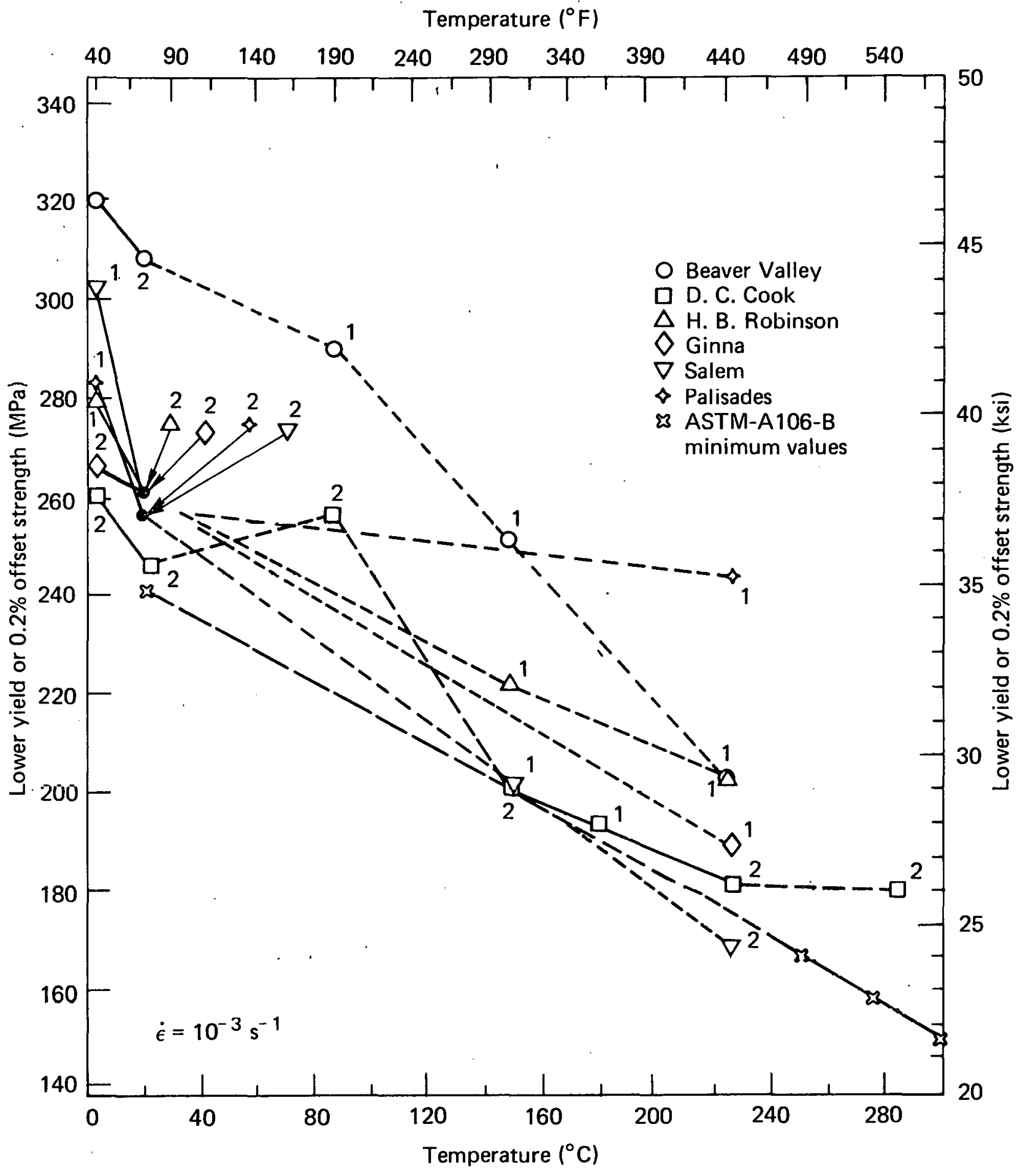

FIG. G.4. Lower yield strength (or 0.2 percent offset strength) as a function of temperature for piping material from six plants tested at the standard strain rate. Materials are Al06-B except Al06-C for Salem. A general decrease in strength is obtained with an increase in temperature except for the anomalous behavior at $88 \mathrm{C}(190 \mathrm{~F})$. All data fall above minimum Al06-B except those for salem at $227 \mathrm{C}(440 \mathrm{~F})$. If more than one test was conducted, average values are plotted. Numbers indicate tests. 


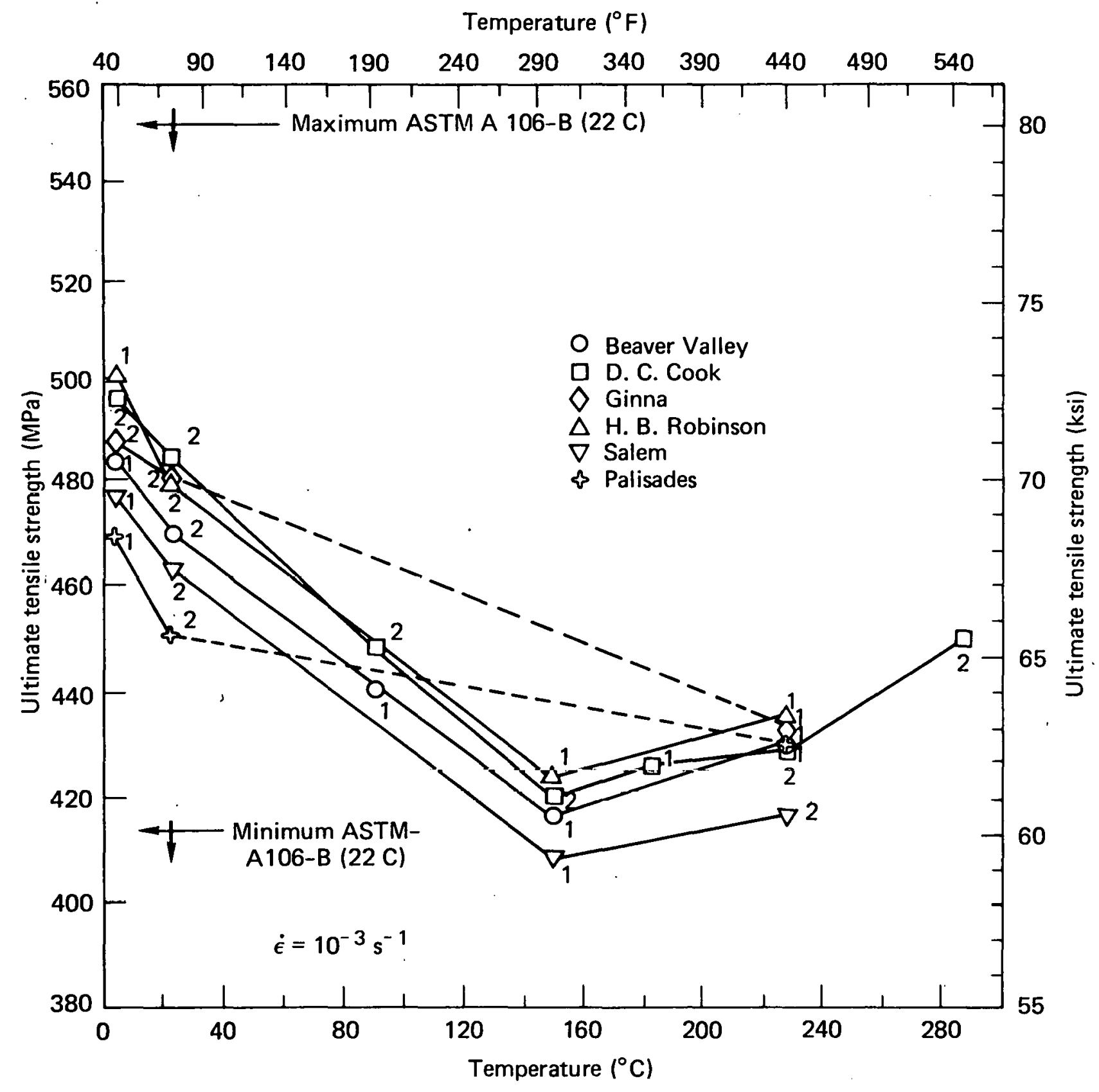

FIG. G.5. Tensile strengths as a function of temperature for piping material from six plants tested at the standard strain rate. All data at ambient temperature fall within the limits of Al06-B. All materials except from Salem (Al06-C) are Al06-B. Note the minimum in data from four plants at $149 \mathrm{C}$ $(300 \mathrm{~F})$. If more than one test was conducted, average values are plotted. Numbers indicate tests. 
Temperature $\left({ }^{\circ} \mathrm{F}\right)$

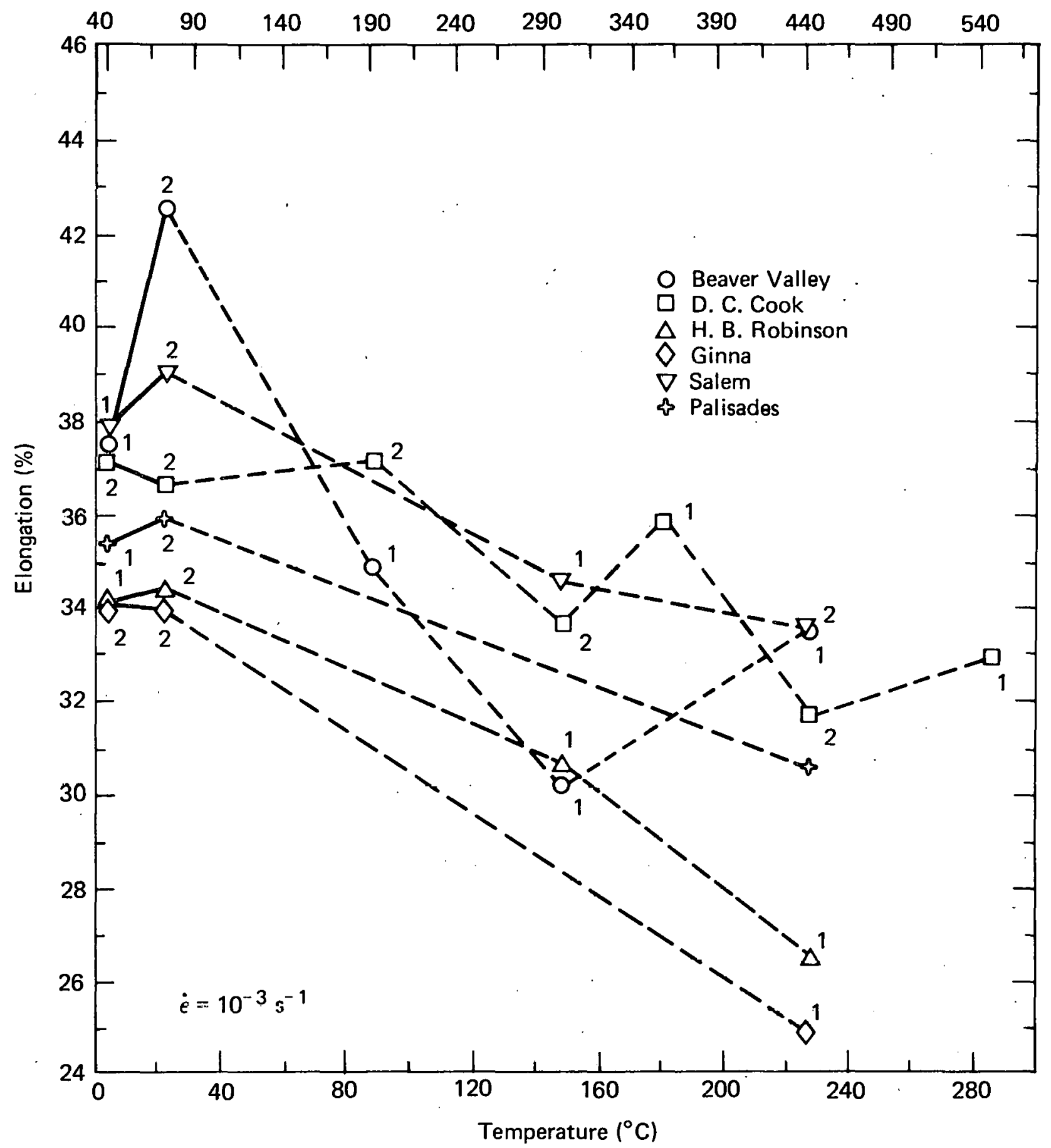

FIG. G.6. Elongation as a function of temperature for piping material from six plants tested at the standard strain rate. Elongation generally decreases with either a decrease or an increase in temperature from ambient, $22 \mathrm{C}$ (72 F). If more than one test was conducted, average values are plotted. Numbers indicate tests. 


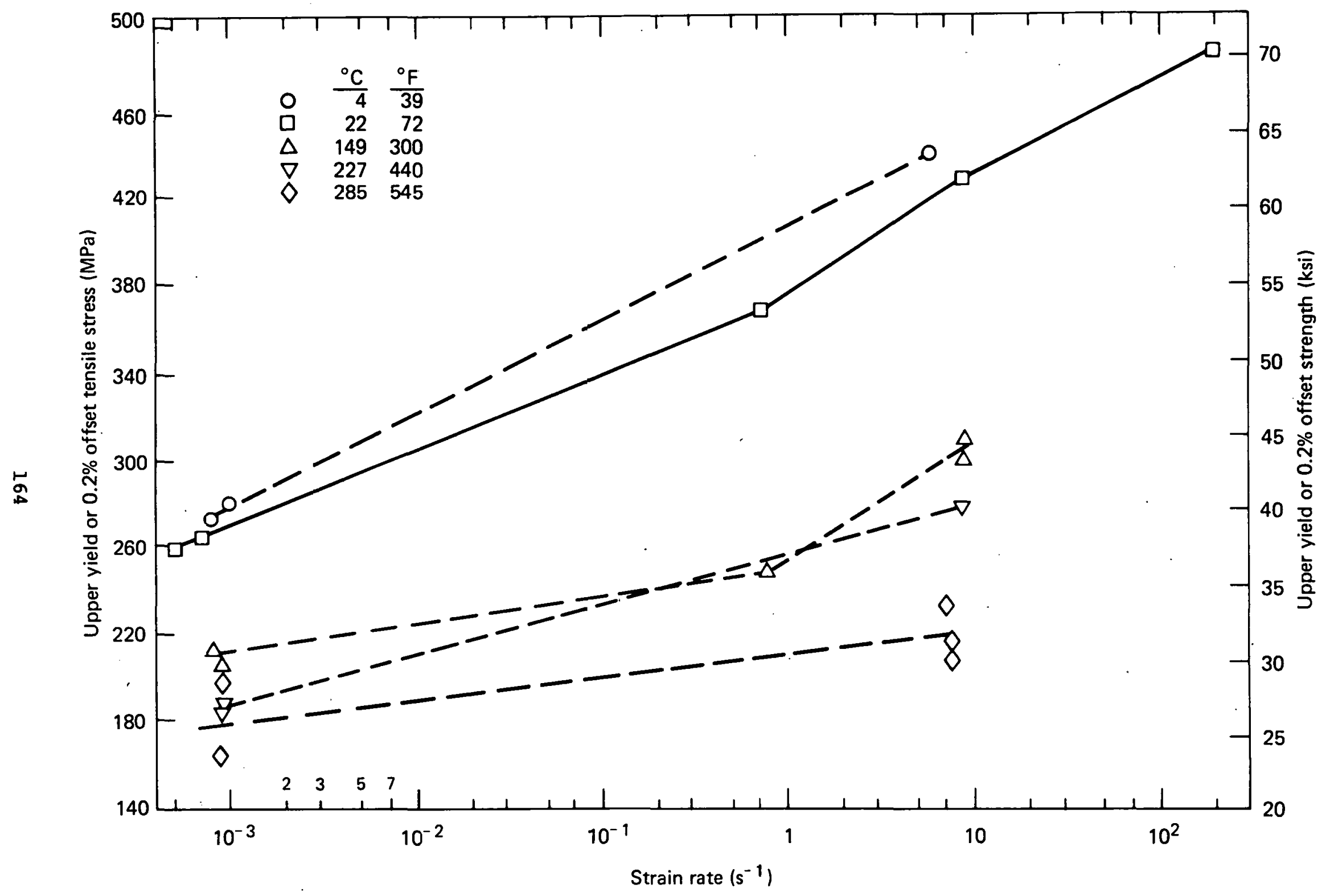

FIG. G.7. Effect of strain rate on upper yield strength (or 0.2 percent offset strength) for D. C. Cook elbow material. The data show a general increase with strain $r a t e$ at all temper atures. 


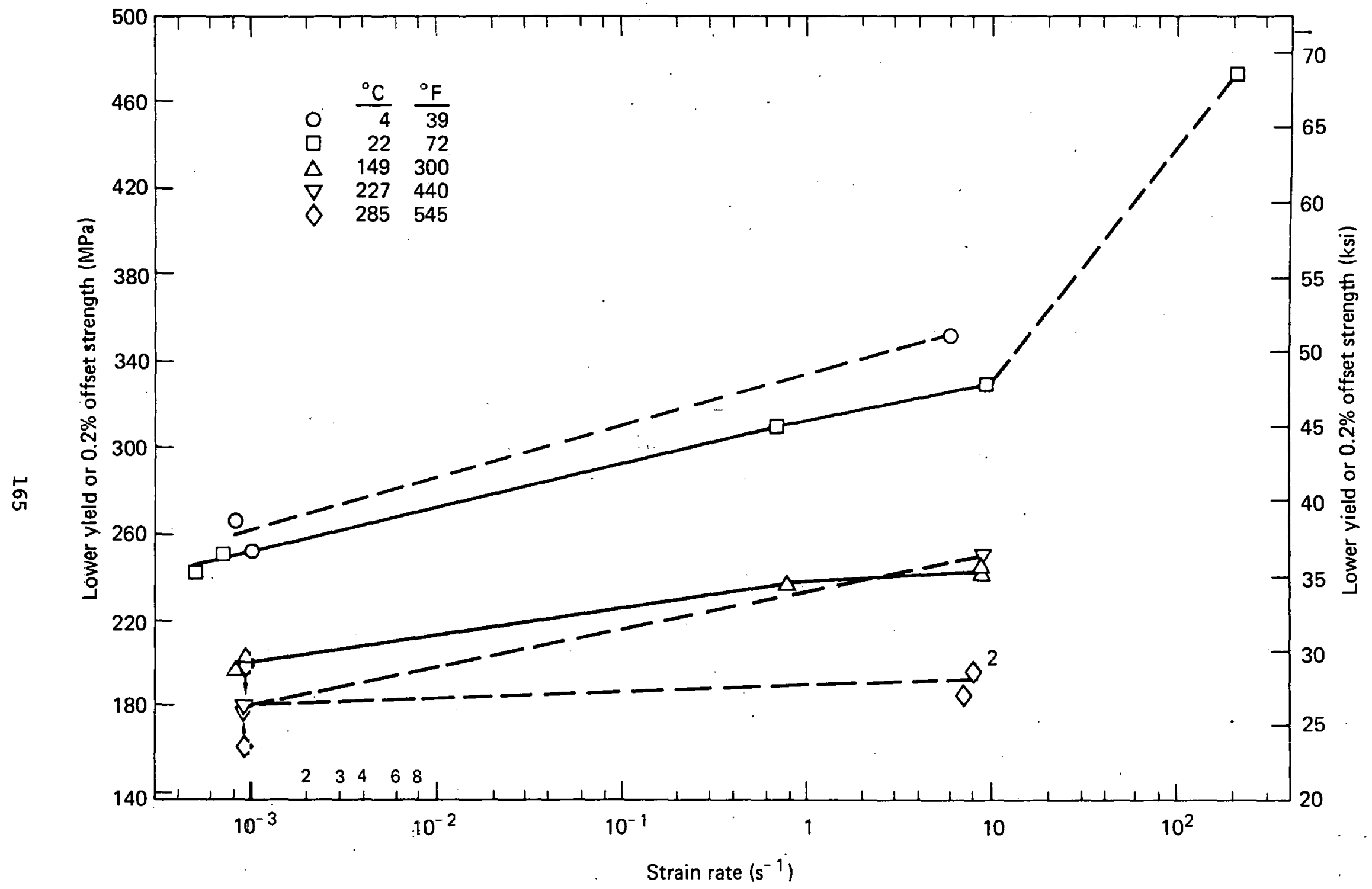

FIG. G.8. Effect of strain rate on lower yield strength (or 0.2 percent offset strength) for D. C. Cook $\in$ lbow material. The data show a general increase with strain rate at all temper atures. 


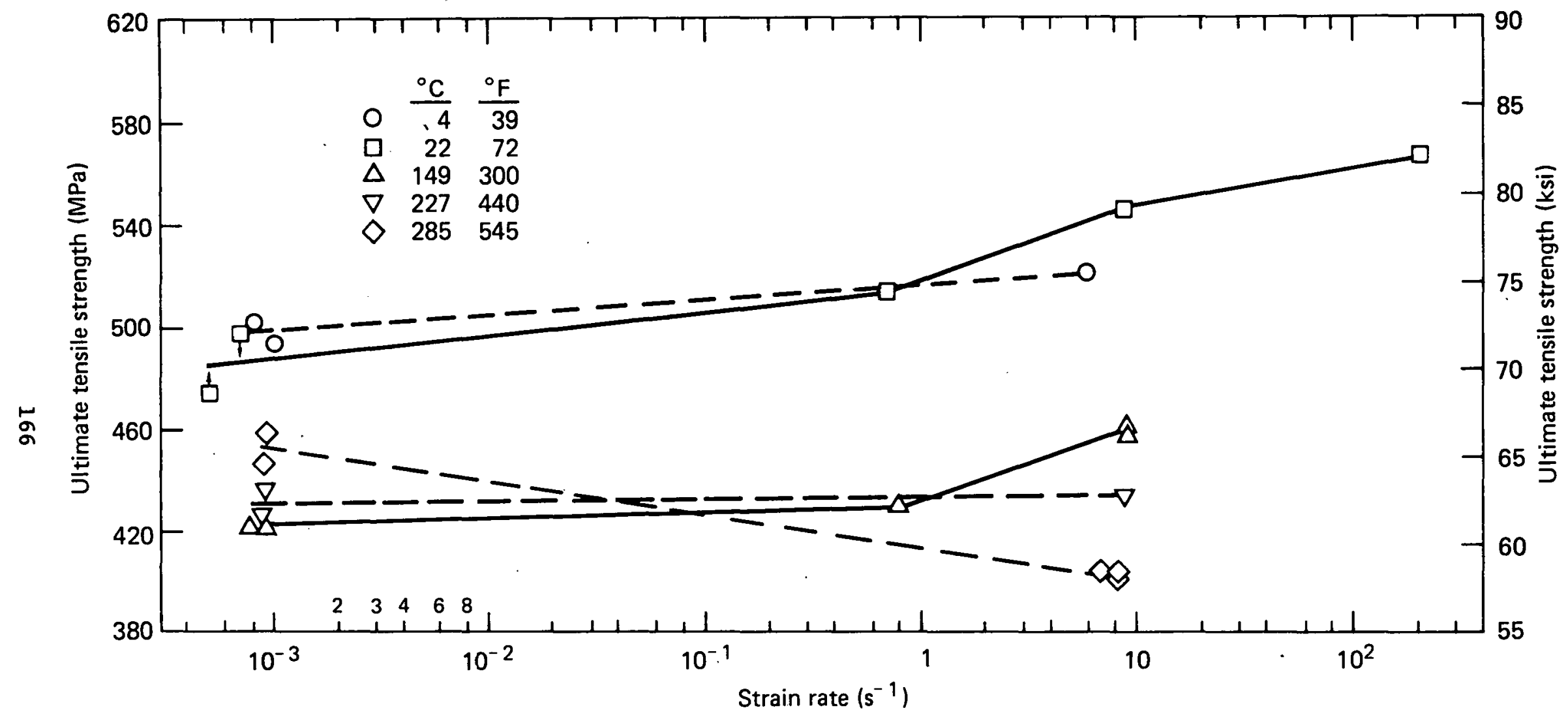

FIG. G.9. Effect of strain rate on tensile strength for D. C. Cook elbow material. The data show a general increase with strain rate at lower temperatures, then no change, and finally a decrease at
higher temperatures. 

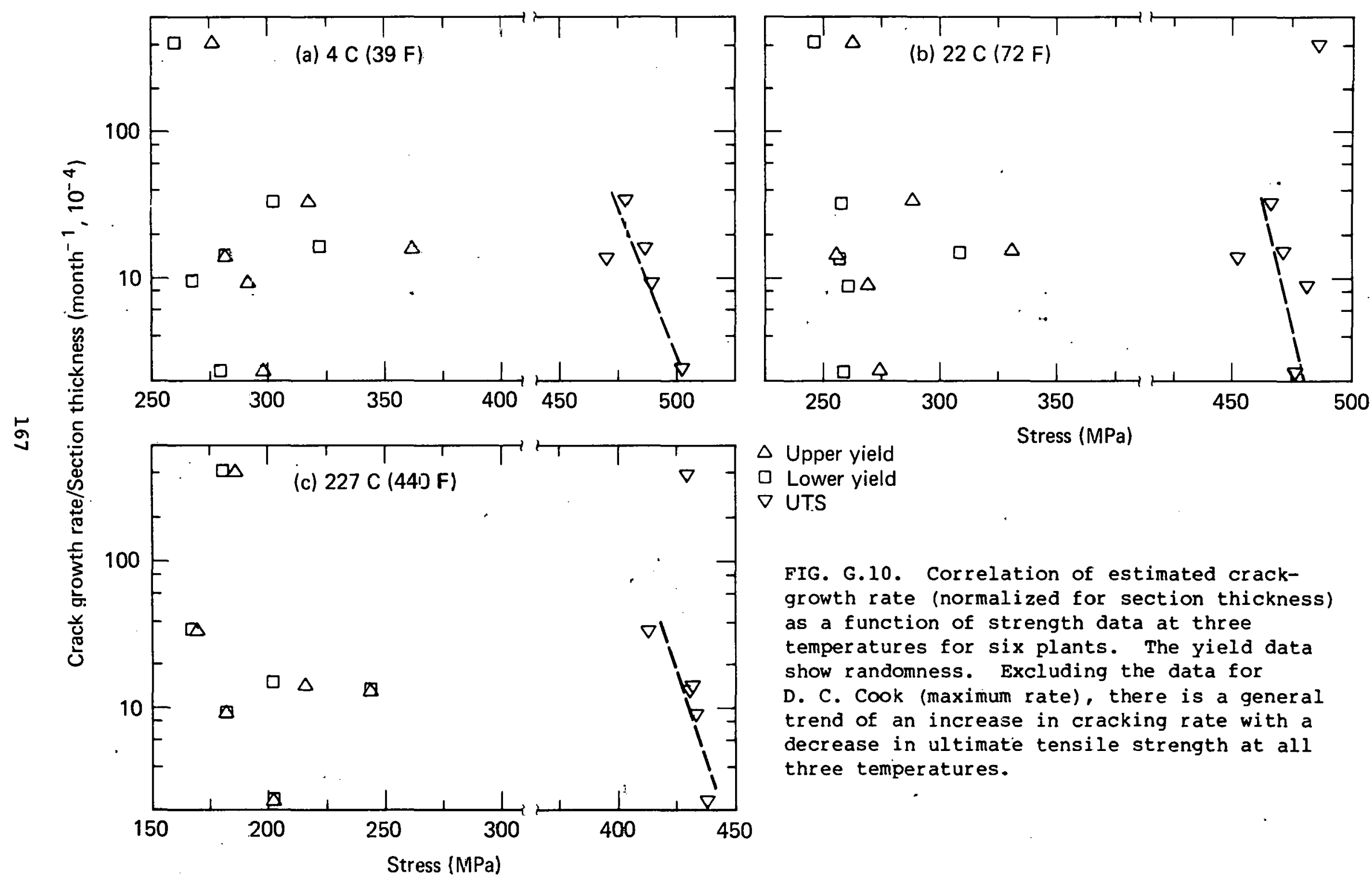

\section{$\Delta$ Upper yield \\ Lower yield \\ $\nabla$ UTS}

FIG. G.10. Correlation of estimated crackgrowth rate (normalized for section thickness) as a function of strength data at three temperatures for six plants. The yield data show randomness. Excluding the data for D. C. Cook (maximum rate), there is a general trend of an increase in cracking rate with a decrease in ultimate tensile strength at all three temperatures. 

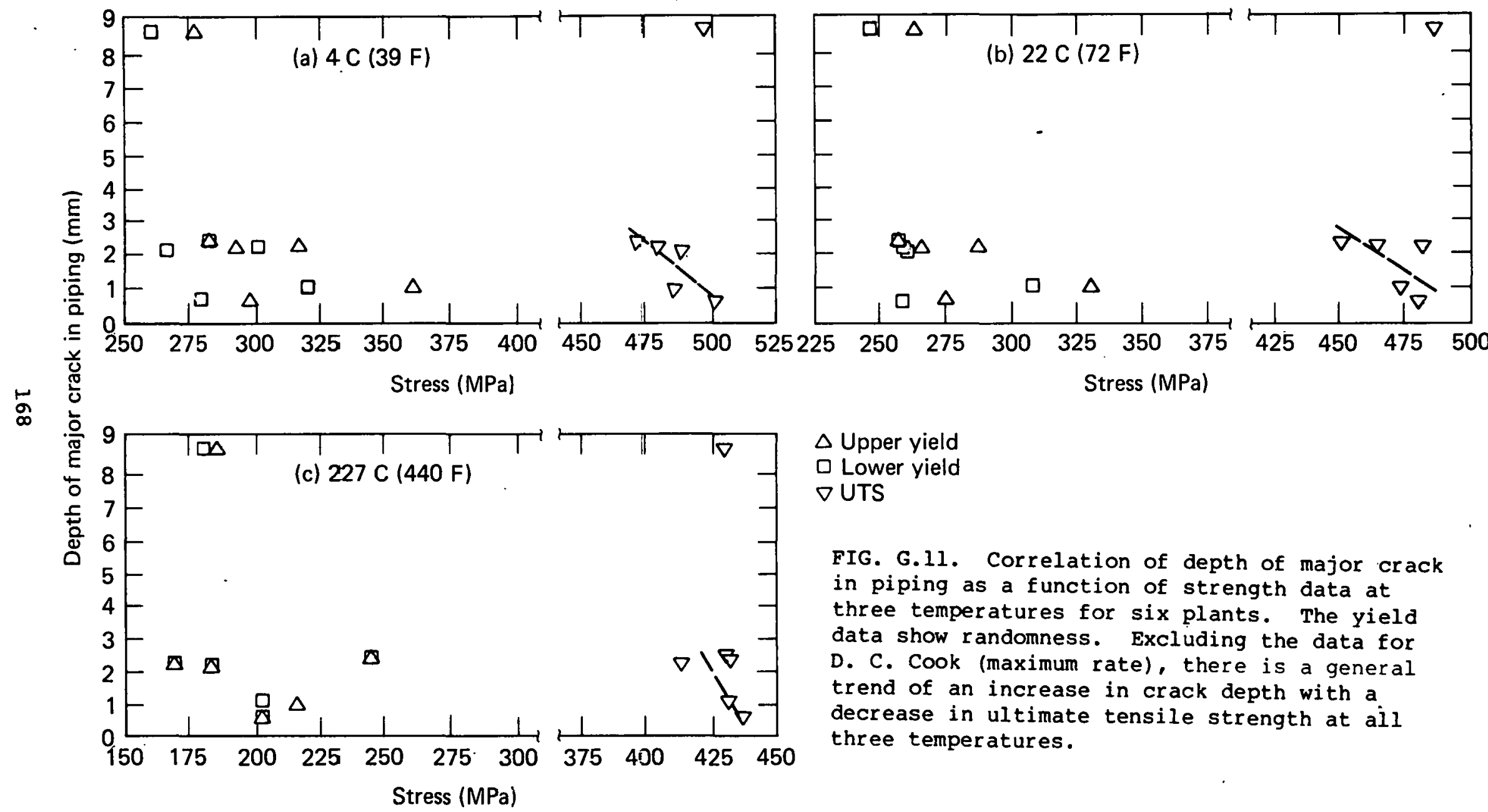

$\triangle$ Upper yield

$\square$ Lower yield

$\nabla$ UTS

FIG. G.11. Correlation of depth of major crack in piping as a function of strength data at three temperatures for six plants. The yield data show randomness. Excluding the data for D. C. Cook (maximum rate), there is a general trend of an increase in crack depth with a decrease in ultimate tensile strength at ail three temperatures. 


\section{APPENDIX H}

FRACTURE TOUGHNESS TESTING

\section{H.1 DETERMINATION OF THE ELASTIC-PLASTIC TOUGHNESS PARAMETER $\mathrm{J}_{\text {IC }}$}

A standard procedure for the determination of $J_{I c^{\prime}}$ a toughness parameter at the initiation of crack growth for metallic and certain nonmetallic materials, was recently approved by ASTM. This method involves using three-point bend or pin-loaded fatigue precracked specimens to determine $J$ as a function of crack growth. Specimens are loaded such that the fatigue crack is extended some small amount, $\Delta a_{p^{\prime}}$ while load versus load-point displacement is recorded autographically on an $\mathrm{X}-\mathrm{Y}$ recorder. The $\mathrm{J}$-integral value associated with a given increment of crack extension is then determined from this load-displacement curve and plotted versus the physical crack growth, $\Delta a_{p}$. At least four data points are required within the specified limits of crack growth for one complete test. A blunting line, which approximates the artificial crack advance due to crack-tip stretch, is then drawn. This estimate of crack tip blunting is calculated from material flow properties, using the average of yield and ultimate strengths. The intersection of the blunting line and the $R$ curve (determined by a least-squares line of the $J$ data points) then defines the initiation of actual crack growth, and, hence $\mathrm{J}_{\text {IC }}$ This procedure is demonstrated in Fig: H.1.

Extension of a fatigue crack from the initial machined notch $(a / w=0.4$ where $a=$ crack length and $w=$ specimen width) to an $a / w$ ratio of approximately 0.55 required about $10^{5}$ cycles. During the final stages of this growth, fatigue-rate data were recorded for comparison to the fatigue crack growth models reported in the literature. The maximum stress intensity was maintained at less than $22 \mathrm{MPa} \cdot \mathrm{m}^{1 / 2}(20 \mathrm{ksi} \cdot \mathrm{in} .1 / 2)$ during this final stage of crack extension. The observed growth rate of $0.038 \mu \mathrm{m} /$ cycle $\left(1.5 \times 10^{-6} \mathrm{in} . /\right.$ cycle $)$ at a stress intensity range of $19 \mathrm{MPa} \cdot \mathrm{m}^{1 / 2}(17 \mathrm{ksi} \cdot \mathrm{in} .1 / 2)$ corresponds to the Paris type fatigue model for ferritic-pearlitic steels*:

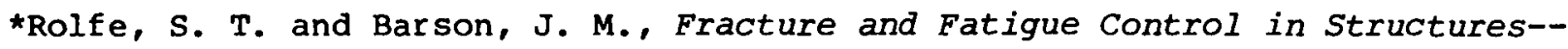
Applications of Fracture Mechanics, Prentice Hall, N.J., 1977, Chapter 8, pp. 232-267.
} 


$$
\mathrm{da} / \mathrm{dn} \simeq 3.6 \times 10^{-10}(\Delta \mathrm{K})^{3.0}
$$

where $\Delta \mathrm{K}$ is in (ksi.in. ${ }^{1 / 2}$ ) and $\mathrm{da} / \mathrm{dN}$ is calculated in (in./cycle).

The heat-tint method of crack growth marking was employed throughout the test program. These data were augmented by qualified compliance unloading crack measurement data obtained in the standard rate testing. Both cold- and high-temperature tests were $r$ un in an environmental chamber and temperature stability was achieved to \pm 1 deg $C$. A thermocouple was mounted on the back side of the fracture specimen to ensure that the specimen had stabilized. All tests employed servo-hydraulic test equipment set in stroke control.

\section{H. 2 HIGH-RATE FRACTURE TESTING}

For high-rate testing, the maximum ram travel was set prior to each run by adjusting the maximum stroke displacement. The test was started with the system in a "slack" state, thus giving the ram time to reach speed prior to loading the specimen. At the end of the predetermined stroke, the ram would hold its position thus enabling the system to become quiescent. A transient recorder monitored time, load, stroke, and loadline clip gauge displacement. A plot of stroke versus time confirmed that the ram velocity was relatively constant from zero to maximum load. The ram velocity was approximately $10 \mathrm{~cm} / \mathrm{s}$ (4 in./s) for all high rate tests. This rate corresponds to a loading rate of approximately $7 \times 10^{5} \mathrm{~N} / \mathrm{cm} / \mathrm{s}\left(4 \times 10^{5} \mathrm{lb} / \mathrm{in} . / \mathrm{s}\right)$. It was observed that the clip gauge was unable to "keep up" with the specimen load-line opening at this rate but did stabilize shortly after the ram stopped. Thus, to obtain the load versus load-line displacement curve, the stroke displacement was used after being "adjusted" to the maximum load-line displacement value. This procedure was verified at the slow strain rate where both stroke and load-line displacement are accurately known. A sample high-rate test record is shown in Fig. H. 2 .

\section{H. 3 TEARING RESISTANCE}

In addition to the fracture toughness, $\mathrm{J}_{I c^{\prime}}$, we also evaluated the tearing slope, dJ/da, and tearing modulus, T. Valid data, used to define the $\mathrm{J}$-resistance curve, were fitted to a linear relation using the method of least 
squares. The resulting slope, in turn, defined dJ/da. This value is important in that it provides a relative measure of a materials resistance to crack extension once crack initiation occurs. It can also be used to evaluate if crack growth will be stable or unstable providing that the "applied" tearing can be estimated.*

\section{H. 4 FRACTURE SPECIMENS}

Compact tension specimens, machined from feedwater pipe sections, were used for fracture-toughness testing. Since all the observed cracking was in the circumferential direction, the L-C orientation was used for all specimens. The minimum wall thickness of the various piping sections determined the maximum specimen thickness. The specimen configuration is shown in Fig. H. 3 . To compare the fracture behavior of the five plants (from which adequate material was available) using specimens of the same size, a thickness of $2.0 \mathrm{~cm}(0.79 \mathrm{in.})$ was chosen. This size requirement imposes a limitation on the extent of "valid" stable crack growth as set in the proposed J Ic test method. ${ }^{\dagger}$ Although this limitation prevents us from developing a "complete" J-resistance curve for large crack extension, the fracture toughness, J Ic' and initial tearing slope, T, can be well established.

\section{H. 5 FRACTURE-TOUGHNESS RESULTS}

The data from the various fracture tests are plotted in Figs. H. 4 to H.12. The results were also tabulated in Tables 5.1 and 5.2 and summarized in the main report. A few further comments on these results and their significance are preaentcd herc.

The average fracture toughness, $\mathrm{J}_{\mathrm{Ic}}$ is $254 \mathrm{~kJ} / \mathrm{m}^{2}$ (1450 in.-lb/in. ${ }^{2}$ ) with maximum deviations from the average value of +15 and -9 percent. The

*Paris, P.C., Tada, H., Zahoor, A., and Ernst, H., "The Theory of Instability of the Tearing Mode of Elastic-Plastic Crack Growth," ASTM STP 668, Landes, Begley and Clark, Eds., ASTM, 1979, pp. 5-36.

tClaṛke, G. A., et al., "A Procedure for the Determination of Ductile Fracture Toughness Values Using $J$ Integral Techniques," Journal of Testing and Evaludtion, JTEVA, Vol. 7, No. 1, January 1979, pp. 49-56. 
corresponding average $\mathrm{K}_{\mathrm{J}}$ value is $229 \mathrm{MPa} \cdot \mathrm{m}^{1 / 2}\left(209 \mathrm{ksi} \cdot \mathrm{in}^{1 / 2}\right)$. The tearing modulus value of 113 for Ginna is quite low compared to the corresponding values of (260 to 334 ) obtained for the remaining plants. As pointed out earlier, the Ginna material generally exhibited the lowest ductility. However, H. B. Robinson has the same ductility as Ginna at room. temperature, and it exhibited the highest tearing modulus in the group. (Refer to Tables 5.1 and 5.2.) The results for the Ginna material are considered questionable as there were insufficient points for a truly valid J-resistance test.

The study of temperature and loading-rate effects on $J_{I C}$ and tearing was conducted using D. C. Cook material (Fig. G.1). Tests were run at three temperatures $\left(3,22\right.$, and $218 c_{i} 37,72$, and $425 \mathrm{~F}$ ) and two strain rates (standard rate, $t_{p} \sim 60 \mathrm{~s}$; high rate, $t_{p} \sim 6 \times 10^{-3} \mathrm{~s}$ ).* The results of these tests were summarized in Table 5.2. The decrease obtained on reducing the test temperature from 22 to $3 \mathrm{C}(72$ to $37 \mathrm{~F})$ is probably the result of entering the ductile-to-brittle transition temperature region. Westinghouse reported ${ }^{\dagger}$ a 50 percent Charpy impact transition temperature at about $2 \mathrm{C}$ (36 F) with the drop in impact values starting at about $65 \mathrm{C}$ (149 F). An initial drop in the Ginna material Charpy energy started at about $22 \mathrm{C}$ $(72 \mathrm{~F}) .^{+}$It is likely that the variation in the decrease in fracture toughness values between 22 and $3 \mathrm{C}$ for the different plants are related to corresponding differences in the transition temperature.

For the temperature increase from 22 to $218 \mathrm{C}(72$ to $425 \mathrm{~F}$ ) the drop-off in $J_{I C^{\prime}}$ for the D. C. Cook material, from a value of 268 to $118 \mathrm{~kJ} / \mathrm{m}^{2}$ ( 1530 to 674 in.-lb/in. ${ }^{2}$ ) is attributed to the change in the Al06 steel flow properties. As the temperature increases within the range of 22 to $227 \mathrm{C} 172$ to $440 \mathrm{~F})$, the extent of discontinuous yielding decreases. No upper yield point is observed at $227 \mathrm{C}$ (which is close in temperature to the $218 \mathrm{C}$ fracture toughness test). We suggest that the variations in initial yield behavior and changes in subsequent work hardening modifies the characteristics of the J-field. This may be responsible for the drop in $\mathrm{J}_{\mathrm{IC}}{ }^{\circ}$

${ }^{*} t_{p}=$ time taken to reach the first deviation from the linear portion of the load-deflection test record. Tests performed at values of $t_{p}$ less than $0.1 \mathrm{~min}$. are considered dynamic $\mathrm{J}_{\mathrm{Ic}^{*}}$ (Reference: ASTM method for determination of $\mathrm{J}_{\mathrm{IC}}$ ' to be published:)

'Westinghouse Users' Group--NRC Meetings at Bethesda, MD, 1979-1980. 
The high-rate tests exhibited a drop in $\mathrm{J}_{\text {Ic }}$ when compared to the standard rate testing at similar temperatures (Table 5.2). The tensile behavior exhibited a much larger yield drop at the higher loading rate; but the range of strain over which yielding occurs with little load change is much greater for the standard loading rate curve. If the region of initial yielding is a major contributor to the initial resistance to cracking, then the effects of loading rate and temperature are consistent.

As we mentioned earlier, a minimum of only four data points are required to establish a "valid" J curve. We have observed cases, however, in which the addition of one or two additional data points have changed the $J_{\text {Ic }}$ value significantly. For the case in which the $\mathrm{J}_{\mathrm{IC}}$ value is reduced, there is generally a corresponding increase in the tearing slope, dJ/da. And similarly, if $J_{I c}$ is increased, dJ/da will drop. While such changes in $J_{I c}$ and $d J / d a$ may be large, the additional data generally do not change the overall "character" of the resistance curve; i.e., the curves are of ten within the experimental scatter band of each other. Further, when comparing materials on the basis of $\mathrm{J}_{\mathrm{Ic}}$ (or its associated $\mathrm{K}_{I C^{\prime}}$ ) alone, we may be led to a false (or incomplete) conclusion. This discrepancy can be observed by comparing the room temperature standard rate and high-rate results of the D. C. Cook feedwater material (Fig. H.8). Although the standard rate $J_{\text {IC }}$ value is 10 times that of the high rate $J_{I c}$ value, the steep tearing slope at the high rate results in higher $\mathrm{J}$ values or crack extensions greater than $0.75 \mathrm{~mm}$ $\left(0.03\right.$ in.). The combination of $J_{I c}$ with $d J / d a$ gives a more accurate representation of the true crack initiation behavior.

\section{H. 6 CORRETATION ATTEMPTS WITH MICROSTRUCTURE}

We attempted to determine whether any significant correlations exist between fracture toughness and crack length or crack-growth rate; no definitive trends could be obtained. The plots are not included in the report. Correlations with tensile properties are discussed in Appendix G. We also attempted to correlate fracture toughness as well as tensile properties with the microstructural characteristics of the various piping materials (Table 4.1), and no general trends were observed. For example, Beaver Valley, which exhibited the highest yield and $J_{\text {Ic }}$ values at room-temperature standard rate, had the finest grain size; the microstructure was spheroidized 
with equiaxed ferrite and it was strongly banded. The corresponding values for Salem are.correspondingly on the low side (except for elongations) and the microstructure for these two plants were very similar. The microstructures are laminar for the plants having the lowest and highest values in UTS; again there is no trend with respect to either grain size or banding (Fig. G.5 and Table 4.1). Beaver Valley had the cleanest steel with respect to inclusions and shows the highest elongation ( 43 percent); by contrast, the Salem steel which probably showed the dirtiest structure of all the plants also showed a high value ( 39 percent); both showed about the same tearing modulus. A number of other examples showing similar contradictions can be pointed out with reference to microstructure and the various mechanical properties. 


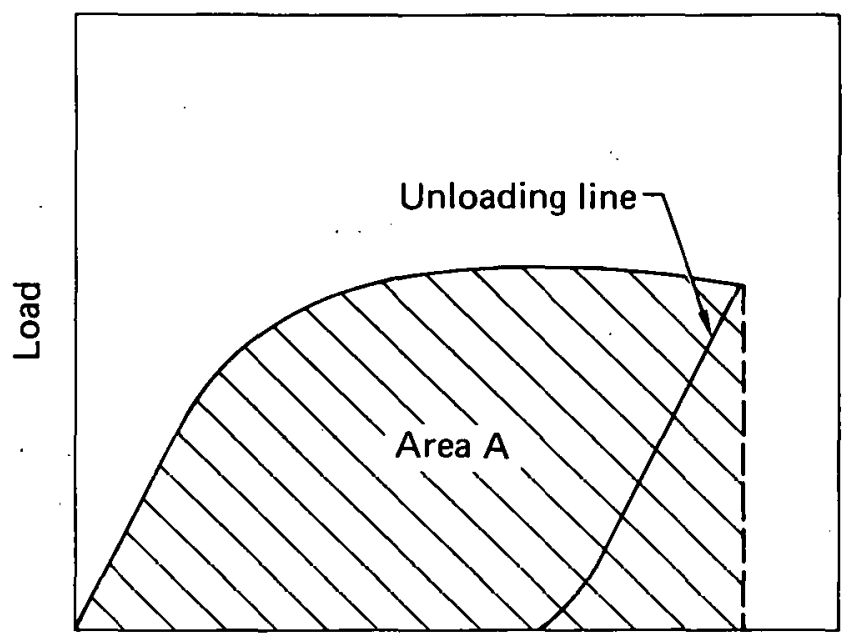

Load-point displacement

$$
\mathrm{J}=\frac{\mathrm{A}}{\mathrm{Bb}} \mathrm{f}(\mathrm{a} / \mathrm{w})
$$

where: $A=$ Area $A$

$B=$ Specimen thickness

b $=$ Remaining ligament

$a=$ Crack length

$w=$ Specimen width

$f(a / w)=$ Tensile correction factor

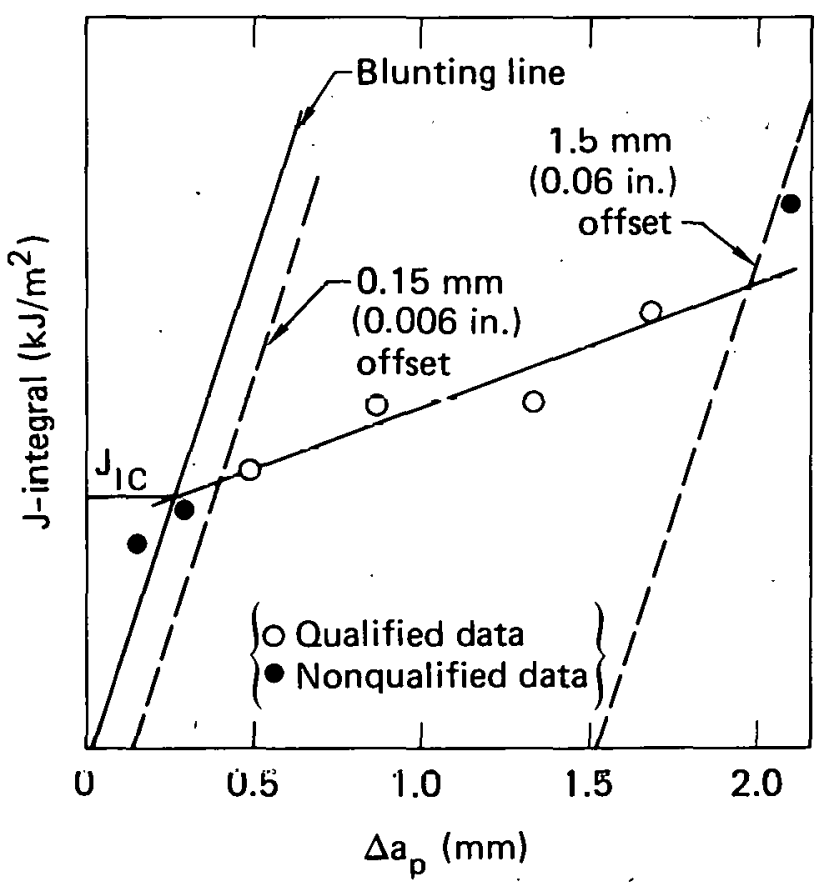

FIG. II.1. Development of $J-\Delta a$ ourve for the determination of $J_{I C}$ : 


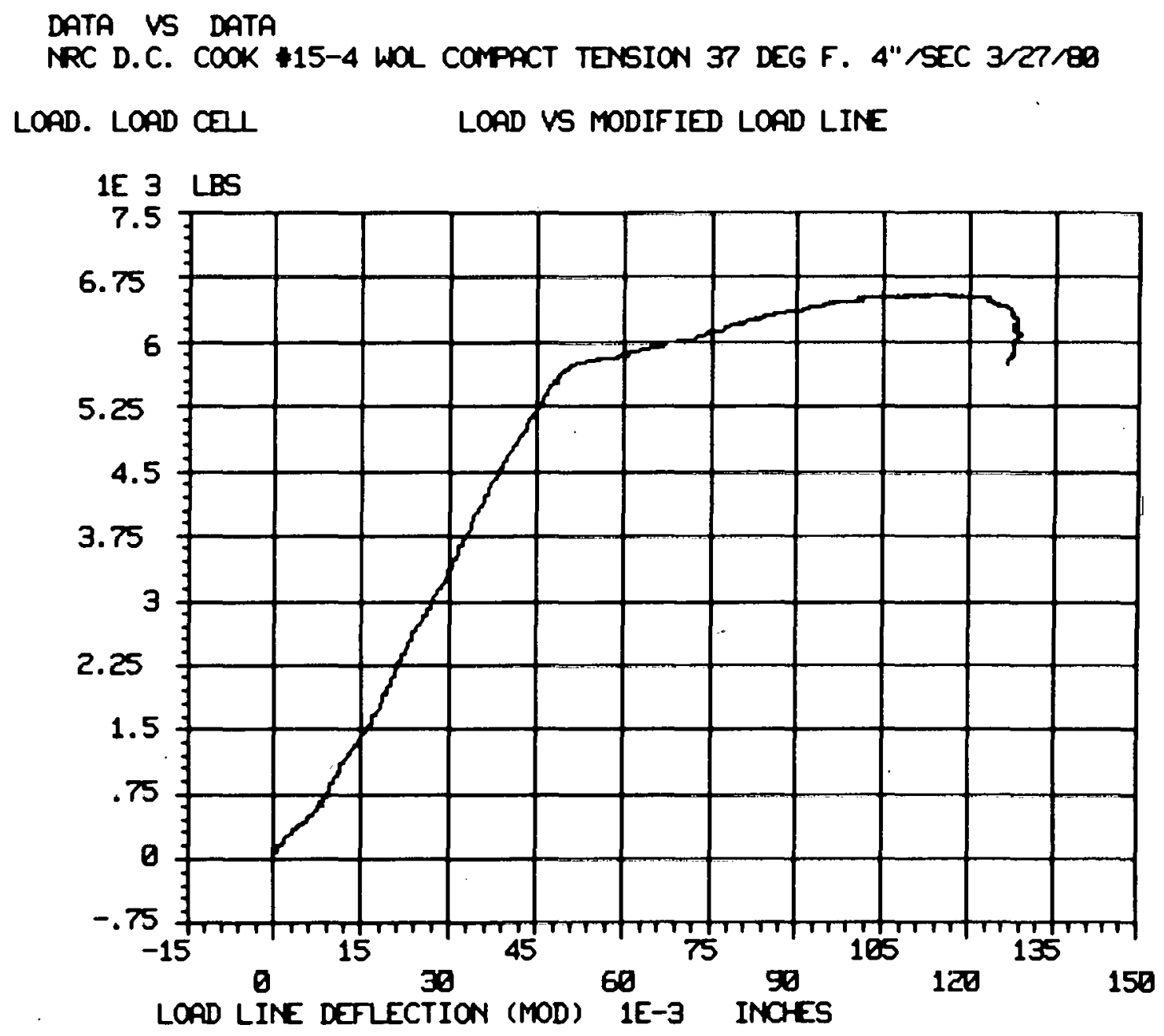

FIG. H.2. Example of high load-rate test showing the load-displacement record. 


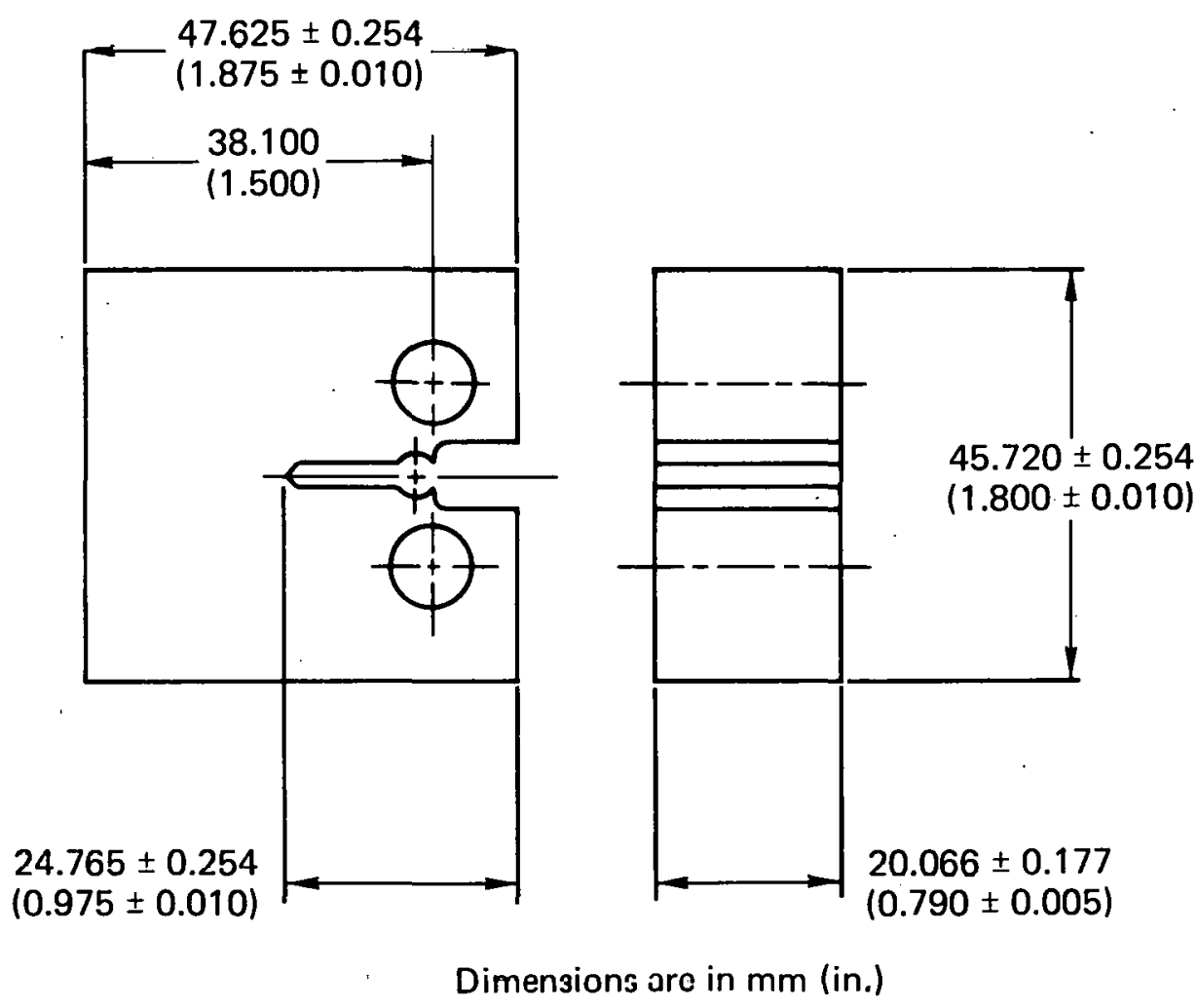

FIG. H.3. Fracture-toughness compact-tension specimen. 


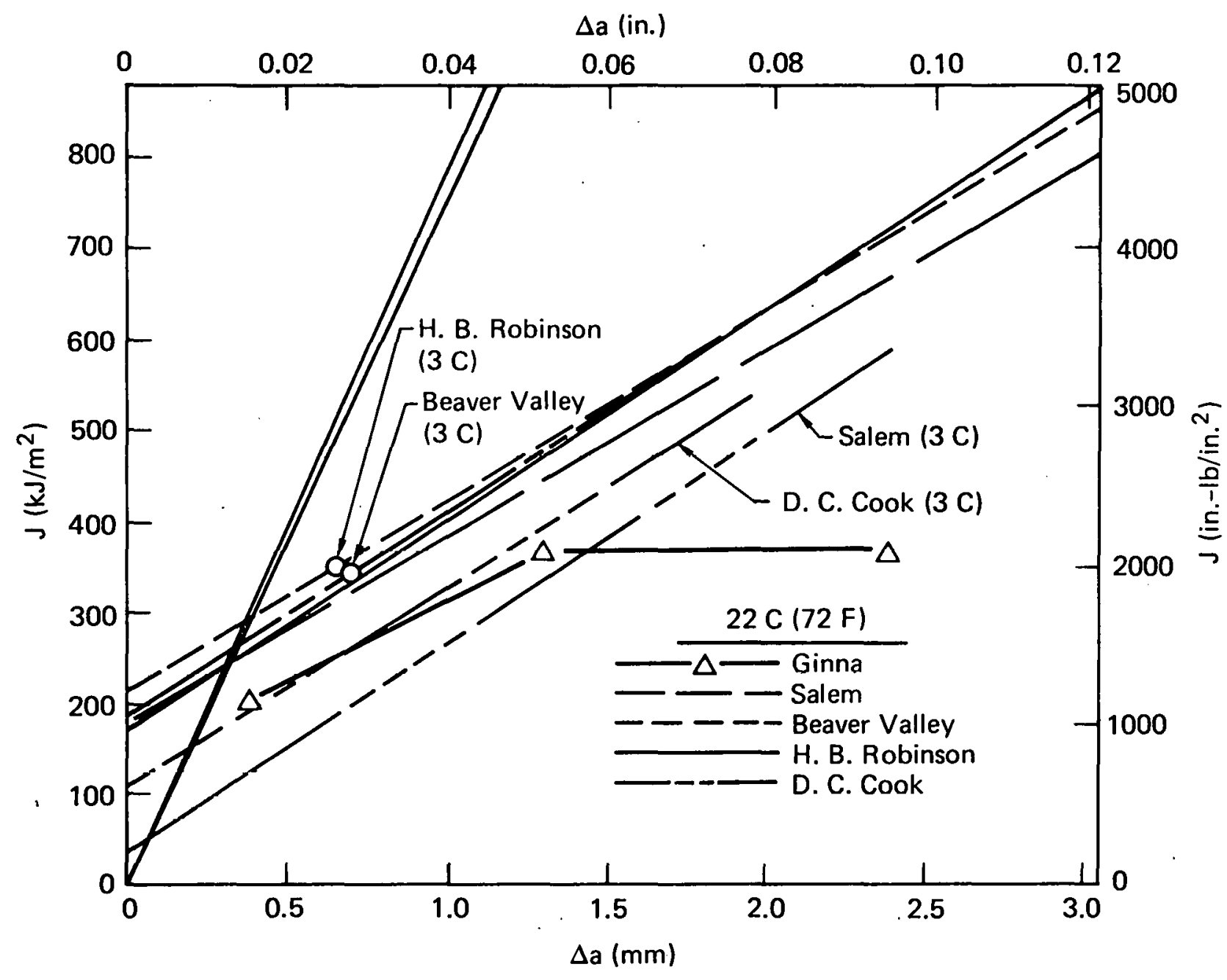

FIG. H.4. J versus $\Delta a$ ( 1 inear regression line) for A-106 feedwater piping from five reactor plants. The unlabeled data were obtained at $22 \mathrm{C}(72 \mathrm{~F})$ and at the standard load rate. Also included, where noted, are data at $3 \mathrm{C}$ ( $37 \mathrm{~F}$ ). 


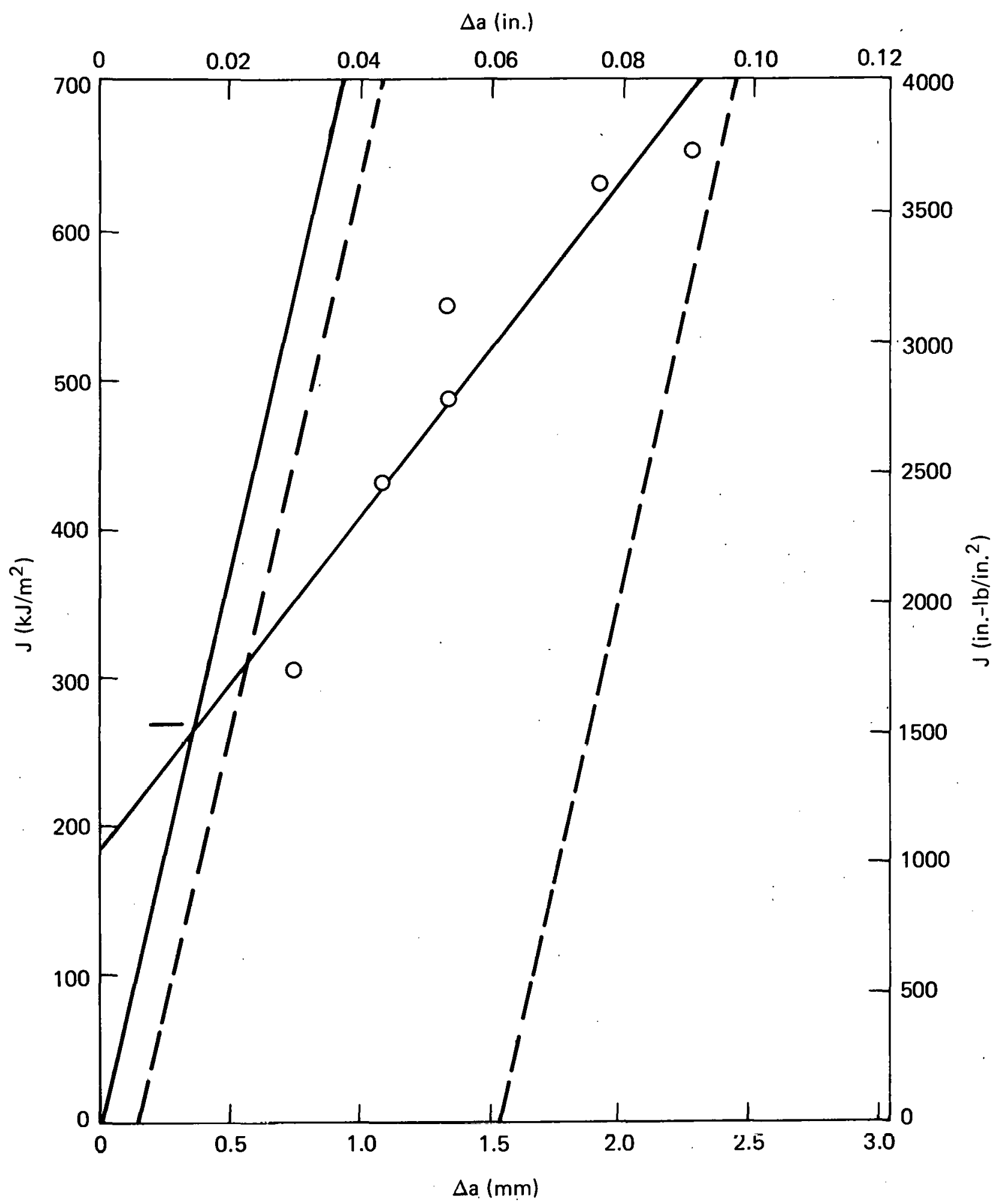

FIG. H.5. J-resistance curve for D. C. Cook feedwater piping at 22 C (72 F) and standard load rate. $J_{1 C}=268 \mathrm{~kJ} / \mathrm{m}^{2}\left(1530 \mathrm{in},-1 \mathrm{~b} / \mathrm{in} .{ }^{2}\right), T=326$. 


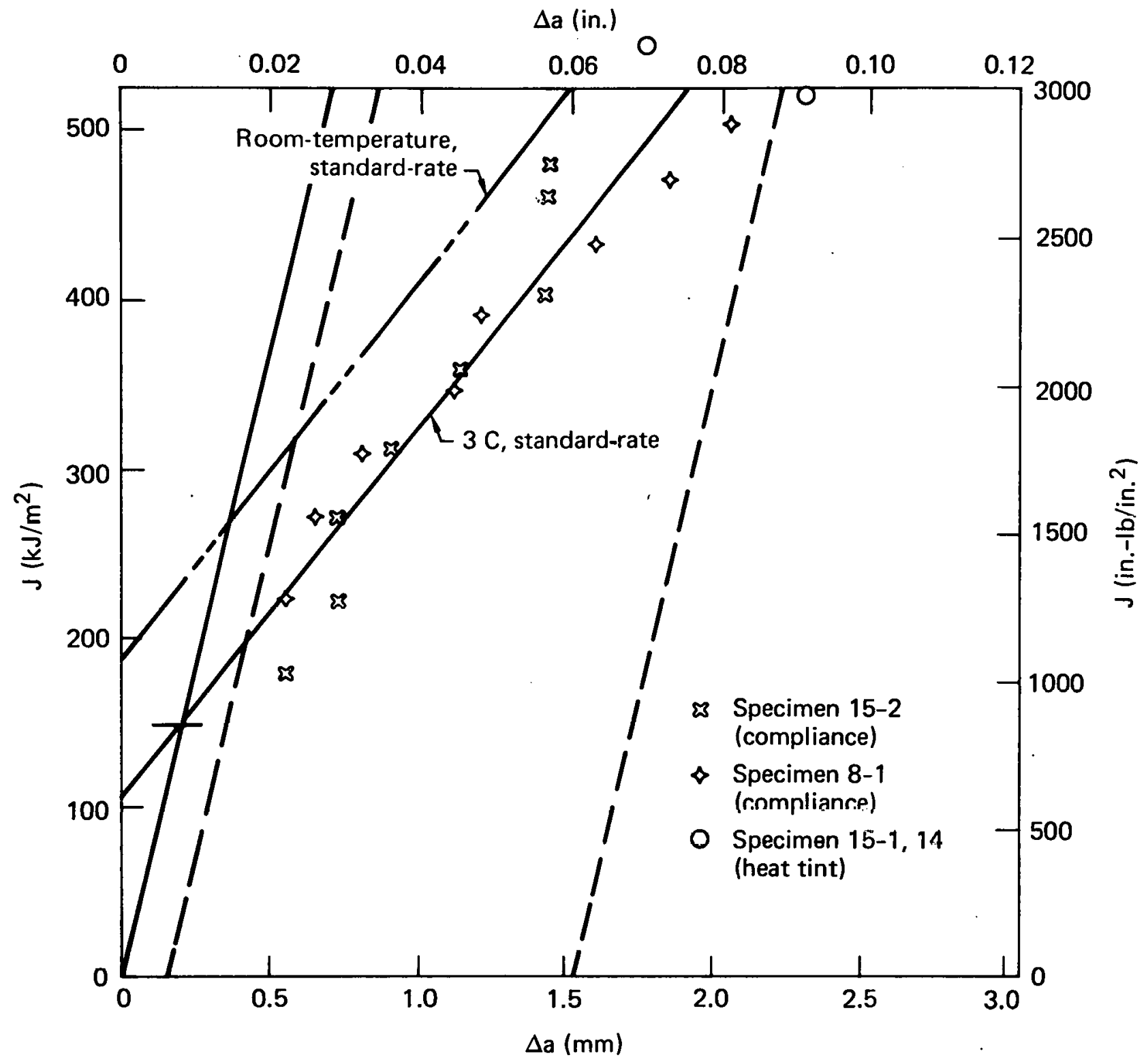

FIG. H.6. J-resistance curve for D. C. Cook feedwater piping at 3 C (37 F) and standard load rate. $J_{I_{c}}=149 \mathrm{~kJ} / \mathrm{m}^{2}\left(851 \mathrm{in.}-1 \mathrm{~b} / \mathrm{in.}{ }^{2}\right), T=303$. (The room-temperature, standard load-rate curve is shown for comparison.) 


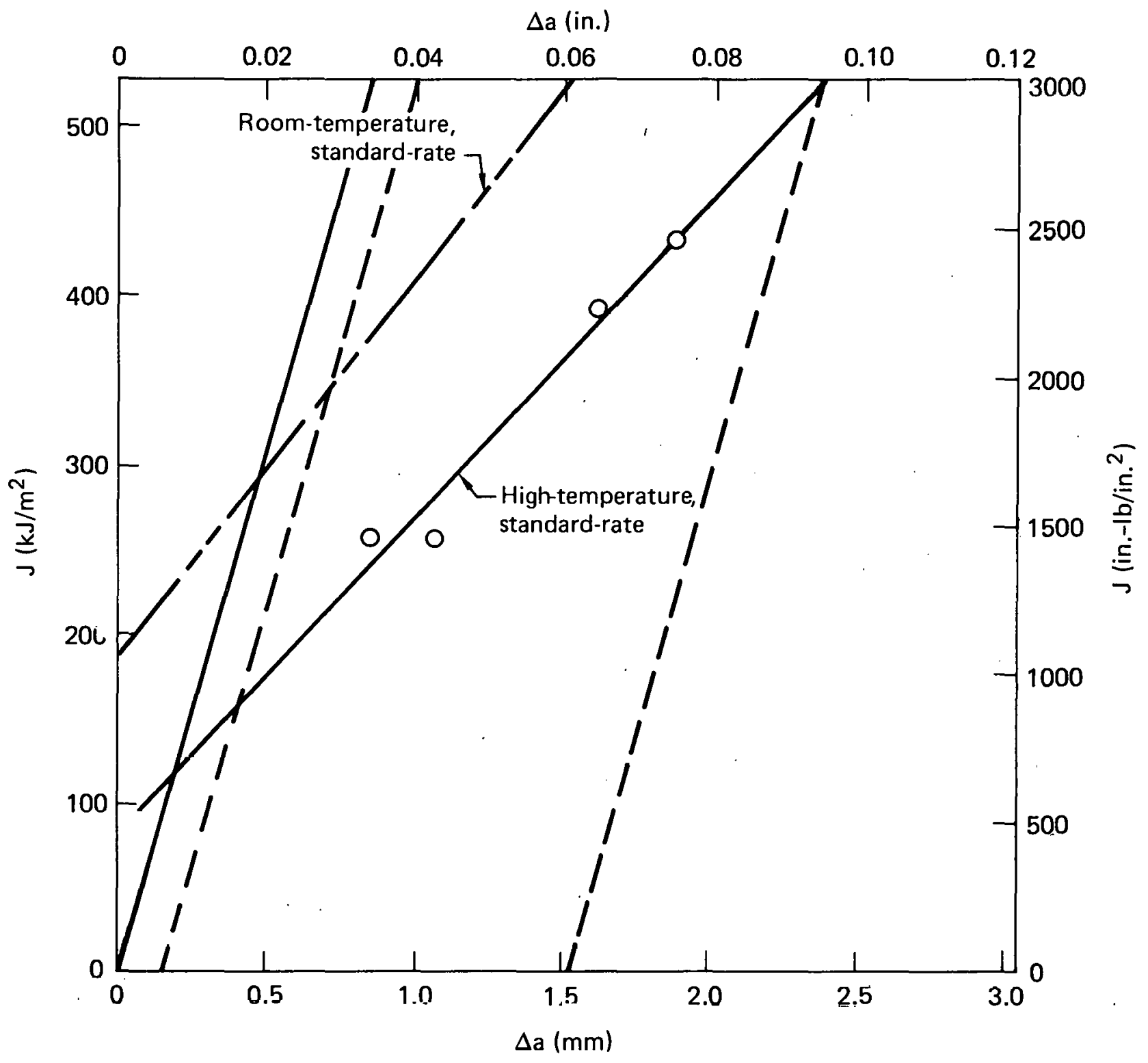

FIG. H.7. J-resistance curve for D. C: Cook feedwater piping at 218 C (425 F) and standard load rate. $J_{I c}=118 \mathrm{~kJ} / \mathrm{m}^{2}\left(674 \mathrm{in.}-1 \mathrm{~b} / \mathrm{in} .{ }^{2}\right), T=385$.

(The room-temperature, standard load-rate curve is shown for comparison.) 


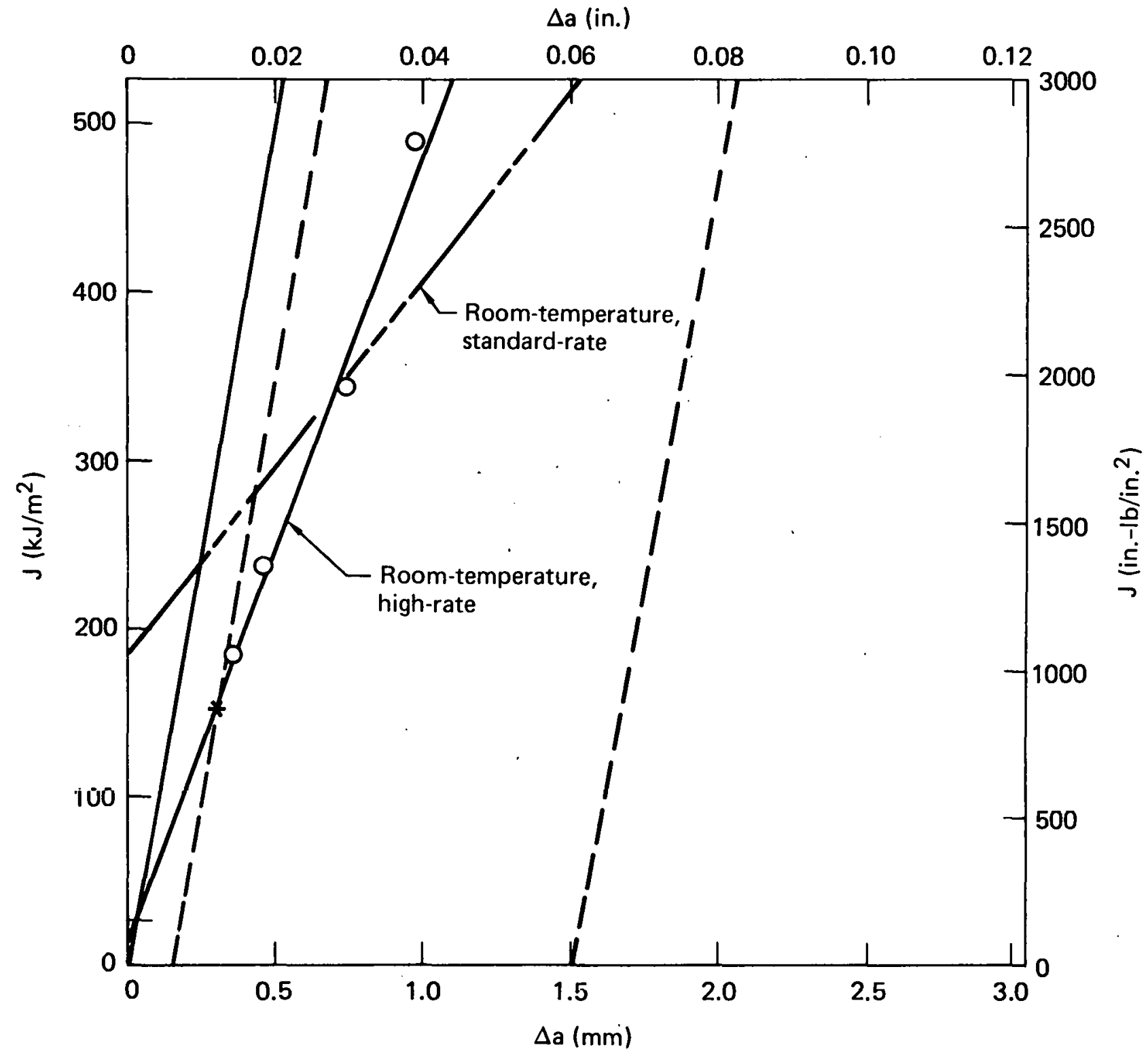

FIG. H.8. J-resistance curve for D. C. Cook feedwater piping at 22 C (72 F) and high load rate. $J_{I c}=27 \mathrm{~kJ} / \mathrm{m}^{2}\left(154 \mathrm{in.}-\mathrm{lb} / \mathrm{in.}{ }^{2}\right), \mathrm{T}=406$. (The room temperature, standard load-rate curve is shown for comparison.) 


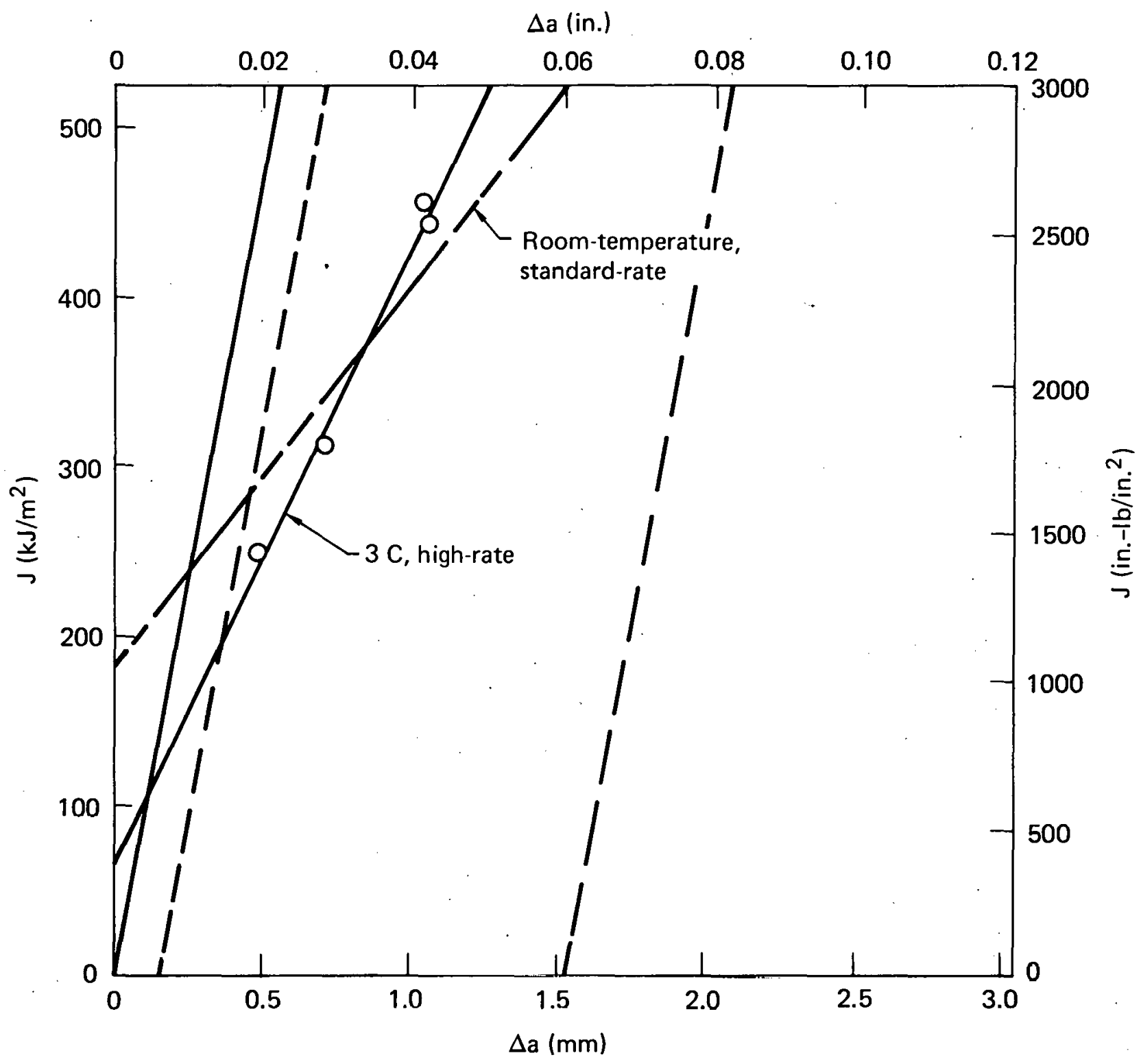

FIG. H.9. J-resistance curve for D. C. Cook feedwater piping at $3 \mathrm{C}$ (37 F) and high load rate. $J_{I_{C}}=111 \mathrm{~kJ} / \mathrm{m}^{2}\left(634 \mathrm{in.}-1 \mathrm{~b} / \mathrm{in.}{ }^{2}\right), \mathbf{T}=323$. (The room-temperature, standard load-rate curve is shown for comparison.) 


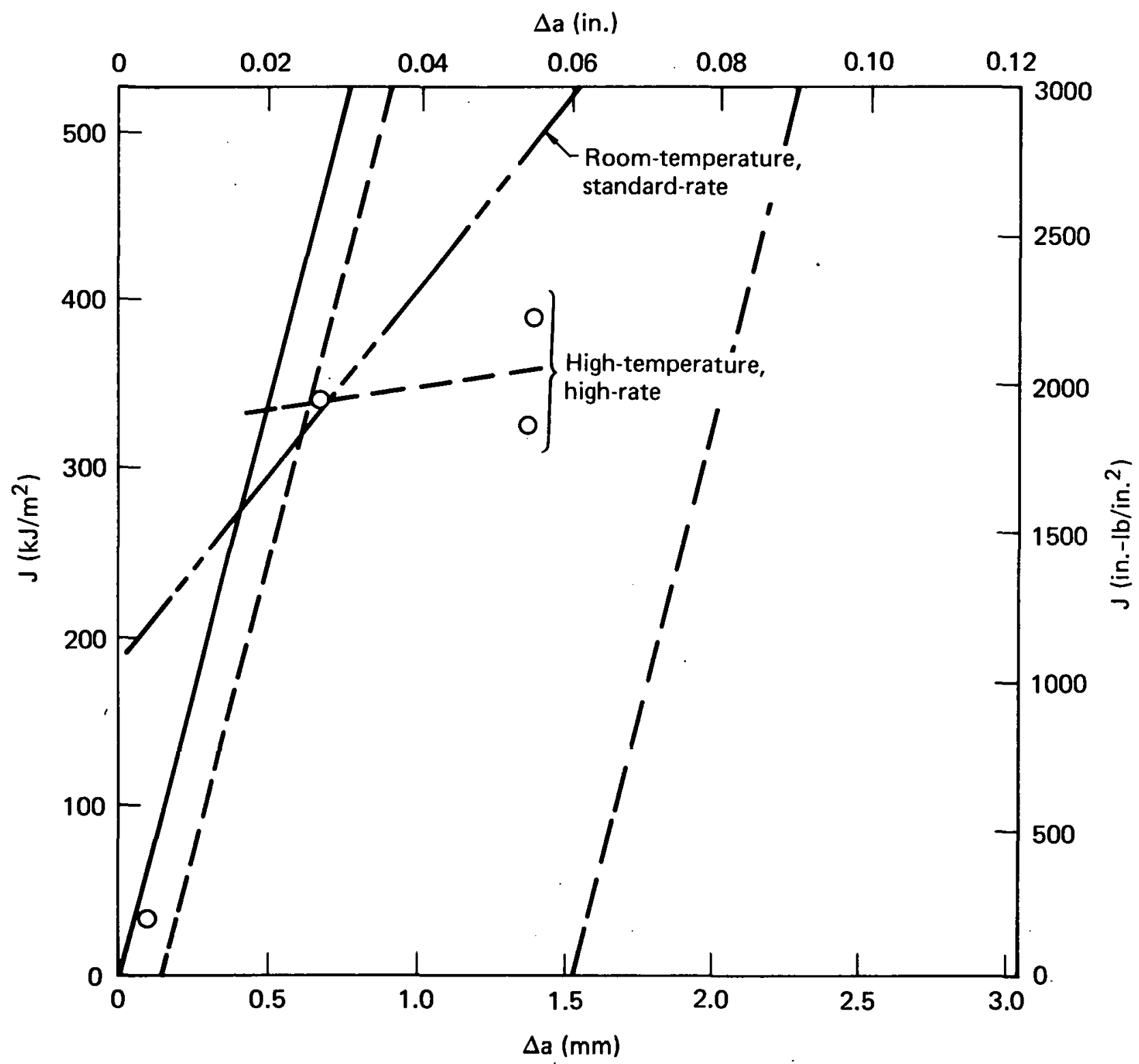

FIG. H.10. Data obtained for high-temperature, $218 \mathrm{C}(425 \mathrm{~F})$, high load-rate J-resistance curve of D. C. Cook feedwater material. (The room-temperature, standard-rate curve is.shown for comparison.) 


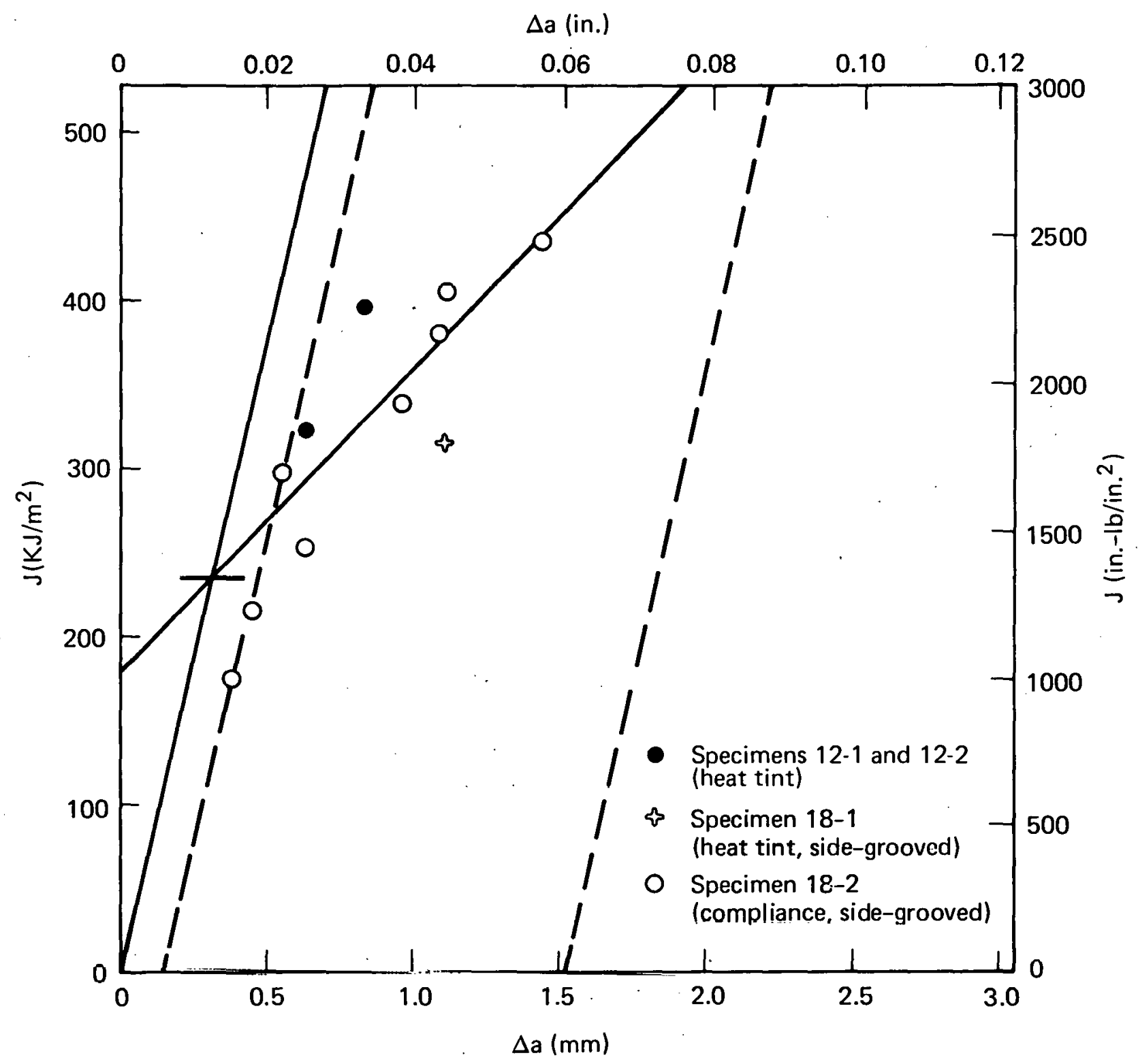

FIG. H.11. J-resistance curve for Salem feedwater piping at $22 \mathrm{C}$ (72 F) and standard load rate, $J_{I_{C}}=234 \mathrm{~kJ} / \mathrm{m}^{2}\left(1335 \mathrm{in} .-1 \mathrm{~b} / \mathrm{in}^{2}\right), T=265$. 


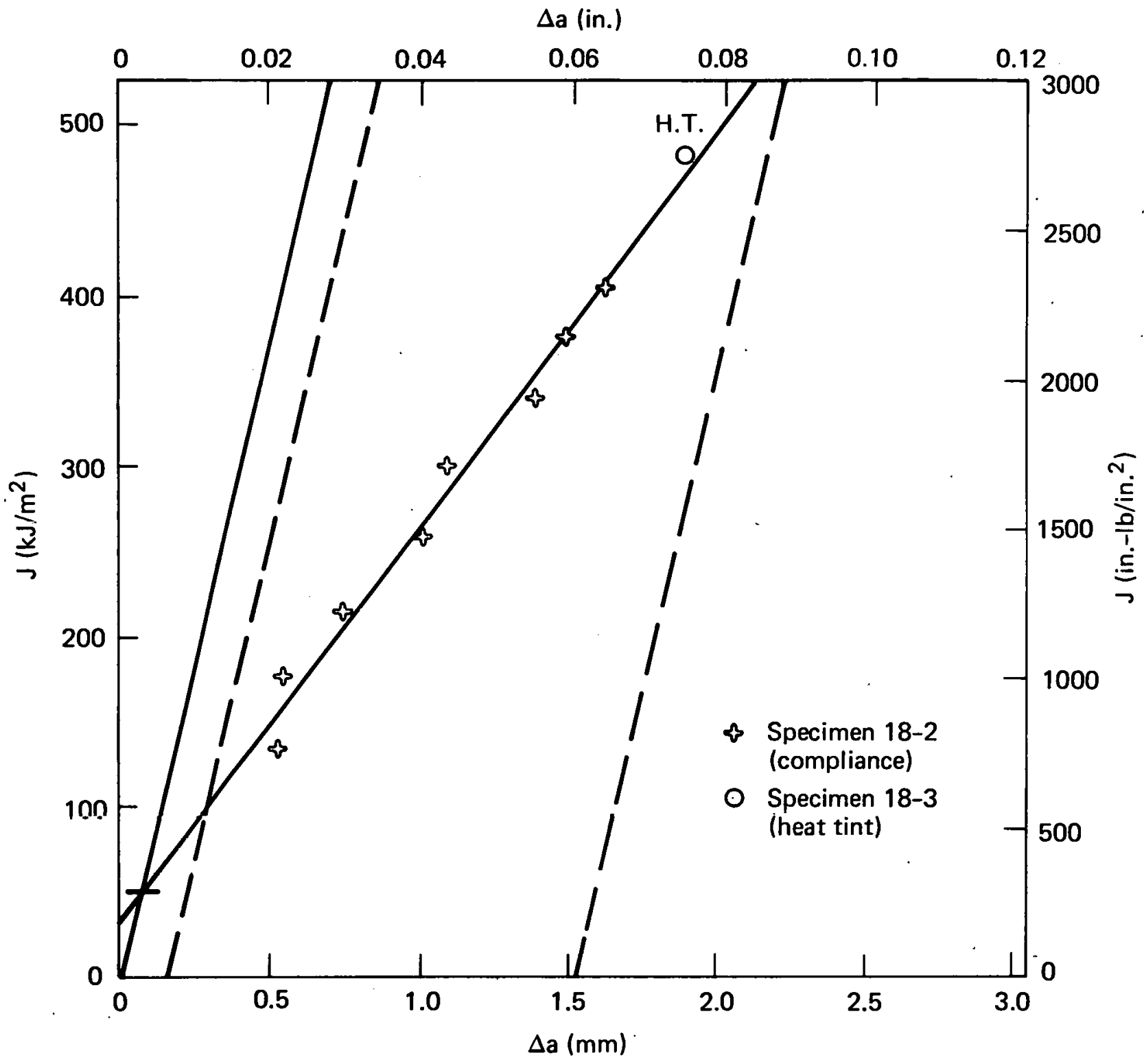

FIG. H.12. J-resistance curve for Salem feedwater piping at $3 \mathrm{C}(37 \mathrm{~F})$ and standard load rate. $J_{I c}=51 \mathrm{~kJ} / \mathrm{m}^{2}\left(291 \mathrm{in},-1 \mathrm{~b} / \mathrm{in} .{ }^{2}\right), T=344$. 


\section{APPENDIX I \\ APPLICATION OF J-INTEGRAL AND TEARING CONCEPTS}

The J-integral, defined by Rice, * can be used to describe the stress or strain singularity at the tip of a crack. It is particularly useful in the elastic-plastic regime since linear elastic concepts are not applicable. As such, J-integral concepts were employed in the evaluation of the material fracture toughness, $\mathrm{J}_{\mathrm{Ic}} \mathrm{c}$ and tearing modulus $\mathrm{T}$. The J-integral can also be used to analyze a structure for safety against initiation and tearing stability of a real or postulated crack. While such an analysis would generally require a detailed elastic-plastic computer evaluation, some approximate limiting cases can be handled. analytically.

For the purpose of this analysis, it is useful to use an energy interpretation of $\mathrm{J}: \mathrm{J}$ is the difference in potential energy dU between two identically loaded bodies having infinitesimally differing crack areas, dA; i.e.,

$$
J=-(d U / d A)
$$

Further, the tearing resistance of a material and the "applied tearing" have been defined by Paris ${ }^{\dagger}$ as

$$
\mathbf{T}_{\text {Matl }}=\frac{\mathbf{E}}{\sigma_{0}^{2}} \cdot \frac{\mathrm{dJ}_{\text {Matl }}}{\mathrm{da}}
$$

and

$$
\cdot \mathbf{T}_{\text {Appl }}=\frac{E}{\sigma_{0}^{2}} \cdot \frac{d J_{\text {Appl }}}{d a}
$$

where $\mathrm{a}=$ crack length

$$
\sigma_{0}=\text { average flow stress }\left(\sigma_{\mathrm{y}}+\sigma_{\mathrm{u}}\right) / 2 \text {. }
$$

*Rice, J. R., "A Path Independent Integral and the Approximate Analysis of Strain Concentration by Notches and Cracks," ASME, J. Appl. Mech., Vol. 35, 1968 , pp. 379-386.

† Paris, P. C, Tada, H., Zahoor, A., and Ernst, H., "The Theory of Instability of the Tearing Mode of Elastic-Plastic Crack Growth," A.STM STP 668, Landes, Begley and Clark, Eds., 1979, pp. 5-36. 
The condition for crack initiation is $J \overline{>} J_{I c}$ whereas, the criterion for unstable crack propagation is given by $\mathbf{T}_{\text {Appl }}>\mathrm{T}_{\text {Matl }}$. Using these concepts, Tada, Paris, and Gamble* have developed a methodology to access the applied $J$ and tearing of a pipe section subjected to its plastic limit moment. ${ }^{\dagger}$ Small axial forces are accounted for by changing the location of the neutral axis and the limit moment. For the Millstone-2, steam generator-1, feedwater pipe inlet the maximum design moment is about $3.0 \times 10^{5} \mathrm{~N}-\mathrm{m}$ $\left(2.2 \times 10^{5} \mathrm{ft}-\mathrm{lb}\right), * \star$ which is approximately one half the plastic limit moment. For a through-wall crack growing in a circumferential direction in a fully yielded section, $J$ is calculated by*

$$
\mathrm{J}=\sigma_{\mathrm{O}} \mathrm{RF}_{\mathrm{J}} \varnothing
$$

where $R$ = average pipe radius,

$F_{J}=$ numerical factor including effects of crack geometry and applied load, and

$\varnothing=$ angle of rotation of the pipe length due to the applied moment.

If we consider a $15-\mathrm{cm}$ (5.9-in.) through-wall crack (approximately 40 degrees around the circumference of the pipe) in the ASTM Al06-B 18-in. schedule-60 feedwater pipe and make some assumption regarding the applied angle of rotation, $J$ can be estimated. For the limiting case in which the angle of rotation at the crack is assumed to be due to a constant moment acting on the full length of pipe between the steam generator and containment wall, then:

$$
J=\sigma_{0} R F_{J} \cdot(M L / E I)
$$

where $L$ is the effective length of pipe which contributes to the angle of rotation--including bending and torsional effects. Under these conditions, with the maximum resolved design moment applied, $J$ is about $3.45 \mathrm{MJ} / \mathrm{m}^{2}$ $\left(20,000\right.$ in. $\left.-1 b / i n .{ }^{2}\right)$. Such an estimate represents an upper bound evaluation of $J$ for the fully yielded section under worst-case operating loads (i.e.. DBE). A more realistic evaluation of $\emptyset$ should consider the change of moment

«Tada, H., Paris, P., and Gamble, R., "Stability Analysis of Circumferential Cracks in Reactor Piping Systems," NUREG/CR-0838, USNRC, 1979.

${ }^{\dagger}$ Perfectly plastic behavior is assumed.

**Memorandum on "Millstone Nuclear Power Station, Unit 2 Feedwater Lines," from Northeast Utilities to NRC, June 18, 1979, Docket No. 50-336. 
in the length of pipe and thus not assume that the moment is maximum everywhere. While conservative methods in design are generally encouraged, the assumed conditions are probably overly restrictive for the current study. Analyzing the same geometry using a stress intensity approach under elastic conditions* yields a $J_{K}$ of $219 \mathrm{~kJ} / \mathrm{m}^{2}\left(1250 \mathrm{in.}-1 \mathrm{~b} / \mathrm{in} .{ }^{2}\right)$ for a uniform maximum design stress of $200 \mathrm{MPa}(29 \mathrm{ksi}) .^{\dagger}$ while this value may be greater than $J_{I c}$ in some cases (i.e., high rate $J_{\text {Ic }}$ ), the crack growth may still be stable providing $\mathrm{T}_{\text {Appl }}<\mathrm{T}_{\text {Matl }}$.

Under the plastic limit moment conditions, the applied tearing can be evaluated from the pipe geometry, material properties, and crack size by**

$$
\mathrm{T}_{\mathrm{Appl}}=\mathrm{F}_{1}\left(\frac{\mathrm{L}}{2 \mathrm{R}}\right)+\mathrm{F}_{2}\left(\frac{\mathrm{EJ}}{2 \mathrm{R \sigma _{0 } ^ { 2 }}}\right),
$$

where $F_{1}$ and $F_{2}$ are functions of crack geometry and applied axial load, respectively. For the Millstone-2, steam generator-1 piping

$$
\mathrm{T}_{\text {Appl }}=0.046 \mathrm{~L}-4.4 \times 10^{-4} \mathrm{~J},
$$

where $L$ is in inches and $J$ is in in. $-1 b /$ in. ${ }^{2}$ For an applied $J$ on the order of $219 \mathrm{~kJ} / \mathrm{m}^{2}\left(1250 \mathrm{in.}-1 \mathrm{~b} / \mathrm{in.}{ }^{2}\right)$, the second term is relatively small. Based on the conservative assumption that the pipe is unconstrained between the steam generator and containment wall, $L$ is estimated to be $20 \mathrm{~m}$ (790 in.). The resulting $T_{A p p l}$ is 37 and is significantly less than the values of

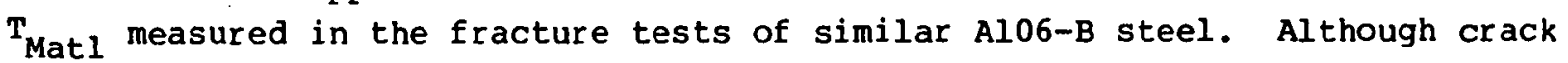
initiation may occur from a 15-cm (5.9-in.) through-wall crack, under maximum design loads, the crack growth should be stable and therefore arrest. The values of $J$ and $T$ obtained herein must be viewed in light of the assumptions made in the analysis. While they represent a general trend, the numerical values should not be regarded as sacred. The analysis serves as a guide for a

\footnotetext{
*J calculated from the stress intensity solution of desired geometry.

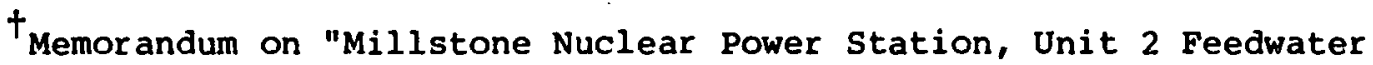
Lines," from Northeast Utilities to NRC, June 18, 1979, Docket No. 50-336.

**Tada, H., Paris, P., and Gamble, R., "Stability Analysis of Circumferential Cracks in Reactor Piping Systems," NUREG/CR-0838, USNRC, 1979.
} 
particular pipe section of the Millstone plant. While the methodology may be generalized to other plants, the actual results are only applicable to the system under study. 